



\section{Revision der}

\section{Unterfamilie/der/Orthalicinen.}

Von

Dr. Hermann Strebel.

/ll

Mit 33 T a f e In.

Aus „Mitteilungen aus dem Naturhistorischen Museum“. XXVI.

(2. Beiheft zum Jahrbuch der Hamburgischen Wissenschaftlichen Anstalten. XXVI.)

Hamburg 1909.

Kommissionsverlag von Lucas Gräfe \& Sillem. 



\section{Revision der}

\section{Unterfamilie der Orthalicinen.}

Ton

Dr. Hermann Strebel.

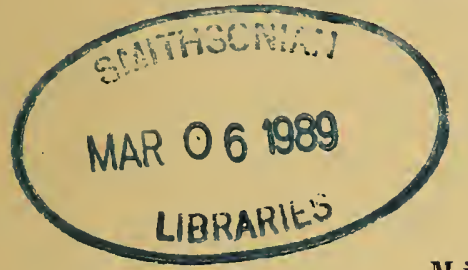

II it 33 T a f e $1 \mathrm{n}$.

Aus „Mitteilungen aus dem Naturhistorischen Museum“. XXVI.

(2. Beiheft zum Jahrbuch der Hamburgischen Wissenschaftlichen Anstalten. XXVI.)

Hamburg 1909.

Kommissionsverlag von Lucas Gräfe \& Sillem. 

Ich habe in meiner Arbeit „Beitrag zur Kemntnis der Famma Mexikanischer Land- und Süßwasser-Conchylien", Heft V, Hamburg, G. J. Herbst, 1882, in Gemeinschaft mit GEong PFEFFER, der die Bearbeitung der anatomischen Befunde ïbernommen hatte, allgemeineres iiber die Gattungen Zebra, Corona und Porphyrobaphe gesagt, und die Gattung Zebra ausführlich behandelt. Seitdem ist das Material des Naturhistorischen Museums in Hamburg ganz bedeutend gewachsen, außerdem aber sind meine Erfahrungen reicher geworden, und bedentende Vorarbeiten haben das Urteil geschärft, so daß ich jener Arbeit manche Berichtigung und viele Ergänzungen hinzufïgen kann. Damals lag mir nur die Arbeit von FISCHER und CROSSE, "Mission scientifique an Mexique et dans l'Amerique Centrale", vor, auf die ich mich hier der Kürze halber mit FC. beziehen werde, wie ich für meine damalige Arbeit SP. gebrauche. Die ebenfalls schon damals benutzte Arbeit von von MARTENs, "Die Binnenmollusken Venezuelas", wird mit M. ${ }^{1}$ angeführt, wälırend ich für die später erschienene desselben Autors in „Biologia Centrali-Americana, Land and Freshwater Mollusca", M. ${ }^{2}$ setze.

. Zuletzt ist dann die alle diese und die ganze einschlägige Literatur zusammenfassende, bedentsame Arbeit von PILSBRY in „Tryon's Manual of Conchology", Vol. XII, mit vielen Abbildungen erschienen, in welcher PILSBRY die Orthalicinen unter die Familie der Bulimidue einordnet. Seine mustergültigen Literaturnachweise ersparen es mir, solche zu wiederholen, denn jedem Fachmann wird dies Werk zur Verfügung stehen, so daß der Hinweis auf dasselbe genïgt, was mit einem P. geschieht.

Das mir vorliegende große Material, das durch guitige leihweise Zuwendung aus den Museen von Berlin und Frankfurt a. M. noch bereichert ist, legte den Wunsch nahe, es durch Wort und Bild in dem Sinne auszumutzen, daß. die große Teränderlichkeit der Formen in dieser Unterfamilie zur Anschauung gebracht, und dadurch für die Abgrenzung der Arten und ihre Lokalisierung eine brauchbare Unterlage geboten werde. In der letzteren Beziehung wird sich freilich durch Fehlen verwendbarer Angaben manche Lïcke zeigen. 


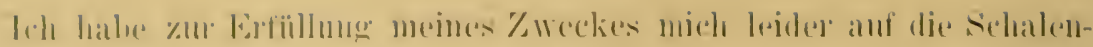

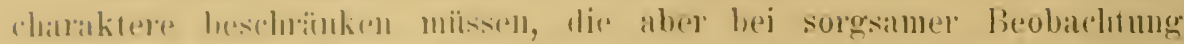

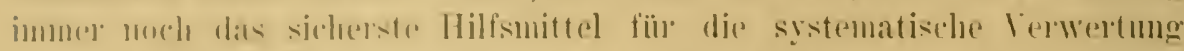

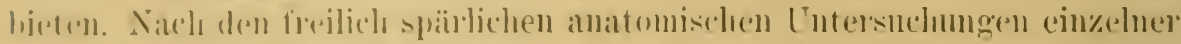

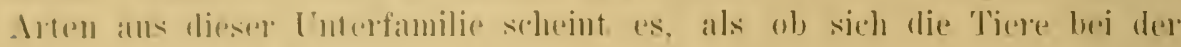

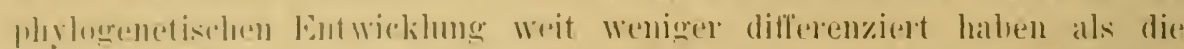

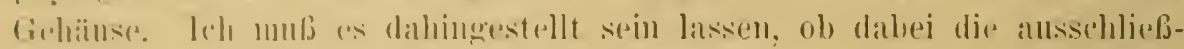

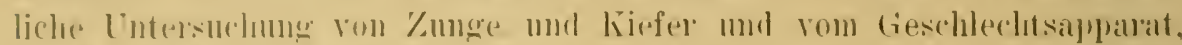

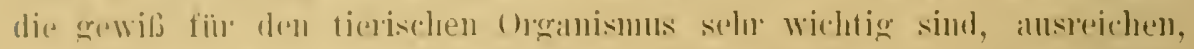
und ob nicht eine grenane veroleichende Untersuchumg der iibrigen 'leile

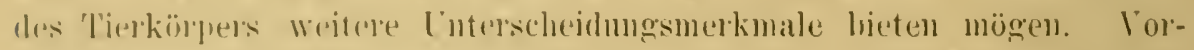

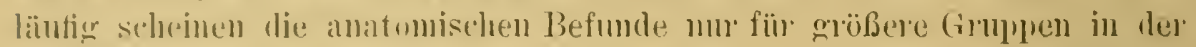
Sistrmatik verwendhar zu soin; ol es aber nicht doch gelingt, die anatomischen Jofunde mit denen der Sohalencharaktere so weit in Ein-

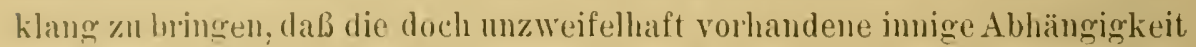
des Gulänses vom 'lierkürper besser zmm Ausdruck komme, als es bisher der Fall ist, muß dor Zukunft ïberlassen bleiben.

Es wan ans praktischen Grïnden merläßlich, nm die hei meinen Studien sidr ercrebenden Differenziermugen der Formen zum Ausdruck zu bringen, für Arten mo Varietäten sowie für die /ansammenfassung in Gattumgen orler Intergaftumgen manche nene Namen zu geben. lle so seln erwïnschte griumliche Turchforschmng so mancher noch wenig uder

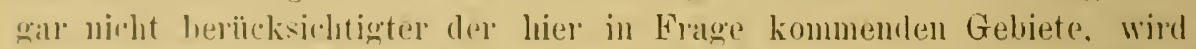

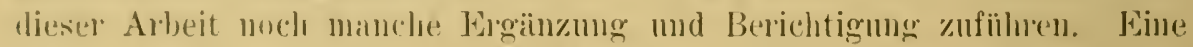

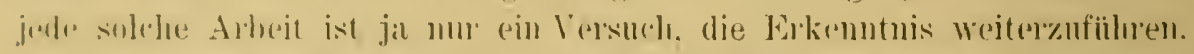

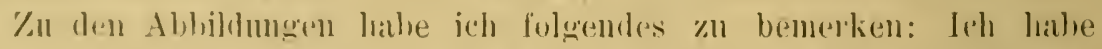

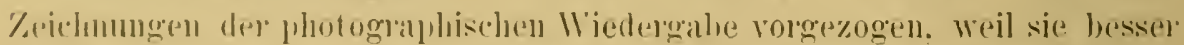

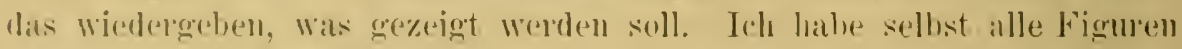

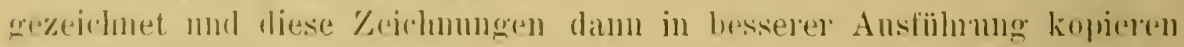

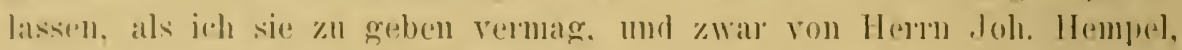

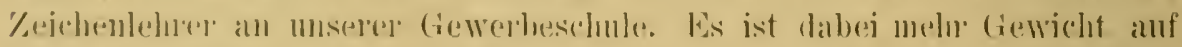

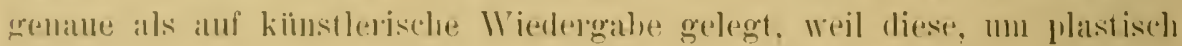
zoll wilken, manches verderken wïrde, Was sichlball sein soll. Aus dem

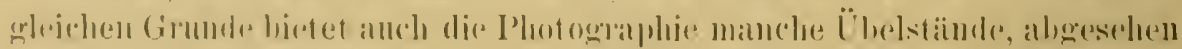

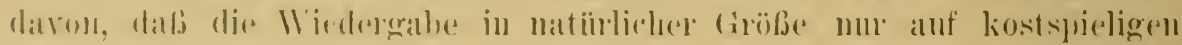

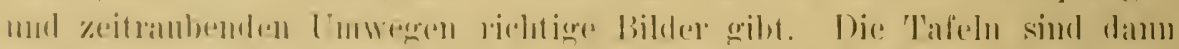

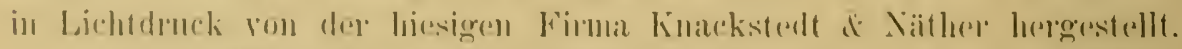

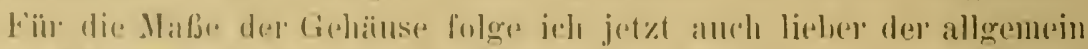

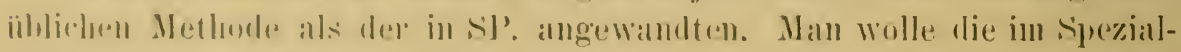

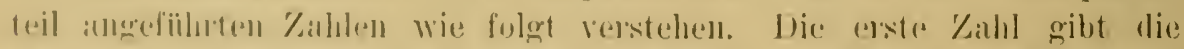

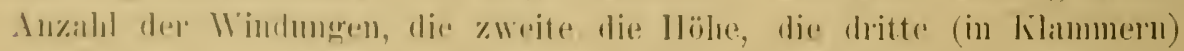

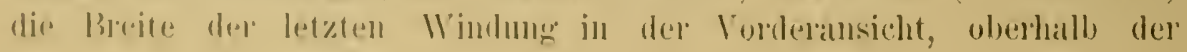


Mündung bis zur gegenüberliegenden Seite, die vierte die größte Breite in der Rückenansicht, die fünfte die wirkliche Hölıe der Mündnng, die sechste deren Breite einschließlich Mundrand bis zum inneren Spindelkontur. Iclı labe für die Breite zwei Maße genommen, weil dafür, besonder's bei älteren Autoren, Verschiedenheit in der Methode herrscht. Die relative Höhe der Mündung im Vergleich zur Höhe des Gewindes habe ich nicht angefülnrt, weil sie unsicher festzustellen ist, und außerdem aus den Abbildungen hervorgeht. Ich habe der Gleichmäßigkeit halber auch für solche Stücke die Maße nach dieser Methode aufgeführt, die schon in meiner frihheren Arbeit oder in Originaldiagnosen verzeichnet sind.

Ich habe zum Schluf noch allen denen meinen Dank auszusprechen, die mir bei dieser Arbeit mit Rat und Tat fördernd zur Seite standen.

Icl nemne dabei besonders die Herren Dr. JoHANnes THIELE vom Berliner Museum, deu leider zu frülı verstorbenen Professor Dr. F. RöNER vom Senckenbergischen Museum in Frankfurt a. M., Dr. H. DOHRN in Stettin, meinen früheren Mitarbeiter Professor Dr. GEORG PFEFFER und Dr. MAX LESCHKE, beide vom hiesigen Naturhistorischen Museum.

\section{Gattung Zebra SHUTTLEW.}

SHUTTLEW. in Notit. Halacol. I, p. 60. SP. V, p. 4.1856. $=$ Oxystyla ScHLÜT. P., p. 101. 18,38

PILSBRY hat, seinem Prioritätsprinzip folgend, den älteren ScHLüTER schen Namen gewählt. Ich kamn ihm in diesem Falle nicht beistimmen, denn es ist ein Katalogname, der an sich schlecht gewällt ist, und dem als einzige nichtssagende Charakterisierung die Überschrift unter der Gruppe Bulimi zur Seite stelit: „Spindel perpendikulär eingerollt." Als einzige Art wird $B$. undatus $\mathrm{m}$. (BRUG.) angeführt. Das entspricht nicht den festgestellten Regeln der Nomenklatur. SHUTTLEworTH dagegen gibt eine Diagnose der Gattung Orthalicus, die er dann in drei Gruppen teilt: Sultana, Zebra und Corona. Bei Zebra geuiigt damn die kurze Diagnose: "testa teniuscula, lineis spiralibus saepe minutissimis decussata, nucleo laevigato."

PILSBRY hat nun diese Gattuug nach geographischen Gesichtspunkten geordnet: 1. Antillen und Florida, 2. Mexiko und Zentralamerika, 3. Siidamerika. Westindien und Florida wird für sich behandelt. Für Mexiko und Zentralamerika und für Südamerika wird p. 111-113 und p. 132-134 je ein Schena gegeben, in dem die Arten nach Schalencharakteren geordnet werden, was mir, nebenbei gesagt, bei der großen Tariabilität der Arten eine kaum zu lösende Aufgabe erscheint. Für die letzterwälnnte 'Tremmung: 


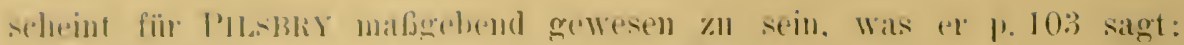

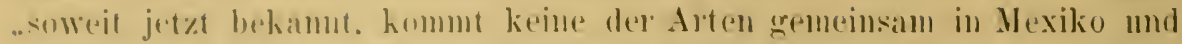

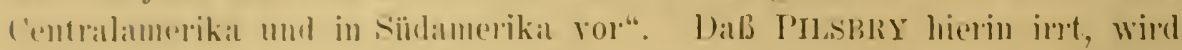
im simezialteile ewiesen werden mel ebenso, dab ringe Arten, die in den g(-)ianuten Festländern rorkommen, anch in Westindien und Florida ilne Vertreter lablem, die sich zum Teil nielot mal als Varietätell absondern

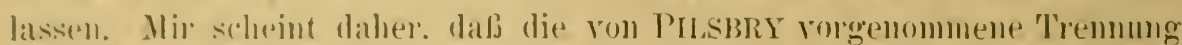

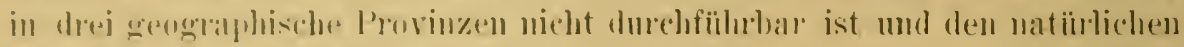

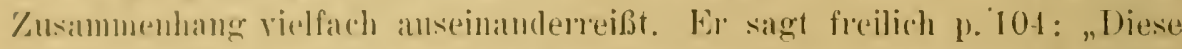

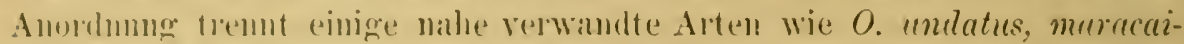
bensis mol feressaci. aber sie ist vielleicht passender als eine strene natioliehe Reilsenfolge." Jeh meine, es lïbt sich sehr wohl beiden Fordermangen geredet werlen, indem man die Gattmog trot\% des oft. Ineinanderibergreifens in typische Gruplen teilt, mol die sie vertretenden Alten in aines nach geographisehen Gexichtspmukten geordnoten liejhenfolge besclureilst. leh wähle dafiir die Reilunfolge Mexiko, Centralamerika,

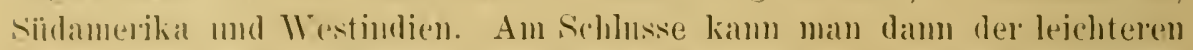
Übersicht halher eine \%usammenstellung der Arten mul ihrer geographischen lerlueitumg machen.

lch rwailnte weiter rorn, lab einige Arten des Festlandes anch Vertreter in Westindien und Florida haben, die sich zum 'Teil nicht mal als Varietioten absondern lassen. Diese später noch zu erwejscule, übrigens

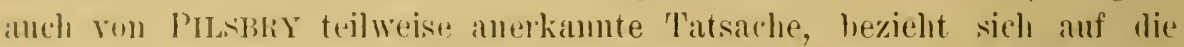
anf den Antillen und in siiden von Florida lehende. von PInsulix als O). undalu nit den Varrotiitenl jumurensis, reses und floridensis zusatmmentgefalde kleine Grople. Wie ist mu dies remeinsame Vorkommen anf-

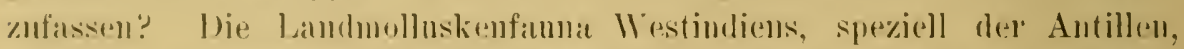

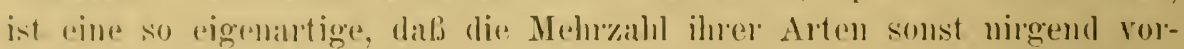
kommt, also für die Antillen antochthon ist. Dazu gethöt aber von dall Grllutirinen mur die (iattumg Liguns $s$. str., olme die iln von PILSBRY

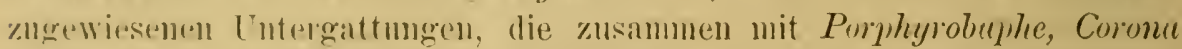
und Orthuticus s. str. antorhthon für Siidamerika sind. D) Gattung Zebra

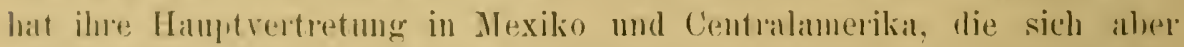

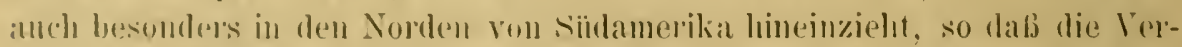
Ireter in Wrstindien und Florida als besondere Anslälfer betraditet

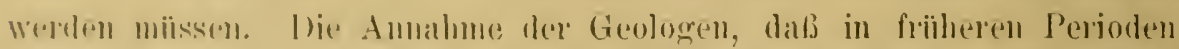

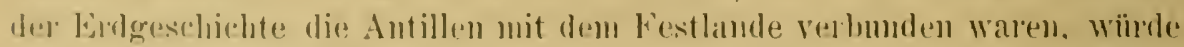
ohne writeres dis erwilmo gemeinsame Vorkommen erklären kömnen,

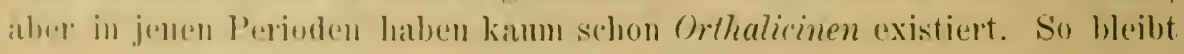

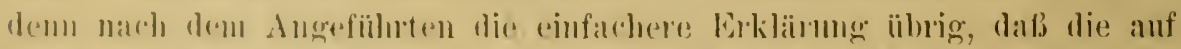
den Antillen und in lilurida ronkommenden Arten dere (iattumg Zebru vom Festlande ank dorthin verschleppt worelen sind, und sich damn dort ein- 
gebürgert liaben, wobei naturgemäß durch die veränderten Lebensbedingungen auch Veränderungen in den Schalencharakteren zu erklären sind.

Es mub hier noch eingeschaltet werden, daß in Sinne der vorangehenden Erörterungen die Insel Trinidad und wahrscheinlich auch die sog. Windwärts-Inseln nicht zu den Antillen bezw. zu Westindien zu rechnen sind, denn nach wohl allgemein gültiger Ansicht ist jedenfalls Trinidad in weit jiingerer Zeit vom Festlande losgelöst, als die Zeit ist, in der eine Verbindung der Antillen mit dem Festlande angenommen wird. Die allgemeine Fauna der Insel Trinidad zeigt noch hente manche dafiur beweiskräftige Übereinstimmung mit der des Festlandes. Das schließt freilich nicht aus, daß, was die Orthaticinen anbetrifft, auch nach der Loslösung vom Festlande die Insel Trinidad noch durch eine oder die andere Art durch Verschleppung bereichert sein mag.

Was mun die Verschleppung anbetrifft, so kann es eine künstliche und eine natïrliche gewesen sein. Über künstliche Trerschleppung liegen, soviel ich weiß, nur bestimmte Angaben für die Antillen unter sich vor, wenn sie auch durchans nicht unwahrscheinlich im weiteren Sinne ist, weun man bedenkt, daß die Tiere ron Land- und Süßwassermollusken vielfach als Nahrung gedient haben und dienen, oder daß die Gehäuse bezw. die Schalen als Schmuck oder Spielzeng gedient haben können. Nach diesen Richtungen hin sind mir freilich für die Gattung Zebra keine Beispiele bekannt. In "Proceed. of the Tictoria Institute of 'linidad", Part. I, March 1894, befindet sich ein Aufsatz von GUPPY, "Notes on the mollusks used as food in Trinidad". Darin wird erwähnt, daß der Borus oblongus, der auf dem Festlande gegessen wird, soviel er weib, in Trinidad nicht mehr als Speise dient, trotzdem außer Meeresschnecken dort auch Ampullarien gegessen werden. Vom Genuß der Landschnecken wie Bul. undatus (unser $Z$. undatus), sagt er, wisse er nichts.

Mit der natürlichen Verschleppung liegt es anders. Tieles darïber wie allch über die Widerstandsfähigkeit der Mollusken enthält die liübsche Arbeit von HARRY WALLIS KEW, "The dispersal of shells", London 1893, worin Beobachtungen und Berichte namhafter Gelehrter und Reisender zusammengetragen sind. Anch CH. T. SIMPsON in "Distribution of the Land and Freshwater Mollusks of the Westindian Region", Proceed. of the U. St. Nat. Museum, Vol. 19, 1894, p. 423 und folgende, spricht von Strömen, die an den Nordküsten Südamerikas ganze Strecken Trald wegschwemmen. Von Bambusstämmen, Pflanzen, Ballast als Beförderungsmittel von Schnecken oder ihrer Eier. Er spricht auch direkt aus, daß Bul. undatus (unser Zebra undatus), eine mexikanische Art (?), jetzt in Florida, Cuba, Jamaika und einigen der Windwärts-Inseln, ein anderes Beispiel der Terschleppung sei.

Jene starke Siidpassatdrift, die sich bis nach Yucatan und Cuba 
hinanf erstreckt, kamn sehom von Ama\%omas- nud Grinocogebieten aus den

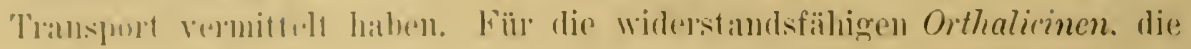
in der trockenen dahreszeit sogar mit rinem alsehliefenden beckel rep-

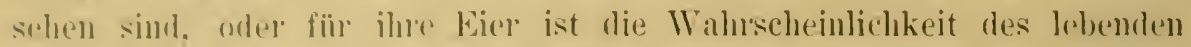
Transpurles durchans nicht so weit abligend, als mancherseits amgenommen wirl. To lïngele dre Transpont danert, mu so schwieriger gestaltet sich freilich die gliblkliche Ankunft, und so erklïrt es sieh vielleicht am

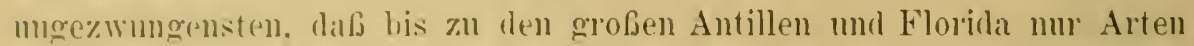
von den nitherliegenden Teilen des Festlandes, wie Venezuela, Columbien mul anch Trindald, gelangt sind und sich dolt eingebürgett haben, wodurch damn im Lanfe der \%eiten durch die veränderten äßBeren Lobensbedingmgen anch cinge Abweichungen ron dem mspringlichen Typus in den Schalenchilrakteren erklïllich sind. Z/um Kapitel der Widerstandsfäligkeit kam irh noch folgendes anfïluren. Unser Mnsenm erhielt kïrzlich von der Westkiiste Mexikos (Tepric) dmch die Post einige Exemplare einer Zebraart, mu in einer Pappschachtol verpackt, die lebend hier ankamen.

Zur Verschleppung giht auch PILSBRY bei 0 . undutus, l. c. p. 108, folgenle Daten, die ich wörtlich iibersetzt anfülren will: „Die tote, glanzlose und etwas rauhe Oberfäche der meisten Jamaika-Schnecken ist scheinbar dem äuferst truckenen Klima des südlichen Teiles der Insel zuzuschreiben. ïstlich von Kingston ist die Art in Fïlle auf Bäumen vertreten, aber auf ain kleines Gebiet beschränkt. Diese Beschränkıng und die T'atsache, daß die Art lımptsächlich in der Nïhe menschlicher Wohnungen lebt, rerulassen C. B. ADAMS zn der Temutung, daß sie in Jamaika durch Menschenhand eingefüht sei. Gegen diese Ansicht spulicht die strenge Individualität der Jamaikarasse ${ }^{1}$ ). Professor CockERELL berichtet mir, diaß Materialien, die sich als Flutauswaschungen des Orinoco erweisen, häıfig an die Sïdküste von Jamaika nach Kingston ausgeworfen werden. Ich wiurde ans diesem Umstande rermuten, daß O. undatus von Trinidad makl Jamaikia duch Vermittelmg eines Bammstammes mit ans dem ITassel ragenden $\ddot{A s t e n ~ g e b r a c h t ~ s e i . ~ W e n n ~ d e m ~ s o ~ i s t, ~ w e r d e n ~ d i e ~ K o l o n i e n ~ r o n ~}$ Flojida und Bahama anf ïhnliche Flutragabunden zurïck\%führen sein." Wejpe heift es dam ams eimem Bericht des COL. H. W. FEIHDEs: „Die Int ist sehr hänfig in Her Nachbarschaft ron Kingston. scheint aber anf dies Gebiet beschrïnkt mul kimn zu Hunderten an Kaktuspflanzen lïingend gesehen werden. Ich hiabe sie auf keinem andern Teil der Insel angrotnoffen. In 188!) brachte ich einen kleinen Korb davon nach Barbados;

2) Dazu möchte ich hemerken, lafi ich die Verschielenheit lieser Form mit den in Columbien nud Venumla lebenlen Vertretern ilerselben Art nicht so berlentend finde, dafs sie sich nicht lache durch dic verinderten Lebensbulingungen, wie Klima und

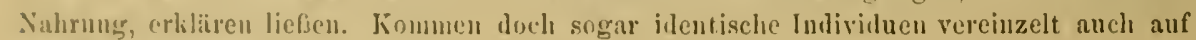
dem Festlinile vor. 
da ich aber bei meiner Ankunft dort bei der Pelikan-Insel in Quarantïne liegen mußte, so schïttete ich sie dort im Buschwerk aus. Später fand ich sie schon in Gärten der Ungebung von Bridgetown eingebürgert."

Für die Tnsel Trinidad, die PILSBRy auch besonders als Fundort für den $O$. undatus in seiner typischen Form angibt, kann ich noch folgendes anführen: Tch fand bei den hiesigen Naturalienhändler, Hermu UMLAUFF, eine Partie Landschnecken, die ein Amerikaner, der von den Inseln Barbados und Trinidad kam, mitgebracht hatte. Die Schnecken sollen von Trinidad stammen, von woher er außerdem eine große Menge Borus oblongus nebst Eiern und Voluta harpa mitbrachte. Diese Schnecken bestanden nun in der Hauptsacle aus einer großen Menge scheinbar lebend gesammelter $Z$. zoniferus, Form naesiotes, die unser Museum von RoLLE mit Etikette des amerikanischen Händlers WEBB als O. unclatus var. jamaicensis besitzt, mit der sie nichts zu tun hat. Ferner waren in geringer Anzahl vertreten: $Z$. undatus, Form maracaibensis, Z. delphinus, Form vividus, Z. livens, Form aberrans, Z. pulchellus, Form prototypus, und sogar je ein Stiick $Z$. macturae und boucardi sowie Orthalicus gallinasultana, Form meobambensis (?), und Corona regatis. Es ist mir leider kein genames Terzeichnis der auf Trinidad jetzt lebenden Landschnecken, speziell der Orthaticinen, bekannt, nur daf nach PILsBRYs Angaben der echte O. undatus und Borus oblongus dort leben. Jedenfalls erscheint es auffallend, daß unter den aufgeführten Arten des Umlanffschen Materials sich auch solche wie $Z$. zoniferus und boucardi befinden, die bisher nur vón der Westseite Mexikos bekannt sind, von wo eine natiurliche Verschleppung zunächst nicht gut vorstellbar ist. Aber die weiten Gebiete der vom Orinoco und Amazonas mit ihren vielen Nebenflüssen durchzogenen Landstriche sind noch viel zu wenig nach Landmollusken durchforscht, als daß sie nicht noch manche Überraschnng bieten könnten. Ich er'wähnte schon in der Einleitung, daß die Gattung Liguns mit Ausschluß der ihr von PILSBRY angegliederten Untergattungen Corona und Hemitulimus für die Antillen autochthon ist, wie andererseits die genannten Untergattungen sowie Porphyrobaphe und Orthalicus s. str. für Südamerika autochthon, da sie anf dieses Gebiet beschränkt sind. Die Gattung Zebra dagegen kommt in allen drei von PILSBRY anfgestellten geographischen Provinzen vor, wenn ich auch annehmen möchte, daß Mexiko, was Reichtnm der Formen und höchste Ausbildung aller Schalencharaktere anbetrifft, ilır Hauptgebiet ist. Was nun die Einzelheiten ihrer Terbreitung anbetrifft, so wird der Spezialteil dariiber manche Aufschlïsse bringen, die ron PILSBRYs Annahmen abweichen, wobei nur solche Vertreter der Gattung berïcksichtigt sein sollen, von denen einigermaßen sichere Fundortsangaben vorlieg'en. Ich möchte aber bei dieser Geleg'enheit doch bemerken, daß manche, besonders in der älteren Literatur verzeiclnete Fundortsangaben 
nodh einer Bestitigumg bediurfru. wie dem anch die Absonderung gut

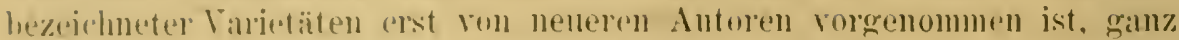
hesonders bou PILSBRY. der, soweit Material vorlag, melı Ahbildumgen hringt, als es sonst ïhlich war, wemn auch ein so hreit angelegtes Werk

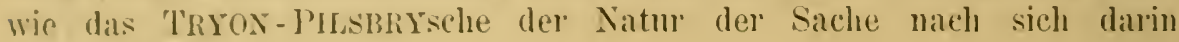
heschrïnken mub.

Über die Schalencharaktere der Gattumg möchte ich zu dem in SP. p. 7 -), (iesagten noch in Ergiinzung und teilweiser Berichtigung zusammenfassend folgendes sagen, das man mit dem von PIIsBRY, l. c. p. 102-103, fiesagten vergleichen mag.

1) $e_{2} 2^{1 / 2}$ Embryonalwindmngen sind ansuahmslos gewïlbt, ziemlich glatt, hornfarbig, glänzend mol ohne \%eichmmg, mur bei einigen Formen tritt eine hull- oder dunkelhrame bis braunschwarze Färbung des Nucleus auf, die sich auf mehr als eine Windung erstrecken kann mo die in ihrem ansHiefenden Verlanfe immer an der Naht am dunkelsten ist. Das Fehlen oder Forhandensein sowie der L'mfang dieser Färbung ist im allgemeinen ein Merkmal der Art oder Varietiit, doch machen sich zuweilen bei Material selbst ron demselben Fundort Abweichungen bemerkbar.

Die Grundfarbe des Gehäuses pflegt auf den mittleren Windungen melı woißlich oder isabellfarbig. später gelblich bis bräunlich zu werden. PILSBRY nimmt wohl mit Recht an, daß die Bänderung wie bei der Subfanilic Bulimulinue einem älteren (ich namte inn in SP. einen idealen) 'Typus znkommt, ob aber die sogenamnte melanochilus-Form, die nur Bänder und keine Streifen außer den Varixstreifen hat, der älteren Form entspricht, ist wohl noch eine Frage, die sich nicht hestimmt mit ja beantworten läßt. Ton den urspringlichen fünf Bändern ist Band 1 nur sehr selten vorhanden, ebenso ist Band 5 nur zuweilen noch durch eine mehr weniger breite Zone um die Basis herm angedentet, nur an jungen Stücken ist es häufig noch scharf ansgeprägt. Die Bänder 2-4 treten, wem Streifen rorhanden sind, nur bei einigen Formen bald einzeh, selten alle drei und selten zusammenhängend, meist unregelmäßjg bis regelmäßig unterhochen auf, sie sind zuweilen anch dentlicher in der Mïndung als anf der Außenseite sichtbar. Wo Bänder fehlen, denten winkelige oder wellige Vorspriinge der Streifen ihre mspringliche Lage an, aber immer mu bei Band 1-4, nie mehr für Band 5. Ich bezeichne der Kürze halber mit Streifen, die in der Anwuchsrichtmng verlanfenden, die anch wohl mrichtigerweise laingsstreifen genannt werden, wïhrend sie wohl richtiger (Qnolstreifen \%n nemen sind. Die Gestaltmng dieser Streifen ist eine vielgastaltige, mul bald verlanfen sie in normaler Richtung, wobei aber viclfah zwischen band 2-3 oder bis 4 ein /usammentließen von zwei

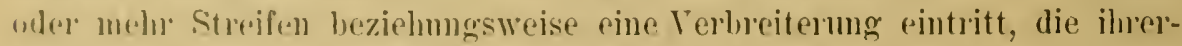
suits oft anch in der lichtmo seln veränderlich ist, indem sie bald 
schräger als ihre ursprüngliche Richtung, bald wellig oder im Zickzack verläuft. Unterhalb Band 4 verschwinden die Streifen mehr weniger rasch, wenn sie nicht vorher schon verschwunden sind.

Aus der vorangehenden Besprechung der Zeichnung ist ersichtlich, daß meine Beobachtungen von denen PILSBRYs abweichen, der p. 102 nur das Torkommen von drei Bändern (0 $\left.2 \begin{array}{llll}0 & 3 & 4\end{array}\right)$ als Rest einer ursprünglich fünfbändrigen Form annimmt. Wenn auch nicht alle fünf Bänder zusammen an einer Form beobachtet wurden, so ist doch ein jedes von ihnen, sei es in ausgewachsenen oder an jungen Stïcken und in verschiedenen Kombinationen bei den verschiedenen Formen der Gattung Zebra nachweisbar. $Z \mathrm{u}$ den 1. c. gemachten weiteren Äußerungen PILSBRYs über die melanochilus-Formen möchte ich folgendes sagen: Ich habe in SP. schon p. 9 unten und bei $O$. ferrussaei p. 21 auf den Parallelismus zwischen melanochilus- und der normal gezeichneten Form hingewiesen, dazu bemerkend, daß die Bänder wohl einem idealen Typus angehören. Und p. 23 bei Form B 3c führe ich außerdem eine albine Form an und füge hinzu: "dieser Albinismus wie auch die als melanochilus bekannte Färbung scheint eben unter Umständen bei jeder Fornı auftreten zu können."

Nach dem heutigen Stande biologischer Forschung kann man wohl Erscheinungen wie Melanismus, Lencochroismus $=$ Albinismus, Xanthochroismus und für die Gattung Zebra auch den Melanochilismus als Heteromorphismus zusanmenfassen, wenn sie auch streng genommen wohl nicht Vorgänge aus gleichen Ursachen sind, aber doch bei jeder Art oder Form auftreten können. Ich werde danach die dahingehörenden Formen, soweit ihre Zusammengehörigkeit nachweisbar ist, mit heteron. melanochilus usw. der betreffenden Art anfïgen. PILSBRY hat trotz der Annalme eines Parallelismus die melanochilus-Formen der betreffenden Art unter eignem Namen zugesellt, was mir nur für solche Formen als Notbehelf angebracht erscheint, deren Zugehörigkeit zu einer normalen Form nicht nachweisbar ist.

Mit der Färbung des Nucleus bezw. der ersten Windungen scheint auch häufig die Breite und Intensität der Färbung des Mundrandes in einem gewissen Parallelismus zu stehen, so daß bei weitergehender und dunkler Färbung der oberen Windungen anch der Mundrand innen breiter und dunkler gefärbt ist. Dem Verhalten des Mumdrandes in der Färbung entspricht auch der die Mundränder verbindende Callus (den ich der Kürze halber nur Callus nenne), wenn er auch heller und selbst ganz farblos sein kann.

Färbung und Zeichnung sind auch innerhalb der Art nicht unbedentenden Schwankungen unterworfen, ebenso geht es mit der Form des Gehäuses, mit der die Form der Spindel zusammenhängt, wenn anch inmer eine gewisse Grenze für die Charakterisierung der Art oder Lokal- 


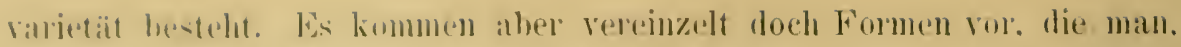

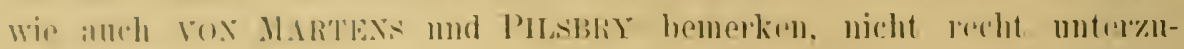
hringerll wrib.

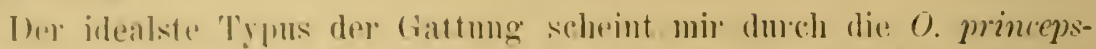

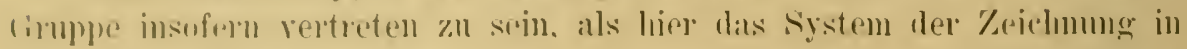
streifen und biindern seine reichste mud komplizierteste Ansbildung findet.

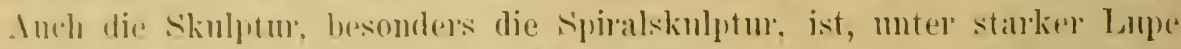

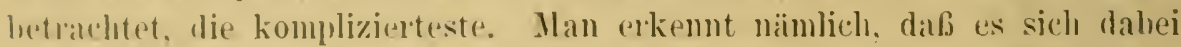
InI seln feine heifen handelt. die aher besonders anf den letzten Windungen

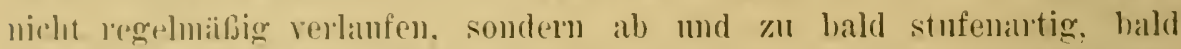
schräg unterlorochus verlanfen oder anch sich verschlingen. I) itı kommen oft noclı gröbere Furhen oder Rumzeln, die strichweise in or Spiralmlen am in schn̈iger Richtung neben hammerschlagartigen Eindriicken anfreten. Bei uberfläthlicher Betrachtung seheint es sich dabei mu mm dir ïbluhe sponalstreifung zu handeln, wie sie tatsiichlich anch an den mittern Windungen elsoleint. Bei anderen Arten kamn diese Siriralsiulptur auch mehr weniger einfach und selı undeutlich werden (O. undahs), damn wieder als regelmäßige scharfe Furhen erschemen.

Ehe ioh mm zmm Spezialteil ïbergehe, miehte ich noch einige liritische Arten in \%usammenhange liesjuechen, da es sich bei der Besprechumg der "inzelıen Arten schlecht einfïgen läßt.

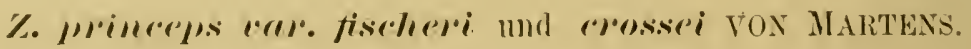

Mit var. fischeri lat VON MARTExs in M. ${ }^{2}$ O. princeps var. $\beta$ von Fischer mo C'Rosse bezeichnet. El sagt davon p. 180: "T'esta conica, ovata latiuscula. Anfract.: convexis. Pintura: fulva, strjgis paullo magis chscuris numerosis paullulum undulatus. Apex: mimute fusco. Perist.: anguste fuscum, callo fusco. Dimens.: $60 \times 35$, Apert: alt. 33,

$$
55 \times 33, \quad, \quad n \quad 30 \text {. }
$$

Jafria: W. Guatemala."

Aul 1.] S.3 haift es dam noch linl\%: "T'esta fulva, strigis fuscescentibus angulatis ('Tab. X, fig. $\tau$ ) $=0$. minceps rar. $\beta$ Fisch. et Crosse. Miss. scientifique au Mlexique, Mollusal I, p. 455, tab. 18, fig. 26. Hah. Wr. Guatemala: Li] Reposo nul sam Isidro near Mazaf(onago (Champion)" mul nach F. Iml C.: . Finatemala without nearer indication of Locality (BOCOUR'T)." Dats letztere ist nicht richtig. dem in der Beschrejbung sagen F. und C.: „Situl Anerustin (Guatemala)."

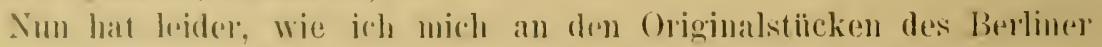

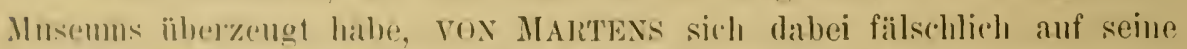

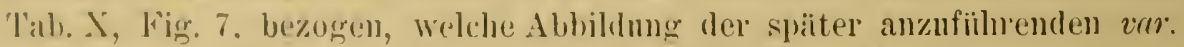
mossri entspluteht, so daß die sehöne Art, die vor MarTexs mit var. 
fischeri bezeichnet hat, gar nicht abgebildet wurde. Infolge dieses Irrtums hat num PILSBRY dieselbe Art 0 . princeps var. deceptor benannt und dabei fraglich F. et C. var. $\beta$ angeführt. Die Bezugnahme auf diese Varietät ist freilich von beiden Seiten eine fragliche, und man hat wohl nur des Fundortes halber, und weil eine oberflächliche Ähnlichkeit vorliegt, darauf Bezug genommen. Herr PILSBRY wird nun wohl mit mir einverstanden sein, wenn ich den Namen, den der verdienstvolle Conchologe von MarTENS beabsichtigt hat, wieder in sein Recht einsetze. Die Beschreibung von VON MARTENS läßt allerdings manches zu wünschen übrig, besonders was die Zeichnung anbetrifft; aber aus der Form des Gehäuses, den Maßen und dem Fundort im Gegensatz zu den entsprechenden Angaben bei der var. crossei ist dentlich ersichtlich, daß die Abbildung auf Tab. X, Fig. 7, sich auf diese Varietät und nicht auf var. fischeri bezieht.

Die var. crossei führt VON MARTENS nicht bei 0 . princeps, sondern bei O. zoniferus STREBEL an. Es heißt davon p. 180: „Testa: subelongata conica, anfract. minns convexis. Pintura: strigis numerosis. Apex: minute fusco. Perist. anguste fuscum, callo fusco. Dimens.: $54 \times 30$, Apert. alt. 28. Patria: British Honduras. Costarica." Auf p. 186 steht dann nur: „var. crosse $i=0$. princeps var. $\gamma$. FISCH. et CROSSE 1. c. I, p. 455, tab. 18, fig. 2 c. British Honduras. Belize (Boucart, Parsons). Costa Rica (VAN PaTTEN in Mus. Berolinense." Hier hätte nun der Hinweis anf Tab. X, Fig. 7, stehen müssen, was ich nach den mit diesem Namen bezeichneten Stücken des Berliner Museums feststellen kann. Da keine Abbildung angegeben ist, wird in $\mathrm{P}$. dafür die Abbildung in $\mathrm{F}$. und $\mathrm{C}$. der var. $\gamma$ kopiert, eine Abbildung, die sich mit größerer Sicherheit der var. crossei anpassen läßt als die der var. $\beta$ an var. fischeri, wenn auch absolute Sicherheit in der Übereinstimmung nicht vorhanden ist; dazu sind auch die kurzen Notizen darüber in FISCHER und CrossE nicht geeignet. Es handelt sich hier auch hauptsächlich darum, festzustellen, was VON MARTENS unter den beiden Varietäten verstanden hat.

\section{Z. ferussaci VON MARTENS und PILSBRY und Z.marccaibensis PFR.}

Auch bei dieser vON MARTENSschen Art sind Irrtïmer untergelaufen. Der ersten Beschreibung in Malak. Bl. 1865, p. 42, ist keine Abbildung beigefïgt, aber es wird auf FÉRUSSAC, Taf. 115, Figg. 1, 4, verwiesen, welche Figuren vorzïglich zu der Form passen, die vON MARTENS später in M. ${ }^{1}$ abgebildet hat. Der Typus des 0 . ferussaci wurde von DEPPE in Tehuantepec gesammelt, und die 1. c. dafür angegebenen Maße sind: $65 \times 33$ und Apert. $31 \times 17$; er ist aber nie abgebildet. Ich schrieb damals in SP., p. 17, über ihn das Folgende: „Die Art ist anf ein Stück begründet, das, wenn auch schlecht, weil verwittert und nachträglich aufgefrischt, 


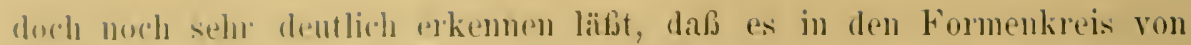

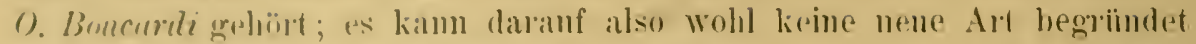
wedell. Zusammen mit diesem stütek liegen nun aber dinige mans-

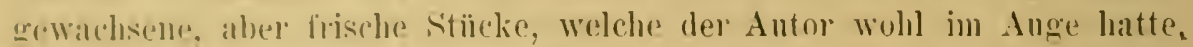

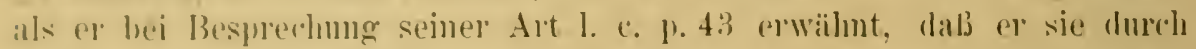
lirin hestimmt anssprechbares Kennzeichen von andoren Stïcken ans

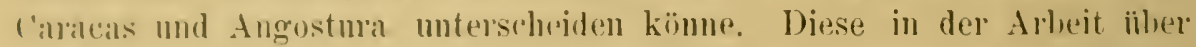
dir Bimnemmollusken von Venezuela pag. 5:2 als 0 . ferussaci angefiilnten mul durch die Albildung anf 'l'af. 1, Fig. (;, gekemmeichnsten Stücke repais(antieren mun allerdings rine sowohl von dem eigentlichen Typus der Art gnt zn muterscheidende wie anch an mo fïr sich charakteristische Form, mul da der eigentliche Typus nicht abgebildet worle, und man wohl in den moisten Fïllen mter $O$. fernssaci das verstehen wird, was rox ManTiss unter diesem Namen in der Arbeit über die Veneznela-

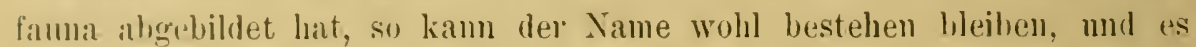
Prïhrigt mur, die Artdiagnose dieser Form besser ammpassen."

Diese Bemerkungen gelten auch hente noch, dem wem anch ron jumen kloineren 'T'ehrantepec-Stïcken mit Sicherheit zurzeit nu' eins rorlixgt, so ist dies doch tatsächlich nur in einer etwas heller bräunlicheren Fïlung von den Venezuela-Stüchen zu unterscheiden, und ich habe damals wohl mit Rocht jene Mafe eines grofen, nicht dazu gehörigen Stiickes ignoriert mud mich an die von VON MARTENS angefïhten FÉRUSSACsehen Abbildunginu und an die in M.', 'T'af. 1, Fig. (i, gebotene, zur Bestimmung vin O. ferussuci von Vox MaRTExs gehalten. In M. ${ }^{2}$, 'Taf. X, Kig. 9, hat vos Malitexs dam das kleme, jetzt noch vorluandene Stiick von LEPIE als O. ferussaci abgebildet, ein Beweis dafuir, daß entweder clas grofestiick schon damals nicht mehr vorhanden war, oder daf vox MARTENS as iufolge jener oben angefïlnten Bemerkung von mir nicht meln als laznghörig ansah, dem sonst wäre doch dem großen Stïck der Vorzug fiir dis Abhildung gegoben. Die letztere Vermutung ist freilich deshall, nicht stichhaltigr, weil das betreffende Stïck anch unter anderem Namen nicht melı vorhanden sein soll.

Nim hat roy MaR'TESs in M.", 'T'af. X, Fig. 8, ein weiteres Stiick, angeblich O. fermssaci, von Kacapa in Guatemala, STOLL leg., stammond, ahgehildet, das in P'. 'T'af. 17, Fig. 17, durch falsche Stellung der Bänder schlecht kopiort ist. Anch dies Stïck des Berliner Juseums liegt mir vor, mul ich kamm bestimmt sagen, daß es in Form, Skulptm mol Färlumg

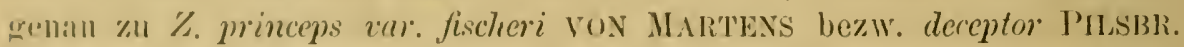
faljt mol mu mansgewatchsen ist. Mir ist mun nicht recht verständlicll,

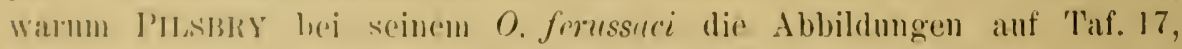
Figg. 1:i-17, für datsselle laalten und insbesondere die Figrg. 14-15 anf

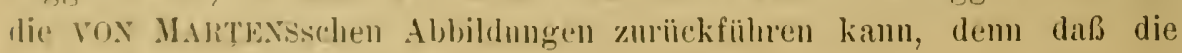


Fig. 17 (nach VON MARTENS) etwas ganz Verschiedenes ist, kamn man eigentlich erst von der Rückseite und vor allen Dingen an der Skulptur erkennen. Jedenfalls können Formen, die den Figg. 14, 15 entsprechen, nicht zu 0 . ferussaci vON MARTENS gerechnet werden. Den Abbildungen und der von PILsbRy für $O$. ferussaci angenommenen Skulptur nach, die allerdings mehr der 0 . princeps-Gruppe entspricht, würde ich diese Stïcke zu $Z$. princeps var. fischeri bezw. zu PILsbrys var. deceptor rechnen. Die angefïhrte Fig. 13 in P. scheint mir ein heterom. xanthus von O. ferussaci vON MARTENS zu sein, wenigstens liegen mir ähnliche Stücke vor. Es will mir scheinen, als ob PILSBRY nur der Fundorte halber die beiden von MarTensschen Typen für ferussaci, M. ${ }^{1}$, Fig. 6, und M. ${ }^{2}$, Fig. 9, für zwei verschiedene Arten gehalten hat, was sie in der Tat nicht sind, und deren Zusammengehörigkeit doch voN MARTENs selbst befürwortet hat. Eine andere Frage ist num, ob die kleine, angeblich von DEPPE in Tehuantepec gefundene Form wirklich dort gefunden ist, oder ob nicht vielleicht Terwechselungen damit vorgefallen sind. Ich finde unter dem reichlichen Material von der Westseite Mexikos kein ähnliches Stück mit solch obsoleter Spiralskulptur, wie sie den Venezuela-, Columbien- und Westindien-Formen eigen ist. Die Tatsache bleibt aber, daß das im Berliner Museum liegende DEPPEsche Stück, das ich anch abbilde und beschreibe, nur eine leichte Variante von dem in M. ${ }^{1}$, Taf. 1, Fig. 6, abgebildeten Stïck ist, und daß beide zusammen maßgebend für das sind, was ich in SP. dem O.ferussaci vON MARTENS zugrunde gelegt habe und was von MARTENs dafül angesehen haben wollte. Allerdings muf ich für einen Teil des damals unter $O$. ferussaci zusammengefaften Materials PILsBRy Recht geben, daß es zu $O$. maracaibensis gehört, abel vorlälufig dtirfte der von MARTENssche Name doch für gewisse Formen noch beizubehalten sein, wie z. B. für die von Rio Hacha, die PIlsBRY p. 139 auch unter anderen Abweichungen anffïhrt, ohne sie durch Namengebung zu bezeichnen, denn vom gleichen Fundorte liegt mir auch diese kleinere Form vor.

Man geht wohl nicht fehl mit der Annahme, daß, wo melrere übereinstimmende Stiicke von einer Lokalität vorliegen, die von anderen Typen der betreffenden Art abweichen, eine lokalisierte Form vorliegt, die abzusondern mir richtiger erscheint. Andererseits kommt es freilich ancls vor, daß Material von angeblich einem Fundorte mehrere verschiedene Typen aufweist, wo dann das Bedenken auftritt, ob es wirklich zusammen an einem Standorte gefunden wurde, oder ob nicht der betreffende Sammler von seinem angegebenen Standquartier aus Exkursionen gemacht hat, die Standorte mit verschiedenen änßeren Bedingungen berührten, so daß die Verschiedenheit des Naterials sich ans den verschiedenen Standorten erklären ließe. 
])as sind die schon erwähnten Sehwierigkeiten, die einer richtigen

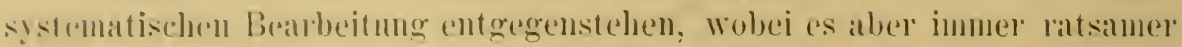

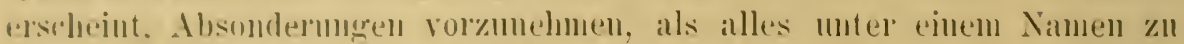
belassen. Plasblil befürwortet dies ja ebenfalls, ist aher im rorliegenden Falle davon ahrewichen Allerdings mub ich sagen, dab grerade bei Z. maracaibensis mul scinen Nohenformen eine scharfe 'Jremmug ver-

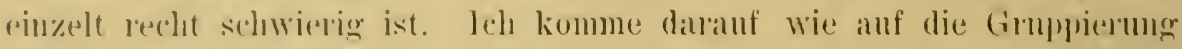

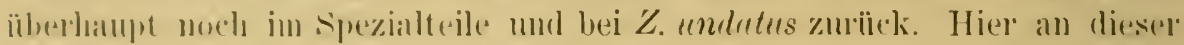
stelle sollte nur das Verdiiltuis des echten O. Jernssaci mol die Beziehmo \%um \%. maracuibensis rö̈tert werlen.

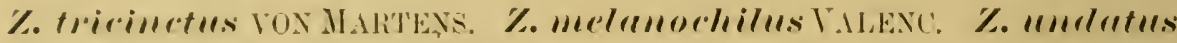

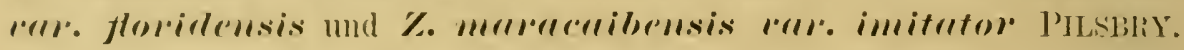

Alle die ebengenamten Formen sind heteromorphe bezw. melanochilusFormen, die von den Autoren, wie ich schon in der Eimleitung erwälnte, mit eignem Namen belegt sind.

Ton slem ältesten Bul. melanochitus VALExc, deutet die Abbildung: in HunBoLDT und BoNPLAND ganz entschieden anf die melanochihssFolm von Z. maracribensis, und zwar der kleineren var. ferussaci, und nicht, wie VON MAR'Texs amnalm, anf die zu $Z$. murs bezw. ponderosus vder auch Z. boucurdi gehörige melanochilus-Form von der Westseite Mexikus. Die melanochilus-Form, die vox MarTexs in M." Taf. 11, Fix. s, fiil $O$. tricinctus abbildet, ist eine der vielen verseliedenen Formen, die sicls muter dem Material von Veneznela befinden. mo die meistens zn Z. marrcribensis gehiinen. VON MARTExs bezieht sich daselbst anch anf meine O. fernssari-Form B' 1, in SP., 'Taf. II, Fig. 2a-d, ferner anf

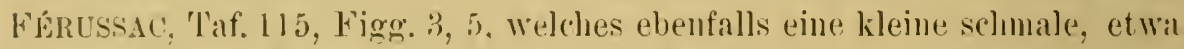
die Rio Hacha-Form darstellt. Die Bezugnalume anf Fiscues und Chossk, Figr. 5.5a, crgibt eine gröbere banchigere Form, desgleichen die auf

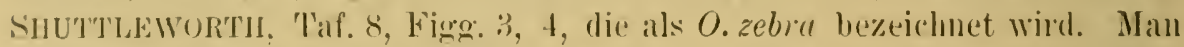
sielit also, daß Vox MARTExs fül seinen O. tricinctus die ganze Stufenlaiter de melatnochilus-Formen von Z. maracabensis in Anspruch nimmt. Irem er dabei hetont, dab seine Art nielit mit der form ron der Westkiliste Mexikos zusammenfällt, so hat el darin liecht, nm nicht mit der

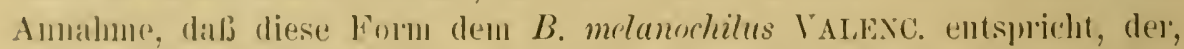

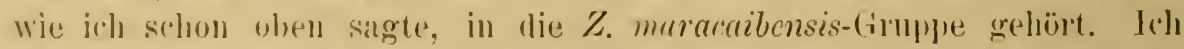

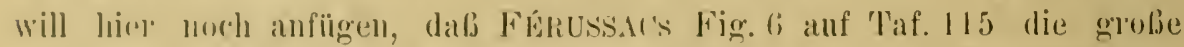

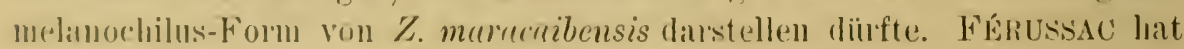

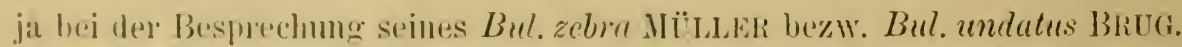

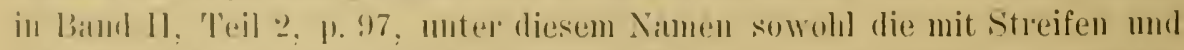

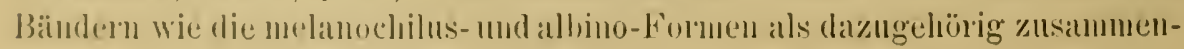


gefaßt; allerdings kommen unter seinen Abbildungen auch Formen vor, die nur fraglich dazu gehören, wie z. B. Figg. 5, 6 anf Taf. 114 und Fig. 1 auf Taf. 117.

Was nun PILsBrys var. floridensis anbelangt, so kamn ich dieselbe sowohl nach seinen Abbildungen, Taf. 18, Figg. 7-13, wie anch nach mir vorliegendem Material von Florida nicht von den melanochilus-For'men des $Z$. maracaibensis unterscheiden, ebensowenig wie die rar. imitator, die er als melanochilus-Form der genannten $Z$. maracaibensis anfïgt. Es ist auch hierfür woll nur der verschiedene Fundort für eine Absonderung maßgebend gewesen, denn er sellost verweist bei der var. floridensis p. 111 auf die große Ähnlichkeit mit O. melanochilus, O. ferussaci tricincta, $O$. maracaibensis imitator; wenn er aber noch $O$. longa-strebeli hinzufügt, so kann ich ihm darin nicht beistimmen, denn die gehört meiner Ansicht nach zu $Z$. boucardi, die er als Tarietät von $Z$. longus PFR. absondert.

\section{Z. undatus BRUG. und Tarietäten.}

Die gute Diagnose in der Encyclop. Méth., p. 320, lantet wie folgt: "Cette coquille à le plus souvent $2^{\prime}$ de longeur et $14^{\prime \prime}$ de diamètre; elle est ovale, très ventrue du côté de la base, et terminée au haut par une spire conique et pointue. Elle est composée de 7 tours lisses, convexes et blancs, qui sont marqué de flammes longitudinales brunes et ondulées et de 3 fascies transverses articulées on continues de la même couleur; on compte ordinairement 3 de ces fascies sur le tour inférieur et 2 seulement sur les trois suivants, cenx du plus hant de la spire sont toujours blancs, hors le point du sommet qui est brun et quelquefois noirâtre. Le tour de la base est très bombé, très convexe et sans aucune apparance d'angle ou de carène; quoique lisse, il est garni tout le long de la suture d'une bordure de stries longitndinales, qui s'affaiblit graduellement sur les tours superiemres, et disparait en totalité sur celle dn sommet. J'ouverture est ovale et presque anssi longue que le milien de la coquille, elle a 13 lignes de lianteur, et sa longeur est de 8 lignes vers le milieu. Le bord de la lèvre droite est simple, mince, tranchant et coloré de brum on de couleur de suie; la lèvre gauche consiste en un feuillet, dont la couleur est semblable, qui est collé sur la convexité du second tour. La columelle est presqne perpendiculaire, un peu inclinée vers la ganche et presque toujours blanche. La partie externe de la cavité offre une teinte lilas clair on fauve, et on y apercoit des traces légères des couleurs du dehors, tandis que la gauche présente d'un bout à l'autre la même couleur que les bor'ds de l'ouverture."

BRUGUIłke zitiert dazı: 1. LISTER, tab. 29, fig. 27?, eine Mißgeburt, die man auf verschiedenes denten kann. 2. FAvandE, 65, Fig. M4, 
diese Figm ist anch nicht mit Sicherheit zn hestimmen; sie zeigt keine bïndel mul kïmte anclı Z. zoniferus oder ähnliches sein. ¿. SEBA 111, 'Taf, :3!. Figg. 5.1, 55, das ist eine melanochilus-Form. 4. MARTINI und ('nkys. 1X, Figg. 1015, 1016. Von diesen ätelen Autoren, zu duen sich

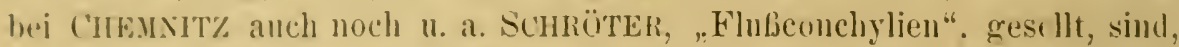
was die Abbildmgen anhetrift, nur die von CHEnNiT\% zn gebramchen. Brilguthe stïft sieh freilich an dem Wort „subcarinato" der leteten I"indumgr. Womit aber offenbar das nach mon sich rasch Terjingende der let\%len Windung gegeniiber dem verhailtuismäßjig hohen kegrelfömugen Gewinde gemeint ist. denn die Abbildungen zeigen keine liante. BRUGUirk: fïgt dann noch hinzu: "quoiqu`il soit évident par la figure de la C' nchyliologie de Martini. que l'espree de cet antem nest pas differente de la mienue." Dallach miissen Brugulkke anch weniger gedrungene bezw. grestrecktere Stïcke vorgelegen hahen, als seine Mabe es andenten. Ich mörhte zn dem CHEmxitzschen Zitat schröTERs noch hemerken, daß nach desien Beschreibung ihm scheinbar anch eine melanochilns-Form vorgelegen hat, demn er spricht nur von dem bramen Streifen am Mundrand, deren narh roickwärts noch melrere vorhanden sein sollen, und von weifer. (irmulfarbe. Interessant ist dabei noch die Notiz, daß el das beschriebene Stiock, für das er sechs Windungen und $1^{1 / 2} \times{ }^{3 / 4}$ Zoll als Mabe angibt, von MARTixi erhalten habe mit der Angabe, daf es ron Jamaica stamme. Es ist doppelt anfallend. dab der spätere CHEMnitz noch die hiiste von Guinea (oder soll es vielleicht Guayana heifjen?) mu dab Bruguière Les Grandes Indes als Vaterland für die Art angibt.

I'Ilsiblil hat mun p. 106 , 'T'af. 27, ligeg. 16-18, die echte 0 . undutu meiner Ausicht nach richtig nach der BRUGUlèrkschen Diagnose heschrieben mnd abgebildet. Seine Fig. 16 entspricht sogar gut den BRUGulèrsehen Mafon, die umgrerechmet $54,1 \times 31,5-29,3 \times 18.1$ ergeben. Daneben rertreten die Fig. 17-18 eine schlankere Form, die sich mehr dem ('H:mstzschen 'lypus nähert. Als Herkunftsolt werden T'rinidad mud dive Grenadinen angegoben, dazn freilich noch nach anderen Autoren St. Vincent, Bahamas und St. Thomas. I'ILsBRy zieht mun, wie schon

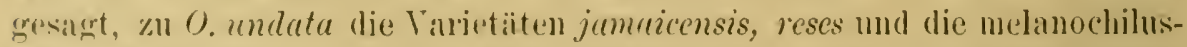
Form floridensis. Fin alle diese Formen kamn man korrespondierende formen anf dem Festlande nachwejsen. wie ans dem Spezialteile sich rgeben wird. Desto mmatiorlicher wirlit darum die aligesonderte Auf-

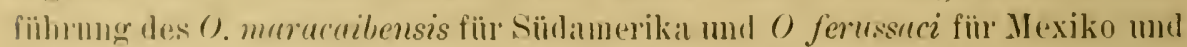
('antralamerika. alles formen, die mit ilnen Varietäten so eng ineinander iibcrgreifen, dalj man für manche Stïrke im \%weifel ist, wohin man sie

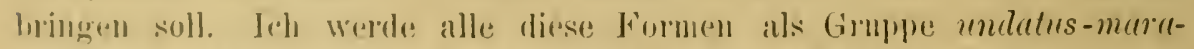

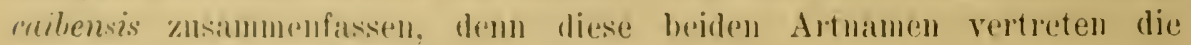
Fonnen, die in ihren typisehen Vertetern sich am leichtesten tremen lassen. 
Ich will hier noch auf eine Notiz in P., p. 111, hinweisen, worin die in TRYons Monographie in American Journal of Conchology, Vol. III, Taf. 13, abgebildeten, auf p. 166 als $O$. undatus von Florida zusammengefaßten Formen von PILsBRY nach Einsicht der Originale richtig gedentet werden. Danach ist Fig. 1 O. undata var. jamaicensis, Fig. 2 var. reses und Fig. 3 O. longa var. uhdeana. Auffallend ist dabei nur die letztgenannte Art, die bisher nur von der Westseite Mexikos bekannt ist. Die Abbildung läßt keinen sclıwarzen Wirbel erkennen, sonst könute 0 . maclurae in Betracht kommen, was eher verständlich wäre.

\section{Z. mars-ponderosus-decolor.}

Ich habe in SP., p. 35, den O. ponderosus von damals unbekanntem Fundorte aufgestellt, und daneben p. 37 den 0 . decolor. Bei der letzteren Art war das unter For'm A, 1 verzeichnete Stïck mit „O. mars, Ecuador" bezeichnet gewesen. Diese Bestimmung war jedenfalls falsch, und der Fundort wird wohl auch nach älterem Mißbrauch dem Fundorte, der für O. mars von PFEIFFER angegeben war, nachgeschrieben sein. Diese Notiz und mein Hinweis auf eine gewisse Ähnlichkeit mit $O$. mars mag PILSBRY veranlaßt haben, die von ihm auf Taf. 54 abgebildete Art, die auch in der Sammlung der Academy als Bul. mars bestimmt war, für meinen $O$. decolor zu halten, zumal ihm 0 . ponderosus nicht vorlag, während sie in Wirklichkeit zu $Z$. mars bezw. meinem früheren $O$. ponderosus gehört. Bei der Revision dieser drei in Frage kommenden Arten hat sich nun herausgestellt, daf. mein O. ponderosus nichts anderes ist als höchstens eine Lokalform von $O$. mars PFR. Um sicher zu gehen, labe ich dann zwei extreme Formen, die in unserem Museum aus der Koll. FiLBY unter $O$. mars lagen, und die sich eben als nicht zu tremnen von den als $O$. ponderosus bestimmten Stïcken erwiesen, an Helru EDGAR A. SHITH in London eingeschickt, der mit gewohnter Liebenswürdigkeit berichtete, daß die eingesandten Stücke allerdings zu den von PFEIFFER in der CUMINGschen Sammlung bestimmten Stücken gehörten. Da nun aber mein $O$. ponderosus sich später als von der Westküste Mexikos stammend erwies, so war mir der Fundort Ecuador einigermaßen befremdlich. Meine darauf bezïgliche Anfrage wurde von Herrn SMITH dahin beantwortet, daß auf der Etikette von PFEIFFERs Handschrift der Fundort "Republik Ecuador, Mr. FrASER" von einer anderen Handschrift hinzugefügt sei. Ich habe aber auch die Herren SOwERBY und FuLTON gebeten, mir mitzuteilen, ob ihnen für $O$. mars ein sicherer Fundort bekannt sei, was negativ beantwortet wurde. FRASER hat allerdings in Ecuador gesammelt, aber immerhin bedarf also der Fundort noch einer zuverlässigen Bestätigung. Ton Juraty, M. Amazonas, liegt freilich ein Stück vor, dessen Fundort wohl sicher ist. Mein $O$. ponderosus ist jedenfalls einzuziehen 
und dureh Z. murs PFR. Zn elsetzen. Während $O$. decolor voubantig als

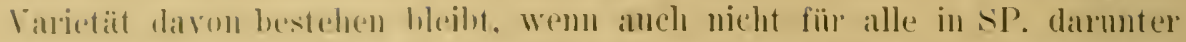

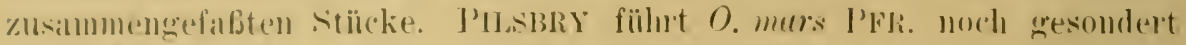

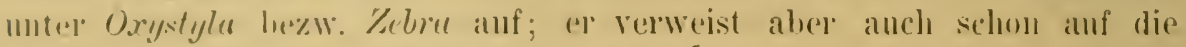
Öhnlichkeit mit $O$. pomderosus mad decolor.

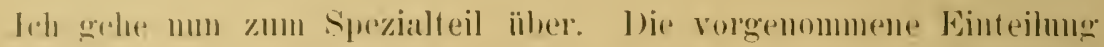

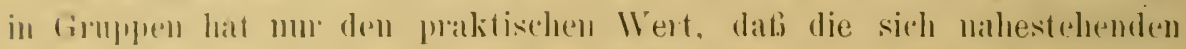
formen zosinmmengehalten werden, wobei indes mehrfach die Abgrenzmngen

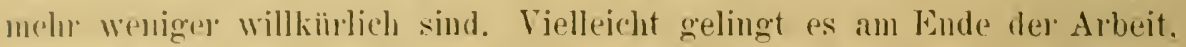
in du Beziehmog noch eine bessere Zusammenstellumg der Beziehmugen

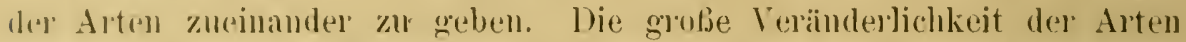
ist shon rom rox MARTENs in der Einleitmog zur Gattmog Orthulicus in

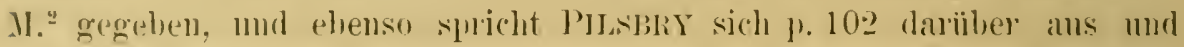
kommt \% demselben Schlul, der anch meinen Erörterungen in der Ënlojtumg \%ngrmule liegrt. Wemn ich im spezialteil zmm Teil die dem \%. princeps mahestehenden Formen als eigne Arten anffïhre, so möge man darauf kein besonderes Gewicht legen; es geschal ans praktischen Gründen. Rationell gesammeltes Material möge später entscheiden, inwieweit solche Arten als Lokalformen anzuselıen sind.

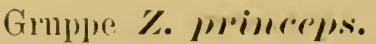

Dies ist die reichhaltigste Grople imnerhall) der Gattmo. iihne deren

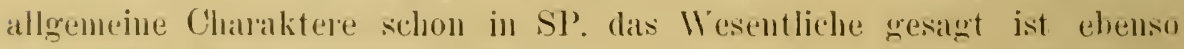
wie in des Einleitumg zur Gattmog.

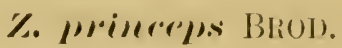

'Tatf. 1, Figg. 1/3, 5/11, 1:3/16. 'Taf. 11, Figg. 21, 25/24, :31/:32. SH', p. 11. JI. ${ }^{2}$, p. 18\%. P., p. 11:, 'T'af. 16, Figg. 1-7.

Vom Fundont des Typus in San Salvador liegt mir kein Material vor: Das rejchlattigste des mir vorljegenden Materials stammt ats Mexiko, dem ich daher den Vorrang gehe. leh habe, weil es sich hies mu viele

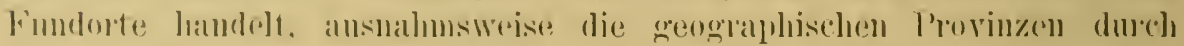
Z̈herschiften anseinandergehalten, die bei andern Ginplen nur ans der Reilnenfolge ersichtich sind.

\section{Misantla mud UHMgegend.}

SP., Form I3, 1. 12, Til. IJT, Fig. I a-d, IV, 1-4.

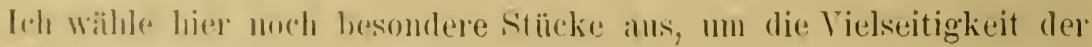
\%eichnumg zи zeigren. 
1. ex Nr.15028. Riickseite des in SP., Taf. IV, Fig. 2, von der Vorderseite abgebildeten Stückes, um zu zeigen, daß Band 2, 3 und sogar 4 auf der letzten Windung fast zusammenhängend durchgeführt sind. Band 4 ist breit, Band 3, 4 sind anch in dem weißlichen Innern erkennbar. Die Spindel ist etwas gewunden und steht etwas schräg zur Achse des Gehäuses.

Fig. 1. $6-49,9 \times(26,8) \times 32,5-27,6 \times 16,2$.

2. Ein zweites Stück zeigt auf der letzten Windung eine deutlichere Zonenbildung als es sonst der Fall ist, da sich die verbreiterten Streifen fast auf den Raum zwischen Band 2 und 3 beschränken und nur selten als solche oberhalb und unterhalb darüber hinans gehen. Die Bänder 2-4 gehen nicht über die hellen Streifen, welche die dunklen beranden, hinweg, so daß sie gegliedert erscheinen und an die var. trifracta PILSB. erinner'n.

Fig. 2. $\quad 6 \frac{1}{8}-53,6 \times(28,3) 35,5-30,8 \times 17,6$.

3. Ein drittes Stiick hat anf der 4 . bis 6 . Windung ein parr ausgeflickte Bruchstellen. In der Torderansicht zeigt es anch gegliederte Bänder (2-4) auf der letzten Windung und im Innern. In der Rückenansicht sind die Streifen auf der letzten Hälfte der letzten Windung zusammengeflossen, und die Bänder 2, 3 sind aus zusammengeschobenen Winkeln zusammengesetzt, so daß hier die Zeichnung und Färbung von $Z$. obductus vorhanden ist.

Figg. 3, 6. $\quad 6^{1} / 4-54,9(28,8) 35,7-30,6 \times 18,7$.

4. ex Nr.15011. Dieses etwas anormale Stiick liat bei sonst typischer Zeichumng eine verdickte und in der Mitte etwas schräg eingefurchte, daher zweifaltig erscheinende Spindel, wie sie bei $Z$. mars typisch ist. An diese Art erimern auch der immen breiter schwarzbram berandete Mundrand, und die sich von dem weißlichen, violett angehanchtem Imnern lebhaft abhebenden dunklen Varixstreifen. Andere dabei liegende Stiicke sind normal.

Fig. 11. $6 \frac{1}{4}-56,8 \times(27,8) 34,5-30,6 \times 17,3$.

5. ex Nr. 1502\%. Plan de Culebras, Weg nach Jicaltepec. Dies Stïck zeigt wiederum eine Partie der letzten Windung in Färbung und Zeichnung von $Z$. obductus, nur füngt hier dann plötzlich wieder die typische $Z$. princeps-Zeichnung an.

$$
\text { Fig. 5. } \quad 6 \frac{1}{2}-57,0 \times(29,7) 36,2-31,5 \times 18,4 \text {. }
$$

6. ex Nr. 15025. Rancho de la. Lima, Weg nach Jicaltepec $=$ SP., p. 13, B 2a. Ich fülıre hierbei nur an, daß zwischen normalen Stücken sich ein Stïck befindet, das bis zur 5. Windung normal, wenn auch matt gefärbt und gezeichnet ist. Dann ist eine starke Bruchstelle vorhanden, von der ab jede Zeichnung fehlt; auf einem hell schmutzig-bräunlich fleischfarbigen Grundton sind nur Tarixstreifen vorhanden, und erst ganz nahe der Mündung sieht man schwache Andentungen von Band 3 und 4.

$$
5^{3} / 4-54,1 \times(27,7) 33,9-31,6 \times 16,6 \text {. }
$$




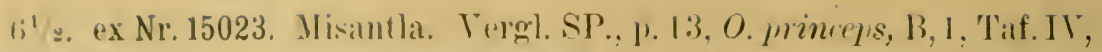

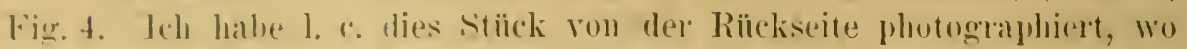

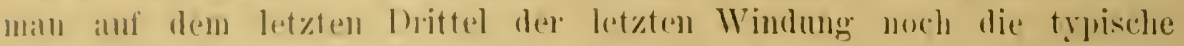

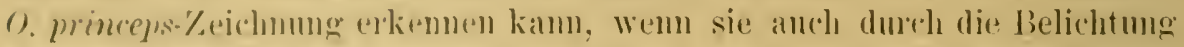
"us molentlich gemorden ist. Ich bilde hier das Stiick in der Turderansicht ab, weil es hiel anflallend der var. trifracta PILsBhy ähnlich rerseleeint.

Fie. 13. $\quad 6^{1} 2-65,4 \times(31,7) 39,0-35.3 \times 20,4$.

7. ex Nr. 15020. Nisantla = SP., 1. 13, Form B. I d. \%. princeps heterm. xanthus. Ein mansgewachsenes stück, schmutzig isaluellfarbig,

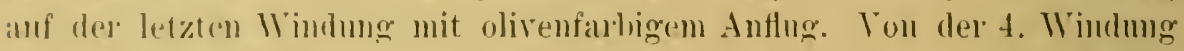
an ist di* typische Zeichmmg his himmter zu Band:3 durch eine nur wenig dumklere Fïrlumg angerlentet. Auf der 3. Windung ist Band 2 ebenso scluwach und Band : etwas dentlicher vorhanden, das damn bis \%ur Miindung durchereht. Interhall, Band :3 erkement man anf der letzten Windumg drei dumklere Zonen, die durch schmale Zwischemämme getremt, sind. ma von denen dic obere breit, die mittlere schmal, die mutere, dunkelste, mu den Nabel hermm wieder breit ist. Dor Mundrand und der rillns sind kastanienbram, das Innere ist weißlich belegt mit gram durchscheinemben hellen Teilen der Yeichnung; in der Dnrchsicht crscheinen die dunkleren Streifen heller als die Gromdfabe.

Fig. 7. $51 / 2-35,2 \times(19,3) 23,2-20, ; 3 \times 11,8$.

\section{IT gebung von Veracruz.}

$\therefore$ Virel. SP., 1. 12, Form A, 1-3, Taf. IT, Figer. 7, 8, 10.

lon den beiden grofen Stïcken gebe ich hier die ncuen Mafse:

Fig. 8. $\quad(3 / 8-61,3 \times(31,8) 38,9-34,1 \times 20,2$.

"10. Fist $7-70,2 \times(35,1) 43,2-336,7 \times 24,0$.

In iilurigen verweise ich anf sil.

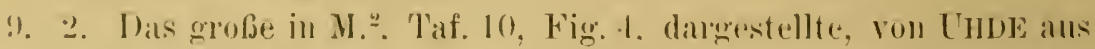
Veracru\% milgehrachte stïck ist, wic ich mich iiberzengt labe, verwittert,

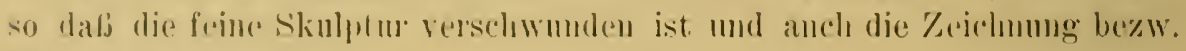
firlumg erelittell hal.

$$
7-7 ., 5 \times(35,5)+3,0-38,1 \times 2: 9,0 .
$$

10. Virgl. sl', 11. 12, Form A, 2, 'Taf. IT, Fig. 5. \%. minceps heterom. cumlluis.

Anstalt des damals hromgrogranen Albinismus, ist es wohl richtiger

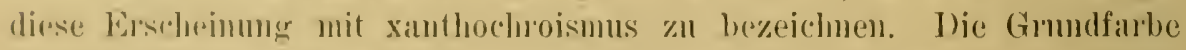

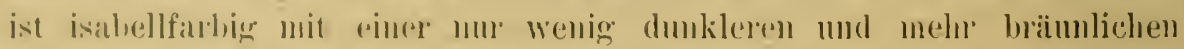

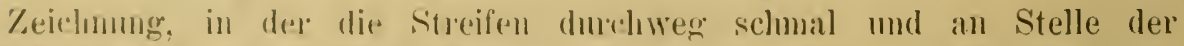
Bïnder :-, 3, 4 wie iihlich winklig vorgezogen sind. Der Mundsanm ist kiatamienthram, der C'allus selı düm mud bräumlich. Dic Schale ist selu 
dïnn und der Nucleus ist nicht gefärbt. Zwei junge Stïcke von derselben hellen Färbung und ebenfalls ungefürbtem Nuclens weichen nur dahin ab, daß zwischen Band 2 and 3 die Streifen, wie bei $Z$. princeps üblich, sehr breit werden. Das große Stïck mißt:

$$
61 / 4-50,9 \times(25,8) 31,3-27,1 \times 15,7 \text {. }
$$

Man könnte versucht sein, das große Stück auf 0 . princeps var. $\gamma$ CRosse \& F. zuriickzuführen, bezw. diese Tarietät anch für eine heterom. xanthus zu halten, abel was unter $Z$. crossei VON MARTENs verstanden sein soll, sind Formen mit dickerer normaler Schale, und anßerdem zeigen die hier dabei gefundenen jüngeren Stücke die normale $Z$. princeps-Zeichmung.

\section{Mirador und Rinconada.}

11. ex Nr. 15019. Plantage Mirador bei Huatusco $=$ SP., p. 15, Form C, 1. Zwei Stücke, die etwas aufgeblasener erscheinen als die vorangehenden Formen; es lassen sich daraus aber keine sichere Schlüsse ziehen. Das größere. Stïck kommt dem Stïck in P. nahe, Taf. 16, Fig. 8, das PIISBRY als Übergang zur var. trifracta ansieht; es ist aber dazu zu bemerken, daß die Bänder auch sonst, sei es strichweise oder gegliedert, bei $Z$. prinreps auftreten. Ich bilde das kleinere der beiden Stücke ab, weil es in der Torderansicht in dem ersten Drittel der letzten Windung den Typus der Zeichmung von Z. pilsbryi milhi aufweist, nämlich das schmale, helle, durchgehende Band unterhalb des gegliederten Band 3. Die Form des Gehäuses weicht aber durch die gewölbteren Windungen ab. Sonst ist die Zeichmung des kleineren Stïckes dieselbe wie bei dem größeren.

$$
6^{1 / 4}-53,9 \times(28,8) 35,5-31,2 \times 19,2 .
$$

Fig. 15. $\quad 5 \% / 8-42,9 \times(24,6) 30,2-25,0 \times 15,8$.

12. ex Nr.1501\%. La Rinconada, Weg von Veracruz nach Jalapa. Das Stïck ist zerbrochen, zeigt aber -dieselbe aufgeblasene Form des vorangehenden Stückes und dieselbe Zeichnmng wie das größere der beiden.

Ich gebe hier im Zusammenhange unausgewachsene Stücke des $Z$. princeps von verschiedenen der vorangehenden Fundorte, um anch daran die Verschiedenheit der Zeichnung zu zeigen.

13. ex Nr. 15013. Hacienda de Quilate (Misantla).

Fig. 26. Ein Stück mit $5^{3} / 4$ Windungen. Es hat die normale Zeichnung, ein sehr schwach angedentetes Band 4, und Band 5 in Form einer hellbramen Zone um die Nabelpartie. Nahe der Mündung treten Band 2, 3, 4 in winkligen Torsprïngen dunkler gefärbt auf.

14. Fig. 25. Das Stück hat $5^{\frac{1}{2} 2}$ Windungen und zeigt auf der letzten WVindung unterhalb Band 3 das helle Band des $Z$. pitsbryi, der 


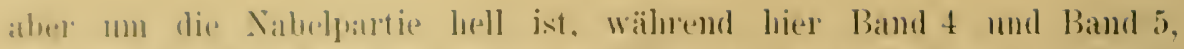

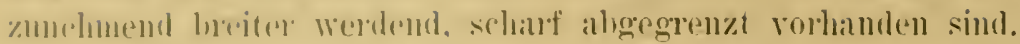

15. ex Nr. 15022. liancho de la Lima, Weg nach Yerllatla (Misantla).

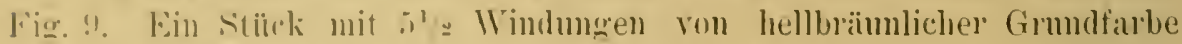
mit schmallun. otwas dmbleren, gewellten streifen in der Vorderansicht. die in den Vorsprïneren an Stelle ron Band 2, 3, \& dunkle Striche zeigen, Jie also eregliederten Bindern entsprechen. Um die Nabelpartie herm ist die bramme Zone des Band j. In der Räickenansicht wird die Zeichmmog not'mal.

16. Veracouz. Das Stiuck Fig. 27 hat $5 \frac{1}{4}$ Windungen und ist dem

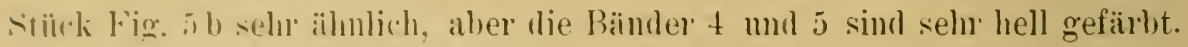
bis stiick lat merkwiuldigerweise mu $21 /$ s Embryonalwindungen.

Yucatan.

17. ex Nr. 15018. Meridat. Tergl. SP., 1. 16, Folm D. Fin Stück. Fis ist roas sthlanker als die vorangehenden Formen, was aher wohl niclit gan\% maßgebend ist, da as mehrere ausgebesserte Bruchstellen anfWrist. Vom vorn gesehen. treten die lneiten, vorn mit winkligen Vorspringen und immerhall, derselben dunkler betonten Stellen der Bänder 2, 3, 4 dentlich hervor. Ire Zone Band j fehlt. Die breiten Streifen in der Torderansicht sind breit weiß berandet, dam ist diese Berandung wieder durel lullhinmes schmale Streifen gegen den Girund aligegrenzt. In der Riickenansicht wind die \%eichmmug muregelmïßig. Band 3 und 4 sind hier anf dem lotzten Viertel durchgefiilnt.

Fig. 14. $6 \frac{1}{4}-53,9 \times(27,2) 34,0-28,8 \times 18 ; 6$.

Westküste von Mexiko.

18. ex Nr.14044. Mazatlan, Kapt. RrsGe leg. \%wei Stuicke zusammen mit $Z$. delphims milhi. Jur Nuclens ist helluram, die stïcke sind festshlalig mud haben die typische Form ron $Z$. princeps, die Grundfalle ist

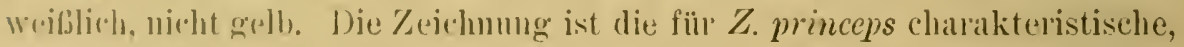

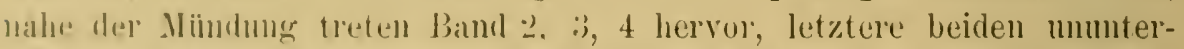
lnochen, anberdem ist Band 5 als dunklere Zone mm die Basis markiert. 1) Mundsamn ist schmal kastanienbram, der Callus lat dieselbe Färbung, ist alue diimn und nur streifenweise verdickt. Das Immere ist weiblich.

Fig. 18. Fast $(i-44,1(24,8) 29,7-25,2 \times 14,6$.

\section{Guatemala.}

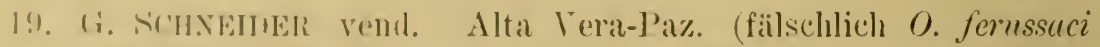

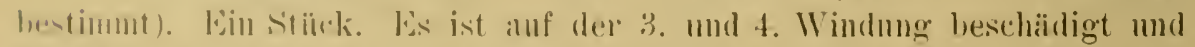

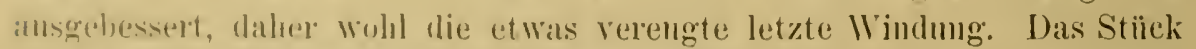
ist sunst in Fïllumg und zeichmmg typiseh und nicht von einzelnen 
Stïcken aus der Misantla-Gegend zu unterscheiden. Auf der mittleren Partie der letzten Windung ist Band 2 unterbrochen, Band 3 durchgehend und sehr dunkel gefärbt vorhanden, Band 4 ist heller, aber dentlich abgegrenzt bis an die Mündung. Mundrand und Callus sind hell kastanienbraun, letzterer streifenweise verdickt, sonst dïnn. Die Spindel ist, entsprechend der etwas anormalen Form des Gehäuses, etwas nach außen gebogen und steht ziemlich schräg zur Achse.

Fig. 16. $\quad 61 / 4-51,8 \times(26,4) 31,5-28,7 \times 15,3$.

20. Kapitän PAEssLer leg. 30. Angust 1907. San José de Guatemala. Ein Stück mit Tier in Spiritus, wovon wohl die etwas trübe Färbung des Gehäuses stammit.

Der Nucleus ist braun, die Grundfarbe gelblich, zuletzt durch Zusammenfließen der Streifen streifenweise braun. Die Streifen sind anf dem Gewinde durchaus typisch zwischen Band 2 und 3 verbreitert, dann werden sie auf der letzten Windumg schmal mit den ïblichen winkligen Vorsprüngen und teilweise rotbramer Konturierung. In den winkligen Torsprüngen sind die Bänder 2, 3, 4, besouders die beiden letzteren, schwarzbram betont, erscheinen also gegliedert. Unterhalb Band 4 tritt eine fast einfarbige bräunliche Färbung auf. Der Mundrand ist unfertig, der Callus ist purpurbraun, das Innere ist bläulich weiß mit durchscheinender Zeichmmg. Die Spindel steht ziemlich senkrecht und ist etwas gewunden.

$$
\text { Figg. 31/32. } 6{ }^{1 / 2}-60,4 \times(31,8) 40,9-35,4 \div 21,8 \text {. }
$$

Das Stück ist in der breiten Form dem in P., Taf. 16, Fig. 8, abgebildeten ähnlich. Inwieweit die var. trifructa PILSBRY bezw. O. princeps var. $\beta$ C. et F. in Frage kommen kann, wage ich nicht zu entscheiden.

Pan a má.

21. H.RoLLE vend. Etikette O.princeps var. crassiuscula CrossE, Hoje, Panamá. Drei nicht ganz ausgewachsene, durchaus typische Stïcke.' Die Bezeichnung var. crassiuscula CROSSE entspricht der var. $\beta$ C. et F. und ist daher falsch. Das größte Stïck hat folgende Maße:

$$
5^{3} / 4-42,5 \times(23,8) 29,5-24,0 \times 15,5 .
$$

\section{? Westindien.}

22. Koll. Scholvien. Etikette O. undatus BRUG., Jamaica. Ein Stück, in Form, Skulptur, Färbung und Zeichnung durchaus typisch. Die dunklen Streifen sind sehr regelmäßig und besonders breit in der Mittelpartie, auf der letzten Windung rotbram konturiert. Der imnere Mundsaum ist verhältnismäßig breit purpurbraun gesänunt und ebenso ist der Callus gefärbt. Das Innere ist weiß mit schwach durchscheinender Zeichnung, die Spindel steht ziemlich gerade zur Achse. Ton Bändern ist keine Spur vorhanden. Die beiden letzten Windungen erscheinen durch 


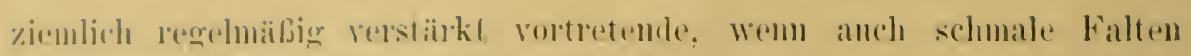
wir gerjeft. Hor Nurlens ist hamm.

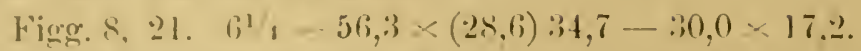

ber Fundort kimute frishlirh erscheinen. doch finder er eine gewisse Bustatiermong dureh diss folerende Stück.

2::. Frankfurtu Musemm. Tamaica, znsammen mit zwei Stïcken \%. murucuibensis, Form jumaicensis. bin totes Stïlk, durchaus typisch, nicht etwa mit Z. mondatus zu rerweeliseln.

$$
\text { Fast } 6-46,0 \cdots(25,8) 31,6-25,7 \times 16,4 \text {. }
$$

24. ex Nr.16747. Vergl. sP., 1. 17, Form. F, 'T'af. III, Fig. 6, augeblich 'Trinidad. List das gröbere der heiden 1. c. angefïhrten Stïcke, dem

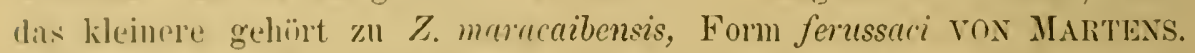
Dils stilck ist 1. ('. gut abgrebildet; es erimmert in der Zeichmung der letzten IIndung an $\%$. delphimus, hat aber eine andere Form; jene Art Zonenbildumg auf der letzten Windung ist iibrigens an sich anch nichts Außergewiohnliches. Die erste Windung ist bram abschattiert, der Mundrand ist schmal bram berandet, der (allus ist anch bram, aber zum Teil algesplitfert. Das Innere ist weif mit sehwach durchscheinender Zeichmung. Ilis stïck ist etwas küustlich aufgefrischt, daher ist die Skulptur zum 'T'ril wenigen' schurf ansgepüigt als beim typischen $Z$. princeps, aber doch noch stellenweise nachweisbar.

PILSJBR will diese Form nicht zu O. minceps gerechnet wissen, abensoweng VON MARTExs in M.?, aber mitel O. undatus finde ich sie anclı nicht anfgeführt. Die Mafe sind:

$$
6^{1 / 2}-52,1 \times(27,3) 32,8-27,5 \times ?
$$

Von Bändern ist Band 2 mm auf der 3.-4. Windung vorhanden, anf der letzten sind Band 3 mnd 4 etwas gegliedert angedentet.

Anch lierfür kamn der angegebene Fundort fraglich erscheinen.

25. Koll. Sicholvies. Ftikette der Linnaea O.-undutus, 'Trinidad. Jas Stidck ist verwittert, daher sind von der feineren Skmptur nur noch stellenweise Spirallinien zu erkennen. Die Form nähert sich mehr deul \%. delphimus, 1. h. sic ist etwas gestreckter als $Z$. princeps, aber doch ander's als $Z$. delphims m. Dils (iehäuse ist ziemlich festsclalig, die ersten

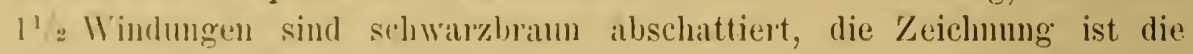
yphische des Z. mineps, und die Streifen gehen bis an die Basis. Ton don Baindern sincl nur wahe dol Miundumg Band 2 und 3 etwas unterlynchin, aher molentlich betont, Band 4 ist etwas dentlicher durchgefüht,

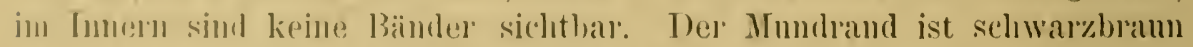
berandet, ehenso ist der callus gefarbt. Die spindel steht etwas schräg

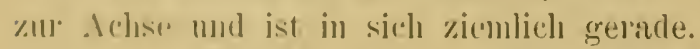

Fig. 28. $\quad\left(i^{1} / 1-53,8 \times(21 ;, 4) 32,6-28,7 \times 16,2\right.$.

26. Ich führe zum Selıluf noch ein Stïck olne Fumdort ans meiner 
ehemaligen Sammlung an, weil es fast genau zu dem in SHUTTLEWORTH Notit., Taf. III, Figg. 6, 7, abgebildeten Stïck von O. princeps paßt, das von Panamá stammen soll (p.6t). Auf der letzten Windung ist Band 2 nicht ganz, Band 3 und 4 ununterbrochen bis zur Mündung in Schwarzbrann durchgefülırt, im weißen Innern dagegen nicht sichtbar. Die Zeichnung ist auf gelblichem Grunde sehr lebhaft und dunkel, die ersten 1\%1/2 Windungen sind dunkelbraun, der Callus ist dïnn und kastanienbraun. Maße:

$$
\text { Fast } 6-46,1 \times(25,1) 30,8-25,6 \times 16,0 \text {. }
$$

\section{Z. princeps, Form trifircta PILSBRY.}

\section{P., 1. c. p. 115, Taf. 17, Figg. 10, 11.}

Ich habe schon bei mehreren Stïcken des typischen $Z$. princeps darauf hingewiesen, daß wenigstens streckenweise die Bänder 2, 3 und selbst 4 gegliedert bezw. innerhalb der winkligen Vorsprünge der Streifen stärker betont auftreten. Mir liegt kein Stück vor, das, wie die Abbildung zeigt, nur schmale Streifen und dabei von der vorletzten Windung an Band 2 und :3 regelmäßig gegliedert aufwiese, annähernd käme höchstens das sub Nr. 20 verzeichnete Stück in Betracht, das ich aber, solange nicht reicheres Material von gleicher Beschaffenheit und von demselben Fundorte vorliegt, nicht als eine abzusondernde Form auffassen möchte. PILSBRY verweist bei dieser Varietät fraglich anf 0 . princeps var. $\beta$ F. et C., von dem es heißt: „crassiuscula, brevior, sub epidermide saturate luteo-fulvescente minus conspicue strigata, peristoma magis incrassatum. Dim. $60 \times 35-$ $32 \times 20$. San Agustin (Guatemala)."

PILSBRYs Stiick stammt von San Salvador, stimmt aber weder in den Maßen noch in der Zeichnung gut mit CROssE und FrscheRs Varietät überein.

\section{Z. crossei VON MARTENS.}

Taf. II, Figg. 19, 20.

M. ${ }^{2}$, p. 1S3, Taf. 10, Fig. 7. SP., O. obductus, Form B, p. 34, Taf. III, Fig. 4 b. P., Taf. 16, Fig. 9. ? O. princeps var. $\gamma$ F. et C., p. 456 , Taf. 18 , Fig. $2 \mathrm{c}$ : minor, tenuinor, strigis magis unmerosis et gracilioribus picta. $45 \times 30-28 \times(17$ nach Abbildung). Belize, British Honduras. P., p. 116, Taf. 17, Fig. 12.

Ich habe schon in der Einleitung über diese Form eingehend berichtet, und wenn auch die Identifizielung mit F. et C. var. $\gamma$ fraglich bleibt, so handelt es sich un die Form, die VON MARTENS O. princeps var. crossei genannt haben .will.

1. Berl. Mus. Nr. 21849. Die Etikette lautet wie folgt: "O. princeps var. $\gamma$ conf. ferussaci", der letztere Name durchstrichen. Später angefügt: "zoniferus var." und mit Bleistift: „crossei". Angeblich Costarica VANPATTEN. Zwei Stücke, davon entspricht das eine ziemlich gut in Form, Färbung 
mul \% \%

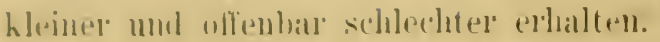

$$
\left(i^{5} 8-51.9-(26,2) 31.2-27,2<15,5 .\right.
$$

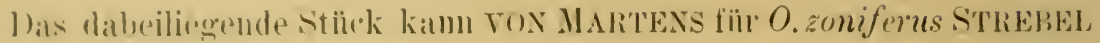

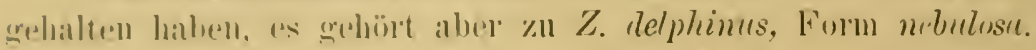

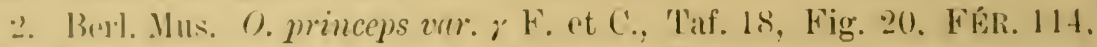

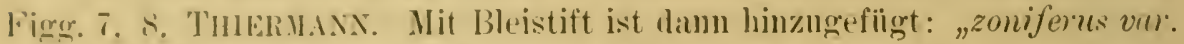
crosei." Wiederun \%wei vershiendene Stïcke, von denen das rine durehans dem sub 1 verzaichueten entspricht. Es ist noch schlechter, weil rewittert mol kilustlich anfgefrischt.

$$
6-50,2 \times(21 i, 1) 31,7-27,7 \times 11,8 \text {. }
$$

Dis zweite Stiick gehört zn Z. fischeri $=$ O. dereptor PILsBRY.

loh ueige zu del Ansicht. dafo mit den beiden vorgehend rel\%einheten Kiistehen Verwechselungen der Stiidke vorgekommen sind. dem vox MARTExs lann mmüglich in beiden Fällen zwei ganz velschedene Stücke für das-

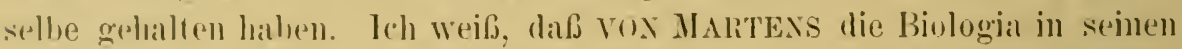
Mubestunden, Ind zwal in seinem Hanse mud nicht im Musemm, verfabt hat. Ibei dem Ilin mul Her mögen leicht Verwechselmngen rorgokommen stin, hesonder's solange das Material noch nicht in den Glaskiistchen wie jetzt, sonder'n in offenten Kiistchen lag.

:. 1)as in SP. obductus, Form B, genamute Matelial, von SARG 1874 in (oban. (illatemala, gesammelt (G. SCHNEInek, als O. ferussari rend.). bestand ans drej Stïrken, von denen nur das grofe (Taf.Jll, Fig. 4h) himher gehört. Ls ist selı gnt erhalten. offenbar frisch gesammelt, wem anch auf der Vordersteite, wie so hänfig, sich eine leichte Abrollmo der hüchsten Töllung bemerkbar macht. Das stïck entspricht aber in jeder Berielıung jenen beiden Stïcken des Berliner Mnsemus, nur ist die Fïrbung der. '\%eichmong besonders anf der ganzen Rïckseite nicht hell rotbram, sonderln graubr:an anf gelblichem Grunde, während sie in der Torderansicht anf dem etwas ahgerollten Teil mehr rothan erseheint, was also durch die Abrollung bewirkt wird. Der Nucleus ist braun abschattiert. bie streifull zoigen anf den weren Windungen vereinzelt noch eine Verhriterung, spätel sind sie aber ziemlich gleichmäbig schmal mo nur an

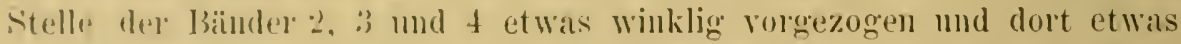
dunkler gefärbh, so dafo undeutlich gegliederte Bänder erscheinen. Hierdureh nähert sich dies stïck entschieden mehr der var. r F. et c., wem

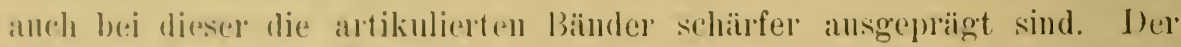

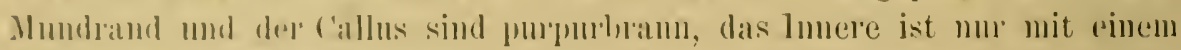

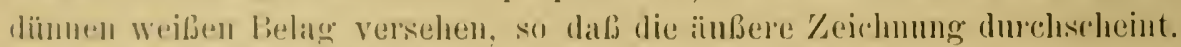

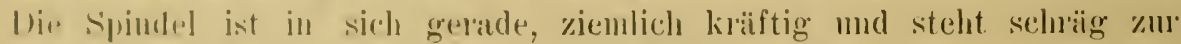
Arlace. bie skulptur ist die fïl $Z$. princeps typische.

$$
\text { Figer. 1!) } \left.20 . \quad\left(3^{3}, 4-57,9\right) \times(28,0) 35,3\right)-31,3 \times 17,8 \text {. }
$$


Wenn auch diese Form in die.Gruppe $Z$. princeps gehört, so möchte ich schon ans praktischen Gründen sie lieber wie auch die folgenden als selbständige Form gelten lassen.

\section{Z. crossei-fischeri n. sp.}

Taf. I, Fig. 4; Taf. II, Fig. 17.

Ein Stiick des Berliner Museums. Etikette princeps $\gamma$ durchstrichen und $\beta$ angefügt. FC. 18, $2 \mathrm{c}$, San Isidro, Guatemala. $2 \mathrm{c}$ ist vergessen in $2 \mathrm{~b}$ abzuändern, als VON MARTENs das var. $\gamma$ durch $\beta$ ersetzte. Es ist das Stück, anf das sich VON MARTENs in M. ${ }^{2}$, p. 183, bezieht, als er unter den Fundorten von var. fischeri auch San Isidro anfühırt.

Es ist verständlich, daß VON MARTENS dies Stïck, das übrigens schlecht erhalten ist, zn den beiden Stücken der echten var. fischeri von El Reposo reclinete, denn die letzte Windung läßt dieselben wolkigen. vorn hell berandeten Streifen und die gegliedert betonten Bänder 2, 3, 4 erkennen. Aber nun tritt an diesem Stück die Eigentümlichkeit auf, daß es bis an die letzte Windung genan die Färbung und Zeichnung der var. crossei zeigt, mit der auch Größe und Form des Gehäuses ïbereinstimmen. Nach dem schon in SP. von mir verfolgten Prinzip, solchen Stiicken den Namen der Arten zu geben, die in ihnen zugleich vertreten sind, habe ich auch hier den Namen gewählt. Ich halte das deshalb für richtig, weil aller Wahrscheinlichkeit nach bei größerem Material sich solche Übergänge vorfinden werden, und weil auch vielleicht tatsächlich eine Bastardbildung vorliegt.

Fig. 17. $\quad 6^{1 / 4}-51,2 \times(25,9) 31,3-27,1 \times 16,4$.

\section{Z. fischeri VON MARTENS.}

Taf. I, Fig. 12; Taf. II, Figg. 18, 22/24, 29/30; Taf. III, Figg. 33/34, 37.

MI. $^{2}$, p. 180, 183. Beschreibung und Referenz FC., var. $\beta$, Taf. 18, Fig. 2 b. Guatemala. El Reposo und Sau Isidro near IIazatenango (Champion). Die Bezugnahme auf Taf. X, Fig. 7, ist falsch.

P., p. 116, var. deceptor PILSBRy, Taf. 24, Figg. 19-24 (nicht Fig. 25). Fig. 20 ist wohl eine albine Form.

SP., p. 34, O. obductus, Form C, Taf. III, Fig. 7 c. PILSBRY zieht mit Unrecht Form A, 4, und Form B hinzu. Erstere scheint mir der Abbildung nach (das Originalstück kamn ich leider nicht erhalten) wirklich zu $Z$. obductus zu gehören, letztere ist var. crossei VON MARTENS (vergl. weiter oben).

O. ferussaci von -Mantens. M. ${ }^{2}$, p. 184, Taf. X, Fig. S. P., p. 119, Taf. 17, Fig. 17 (schlecht kopiert).

O. isabellina von Martens. II. ${ }^{1}$, p. 190, Taf. I, Fig. S. P., p. 142, Taf. 31, Fig. 66.

1. ex Koll. ScHolvIEN, ein Stïck leider ohne Etikette bezw. Fundort. Es ist, wenn auch kleiner, doch sehr gut zu P., Fig. 27, stimmend, 


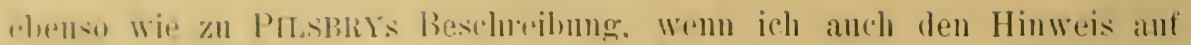

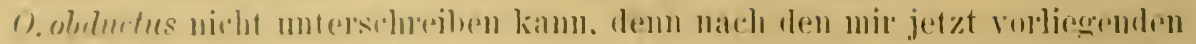

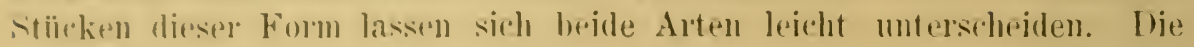
skulpur ist scharf asurepüigt die des Z. minceps, an den vorliegenden

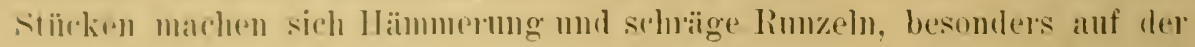
lefoten Windmo viellejeht otwas mehr bemerkbar. Die erste Windmog isl kastanienbram absehattiert, die Grundfarbe ist oben hornfarbigr, damn etwats weibliches. damm zmmehmend hell gelbbram. Die Streifen sind dmkelluran woblich bulegt, elscheinen daher granbraun; sie sind in der Ilifelpartie zum 'Teil verbreitert und an Stelle der Bänder winkelig vorgezogen und nach rorn melı weißlich berandet; sie setzten sich nicht ïber Band 4 fort. so dab die \%one un den Nabel ziemlich einfarbig ist. Vun der 3. Windung an tritt Band 2 zuerst gesclolossen, dam mimterbrochen. d. l. in den winkligen Vorsprüngen dumkelbraun betont, auf, das gleiche gilt vou Band :3. Band 4 ist wie mmer weniger stark ansgepraigt umd melı ans dmkler'n und letleren Winkeln zusammengeset\%t, nur nahe

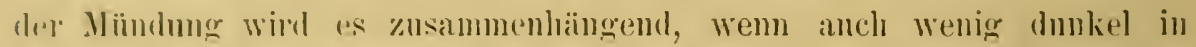
Fanbe. Anf der letzten Irindung ist Band 2 ganz verschwunden. mur

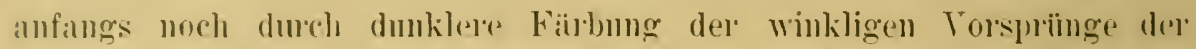
Streifen angedentet. Der Mundrand ist sclumal berandet mol wie der ('allus purpublam. Das Immere ist weiblich, etwas violett angehancht. mit schwach durchseheinender Zeichnung. Die Spindel ist ziemlich dium mul stelit etwas schüag zmr Achse.

Fig. :30. Fast $\left(3^{3} / 4-59,3 \times(29,2) 37, ;\right)-31,4 \times 19,0$.

2. Berl. Musem. El Reposo, Guatemala (Champion). \%wei Stïclie, wis sie den Maßen nach in M. ${ }^{2}$, p. 180, unter var. fischeri anfgeführt sind. Die Stiicke muterscheiden sich ron dem voraufgehenden mur dadurch, daß die streifen vorn meln gelblich als weißlich berandet sind, mo daß die Biinder erst auf der vorletyten und letzten Windung, wenn anch in dersolben oben angedenteten Weise, doch weit weniger stark betont anftroten. Bei dem Stiick Fig. 2:3 sind im Immern die Bänder dentlich erkrmular, wie es ja anch bei den Abbildmgen in P. zum 'Teil der Fall ist. An briden Stiblen ist die spindel kräftiger ansgebildet, wie es ebenfalls hei PHasloris Furm der Fall ist.

Figg. Is, 2.2. $\quad(11 / 2-57,8 \times(29,8) 37,0-31,4 \times 18,8$.

Fig. 23. $\quad\left(i^{1} / 2-60,0-(30,5) 37,8-32,6 \times 18,7\right.$.

3. Burl. Mnsemm. Ein Stück ex Koll. 'THERuAN zusammen mit

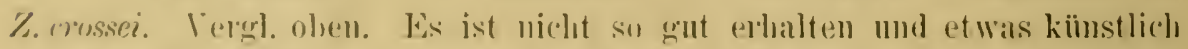

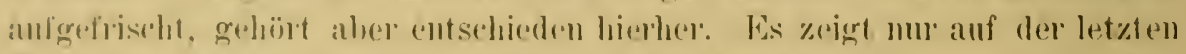
I'indung alie gregliederten, stailker betonten Bïnder in der etwas verWascluentru \%eirlummg.

$$
\text { ii } \quad \text { i) } 1,2 \cdots(26,1 ;): 3,2,5-28,0 \times 16,7 .
$$


4. Berl. Museum. O. ferussaci von Martens. Zacapa, Guatemala, StolL, Biol., Taf. 10, Figg. 8, 10. Die letztere Figur ist Kopie einer Skizze des lebenden Tieres nach STOLL.

Es ist ganz unverkennbar ein unausgewachsenes Stïck des Z. fischeri. Die 1. c. Abbildung läßt nicht die stark unterbrochenen Bänder (besonders Band 3) erkennen. Band 2 ist auf der 3. und 4. Windung schon gegliedert vorhanden, dann versclıwindet es auf der letzten Windung. Sonst verhält sich das Stïck ganz typisch.

Figg. 24, 29. $5 \%$ - 43,0 $\times(24,6) 30,1-24,6 \times 15,1$.

5. Berl. Museum. Ein Stiick in Farblolz von Per'nambuco. ED. MüLLER. Die Etikette gibt den Nameu 0 . obductus SHUTTLEW., aber es liegt ein kleiner Zettel mit VON MARTENS' Handschrift dabei: „princeps var. $\beta$ F. et C."

Ton diesem Stïck gilt das gleiche, was bei dem vorangehenden gesagt ist. Die hellen Säume der Streifen treten weniger deutlich hervor, wie es stellenweise auch bei den sub 2. verzeichneten Stücken der Fall ist.

Fig. 12. Fast $6-45,8 \times(25,3) 31,2-25,8 \times 16,0$.

Die beiden sub 4. und 5. verzeichneten Stïcke sind nicht von PILSBRYs Abbildung von O.ferussaci, Taf. 17, Figg. 14, 15, zu unterscheiden.

6. Berl. Museum. Nr. 8876. O. isabellina von Martens. Peru. Mus. Neuchatel. VON TschUdI.

Zwei unausgewachsene Stïcke, die zweifellos hierher gehören. Das eine Stïck, Figg. 33/34 a, hat merkwürdigerweise einen farblosen Nucleus, das andere nicht, und Band 2 und 3 treten erst anf der 4. Windung gegliedert anf. Ton dem anderen Stïck, Fig. 37, gebe ich nur die Torderansicht, weil bei ihm Band 2, 3, 4 (erstere beiden von der 3. Windung an) hier fast unuterbrochen auftreten, in der Vorderansicht werden damn die wolkige Zeichnung und die Bänder durchans typisch. Das einzige, worin diese beiden Stïcke von den anderen abzuweichen scheinen, ist, daf das Gewinde etwas konischer von der unteren Hälfte des Gehäuses absetzt. Während das Stück Fig.37 mit dem farbigen Nucleus auch dementsprechend braunen Mundrand und Callus hat, sind diese Partien bei dem Stiick Figg. 33/34, dem farblosen Nuclens entsprechend, auch nicht gefärbt. Das unansgewachsene Stadium dieser beiden Stïcke erlaubt indes, keine verallgemeinernde Folgerungen ans diesen Abweichungen zu ziehen. Die Skulptur ist die typische.

Figg. 33/34. $\quad 5 \%$ - 37, $1 \times(20,8) 25,6-21,8 \times 13,3$.

Fig. 37. $\quad 5 \% \frac{5}{5}-36,5 \times(20,5) 25,4-21,0 \times 13,4$.

Die Abbildung in M. ${ }^{1}$, Taf. 1, Fig. 8, ist nicht gerade sehr charakteristisch und in der Kopie in P., Taf. 31, Fig. 66, nocl weniger. 


\section{\%. muremliferus 11 . st.}

'T’af, Ill, Firg. 38.

J1. ${ }^{2}$, Taf. 10, Fig. 6. Im 'Text wirl thas Stiick nicht erwähut, in der Tafelerklärmug steht nur: (). mincrps smaller specimen with reduced streaks, costarica."

Es ist rin merkwindiges stïck, das in seiner Form und in der, hesonders

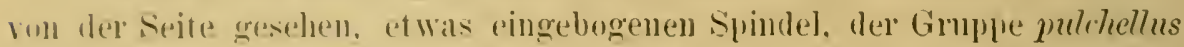
slox male komm1. Es ist aber hornfarbig mit mgefälotem Wirbel, wird

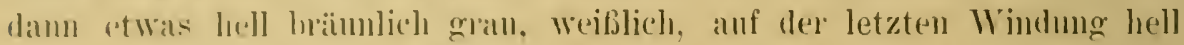

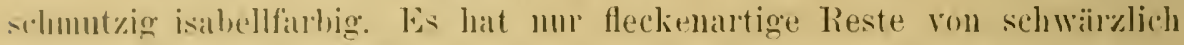
liramen streifen, zumeist dolt. Wo sonst die streifen winklig vorsuningen.

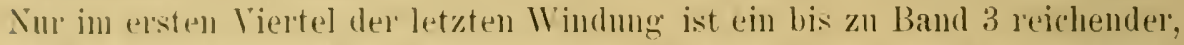
nall vol'n zackiger streifen vorhanden. Aubertem sind auf der vorletzten

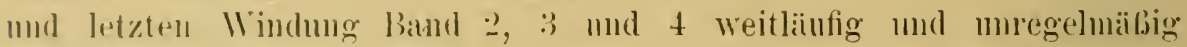
aregliedert angerlantet, Woron anf dem letzten Drittel der letzten Windumg anben mur seln mudentliche Reste sichthar sind, die sich aber in der Durchsicht dentlicher erkemen lassen. Fs sind hier anch Spmen zu erkemnen, dab die dunklen Flecke der Bänder bezw, die dumklere Betonung derselben in den winkligen Vorsprüngen der Streifen nach rom hell betandet sind. I ats lnnere ist hell schmutzig violett angehancht, der Mundrand ist nicht gefärl,t, anch del Callus nicht. Die weibe Spindel steht wenig schräg zur Aclsse, sie ist, ron del Seite gesehen, etwas eingebogen, sogar in der llitte schwach eingeknickt. Unten ist der Callus etwas plattenartig anfgrelegrt, fast, als ol ein Nabelspalt vorhanden wïre. Die skulptur ist die typische der Z. minceps-Gimple.

Fig. 38. $\quad 5^{3 / 4}-38,7-(21,1) 25,5-22,0 \times 13,3$.

J) Abbildum der Vorderseite in M. ${ }^{2}$ l. c. ist recht gut bis auf die Spindel, an der die mutere Partie des Callus sowic die Einknickung sehr iibertiehen sind. Jeh habe zur Abloildung die Rïckseite gewällt und danchen die sindelpartie noch eimmal wiederorgeben.

Sieht man genau zu, so lïbt sich in Fäibung und Zeichmmg der 'Typus von Z. fischeri erkemen, aber die Form des Gohäuses mo drer spindel weichen ab. Da ein Fundort gegeben ist, so gehe ich dieser Furm lieber eincn Namen, es mag sich später bei weiterer Durehforselımg des febietes ergeben, ol, es sich wilklich mu eine selbstindige Form oder 1111 แn eine abmorme Ansbildung handelt.

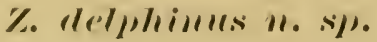

biese Form muterseheidet sich ron $Z$. minerps num durch die

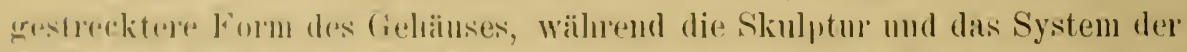

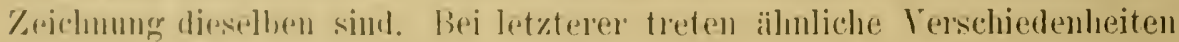
auf wie bei $\%$. princeps, und anch die Bänder sind zuweilen mu duch winklige 
Vorsprünge der Streifen vertreten oder sie sind streckenweise durchgeführt oder gegliedert, aber immer nur sehr undentlich. Die Grundfarbe wird anclı nach den unteren Windungen zu gelblicher, der Nuclens ist meist farblos, aber individuell auch mal hellbraum. Der Mundrand ist schmal dunkelbraun besäumt und ebenso ist der Callus gefärbt. Die Spindel steht etwas schräg zur Achse und ist mehr weniger kräftig, meistens ein wenig, aber bei einzelnen Formen auch kräftiger gewunden. Diese Form gliedert sich einerseits innerhalb ein und desselben Fundortes in verschiedene Unterformen, die ich neben der typischen Form mit heterom. melanochilus und pumilio bezeichne. Dann treten, soweit mir sichere Fundorte vorliegen, je nach dem Fundort zwei verschiedene Typen auf, die ich mit Unterformı nebulosus und vividus bezeichne. Wo keine oder nux unsichere Fundorte vorliegen, werde ich die Stücke in die gut begriundeten Gruppen eimreihen.

\section{Z. aelphinus, Form nebulosus $\% . f$.}

Taf. III, Figg. 35/36, 39/41, 47, 49/50.

SP., p. 16, O. princeps, Form E, partim.

Diese Form zeichnet sich durch einen stärkeren Belag der schwarzbrammen Streifen mit Weiß aus, so daß die Zeichnmng etwas verschwommen wirkt.

1. Kapt. RINGE leg. Mazatlan. Nr. 14044. Sechs ansgewachsene und viele kleine Stücke, unter letzteren befindet sich nur ein Stïck mit bräunlichem Nucleus, sonst ist der Nucleus farblos. Unter den ausgewachsenen rechne ich drei zur heterom. pumilio und ein zu leterom. melanochitus.

$$
\begin{aligned}
\text { Fig. } 35 . & 61 / 4-49,9 \times(24,9) 29,2-25,9 \times 14,8 . \\
" \quad 36 . & 6^{3} / 8-54,4 \times(25,2) 30,9-27,7 \times 15,4 .
\end{aligned}
$$

2. ex Koll. Scholvies. Mazatlan. Acht zum Teil verwitterte Stücke, von denen drei einen lıellbraunen Nucleus haben. Ich wähle zwei der Stïcke ihrer besonderen Zeichnung halber zur Abbildung ans.

$$
\begin{array}{cl}
\text { Fig. 39. } & 6^{3 / 8}-50,5 \times(24,4) 31,2-26,1 \times 15,6 . \\
\Rightarrow \quad 40 . & 6-44,9 \times(22,6) 28,0-24,6 \times 13,4 . \\
& 6^{1} / 4-48,2 \times(24,6) 29,8-25,5 \times 14,9 . \\
& 5^{7} / 8-39,2 \times(19,3) 24,0-20,5 \times 11,2 .
\end{array}
$$

3. RoLLE vend. als princeps var. crassiuscula. Colima. Durchaus typisch mit farblosem Wirbel.

Fig. 41. $\quad 6 \% \frac{8}{3}-52,7 \times(25,3) 30,8-26,7 \times 15,2$.

4. SP., p. 16, O.princeps, Form E, 1, partim. WESSEL vend., ohme Fundort. Zwei Stiicke, davon eins mit hellbraunem Nucleus.

$$
6^{3} / \mathrm{s}-51,4 \times(24,7) 31,0-25,5 \times 14,8 .
$$

5. Nr. 15706 aus meiner ehemaligen Sammlung. Etikette Bul. undatus. 


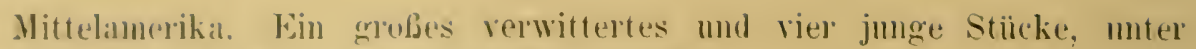
letztren

$$
\left(i^{3} \times-51,9 \times(\because 4,9) 30,3-27,0 \div 1 ;, 0 .\right.
$$

1. ex kivll. somst. Etikette O. bensoni. Anazonenstrom. Ein stinck mit firblusinm Nuclens.

Fig. 47. Fast $1 i^{3} / 4-58,2 \times(27,3) 33,4-28,8 \times 17,0$.

7. ex loll.sonst. Win stïck olne Etikette, der Wirbel ist ansgebrochen.

$$
6^{12}=52,3-(25,0) 31,0-27,2-15,3.3 .
$$

8. ax Koll.schobrax. Olme Etikette. Eim Stïck mit farb]osem Wirbel.

$$
\left(3^{1 / 8}-18,2 \times(2: i, 9) 30,1-25,2 \times 15,1\right. \text {. }
$$

9. ex No.15010. Luter dem in Veracrus am Strande gefundenen Matcrial befinden sich zwei Stïcke, mansgewachsen, die hierler grehören. Wirlel farblos.

$$
5^{5} \times-38,5<(19,8) 2: 3,9-20,5-11,5 .
$$

10. Berl. Mnsenm, ex Nr.2184!), zusammen mit Z. crussei VON MAI'TES. ('ustaricar. VAI PATTEX. Nucleus farblos.

$$
\left(i^{3} / 8-50,7<(23,6) \geq 8,3-25,5 \times 14,3 .\right.
$$

11. Rolie vend. mit falscher Ftikette zoniferus STREbEL. Misantla.

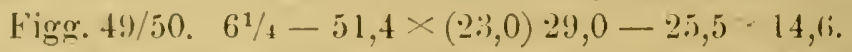

J)as Stïck ist fast identisch mit dem vorangelenden des Berl. Museums. Wie ans der Abbildung resiclatlich ist, hört mit der vorletyten Windumg die V'erlneiterung der Streifen anf, sie werden schmal und zeigen nur an Stelle der Bänder 2 mnd :3 winklige Vorsprimge. Anf dem letzten Drittel dere letzten Windung velschwinden die Streifen fast ganz, und anfer drei dunkelbramen Varices sind nur ganz selıwache Andentungen von Band 2, 2,4 rorhanden. Bei dem Berliner Stiick setat sich die Verheiterung der streifen nocls etwas ibler die rorletate Windung fort, und dic Bänder : mod :3 sind durch eine leichte dunklere Betonmg innerhalb der winkligen Vol'snoünge ctwas dentlicher markiert; dam tritt anf dem letzten Viertel

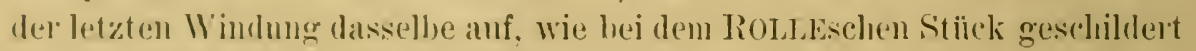
wmole. Mir scheinen beide stïcke, die etwas abweichend rom normalen 'Typus der Form nebulosus sind, von dem gleidhen Fumdort zu stammen; welcher Fundort das ist, muß dahingestellt bleihen, dem die RoLbesche Ertikette ist falsch, und bei dem Berdiner Stïck kömnte anch eine Verweelshlung der Kästen vorliegen, dem die Etikette palst zu dem dabeiliegrenden Stück $/ 2$. crossei und nicht zu diesom.

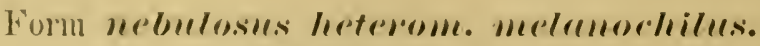

'Tif. 111, lig. 45.

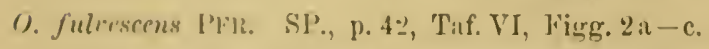

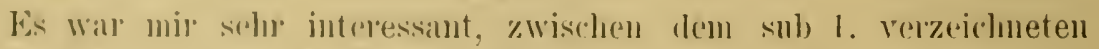
Mazatlan-Material zwei stiucke zn finden, die sich durchans mit dem l. c. 
beschriebenen und abgebildeten $O$. fulvescens, für den PFEIFFER keinen Fundort kannte, decken. Es ist dieselbe gestreckte Form wie die mit Zeichnung versehenen Stïcke, und auch an diesem Stück ist wie bei O. fulvescens das Band 3 durch einen helleren Streifen angedeutet.

1. Nr. 14044. Kapt. RINGE leg. Mazatlan. Ein Stiick.

Fig. 45. $\quad 6^{1} / 4-50,9 \times(24,6) 30,5-26,8 \times 14,8$.

2. ex Koll. SoHST. Mazatlan. Ein Stück.

$$
6^{5} / 8-55,6 \times(26,3) 33,1-29,4 \times 16,0 .
$$

3. Dazu gesellt sich der PfeIFfersche Typus, SP., p. 42, T'af. VI, Fig. 2 b. Maße:

$$
6^{3 / 8}-51,1 \times(24,1) 29,7-25,3 \times 14,2 .
$$

4. ex Koll. Scholvien. Etikette der „Linnaea“. O. undatus var., Magdalenenstrom. (Sehr unsicher.) Ein Stïck, genan wie das sub 1. verzeichnete.

$$
61 / 8-47,4 \times(22,9) 28,0-25,4 \times 13,9 .
$$

5. SP., p. 42. Wessel vend. von Rio hacha. Zwei Stiicke. Yergl. das darïber l. c. Gesagte.

$$
\begin{gathered}
6-42,2 \times(20,0) 24,5-22,0 \times 12,5 . \\
5^{3 / 8}-30,6 \times(17,0) 20,6-17,5 \times 10,6 .
\end{gathered}
$$

Es läßt sich bei diesem etwas unsicheren Fundort nicht sagen, ob es die melanochilus-Form von dieser Form nebulosus oder von der Form vividus ist.

\section{Form nebulosus, heterom pumitio n. $f$.}

Taf. III, Figg. 43/44, 46, 48; Taf. IT, Fig. 51.

Wie ich schon weiter oben anfülurte, sind zusammen mit der typischen Form 1. von Mazatlan drei Stücke einer kleineren Form gefunden, von denen sich nicht mit Bestimmtheit sagen läßt, ob sie eine individnelle Abweichung sind, die zusammen mit der größeren Form vorkommen, oder ob sie etwa für sich an einem anderen Platz bei Mazatlan gefunden sind, so daß es besser ist, sie vorläufig abzusondern. Die Spindel ist durchweg gewundener. Da noch ähnliche Stiicke von anderer Herkunft vorliegen, so werde icl sie hier anreihen.

1. Nr. 14044. Kapt. RINGE. Mazatlan. Drei Stücke.

Fig. 48. $\quad 6^{1 / 4}-46,1 \times(22,3) 27,1-23,0 \times 12,8$.

$$
\text { " 46. } 6^{1 / 2}-45,6 \times(21,8) 26,2-23,5 \times 13,3 \text {. }
$$

$$
6^{1 / 4}-44,6 \times(22,0) 27,1-23,3 \times 13,0 .
$$

2. Vier Stiicke, die zusammen mit dem bei der typischen sub 4 . verzeichneten Form lagen.

Fig. 44. $\quad 6^{1 / 4}-43,6 \times(21,0) 26,6-22,0 \times 13,0$.

" 43. $6-39,6 \times(19,3) 24,0-20,8 \times 11,6$. 


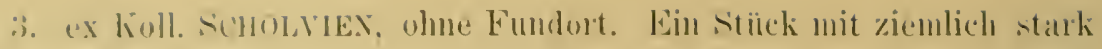
gewmintencr spindel.

$$
\left(i^{1} 1-15,4<(21.5) 25,8-2.2,3 \times 12,3 .\right.
$$

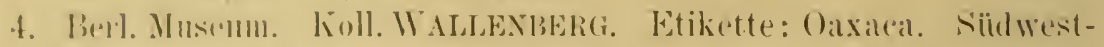

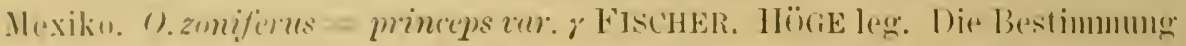

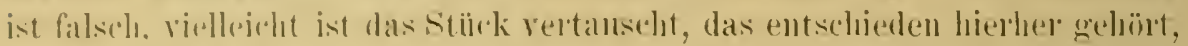
Wenu anch die Streifen Wentger stak mit Weip helengt sind. Anch dies Stïrk hat eine ziomlich stark gewmome spindel.

$$
\text { Fig. 51. } \quad 6-39,9 \times(19,1) 23,1-20,4=11,1 .
$$

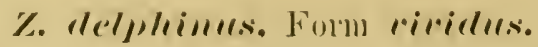

'T'al. 111, Fig..4:; 'T'af. 11, Figer. 52/53, 55/57, 5!!.

Diese form molerschejdet sich von der mit Form nebulusus bezedmeten

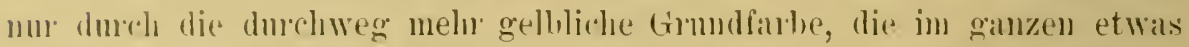

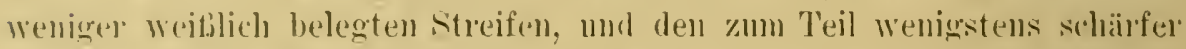
zonturtig abgegrenzten 'Teil der verbreiterten Streifen, die sich zwischen der stelle ron Band 2 und 3 befinden. Die dunkelbrammen Streifen sind schmal rötlich konturiert. Band 3 ist auf der letzten Windmng zum Teil dureh stärere Brtommg immerlıalb der winkligen Vorsurïnge der Streifen markiert, Band 4 ist elendaselbst, wie iiblich, dureh etwas dmnkler mud laeller abwechselnde winklige Figmen gehildet. T)er Wirbel ist hram oder farblos. Dia Sindel steht sehriig zm Achse mol ist in sich fast gerade.

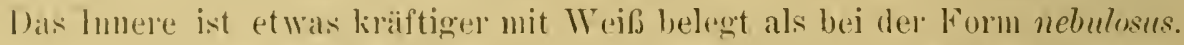

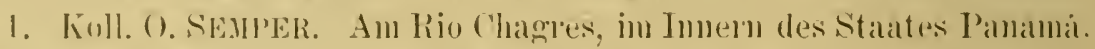

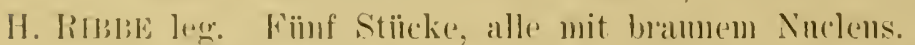

$$
\begin{aligned}
& \text { Figre. 5i5.5. }\left(i^{1 / 1}-52,5 \quad(25,0) 31,3-28,6 \cdot 16,4\right. \text {. } \\
& 61 / 4-52,7 \times(26,2) 32,1-28,2 \times 16,5 .
\end{aligned}
$$

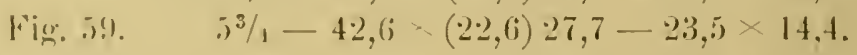

$$
\begin{aligned}
& \text {, 万人. } 51 / 2-37,9 \times(21,6) 26,3-22,2=13,9 \text {. }
\end{aligned}
$$

?. Ni. is18. Wadals leg. Nell-Gramada. Fin Stüek mit hammem Nuclons. Die Zomenbildmer tritt hiel nicht so dentlich lervor wie hei

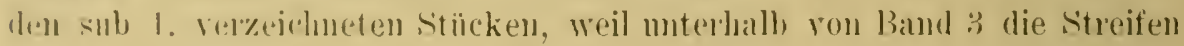

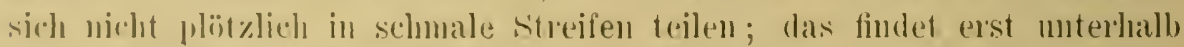
Band \& statt. Nahe ler Mïndmog hören die Streifen gan\% anf, mod hier

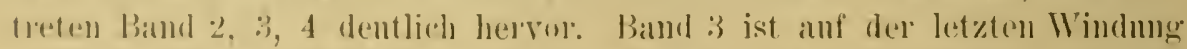
ande gregliedert mal stäliel botont. Die spondel ist besonders in der

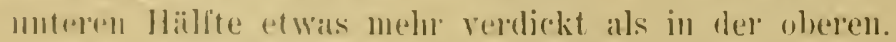

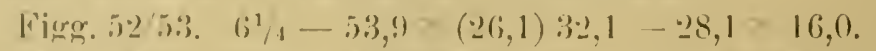

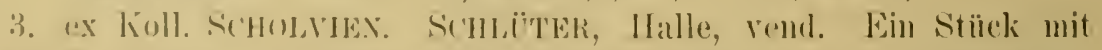

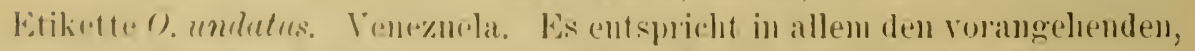
besonders in der Vorderinsicht, nur sind die streifen in der Mittelpartie 
noch breiter und ziehen sich, wie bei dem vorangehenden Stiick, tiefer nach unten, so daß auch in der Rückenansicht die dentliche Zonenbildung: fehlt. Auch bei diesem Stück sind nahe der Miundung, wo die Streifen schwächer werden, Band 3 und 4 schwach ausgeprägt. Die Spindel ist normal, der Nucleus selbst ist ausgebrochen, so daß man nicht bestimnt sagen kann, ob er gefärbt ist oder nicht, doch scheint eher das letztere der Fall zu sein.

Reichlich $6-50,8 \times(24,9) 30,5-26,3 \times 14,6$.

4. Aus meiner ehemaligen Sammlung, WEssEL vend., Etikette O. bensoni, REevE. Amazonenstrom. Ein Stïck, vergl. SP., p.16, O. princeps, Form E, Taf. III, Fig. 5, das ich hier' noclımals abbilde, weil es in del' photographischen Wiedergabe in der Form verzeichnet und in der Zeichnung unklar erscheint. Ni. 15708.

Fig. 42. $\quad 6^{3} / 8-51,4 \times(24,4) 30,1-25,2 \times 15,9$.

Als fraglich, ob sie zu dieser oder zur Form nebulosus gehören, verzeichne ich folgende Stücke, die sämtlich einen farblosen Nucleus, eine ziemlich lebhafte Färbung der Zeichnung und die Zonenbildung zeigen. Die Form ist dieselbe schlanke, aber keins der Stücke ist ausgewachsen. Die Spindel ist bei allen schon etwas gewunden.

1. ex Koll. SchoLviEx. Drei Stücke olne Fundort, das größte hat folgende Maße:

$$
55 / 8-39,0(19,7) 24,3-21,6 \times 11,8 .
$$

2. UnLAUFF ded. Zusammen mit den vielen schon in der Einleitung erwähnten Arten von Trinidad, unter denen $Z$. zoniferus, Form nccesiotes, am stärksten vertreten war. Ein junges, durchaus typisches Stïck, das vielleicht zu der Unterform pumilio gehören kann.

$$
5^{1 / 2}-33,6 \times(17,5) 21,0-18,3 \times 10,3 .
$$

3. $\mathrm{Nr} .5687$. Ein altes Stiick unserer Sammlung, bei dem zwei Etiketten liegen, eine in einer unbekannten Originalhandschrift, $B$. undatus LA.r., St. Domingo, die andere, von Musemmsbeamten geschriebene, $B$. undatus BRUG., Mexiko.

$$
5^{3} / 4-38,9 \times(20,4) 25,0-21,3 \times 12,5 .
$$

\section{Z. alphinus, Form intermedius $u . f$.}

Taf. XYI, Fig. 254/255.

Berl. Museum. In einer Schachtel liegen zwei Stiicke mit zwei Zetteln, von denen der eine, zoniferus var. crossei, von VON MARTENS' Handschrift, der andere, O. undatus BRUG., angeblich Costarica, Nr. 21848, VAN PATTEN angibt. Das eine Stïck ist ein typischer $Z$. maracaibensis var. jamaicensis 


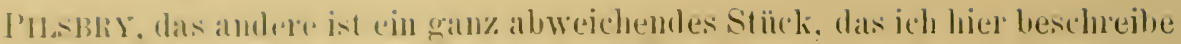
mul neu benemes. bride Zettel sind rerkehrt.

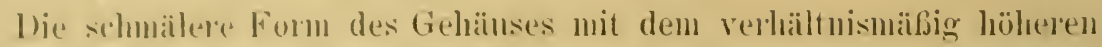

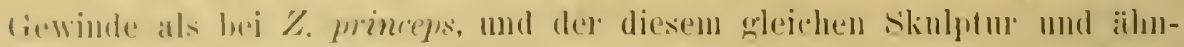

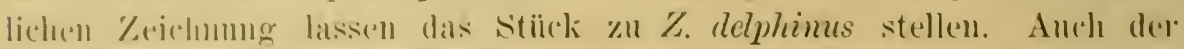

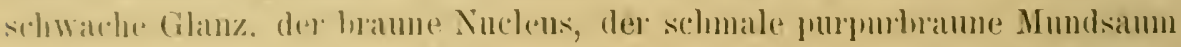
mod dor chenso gefähte ('allus, sowie die ziemlich semblechte spindel stimmen mit $Z$, defplimas iiberein. Alweichend sind 1, die bedentendere Grißße. 2. die Weibliche Grundfarbe, 3. die nicht so starke Verbreiterung der streifen zwischen band 2 nnd 3, die aber ebenfalls nach oben nud unten gegaluelt sind; nalse der Mindung werden sie aber ebenfalls

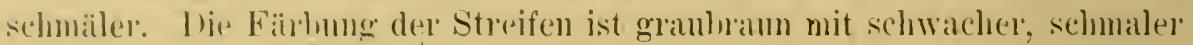
linturermog in Rothram. Ahweidend ist ferner. von del volletzten Windmog heginnend, ein etwas stärkeres Betonen der Bänder 2, :3, 4, besonders :3 und 4 , immerhalb der winkligen Vorspninge der Streifen, Band 4 ist sugar auf dem letzten Drittel der letzten Windung anfier der Betommg noch in graubruner Färbung dureligefüht. In dem weißlichen, glänzenden Innern markicren sich die. Tarixstreifen und besonders die Bänder : mul $_{4}$ in lebhaft kastanienhramer Färbmg, die wie anßen stäkere Betommg an den liveuzungstellen der Streifen zeigen. Es mag sein, daf die Abweichmng in dem Erscheinen der Streifen anch im Innern, an dem etwas dünnschaligeren Gehäuse liegt.

$$
6{ }^{1} / 2-59,8 \times(27,3) 32,7-29,9 \times 16,7 .
$$

()h mit diesen bejelen Stiicken ene Verwechshmg vorgekommen ist, muf irh dahingestelt sein lassen. Wenn für die hier beschichene form der Fundort ('ostallical verstindlich ist, so ist dies weniger der Fall bei dem Z. marucuibensis var. jumaicensis. Beile Stïcke sind frisch und gut erhalterl.

\section{2. virllaredsomi H. sh).}

'T'af. IT, Figg. 60/6:2.

(iehïnse ziomliole festschalig, oval-konisch, mattolämzend, mit 5 bis

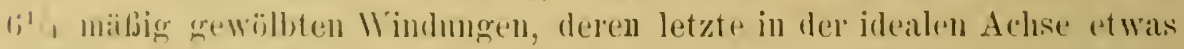

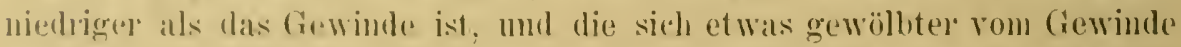

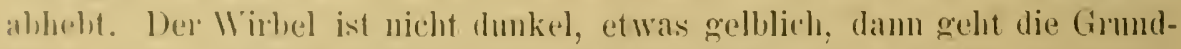

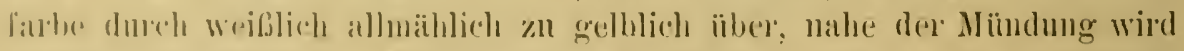
sio fast orangefolbig. Die \%eichmung besteht ans anfangs bramen, mehr mu mehr mit Weifs belegtan und dahes nebelatigen Streifen, gan\% ähnlich wir bri Z. defllimus, Form nebulosus, aber es fehlt hier die ans breiten

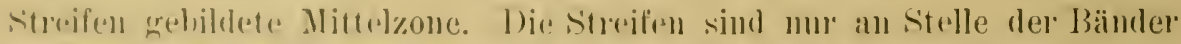
umregeluablig wellig rorgezogen, unterhalb der stelle ron Band 4 bleibt 
eine einfarbige Zone. Der Mundrand ist schmal purpurbram berandet, mnd der scharf abgegrenzte Callus hat dieselbe Farbe. Das Innere ist bei zwei Stïcken weiß, mit schwach durchscheinender Zeichnung, bei einem mit dentlicher durchscheinender Zeichnung. Es ist nur ein rückständiger Varixstreifen vorhanden. Die Skulptur ist die typische des $Z$. princeps.

Fig. 60.

$$
6^{1 / 4}-44,1 \times(21,7) 26,8-23,2 \times 12,2 .
$$

$$
\begin{array}{lrr}
" 61 . & \text { Reichlich } 6-47,0 \times(23,3) 27,6-25,3 \times 13,4 . \\
& 62 . & 63
\end{array}
$$

Das letzte Stück hat ein etwas höheres Gewinde, und die letzte Windung setzt sich weniger gewölbt vom Gewinde ab, es nähert sich daher in der Form mehr dem Z. delphinus, Form nebulosus, heterom. pumilio, der aber in der Zeichnnmg und der etwas gewundenen Spindel abweicht.

Die Stücke gehören dem Berliner Musenm und lagen bei einem als 0 . ponderosus bestimmten Stück. Fundort Tepic, N.-IV.-Mexiko. IV. RICHARDSON.

\section{Z. selectus $n . .81$.}

Taf. IV, Figg. 54, 58, 63.

Das Gehänse ist ziemlich festschalig, im ganzen weniger oval konisch als $Z$. delphinus, das Gewinde ist etwas niedriger, und die letzte Windung verbreitert sich etwas mehr. Die Skulptur ist die typische. Die Grundfarbe ist anch nach unten zumehmend gelblich. Die Zeichnung hat Ähnlichkeit mit der von $Z$. crossei insofern, als auf der letzten Windung nur anfangs noch eine Terbreiterung der Streifen zwischen Band 2 nnd 3 stattfindet, dann werden die Streifen gleichmäßig schmal und nur an Stelle der Bänder 2, 3, 4 winklig vorspringend. Anfangs findet auch noch eine etwas stärkere Betonung der Bänder 2, 3, 4 statt, später nicht mehr. Der Nucleus ist farblos, der Mundrand und der Callus sind auch vollständig ungefärbt. Das Innere ist weißlich belegt, nahe dem Mundrande etwas verdickt und leicht schmutzig rosa angehancht, sonst scheint die Zeichnung durch. Die Spindel ist weiß, wenig stark und etwas eingebogen; sie steht etwas schräg zur Achse.

1. Ein Stiick ans dem Berliner Museum, Nr. 25568, mit Etikette des Malak. Tauschvereins. O. undatus BRUG. Trinidad. Ein Zettel von VON MARTENs' Handschrift besagt: ,princeps rar. $\gamma$ F. et C. Taf. 18, Fig. 2 c." Es ist aber weder diese Varietät noch etwa $Z$. crossei von MarTEns, die in jeder Beziehung abweichen.

Figg. 54, 58. $\quad 61 / 8-50,5 \times(25,1) 32,3-28,2 \times 17,0$.

2. Nr. 15916. Vergl. SP., p. 34. O. obductus, Form B, Taf. III, Fig. 4 a (exkl. 4 b). Coban, Guatemali. SARG leg., zusammen mit Z.crossei 3. 


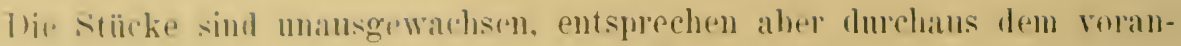
ureliendert.

$$
\begin{array}{r}
\text { Fin. 6.3. Filst } 53 / 4-38,7 \times(20.4) 25,0-21,5 \times 12,8 . \\
51 / 4-26,6 \times(15,5) 18,7-16,1-9,6 .
\end{array}
$$

Z. "le!

Taf. IV. Figg. 64/67.

Narhichtshl. 1895, Tol. 27, p. 131.

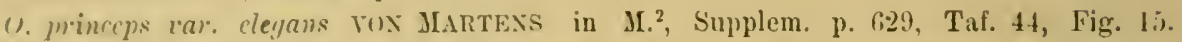
I', XII, p. 117; XIIV, p. 164; Taf. 24, Fig. 12. ?P., p.117, minceps rar. deceptor, Form perlonya, Taf. ¿4, Fig. 25.

RoI.LEs kurze, noch dazu nicht ganz zutreffende Notiz uiber diese nen ron ilum anfgestelle Art wird von vos MArTess anch nicht weiter "roïn\%, als dafs ale eine ,only attenuated rariety of $O$. minceps" nennt. l'h halte sie höchstens meinem $Z$. delphinus näherstehend, aber doch für vine gute Art. die ich daher neu beschreibe.

(łehänse festschalig, hreit spindelförmig, mit kiurzerer letzter Windung, als das Gewinde ist. Die 61,2-7 Windungen sind etwas schrig anfoerollt, mitchmäßig gewiilbt, mnd die letzte ist bei dem gröbten Stiick stmmpf, hei den minder großen zunehmend dentlicher in der Mittellı̈he gekielt. Fs ist matt glämzend, dentlich fein gestreift, an der Naht etwas schürfer fuin gefaltet, sonst mit der typischen feineren Spiralskulptur ron Z.princeps. 1) Wirhel ist fallos; auf die hornfarbigen ersten $2 \frac{1}{2}$ Windungen folgt cine weißliche Grmafarhe, die dam nach den untersten Windungen mehr grelblich wird. Die dunkelbramen, etwas weißlich belegten Streifen fließen ähnlich wie bei $Z$. delphinus zwischen den Stellen von Band 2 und 3 zusimmen, um sich dam nach unten zn wieder zu gabeln. Unterhalb der Stello ron Band 4 ist cine fast einfalbige Zone. Die Bänder werden mur durch dic winkligu Vorspringe der Streifen markiert. Tor Wachstumsabschlissen pfleart sich eine Zone zn befinden, anf der die Streifen anssetzen. Ter Mundrand ist imen ziemlich breit rosalansfliefond berandet. Do ('allus ist farhlos bis rosafarbig, besmolers mach unten zu, das Imnere ist weilj holegt, mit schwach dmchscheinender Zeichmo. Die spindel ist weif, ziemlich kiäifig und melı weniger gewunden; sie steht ziemlich s.'lıräg zur Achse.

Fundort: Colima.

lels liabe oben als flagliches Symonym PILSBRYs Form perlonga

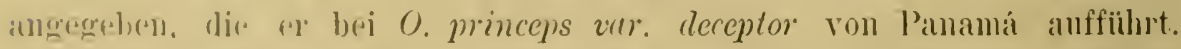
berchreilumgr mud Abbildumg lassen sich recht gout aupassen, letzterer

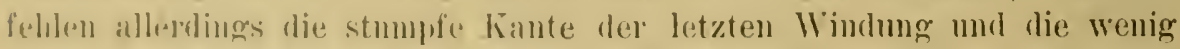

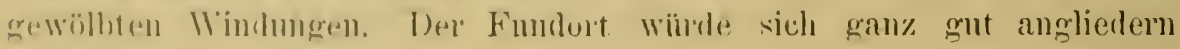


lassen, demn manche der Formen von der Westseite Mexikos dringen bis nach Centralamerika vor.

1. Das von von MarTens abgebildete sogenannte typische Stïck zeigt an der Spindel in der Mittelhöhe eine schwache Furche, die aber bei den anderen Stuicken nicht vorhanden ist. Die Maße sind ursprïnglich mit $62,0 \times 28,5-28,0 \times 14,0$ angegeben. Meine Maße dieses Berliner Stückes sind folgende:

$$
\text { ca. } 6 \frac{1}{2}-61,0 \times(26,0) 30,0-29,4,14,1 \text {. }
$$

2. RoLLE vend. Vier Stiicke, von denen das größte an der Mündung nicht ganz vollständig, daher ergänzt ist; es ist zum Teil mit einer ockerhaltigen Erde bedeckt.

$$
\begin{array}{ll}
\text { Fig. 65. } & 67 / 8-62,3 \times(28,2) 34,3-30,0 \times 16,6 . \\
\text { Figg. 66/67. } & 61 / 2-58,7 \times(25,8) 31,6-27,9 \times 14,4 . \\
& 61 / 2-56,2 \times(27,0) 31,3-28,2 \times 14,8 . \\
& 61 / 4-49,2 \times(24,6) 27,9-26,4 \times 13,4 .
\end{array}
$$

Zwei weitere, etwas verkalkte Stïcke, denen daher die gelbliche Cuticula fehlt, waren wohl deswegen und wegen ihres hohen Gewindes oblongus bestimmt, denn alles, was ein so hohes Gewinde hat, pflegt diesen Namen zu bekommen; sie gehören aber hierher. Das große, etwas mißgebildete Stück mit der sehr stark verdickten Spindel bilde ich ab.

$$
\begin{array}{ll}
\text { Fig. 64. } & 7-62,0 \times(25,6) 30,4-27,7 \times 14,9 . \\
& 63 / 4-55,2 \times(25.1) 29,0-25,5 \times 13,7 .
\end{array}
$$

\section{Z. nobilis ROLLE emend. STREBEL.}

Taf. V, Figg. 68/69.

Nachrichtsbl. 1595, Vol. 27 , p. 131.

O. zoniferus var. nobilis VON MARTeNs in $\mathrm{MI}^{2}$, p. 629 , Taf. 44 , Fig. 16. P., p. 11 S, und XIV, p. 164, Taf. 24, Fig. 14.

Auch hierfür ist die kurze Notiz RoLLEs ungenügend und zum Teil unriclitig. Er sagt davon zusammenfassend nur, daß sie sich zu $O$. zoniferus wie elegans zu 0 . princeps verhält. VON MARTENS beschreibt sie auch nicht und nemnt sie ebenfalls nur "an attenuated variety of $O . z o n i$ ferus", was ich ebensowenig zugeben kann. Ich halte die Form für eine gute Art und beschreibe sie neu. Gehäuse, Form der Windungen, Skulptur und Form der Mündung und Spindel sind genan wie bei Z. elegans, nur Färbung und Zeichnung weichen $a b$ und das Gehäuse ist kleiner. Die ersten $2 \frac{1}{2}$ Windungen sind erst purpurschwarz, damn heller abschattiert. Darauf tritt eine isabellfarbige, nur wenig dunkler werdende Grundfarbe auf. Die Zeichnung besteht aus schmalen, brännlichgrauen Streifen, die sich nur wenig von der Grundfarbe abheben, und die sich häufig, besonders auf den beiden letzten Windungen, miteinander verzweigen, olne mit- 


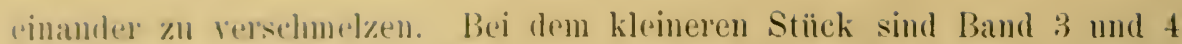
iut der letzten Windumg. Wem anch nicht stark, doch dentlich markiert, bej dem grifseren wonger dentlich, aber bei beiden ist die Zone zwischen liand :3 und 4 etwas dmokler gefälbt; anch liel tritt muterhalb Band 4 vine ziemlich gleichü̈ßig gefärlte Zone auf. Die Varixstreifen sind schwar\%, der Mundrand ist mittelmïßig breit, purpurschwarz austließend wesimunt, mol der scharf aligegrenzte Callus zeigt dieselbe Färbmug. Das Imnce ist weib, violett angehancht, mit gar nicht oder schwach durchseleinender Zeichnumg, aber dentlicher durchseheinenden Tarixstreifen.

Fundort: Colima.

Die Roldeschen Maße sind: $59,0 \times 29,0-28,0 \times 16,0$.

1. Das Berliner Stiick, (lessen Spindel etwas weniger ansgebogen ist, als die Zoichnmmg l. c. es zeigt, hat folgende Mabe (der Wirbel ist alsigehochen):

$$
\text { ?. Fast } 7-59,0 \times(26,2) 31,1-28,3 \times 15,2 \text {. }
$$

2. Rothli vend. Ein Stiick; auch an diesem ist der Nucleus ansarelorochen.

Figg. 68/69. $66^{5} / 8-53,6 \times(24,2) 28,3-26,4 \times 12,6$.

An diesem Stïck ist die Spindel gewmolener als an dem Berliner Stiick.

\section{2. mobilis, Form prellida m. $f$.}

'Taf. $\mathrm{V}$, Figg. $70 / 71$.

? (). colimensis n. sp.? ROLLE 1. c. p. 131. P., p. 11S. "Differt ab Orth. princeps testa solidiore, columella multo magis contorta. $5 S, 0 \times 30,0-2 S, 0>15,0$. Eine zwischen (). princeps und $O$. ferussaci stehende Form, von der leider nur tot gesammelte Exemplare vorliegen. Sie scheint mir spezifisch verschieden."

Das mir vorliegende Stïck gehört dem SENCKENBERGschen Museum in Frankfurt a. M. md ist O. colimensis, Colima, bezeichmet. Weder das Buline Musenm noch wir besitzen diese Form, die ich als Varietät zu 7. nobrtis stellan muf. Da wïrde der Name colimensis schlecht passen, la der \%. mbilis anch von Colina stammt. Die Form mub sowieso nen heschriehen werden, da RoLLks Angaben weder geniigend noch ganz zutrelfend sind.

Das Gehäuse zeigt denselben Aufban und die gleiche Form der l'indungen und der Mïndmg wie $Z$. nobilis, es ist nur größer und ein "ronig hrejter im Verhältnis zur Hölı. Auch die Skulytur und das System

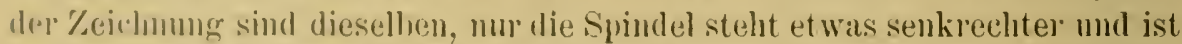
mu "reng gremulen. Die Grudfarbe an diesem schembar ziemlich frischen

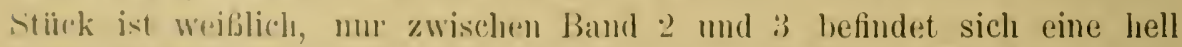
graubrïnuliche \%one, die nicht, ganz bis an stelle von Band 3 reicht, damn eine ebensolehe Zone, die den Zwischemaum zwischen Band 3 und 4 
ausfüllt. Die Streifen sind auch hell bräunlichgran, vereinzelt sich velzweigend und an Stelle der nicht markierten Bänder winklig vorgezogen. Die etwas schwärzlich grauen, schmalen Varixstreifen sind graubraun besäumt. Der Wirbel ist farblos, uur gelblich, der Mundrand ist purpurbram, volett ausfließend und ziemlich breit, der Callus ist dünn, streifig und kastanienbraun, das Innere ist weif, mit schwach durcllscheinender Zeichnung.

Figg. 70/71. $\quad\left(6^{5} / 8-59,2 \times(27,5) 32,8-29,6 \times 15,7\right.$.

\section{Z. quagga n. sp.}

Taf. VI, Figg. 92/94, 96.

Gehäuse festschalig, oval-spindelförmig, matt glänzend, mit $6 \frac{1}{2}-6{ }^{3} / 4$ wenig gewölbten Windungen, deren letzte in der Mittellölie stumpfkantig, bei jüngeren Stïcken deutlicher kantig ist. Die Grundfarbe ist weißlich; nach den unteren Windungen zu gelblich werdend, die Spitze ist gelblicher, der Nucleus ungefärbt. Die Zeichnung besteht aus schwarzbraunen, etwas rotbraun beränderten Streifen, die auf den oberen Windungen ziemlich senkrecht, auf der letzten Windung bis zur Stelle des Band 3 sehr schräg nach vorn gerichtet verlaufen, dann wieder zum normalen Terlauf zuriickkehren. Sie sind auf den mittleren Windungen meistens nach oben gegabelt, und dazwischen gehen meistens noch kurze Striche von der Naht ab. Auf der letzten Windung setzen die Gabelungen nach oben häufiger aus, unterlalb Band 3, oder erst unterhalb Band 4 treten wieder die Gabelungen in zwei oder mehr Abzweigungen auf, die dann bis zur Basis gehen, wenn sie hier auch meistens schwächer in der Färbung werden. Bänder sind nicht vorhanden, auch keine Varices. Der Mundrand ist innen bald schmal, bald breiter schwarzbraun bis heller braunviolett ausfließend berandet, der Callus ist kastanienbraun und nicht sehr dick. Das Innere ist weiß mit durchscheinender Zeichnung. Die Spindel steht wenig schräg zur Achse und ist bald kaum, bald stärker gewunden. Die feinere Skulptur ist die des $Z$. princeps, die Falten sind an der Naht schärfer ausgeprägt, im weiteren Verlaufe treten auf der letzten Windung in ziemlich regelmäßigen Zwischenräumen einzelne der feinen Falten dentlicher hervor, so daß hier das Gehäuse ein gerieftes Aussehen erhält.

Figg. 92/93. $6 \frac{1}{2}-53,0 \times(24,8) 29,3-26,1 \times 13,4$.

$$
\begin{array}{r}
94,96 . \quad 6^{5} / 8-49,7 \times(23,7) 27,5-24,2 \times 12,6 . \\
6^{1} / 8-45,0 \times(23,0) 26,6-23,3 \times 12,4 .
\end{array}
$$

Im ganzen sieben Stücke, mit Etikette von RoLLE. O. lividus VON MARTENS. Colima, eine Bestimmung, die falsch ist. Diese Form steht dem $Z$. elegans sehr nahe. 


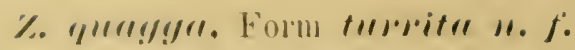

T'af. T. Hig. 78.

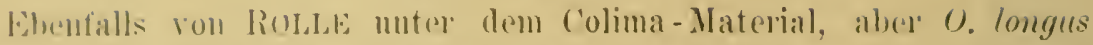
leetimm. Fin stible, das sich vou den voramgehenden mur durch das

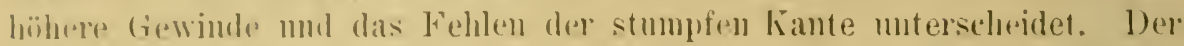

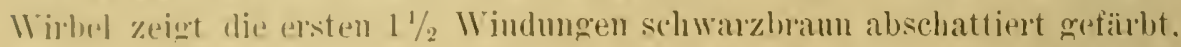
Wak bei den volangehenden Stücken nicht der Fall ist. Das Stück ist anben efwas rerwittert bezw. abgerollt, so daf von der femerem skuptur mu moch stulenweise etwas zn erkemmen ist. Ich vermute fast, daß in diesem stück dis ansgewachsene Form der Art gegeben ist, so dals mur den nicht ansgewaclsenen die melw weniger sichtbare Kantung der letaten Mindung zukommt, aber da es sich mu m ein Stiick handelt, so ist ror औ.9. Hand nicht zu entsclieiden, ob es sich hier mu eine individuelle oder mu rime lokale Abweichmo handelt. so mag es dem vorlänfig für sich hloiben. \%. longus hat einc andere Form des Gehinses und rine versclitedene färlmung mud Zeichmmo.

$$
\text { (i-5-5,8 } \times(27,5) 32,8-28,6 \therefore 15,3.8 .
$$

\section{\%. livenS SHCT'TLEWORTH.}

T'af. T, Figg. 7:/7:3.

V(rgl. suctemowontu, Notit. p. 64, Taf. III, Fig. s. P., p. 118, Taf. 2:, Fig. 15.

l)as tieluanse ist den roligen in der Form älunlich. aber da das stiuk nicht gan\% ansgewachsen, ist es auf der letzten Windung in der Nittelhöhe schälfel kantig und im ganzen kleines und dïmschaliger. Die skulptur ist die des Z. princeps. Es erimert oberflichlich an die klemere lorm ron $Z$. ferussaci VoN MARTExs be\%w. muracuibensis, hat aber ein hüleres Gewinde. I)ie Grundfarbe ist weißlich, die ersten zwei Windungen sind ast bramschwar, dam bram abschattiert. Die zeichmmg besteht ans braumen streifen, die in der Mittelzone breit, nach oben mol nach unten grogabelt sind, vereinzelt anch nicht gegabelt. Sie stehen nicht so

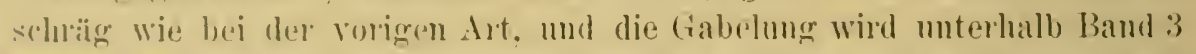
schwärher in Farbe mul hört bei Band t anf; nahe der Mïndung sind um zimlich schmale streifen rorhanden. Anf der letzten Windmg ist Band is strllumeise durchgefühnt und Band + gegliedert, d. l. an den

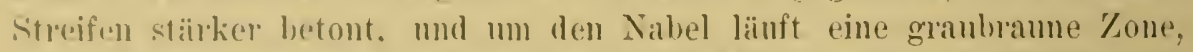

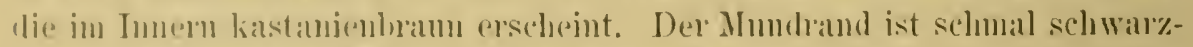

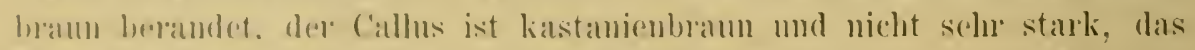

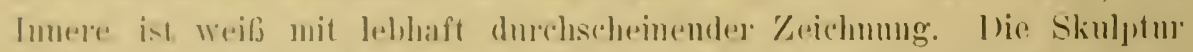

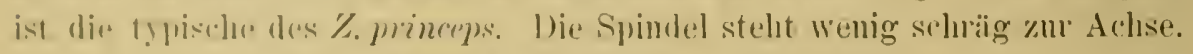

$$
\text { i) } \%=31 ;, 0-(1 ! 1,0) 21,8-19,2=15,3 \text {. }
$$

Diss Stïrk ist yon Coban; Gmatemalat, mul mit Etikette von 
G. SchneIder in Basel, O. ferussaci, versehen, welche Bestimmung begreiflich, wenn sie arich nicht richtig ist, da nur eine oberflächliche Ähnlichkeit vorliegt. Das Stïck paßt gut zur Abbildung in SHUTTLEWORTH, dessen Original freilich größer, aber anch woll kaum ansgewachsen ist, auch die Beschreibung paßt bis auf die fehlende gelbliche Färbung, so daß ich glaube, es mit Recht dieser Art zuzuweisen, trotzdem der Typus angeblich in der Nähe von Veracruz gefunden sein soll.

\section{Z. livens, Form abervous n. f.}

Taf. V, Figg. 74/77, 79/82.

1. Von RoLLe mit Etikette "Zwischen O. ferussaci und O. lividus". Colima. Vier Stïcke, die ich trotz einzelner Abweichumgen in der Zeichnung dem vorigen Stiick anreihe. Sie haben die gleiche Form, sind aber kräftiger in der Schale, und ihre Grundfarbe ist gelblich, der Wirbel ist ebenso dunkel gefürbt, der Mundrand ist breiter purpurschwarz im Innern gesäumt, und anch der Callus ist scharf abgegrenzt purpurschwarz. Die Zeichnung weiclt nur dahin $a b$, daß die Streifen zum Teil in der Mittelpartie schräg wie bei $Z$. quagga gerichtet und daß sie in der Mittelpartie breiter sind. Anch bei diesen Stiicken wird die Gabelung unterlaalb Band 3 etwas schwächer in der Färbung und hört unterhalb Band 4 fast ganz auf; es fehlt aber die dunkle Zone um den Nabel, die hier hell orangefarbig ist. Yon den Bändern ist Band $3 \mathrm{nur}$ an einem Stück am Anfang der letzten Windung eine Strecke dentlich durchgeführt, an einer anderen sehr andentlich, während Band 4 teils unterbrochen, teils durchgeführt und ebenfalls orangefarbig ist. Das Innere ist weiß, mit scliwach durchscheinender Zeichmung. Es ist nur ein Varixstreifen vorhanden. Die Skulptur weicht nicht $a b$, sie entspricht besonder's anch in dem Gerieftsein der letzten Windung dem $Z$. quagga. Die Spindel steht wenig schräg zur Achse, sie ist schwach gewunden und besonders nach oben zu verdickt.

Figg. 76/77. $\quad 6^{5} / 8-51,9(24,9) 28,4-26,4 \times 13,3$.

Fig. $75 . \quad 63 / 8-47,5(23,1) 26,8-23,8 \times 12,1$.

" 74. $\quad 6^{3} / 8-45,0(23,0) 26,6-24,0 \times 12,7$.

$$
63 / 8-47,1(23,2) 27,0-23,0 \times 12,5 \text {. }
$$

Das Stiick Fig. 75 weicht dadurch $a b$, daß die Kantung an der letzten Windung nur sehr sclwwach angedentet ist. Nahe der Mündung verlaufen die Streifen in der Mittelpartie auf der Rückseite wieder ebenso schräg wie in Fig. 77.

Im SencKenBerGschen Museum befindet sich von derselben Provenienz ein Stiick.

$$
6{ }^{1 / 4}-48,0(23,4) 27,2-24,8 \times 12,3 .
$$

Ein fünftes Stück, das bei $Z$. longus lag, ebenfalls von Colima (ROLLE), dürfte den Typus der ausgewachsenen Form für die vorangehenden dar- 


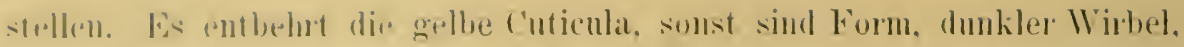

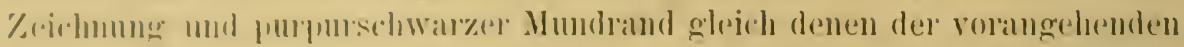

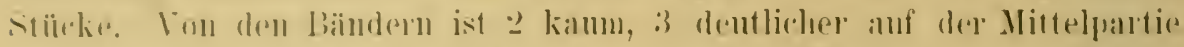

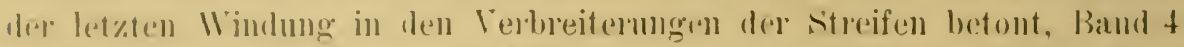

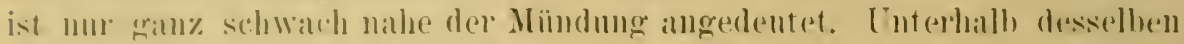
hetindet sidh nul dine helle \%one. Der ('allus ist kastanienhramu und "twas streitig. dic spindel stelat schrig \%ur Achse und ist etwas gewmolen, in wre muteren Hailfte ctwas verdickt und menten brïmlich gefarbt.

Fign. i!) S0. $7-60,7 \times(26,8) 31,6-30,0 \times 15,2$.

Nach diesem Stïck, das ich ohne Bedenken hier ameihe, scheint mir das in F. und C.. 'T'af. 18, Fig. 6. abgebildete Stück vielleicht auch hierhel' zu gehören, das PIIsBRY nur schembar mit Recht zu Z. longus riehen will, doun as fehlt ilm der oval-konische Anfban, den das hiel abgebildete stiick lat. und der es von $Z$. longus entschieden tremnt.

Wenn die hire heschriebene Form duch die gelbliche Fiobung hesser der Diagnuse SHUTTLWORTHs von O. livens entspricht als das in der Zeichmung vielleicht typischere Stuck Fig. $40 \mathrm{a}$, b, so bietet anch die Fig. 7r:7 in der Vorderansicht in dieser Beziehmug grofe Älnlichkeit mit der Abbildung in SHutTLEworth, die nur die Vorderansicht gibt. Aler shu'TLEwoR'TH bemerkt selbst, daf die gewellten Streifen „zuweilen breiter und dumkler" sind. Die erwähnten "schmalen mo modentlichen" zwei Bänder anf der letzten Windung sind der Abbildung nach die Bïnder :3 und 4, dieselben, die anf meinen beiden Formen zum 'Teil angedentet sind. Die Verschiedenhejt der Fundorte bedingt an sich wohl manche Abweichmug, mol wem die Form aberrans in der kräftigeren Schale von SHuTtLEworTHs Typus abweicht, so möchte ich dazu bemerken, daß alle mir rorliegenden Arten del Westkiiste Mexikos sich durch kraftigere siclatle allszeichnen.

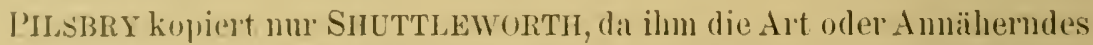
nicht vorgelegen hat. Er begrindet dic Unhaltbarkeit des BECkschen liatalognamens, del dureh MürCus Anskmuft daribler nicht halthaner wird, drmu der Hinweis anf FErLssacs Fig. 2, 'Taf. 115, ergibt eine alline Form, die mir freilich cher zur maracubensis- oder undatus-Gruple als z 0 . longus \%u gehïren scheint. Der mach rox MARTExs in SP., p. 32, angefïhnte und anf Taf. XI, Fig. l!!, abgebildete $O$. livens gehört, wie P'IJSBRY mit Recht anfuiht, zu Z. uhdermus.

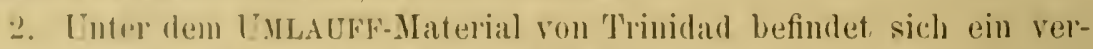
wittertes stiok, dats ich der form mol \%eichnmer nach hierher rechnen

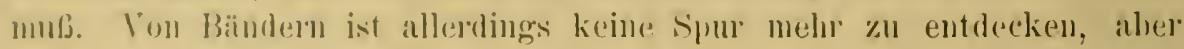

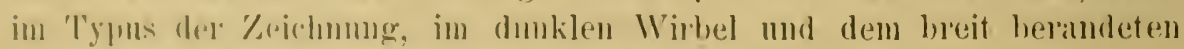
Immin des Jundrandes ist keine Abweichung.

$$
\text { Figg. } 81 / 8 \%, 6 \%-54,6 \times(25,5) 30,5-26,5 \times 14,7 \text {. }
$$




\section{Z. tepicensis n. sp.}

Taf. VI, Figg. 97/98.

Diese Art steht im allgemeinen Typus zwischen $Z$. delphinus, Form vividus, und $Z$. elegans, sie hat mit beiden Ähnlichkeit in der Färbung und Zeichnung, hat ein verhältnismäßig höheres Gewinde als Z. delphinus und ein nicht ganz so hohes Gewinde als ansgewachsene Stïcke von $Z$. elegans, die letzte Windung ist undeutlich stmmpfkantig, was bei elsterer Art nicht, bei letzterer Art deutlicher der Fall ist.

Besondere Merkmale sind folgende: Die Grundfarbe ist oben etwas rötlich hornfarbig und wird nach den unteren Windungen zunelnmend bräunlich gelb. Die erste Windung ist purpurschwarz, braun abschattiert, die Streifen sind bramschwarz, etwas belegt, und erscheinen daher dunkel bräunlich grau; sie sind ab und zu rötlich besäumt. Auf der letzten Windming erscheint Band 3 mudeutlich und stellenweise durchgefïlnt. Band 4 ist nur nahe der Mündung undeutlich sichtbar, und die Streifen setzten sich unterhalb derselben noch abgeschwächt fort. Der Mundrand ist außen schmal, innen breit ausfließend purpurschwarz gesäumt, von gleicher Farbe.ist der scharf abgegrenzte Callus. Das Innere ist bläulich weiß nit schwach durchscheinender Zeichnung. Die Spindel steht schräg zur Achse und erscheint gerade, wenn sie auch, von der Seite gesehen, etwas gewunden ist.

Das Stiick ist von Dr. HACKER aus Tepic per Post eingeschickt, es hatte noch den mit Borke verklebten häutigen Deckel. Das Tier streckte sich in warmem Wasser wiedel aus, wurde damn getötet und harrt der weiteren Untersuchung:

$$
61 / 2-55,2 \times(26,2) 31,7-28,2 \times 15,2 .
$$

\section{Z. tepicensis, Form rollei $u . f$.}

Taf. V1, Figg. 95, 99/100.

Diese Form ist der typischen Art in Färbung und Zeichumng sehr ähnlich, nur daß bei der letzteren die Zonenbildung durch breite Streifen in der Mittelpartie deutlicher und von der vorletzten Windung an durchgeführt ist. Der wesentlichste Unterschied besteht in dem rascher Breiterwerden und den etwas flacheren Windungen, deren letzte dentlicher, wenn auch stumpfkantig gekielt ist. Es ist sehr fraglich, ob selbst das größte der Stïcke ausgewachsen ist, wodurch die Kielung modifiziert werden könnte, was vielleicht gar nicht oder weniger der Fall bei den folgenden Charakteren wäre. Die erste Windung ist purpurschwarz, die folgende braun abschattiert, der Mundrand ist beiderseits schmal purpurschwarz berandet, und von gleicher Farbe ist der Callus, der aber nicht so scharf 


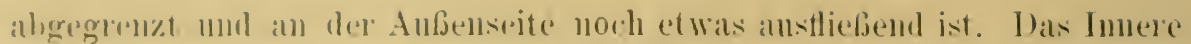

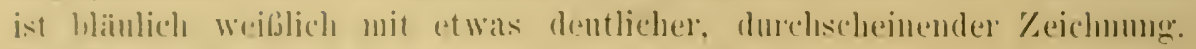

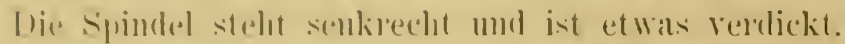

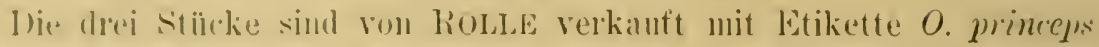

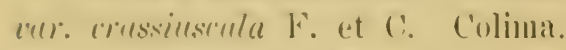

$$
\begin{aligned}
& \text { Figg. } 9 ! 1 / 100 . \quad\left(i^{1} \%-51,3 \times(2,5,7) 30,0-26,0 \times 15,2\right. \text {. } \\
& 1 ; \%-41,7=(2,5,9) 2 ! 11-24,2 \times 14,7 \text {. } \\
& \text { Fig. (15. } \quad 53 / 4-37,7-(21,7) \div 2,2-20,4 i-12,2 .
\end{aligned}
$$

bas siscklisbligsche Musem hesitzt ein stïck der gleichen Art alls dersellyen berngsinuelle.

$$
1 i 1 / 4 . \quad 41,1 \div(24.1) \geq 8,1 i-23,7 \times 13,8 .
$$

\section{Z. miiller.i 11. s/1.}

V(regl. (). zobre. O. F. JlutLeI in SP., 1. 24 , Taf. 11, Fig. 20.

PIlsTRY, 1). 108, stellt diese Form fraglich zal Z. undatus vur. jumuirensis, wohin sie schon der gewmolenen Spindel und der Zeichmmor

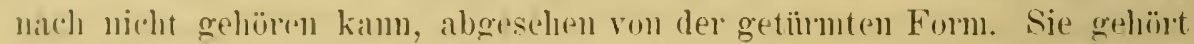
olfenbar zu der Fama der Westseite Mexikos, mol iln wird wohl vou den beiden 1. c. elwähnten Zatteln lerjenige „Mazatlan" zufallen. Sic

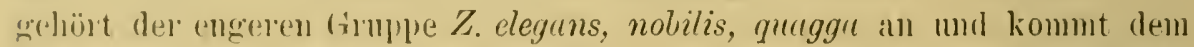
\%. nobitis, Fo'm pullidu, am nächsten. Ich brauche der 1. c. gegebenen Pesclureibmug nichts hinzuzufügen. Die Maßje sind:

\section{Fast $7-57.0 \times(-5,5) 30,0-20,8 \times 13.9$.}

Ia die mit dem Namen zebra, MïLlak, belegte Art niclit moln

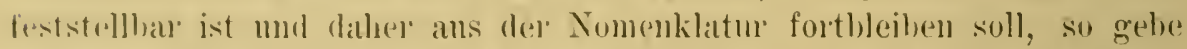

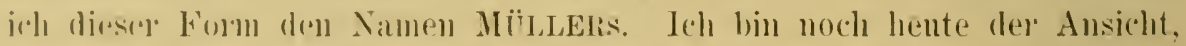
dalj diese Fonm flagliels als gute Art hezoichnet werden kam. Die Famm des Westahhanges der Mexikanischen Kordillere bietet eine solche Fiille

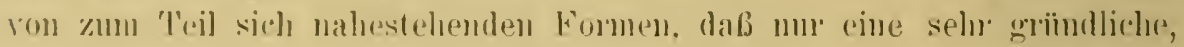

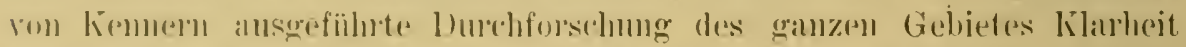

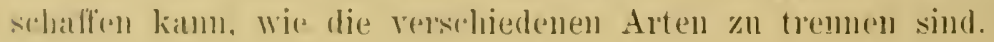

\section{2. pilshryi $11 . f$.}

'Tilf. V], Figge. 83/8s, 90/91.

Verol. 1). julidellus rar. prototylues partim. P., p. 137, Taf. 2s, Figg. 34-35.

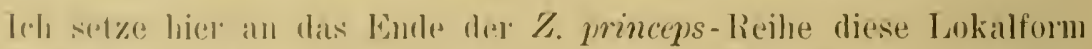

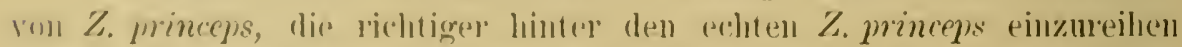

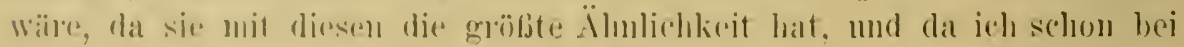

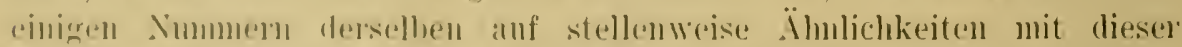

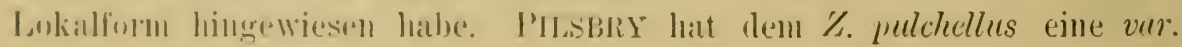


prototypus angereiht, p. 137, und gibt dazu Taf. 28 die Abbildungen Figg. 30-37, die mir nach dem vorliegenden Material zwei verschiedene Formen zu sein scheinen. Für die Figg. 34, 35, die der hier vorliegenden For'm auch seiner Beschreibung nach zu entsprechen scheinen, gibt er Barcelona in Veneznela als Herkunft an; meine Stücke stammen, soweit der Fundort ganz sicher ist, von Baranquilla (Columbien). Danach mïßte ich die Form eher prototypus nemnen, aber unter den von PILsbry abgebildeten anderen Stiicken, Figg. 30-36 und besonders Fig. 31 und 36, befinden sich Formen, die ich allerdings dem $Z$. pulchellus zuweisen möchte, und für die ich daher lieber PILSBRYs Bezeichnung prototypus anwenden will, denn sie zeigen immerhin, wenigstens in den mir vorliegenden Stïcken, die Hauptmerkmale von $Z$. pulchellus, nämlich die feinen, dichter gedıängten Streifen, die weißen Binden und die mehr weniger eingebogene Spindel.

Die mir in melrreren gleichartigen Stücken vorliegende Form gehört durch Form des Gehäuses, Skulptur, Färbung, System der Zeichnung und Mündungspartie zu den echten $Z$. princeps-Formen. Der Wirbel ist teils farblos, teils mit brann abschattierter erster Windung; in der Zeichnung macheu sich folgende Abweichmingen als durchgehend bemerkbar. Band 3 wird schon auf der vorletzten Windung oberhalb der Naht sichtbar und setzt sich dann bis zur Mündung, nur ab und zu unterbrochen, fort, aber das dasselbe nach unten begrenzende schmale weiße Band erscheint nur anf etwa der ersten Hälfte der letzten Windung, zuweilen sogar hier etwas undeutiich und mehr durch die Unterbrechung der Streifen erkennbar; sehr selten setzt es sich bis zur Mündung fort. Der Raum zwischen Band 3 und 4 ist meist nur durch kurze Streifen oder Flecke ausgefiullt. Band 4 besteht meistens nur aus Flecken, seltener erkemnt man noch in ilmen die winkligen Torsprüuge der Streifen. Darauf folgt eine mur selten noch durch ansfließende Streifen unterbrochene Zone der Grundfarbe, auf der zuweilen noch, wemn auch undentlich, Band 5 auftritt, das bei jungen Stiicken dentlicher ist. Der Mundrand ist schmal schwarzbrann berandet, der Callus ist farblos bis hellbraun, nach imnen zu heller werdend. Das Innere ist weiß mit lebhaft durchscheinender Zeichnung.

1. Rolle vend. Costa-Rica. Drei Stiicke, vou denen zwei jung sind. Figg. 87, 88. $5 \frac{1}{2}-42,4 \times(21,2) 25,2-23,0 \times 13,2$.

2. Koll. O. SEIrPer. Etikette: zebra NüLLER. Sombrana bei Baranquilla an der Mündung des Magdalenenstroms, Waldis leg. Fünf Stïcke. Fig. 83. $\quad 5 \frac{3}{4}-43,2 \times(23,0) 28,6-25,8 \times 14,8$.

". 84. $\quad 53 / 4-41,8 \times(23,5) 28,6-25,4 \times 14,6$.

3. Koll. O. SEMPER. Baranquilla. General NOLCKEN leg. Drei Stücke, durchaus entsprechend.

4. Nr. 15700 ans meiner ehemaligen Sammlung: Chonchomayo, oberes Peru. Acht Stiicke. 


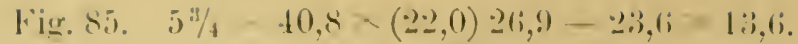

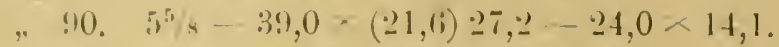

$$
\begin{aligned}
& \text { "s(i. } 53 / 4-38,0=(21,5) \cdot 2(i, 1 i-23,4 \times 13, i \text {. } \\
& \text { " 91. } \quad i^{\prime} / 4-28.4 \times(16,4) \geq 0,0-17,1 ; \times 10,1 \text {. }
\end{aligned}
$$

5. Loll. Scmondex. (Ohne bitiette. Sebade, dats von diesen fïnf slïtkelı, unter denen sieh zwei stïcke heterom. melanochilus befinden, kein fiundert angegeben ist. Die drei mit Zeichmmg versehenen Stiicke sind durchatus tyjiscelt.

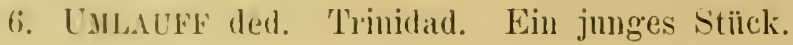

\section{Z. pilsming, heterome. melamochilus.}

'Taf. VI, Fig. 89.

1) ite heiden volstelend sub 5, erwälnten stiicke dieser For'm entsurdem in dor For'm des Gehäuses genan den vorangehenden mit zeichmung versehenen Stïrken, so daß sie olme Frage zusanmengehören. Sie haben Rand 3, f scharf ahgegrenzt und dunkelbram, Band -2 an einem der Stiicke auf der letzten Windung schwach angedentet, Band 5 an beiden Stiicken sehwach in Farbe. Das andere abgebildete stiick zeigt nahe der Miundung miterhalh Band :3 die schmale lselle Binde schwach, abs doch deutlich. Jer Nuclens ist dunkel, der Mundrand ist schmal schwarzbram berandet, und der (allus ist farblos, mur oben leicht hellbraun getont.

Fig. 89. $51 / 4-30,8 \times(18,4) 22,4-19,3 \times 11,9$.

$$
51 / 4-31,9 \times(18,8) 23,4-19,8 \times 12,0 \text {. }
$$

\section{Gruppe \%. lividlus.}

Dirse Girupe zeichnet sich vor den Formen der Z. princeps-Gruple daduch ans, dafs die Windungen, besonders die letzte, schräger verlanfen, so dab der Mundrand, die Miundumg und ebenso die Spindel schräiger zur Aclıse stehen und daf der obcre 'T'eil der letzteren weiter zurtickliegt. Bei jüngeren stiicken sind diese Charaktere etwas weniger dentlich entwickelt. In SP. habe ich bri der Beschreibung der Art 1). 29) diese Charaktere nicht gremannt und die Suindw sogar fälschlich mit nenig seluräg zur Achse stehend geschildert, anch in der Abbildnng, 'J'af. X1, Fig. 18, falsch gezeichnet, wemn anch gerale das ansgewählte stück eine otwas weniger schrägr

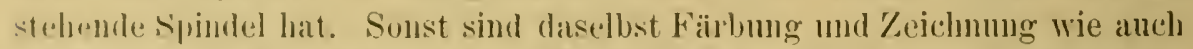
die skulptu; die iibrigens der des Z. minceps entspricht, richtig geschildert.

\section{Z. lividlls VON MARTENS.}

'T'af. III, Figre. 101/106.

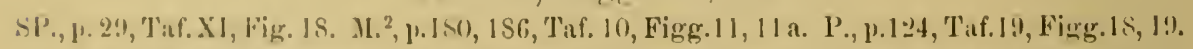

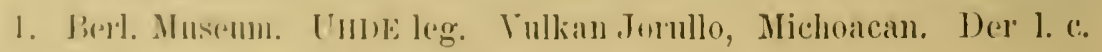
abgebildete 'Tyms, dessen Malde folgende sind:

a)

$$
7-78,7 \times(31 i, 7) 45,0-43,5 \times 2: 3,2 .
$$


b) Drei weitere Stïcke. Etikette nur UHDE, Michoacan. Das eine dieser Stiicke zeigt nur die erste Windnng braun abschattiert, und ist im ganzen etwas heller gefärbt; auf der 3. und 4. Windming ist Band 1 deutlich, wenn auch etwas unterbrochen vorhanden, was bei keinem der sonst mir vorliegenden Stiicke der Fall ist, so daß es hierin dem $Z$. zoniferus entspricht, aber sonst ist es in der Zeichnung typisch. Band 3 ist bei allen anderen Stücken auf der letzten Windung fast immer streckenweise dentlich ansgeprägt, Band 2 und 4 selten und nur nahe der Mündung und undentlich. Das hier hervorgehobene Stiick (das erste der Maßliste) zeigt nur eine undentliche Spur von Band 2, 3 mahe der Mündung, aber deutlicher im Innern.

Fig. 101. Fast $6 \frac{1}{2}-62,8 \times(31,1) 38,9-35,6 \times 19,8$.

" $63 / 4-68,5 \times(32,6) 38,8-36,2 \times 20,5$.

Fịg. 102/103. " $67 / 8-62,8 \times(30,4) 35,5-32,5 \times 17,5$.

Das letzte Stiick ist das in SP. abgebildete, es ist verhältnismäßig schmal. Das Band 3 ist in jener Abbildung zu stark liervorgehoben, auch die Zeichnung der Streifen ist wenig charakteristisch, und, wie schon gesagt, ist die Spindel zu senkrecht gezeichnet.

c) Zwei weitere kleine Stiicke, ebenfalls UHDE, Michoacan, bezeichnet. Das kleinere dẹselben hat auch nur eine braune erste Windıng. Es ist dies wie die nachfolgenden eine kleine Form.

Fig. 106. Fast $6-48,5 \times(25,0) 30,1-27,7 \times 15,5$.

$$
6-44,6 \times(22,6) 26,9-24,6 \times 13,6 .
$$

2. Berl. Museum. Ein Stïck. Etikette Bul. undatus, Mexiko, DAvID, hinzugefügt: $O$. lividus. Es ist durchans typisch.

$$
61 / 4-52,6 \times(26,5) 31,128,7 \times 15,8 \text {. }
$$

3. Alte Sammlung Nr. 5685. B. zebra. Mexiko. Zwei durchaus typische Stïcke.

$$
\begin{aligned}
& 65 / 8-58,2 \times(29,3) 33,7-31,6 \times 17,6 . \\
& 6 \% / 8-52,3 \times(27,0) 31,4-29,2 \times 16,3 .
\end{aligned}
$$

4. Berl. Museum. DunkeRsche Sammlung. Etikette Bul. zebra. Rio Tapia, in der Ebene zwischen Puerto Dibuc und Tricnta, 12 Meilen von Rio Hacha. TETENS. Ein Stiick, das nur, außer der schmalen Form, darin abweicht, daß das erste Drittel der letzten Windung wieder die breiten und unten gegabelten Streifen der Z. princeps-Zeichnung aufweist; damm wird die Zeichnnng wieder typisch, wie auch die obere dunkle Färbnng, Mundrand und Callus typisch sind. Die ziemlich starke Spindel ist unten noch braun gefärbt. Es sind etwas mehr Varixstreifen als sonst vorhanden.

Figg. 104/105. $63 / 4-59,4 \times(27,8) 34,2-31,0 \times 16,9$.

Die in SP., p. 30, Taf. IV, Figg. 6, 9, als For'm C angefïhrten beiden Stïcke gehören nicht hierher, sondern zu $Z$. zoniferus. Sie sind in $\mathrm{P}$. noch unter $C$. lividus aufgefiilnt. 


\section{\%. Irrelieri "1. sty.}

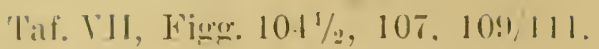

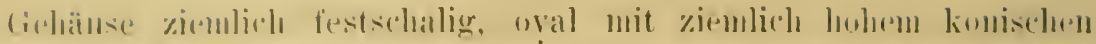

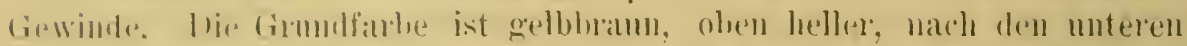

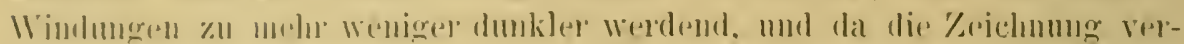

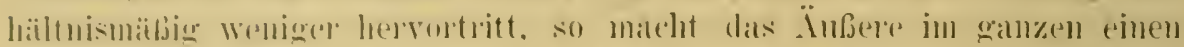

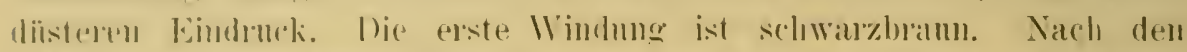

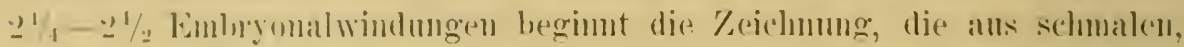

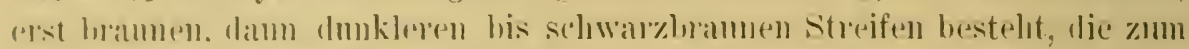
'Teil rotbratu berandet sind. und die im weitren Verlanfe zwiselen den stellen von Band ? nnd : bis 4 al, mol \%n in etwas lueitere Streifen \%nsimmentlieljen mal an Stelle dieser Bänder mejstens meln wellig als winkligr ansbiegren. Unterlablb hand t ist cine cinfarbige rone. Vereinzelte schwarkanne Varixstreifen treten anf, an denen sich nach ridckwärts immer eine \%one anschlieft, auf der die streifen zusammenfließen. Der Jumband ist innen breit funpurschwary ansfliebend gesäumt. und von greidher Farbe ist der scharf alogegrenyte ('allus. Das Imnere ist weiß, etwas riolett, hei lem dunkleren Stück Fig. 109110 meln bäulich angelancht mit schwarla durchscheinender zoichmmg. Die Spindel ist ziemlich kraiftig mon steht etwas schnäg zmr Achse. Die Skulptur ist die typische des \%. mineps, an der Naht ist die Faltung ziemlich scharf ansgeprägt.

Die fiinf Stiicke sind ron Herm Dr. PAUt, HACkER bei T'epic, Westlibste ron Mexiko, gesalmmelt mol kimen, allerdings mit dem iiblichen

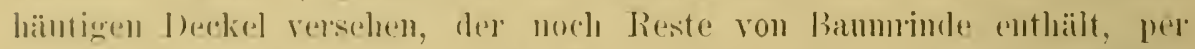

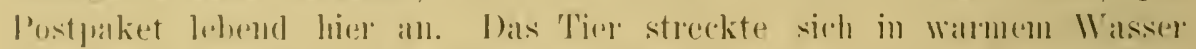

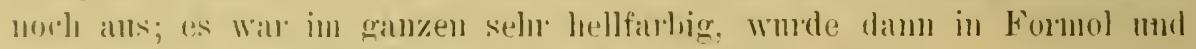

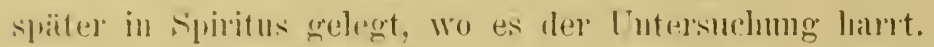

$$
\begin{aligned}
& \text { Fige. 105110.7 - } 72,6(30,2): 37,6-31,7 \times 18,3 .
\end{aligned}
$$

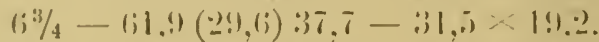

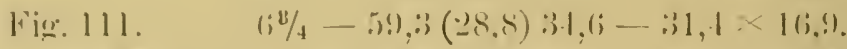

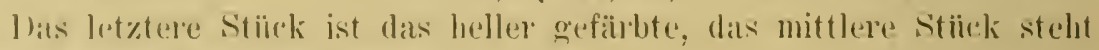
in les Fö̈lmor zwischen beiden.

Von den beiden jungen stiicken hat das gröbere einen mogefäbten

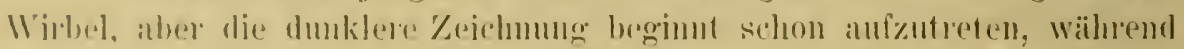

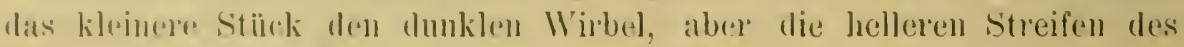
vilicless figr. $111 \%$ \%eigrt.

$$
\begin{aligned}
& \text { Fig. 107. } 53 / 4-11,9=(23,0) 27,01-21,0 \times 1+, 0
\end{aligned}
$$

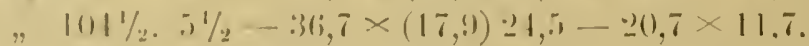

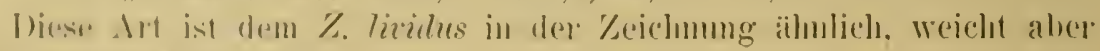

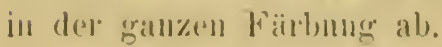




\section{Z. hackeri, heterom. xanthus.}

Taf. VII, Fig. 108.

Bei den Stiicken des $Z$. miles und mars von Dos Arroyos bei Acapulco, H. Syıтн leg. und dem Berliner Museum gehörig, lag ein mnaus gewachsenes Stiick, das ich wie oben bezeichnen will, da es den vorstehenden jungen Stücken selır ähnlich ist und nur in der deutlicheren Kantung der letzten Windung abweicht. Es ist isabellfarbig mit hellbraunen gewellten Linien gezeichnet. Auf der letzten Windung nahe der Miindung verschwinden die Streifen, und es treten hier Band 2, 3, 4, wenn auch schwach, doch dentlich hervor. Die hellere Zone mnterhalb Band 4 tritt im Innern rein weif hervor, wird aber nach unten noch wieder durch die außen etwas, innen stärker dunkle Zone, die dem Band 5 zu entsprechen pflegt, abgegrenzt. Der Mundrand ist unfertig, der Callus ist hell kastanienbraun, das Imnere erscheint weifo mit hell kastanienbrannen Streifen. Die Spindel steht etwas schräg zur Achse und ist in sich gerade.

$$
6-43,6 \times(24,0) 28,3-24,3 \times 14,1 \text {. }
$$

\section{AOniferus STREBEL.}

T'af. VIII, Figg. 112-115, 118-119.

SP., p. 28, Taf. I, Fig. 7 b; Taf. III, Fig. 3; Taf. IV, Figg. 6, 9. II. ${ }^{2}$ p. 1S0, 186. P., p.123, Taf. 23, Fig. 12.

Zn der in SP. gegebenen Beschreibung habe ich nur weniges hinzuzufügen. Die schrägere Aufrollung der letzten WVindnugen und der infolgedessen sehr schräg zur Aclıse verlaufende Mundrand entsurechen der Gruppe Z.lividus, treten aber nur bei ausgewachsenen Stiicken auf. Band 2 auf den oberen Windungen fehlt zuweilen ganz. Die hellere Zone unterhalb der Stelle von Band 4 ist nur bei größeren Stïcken deutlich und dann meist nur anf dem letzten Drittel der letzten Windung; wo die Streifen immer schmäler werden, dichter gedrängt stehen und schwächer ansgeprägt sind. Die Streifen gehen bei nicht ausgewachsenen Stïcken bis an die Basis, bei größeren Stïcken im Anfange der letzten Windung auch noch, wenn auch allmählich schwächer werdend. Die Skulptur ist die des Z.princeps. Ich will noch bemerken, daß bei einigen Stücken der. Wirbel nicht gefärbt und daß der Callus hell kastanienbraun, dïnn und streifig ist.

1. Rancho, del Platanillo, unweit Iguala im Staat Guerrero. Aus den typischen Stiicken bringe ich noch einige extreme Formen und junge zur Abbildung, wodurch die in SP. gegebenen Abbildungen in erwünschter Weise ergänzt und zugleich in natïrlicher Größe wiedergegeben werden. 


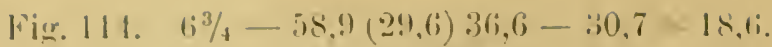

.. 11.2. $61 \%$ - $53,0(28,1) 34.8-30,2=18,2$.

. 113. $61 \% 2-58,4(26,0) 33,2,6-27,4 \div 16,7$.

.. 11!. $63^{1 / s}-53,9(29,1) 35,5-28,9<18,0$.

" $118.53 / 4-41,4(2,2,3) 27,0-23,6 \times 14,1$.

.. 115.51\%-32,2 17,9$) \div 2,3-18.6 \times 11,3$.

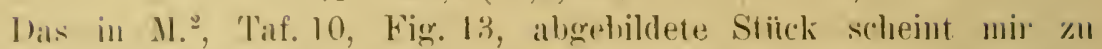

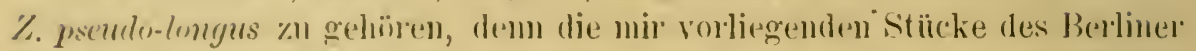
Musemms rom Vental de $/ 20$ pilute füluse ich weiter mten an, und das groilseres stiick soll nicht vorhanden scin.

2. Iclı fïgre lies die beiden in Veracruz gefumdenen und in sl? muter 7. lividus, form C. anfgefiilıten Stïcke an, die nach genanem Vergleich

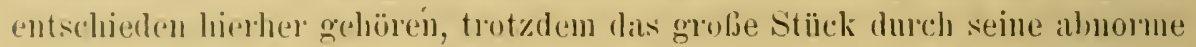
Grölje und die Mißbildung an der Basis der letzten Windung schemball etwas anderes ist.

$$
\begin{aligned}
& \text { SP.. T'if. IV, Fig. 9. } 7-77,5 \times(35,3) 42,7-42,8 \times 21,3 . \\
& " \quad " \quad " \quad \text { 6. } 66^{5} / 8-55,7 \times(28,6) 34,4-30,0 \times 17,2 .
\end{aligned}
$$

\section{\%. amifirms, Folm meriom m. $f$.}

Taf. TIII, Fign. 116/117, 124/126.

1. SP., 11. 29, Taf. I, Fig. 7 h.

lch füln'e dies stïck gesondert an, weil ein seln älnliches Stiick im Berliner Musem liegr, das vom einem anderen Fumborte ist, wem mein Stiisk amblo ans derselben Quelle wje die typischen stiicke stammt, womit foreilich nicht gesagrt ist, dafo es damit zmsammen gefunden wome. Diese Stïcke näher'n sich in der etwas lehhafteren Färbung der Zeichnung und in del ancl) anf der lutzten Windung vorherrschenden Terbreiterung der Streifen zwischen Band 2 und 3 selı der folgenden Form, die aber klemer mol noch Jebhafter gefarht ist und anch ans einer anderen Gegend stammit.

Fimg. 116/117. $\left(3^{3} / s-(30,2 \times(29), 2) 37,2-\$ 33,5 \times 19,3\right.$.

2. Berl. Mlsemm. O. zmiferus, Chilpancingo, Stat Guerero.

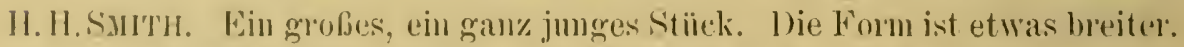

Firg. 124/125. $\left(3^{1 / 8}-60,7 \times(30,8) 38,3-35,2 \times 20,0\right.$.

Fig. 126 . $5-28,1 \times(16,5) 20,0-17,4=10,5$.

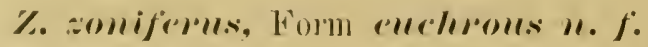

'T'uf. V]II, ligg. 120/123, 127; 'Taf. IX, 1Hgg. 128/129.

?'., 'Taf. 23, Fìg. 10; ? Fig. 12. 31. ${ }^{2}$, Taf. 10, Fig. 12.

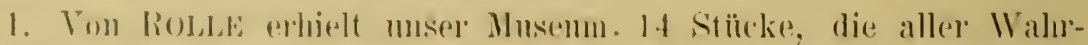

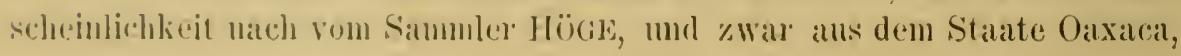


stammen. Sie weichen vom Typus in der lebhaften Fürbung der Zeichnung ab, die braunschwarz, vielfach mit Braunrot konturiert ist, und zwar besonders breit an den breiten Streifen der Zone zwischen Band 2 und 3, die dadurch bei den meisten Stïcken sich auf der letzten Windung dunkler abhebt. Kein Stück zeigt die helle Zone an der Basis, die Streifen gehen bis hinunter und biegen an Stelle von Band 4 nur etwas wellig ans. An keinem der Stücke ist das Band 2 oben gegliedert durchgeführt, es wird nur durch die winkligen Vorsprünge der Streifen markiert. Varixstreifen kommen nur vereinzelt vor. Ob von den Stücken die größeren ganz ausgewachsen sind, kann fraglich sein, wemn sie auch schon einen schmal kastanienbraunen Mundrand haben. Der Callus ist dünn, kastanienbraun, nach oben zu meist schwächer werdend. Der Nucleus ist farblos, Mündungśpartie und Spindel entsprechen dem Typus.

Figg. 123, 127. $\quad 6^{1 / 8}-50,2 \times(26,3) 32,0-27,9 \times 16,5$.

Fig. 122.

$" 120$.

$6^{1 / 8}-45,6 \times(24,5) 29,1-24,8 \times 14,6$.

" 121.

$5^{3} / 8-30,2 \times(16,6) 21,6-18,3 \times 11,2$.

$4^{5} / 8-21,4 \times(13,5) 16,9-13,2 \times 9,2$.

2. Eigenartige Abweichungen zeigen die beiden folgenden Stïcke, besonders durch folgendes: Die Grumdfarbe ist weiß, nicht gelb, die ebenfalls lebhaft braunschwarzen, nur auf der letzten Windung rötlich konturierten Streifen sind in ihrer Verbreiterung in der Mittelzone bei dem größeren Stïck schräg nach vorn gerichtet, ähnlich wie bei $Z$. quagga und $Z$. tepicensis, For'm rollei, während sie sonst bei $Z$. zoniferus, sowohl dem Typus wie der Form euchrous, in der Anwuchsrichtung verlaufen. Das kleinere Stück entspricht allerdings dieser Forderung. An beiden Stiicken sind am Anfang: der letzten Windung Band 3 und 4 eine kurze Strecke durchgefülırt, Band 4 breiter und länger als Band 3 . Sonst ist alles typiscl.

Es sind dies die Stücke des Berliner Museums, deren Etikette besagt: O. zoniferus, Venta de Zopilote, Staat Guerrero. 2800'. H. H. SuITH leg. Das größere, in M.'2, Taf. 10, Fig. 13, abgebildete Stück soll nicht vorhanden sein; ich halte es, wie schon gesagt, für nicht hierher gehörig.

Figg. 128/129. $\quad 5 \% \frac{3 / 4}{5} 42,4 \times(22,5) 27,3-24,4 \times 14,0$.

$51 / 4-35,0 \times(19,8) 24,0-21,1 \times 12,7$.

\section{Z. zoniferus, Form naesiotes n. $f$.}

Taf. IX, Figg. 130/145.

1. Diese Art steht dem $Z$. zoniferus so nahe, daß man olne weiteres an eine Verschleppung denken muß. Freilich kann man sich eine solche zunächst schwer vorstellen, da die Stammform an der Westseite Mexikos lebt. Es kommt aber ein wenn auch junges Stück erklärend hinzu, das sich unter Z.undatus-maracaibensis-Formen tot in Pockliolzstämmen vorfand, 


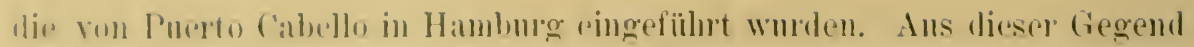

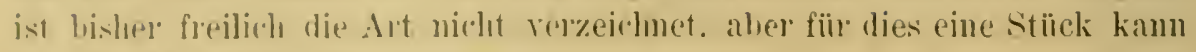
der Fumblort nicht fraglich sein.

II"ir bei der Z. undutus-maracaibensis-(vimple so ist anch hier, wohl

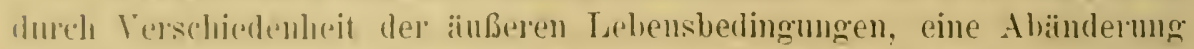
ringetroten, dies sich aus folgonder buirtermg der Schalencharaktere ergibt. hir nichıt unbedentenden individnellen Verschiedenheiten, welche immerhalh les groben Materials vorkommen, wïrden in anderen Fällen leicht eine Anfstollumg von Varietiten begriunden lassen, von der ich aber hier absehen mub. Weil die zusammengehïrgkeit zu iberzengend wirkt.

Das (iohänse ist durehweg dickschaliges und entweder schlank bezw. oval-konisclı, aber anch gedrumgener, ovaler mo mit kürerem Gewinde; is ist glanzlos oder mattglünzend. Bei dem selı großen mir vorliegenden Material hin ich in der Lage, die Tariationsweite sowohl in der Form wie anch in der '/eichmmg zur Anschammg zu bringen. Die Grundfarbe ist Weiplich, von den gelblich hornfarbigen ersten Windungen abgesehen, und hekommt nach den unteren Windungen zn mehrach einen gelblichen Anflug; sje lanm aber anch durchweg gelhlich sein. Die anfangs bramen Streifen werden zumehmend blamgrau oder grinlichgran. Wälıend sie anfangs noch die Neigung haben, wie beim 'Typus sich zwischen der Stelle ron Band 2 und 3 zu verbreitern, markiert sich die Stellung der Bänder 2, 3,4 spaitel meist nur durch wellige Vorspriinge. Vuweilen tritt damn auf ler Jetzten Windung an Stelle von Band 2 und 3, stärker noch bei letzterem und seltener bei Band 4, ein fleckenartiges Znsammenfließen anf, das bald schwach, bald deutlicher ansgeprägt ist. Eine eigentliche Zonenbildung tritt bei dieser Form nicht auf, nur um die Basis herum, umterhalb Band 4. tritt schon bei jiingeren Stiicken eine hellere Zone auf, die sich auch im Innern durch hellere, meist etwas bräunliche Färbung vou dem melu blau oder violettgranen Imnern abhebt. Hie erste Windung ist anch hier entwedu ungetiuht oder loram ahschattiert. Die Varixstreifen treten hald vereinzelt, bald häinfiger anf und sind schwarybram wie der schmal besäumte Hundrand und her schanf abgegrenzte ziemlich dicke Callus. Dis Spindel

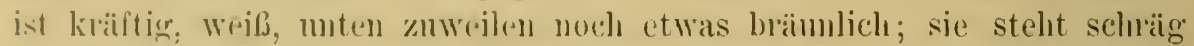
\%ur delse und ist in sich von vorn gesehen gerade, von der Seite geselsen mehr weniger atwas angebogen. Die Skulptur ist die typische des \%. minceps, bej jungen Stiicken dentlich ansger)rïgt, bei größeren auf der let»ten W'indıng häufig undentlich.

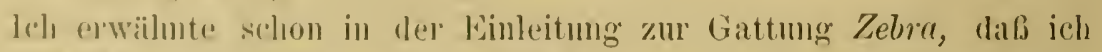

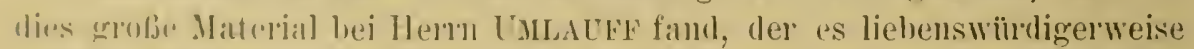

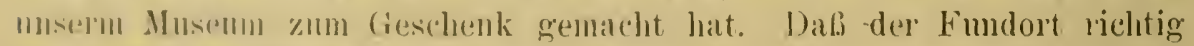
ist, seheint zwcifellos, höchstens könnte es sich noch um Barbados handeln, von woler sonst :ihnliche, wenn anch etwas kleinere Stïcke aus anderen 
Qnellen vorliegen. Ich gebe nun eine Reihe von Abbildungen, die ans der großen Menge ansgewählt sind, um möglichst alle Verschiedenheiten in Form und Zeichnung vorzufüluren, eine Verschiedenheit, die ähnlich der von $Z$. princeps aus der Misantla-Gegend ist, wo gleichfalls ein reiches Material vorlag. Die Figg. 130, 134/135, 139, 142/143 vertreten den Typus mit weißlicher Grundfarbe und den mehr blangranen, dichter gedrängten Streifen, die Figg. 131/132, 137 den Typus mit gelblicher Grumdfarbe, der anch meist etwas bauchiger ist, die Figg. 132/133, 142/143 den Typus mit weißer Grundfarbe und weitläufiger stehenden Streifen und endlich die Figg. 136, 138 einen Typus mit größeren Flecken in den Streifen, der anch zugleich von kleinerer Form ist.

Fig. 130.

" 131.

" 135.

$" 136$.

134.
$61 / 4-58,3 \times(27,8) 35,1-31,8 \times 19,1$.

$6-55,1 \times(27,8) 34,6-32,2 \times 18,2$.

$61 / 4-57,8 \times(28,7) 36,1-32,7 \times 19,7$.

Fast $6-43,6 \times(22,5) 27,2-24,9 \times 15,0$.

$" 6-52,0 \times(24,1) 29,3-29,4 \times 16,5$.

$-52,9 \times(25,7) 31,7-27,8 \times 16,0$.

$6-47,8 \times(24,0) 28,9-24,5 \times 14,4$.

$57 / 8-48,5 \times(24,3) 30,1-27,6 \times 16,0$.

$51 / 2-37,6 \times(20,8) 25,0-21,3 \times 13,1$.

$53 / 4-49,1 \times(25,5) 32,9-30,2 \times 17,7$.

$5 \frac{3}{4}-48,7 \times(26,3) 32,2-28,8 \times 16,5$.

$5^{3 / 8}-35,5 \times(20,8) 24,9-21,2 \times 12,7$.

$48 / 4-28,6 \times(17,2) 21,3-18,8 \times 11,4$.

$41 / 4--18,0 \times(11,6) 14,3-11,6 \times 8,5$.

$" 141$.

tte von W.F. WEBB, Rochester, N. Y.

O. undata

var. jamaicensis PILSBRY. Barbadoes. By PILSBRY. Danach scheinen diese zwei Stücke von PILSBRY selbst zu stammen, der sie dann offenbar verkannt hätte; denn mit der $Z$. undatus-Gruppe haben sie nichts zn tun, so daß ich eher an eine Terwechslung seitens des Händlers glanbe, der sie vielleicht glaubte mit anderen von PILSBRY als $O$. undatus erhaltenen Stïcken identifizieren zu können, denn alles, was von der Gattung Zebra auf Westindien vorkommt, wird ja meist für $Z$. undatus gehalten, eben weil es dort vorkommt. Die Stücke sind durchans typisch, nur kleiner.

Fig. 144. $\quad 5 \frac{3 / 4}{4}-44,0 \times(22,8) 29,0-25,2 \times 15,8$.

"145. $5 \% 4-45,4 \times(23,0) 29,4-26,6 \times 15,4$.

Ich laabe das eine Stïck von vorn, das andere von der Rückseite abgebildet. Das letztere zeigt nur sehr schwach die Flecke an Stelle von Band 3.

3. ROLLE vend. Etikette "Linnaea". O. zelra MÜLLIER. Barbados. Ein ansgewachsenes und ein junges Stück. Das größere gehürt dem kleinen Typus an und ist selır ähnlich dem Stück Fig. 136. 


$$
\begin{aligned}
& 5 \%-31.0 \times(21,0) 25,(0-21,3 \times 13,8 . \\
& 4 \%=0.2-(12.8) 15,8-12,7 \times 8,5 .
\end{aligned}
$$

1. I'nertu ('ilnello (?). In Astlöchern ron Pockholz tot in Hamburg impurtiert. bin junges stïck.

\section{\%. rexums $11 . \mathrm{sp}$.}

'Taf. X, Figg. $146 / 147$.

I h shliefe hiel ein Stiick an, das sich ebenfalls unter dem Material ron UMdAfFF yom Trinidad befindet, und das durch die melı oval-konische Form und die weniger schräge Aufrollung nicht mehr in lie Gruppe Z. lividus gehürt und sich durch die eingebogene Spindel und die doplyelte Fleckenreilie an Stelle von Band \& und 3 (schwächer in Band 4) dem Z. mulchelhs niiltert. Aher yon diesem weichen wiedermm die Form und die weniger foincul und weniger dicht gedringten Streifen ab.

Das Gehäuse ist festschalig, etwas glänzend und hat die Skmlptmr des \%. jminceps. Die Grundfarbe ist durchweg gelblich, oben etwas heller. Die weiflich belegten branen Streifen, und ilne dadurch, besonders anf der letzten IIindmo, bedingte grimlichgrane Färbung erinnern sowohl an Z. delplimus, Fin'm nebulosus, wie an einige Stiicke des rorangehenden $Z$. zoniferus, Form nuesiotes. Abgesehen von der Form erinnern Färbung und Zeichmmg auf (ler Rillkseite stark an die Fig. 189), nur daß anch an Stelle von Band 2 die dunkleren Flecke vorhanden sind. Das Stiick Fig. 139 hat ja anch eine etwas eingebogene Spindel, aber nicht so stark wie das rorliegrende. Die erste Windung ist anch schwarzbram abschattiert, aber der Mundrand ist anch nur kastanienbraum wie der dïnnstreifige Callus, und das Imnere läßt die Zeichmung selı dentlich durchscheinen.

$$
6-46,9 \times(24,4) 29,3-27,5 \times 16,2 \text {. }
$$

\section{Gruppe \%. pulrhellus.}

Diese kleine Grmple wird duch die Form prototypus dem Z.zoniferus,

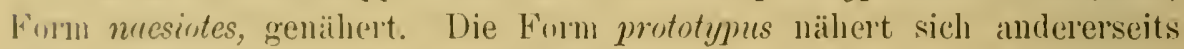
lur h \%. pitsbryi der Z. minceps-(irmpe.

In ihren typischen Formen ist sie oval mit getiumtem Gewinde und hat cinc eingebogene Spindel. Die Zeichnung besteht aus schmalen, zienlich dirht gedräingten streifen, die an Stelle der Bänder 2, 3 und 4, sei es in ainzolnen dersalluen oder in allen, in dunkelbrame, etwas belegte Flecke zns:ummenlliefun oder mu wellig bis winklig vorspringen. Die Bänder 2,3 mut 1 sind anferdem (ein\%lne von ihnen oder alle) in diesen Flecken

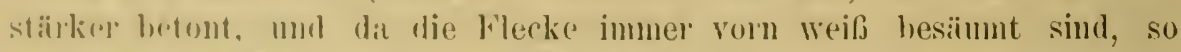

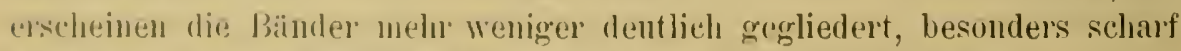
(l)gegrenz, wenn die Flecke nur schmal, melı ffeilfürmig sind. 


\section{Z. pulchellus SPIX (PILSBRY).}

Taf. X, Figg. 150/151, 154/156.

P., p. 135, Taf. 2S, Figg. 27-29.

SPIX' typisches Stuick, Taf. 9, Fig. 2, ist in der Form sehr verzeichnet, zeigt auch nicht die gegliederten Bänder, sondern nur wellige Ausbiegungen der schmalen Streifen. Ein derartiges Stïck liegt mir nicht vor, und befindet sich auch nicht unter den Abbildungen im PILSBRY, die ich nach dem mir vorliegenden Material für typisch halte, während die in SHUTTLEWORTH, Notit., p. 62, und vor allem die auf Taf. 4, Fig. 67, daselbst abgebildete Schnecke mir nicht hierher zu gehören scheint; Größe, Form und Zeichnung entsprechen durchaus nicht, wenn die Zeichnung nicht ganz verfehlt ist. Leider liegen mir nur wenige Stïcke mit sicherem Fundort vor, nach denen ich aber ausdrücklich feststellen muß, daß sie die typische Skulptur von $Z$. princeps haben, da PILSBRY nur von dicht gedrängten, feinen Spirallinien spricht. Der Wirbel ist bald ungefärbt, bald braun abschattiert. Die charakteristischen Merkmale der Zeichnung sind die meist feinen, dicht gedrängten Streifen, die im ganzen der Anwuchsrichtung folgen und nur. an der Stelle der Bänder entweder wellig ansbiegen oder zu Flecken zusammenfließen. Die Bänder sind meist dunkel und weißlich gegliedert, aber das Weiß kann anch bräunlich werden, und von den Bändern 2-4 fallen zuweilen 2 und 4 aus. Innerhalb der Mündung bemerkt man vielfach an der Basis eine mehr weniger breite hellere Zone.

1. Koll. Scholvien. O. zebra, Bahia. Vier Stiicke, darunter mur ein ausgewachsenes, welche genau P., Fig. 27, entsprechen, weshalb eine Abbildung unnötig ist.

$$
5^{3 / 4}-40,9 \times(21,9) 26,6-23,7 \times 14,8 .
$$

2. Aus meiner ehemaligen Sammlung. Etikette $O$. bifulguratus REEVE, Brasilien. ZweiStücke, das größere durchaus dem vorangehenden entsprechend.

$$
\begin{aligned}
& 55 / 8-38,0 \times(20,5) 25,2-21,9 \times 13,6 \\
& 51 / 2-32,2 \times(17,8) 21,6-19,0 \times 11,6 .
\end{aligned}
$$

Das kleinere Stïck weicht dadurch ab, daß Band 3 auf der letzten Windung durchgeführt ist und unterhalb eine schmale helle Zone zeigt, die dann durch die Flecke unterbrochen wird. Band 4 ist auch durchgeführt, breiter und nur durch dunklere Flecke der Streifen unterbrochen. Ich werde ein ähnliches größeres Stück, das sich unter 3. befindet, abbilden.

3. Nr. 5473, alte Sammling. O. phlogerns ORB. Ohne Fundort. Zwei Stücke. Das größere entspricht in der Zeichnung durchaus der Fig. 27 in P., ist aber viel schlanker. Das kleinere zeigt auf der Torderseite bis zum Varixstreifen genau die unter 2. erwälnte Zeichnung des kleineren Stïckes, während auf der Rückenseite wieder die Zeichnung von P., Fig. 27, auftritt. 


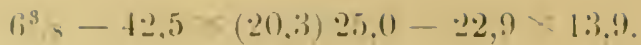

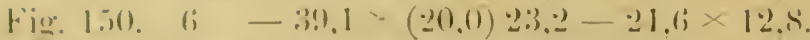

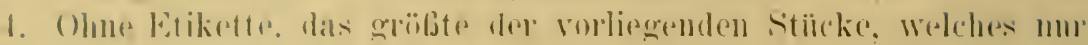

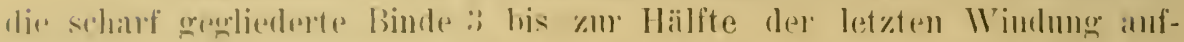

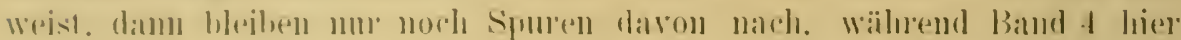

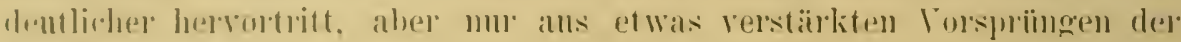
streiten bestelit.

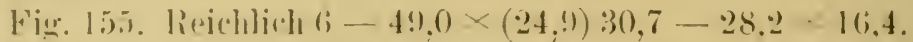

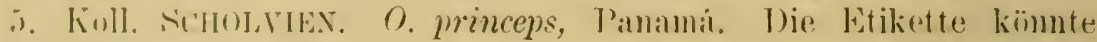

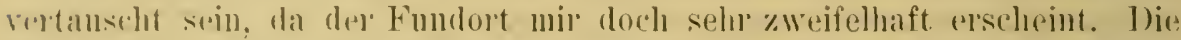

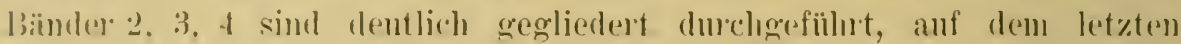
brittel der letzten 11 indung allerdings undentlicher und mu durch Vere stïlkmg der welligen Vorspriunge der Streifen angerlentet. Es fellt in dell cregliederten Bändern das Weif.

Fig. 156, $61 / 4-43,7 \times(22,7) 27,5-24,0 \times 14,8$.

(i. ('x Koll. SuHst. Ohne Etikette, ein Stïck wie 1'., Fin. 27.

7. Alte Sinmmlmng Nr. 5(is!). Ohne Namen mu Fundont. Ein stiuck wie Fig. 15f, aber in den Bändern zeigen sich weife Flecke.

Fig. 154. (i - 46,2) $(23,3) 28,5-26,2 \times 15,6$.

8. TMLALFF ded. Insel Trindad. Zwei Stiicke, zmsammen mit Finlul prototypus 4.

Fig. $151.51 / 2-35,0-(19,2) 22,6-20,2 \times 11,7$.

\section{\%. pulrlellus, Fol'm mototymus PILSB.-STREBEL.}

T'af. X, Figg. 148/149, 152/153, 157, 159/160.

Vergl. P., p. 137, Taf. 28, Figg. 31-36.

Ich verweise auf das bei 7. pilsbryi Gesagte. Fü die Entscheidung der Zugehörigkeit der mir vorliegenden Stïcke habe ich besonders die when angefülnten Fignem im Auge, wemn auch bei den größeren Stiicken die sprindel mehr eingebogen ist als bei den jïngeren, zu wellom alleh lie Figruen in P. gehören. Soweit die Stücke gont erhalten sind, zeigt sich

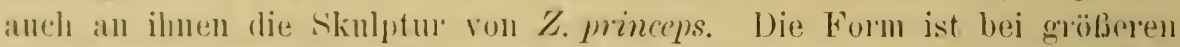
Stïcken wenigure schlank, be\%w. das (iewinde ist kiïzer als bej $Z$. pulchellus. Die erste Windume ist bramschwar, die Grundfarbe ist gelblich weif his orangufarbig und besonders auf der ober'n Hälfte der let\%ten Windung

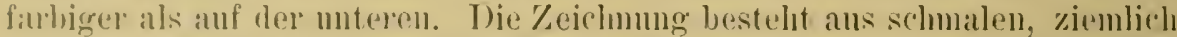

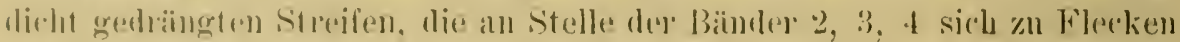

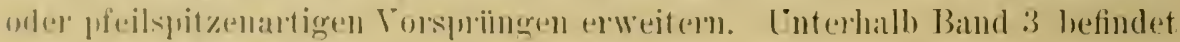

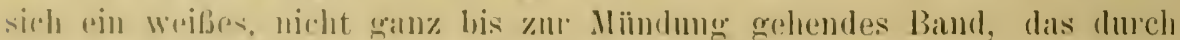

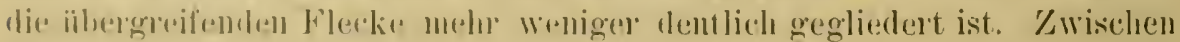
land I und j jist an jungen Stiicken, bei denen Band 2-5 dentlich aus- 
geprägt ist, eine hellere Zone. Der Mundrand ist schmal kastanienbraun besäumt, außen melir braunschwarz, und der Callus ist farblos oder teilweise hellbräunlich. Das Innere ist weißlich belegt mit durchscheinender Zeichnumg.

1. Berl. Museum. Koll. DunKER. Bul. undatus var., Bahia (BESCKE). Figg. 148/149. $\quad 5^{3 / 4}-41,2 \times(21,9) 27,5-24,0 \times 14,8$.

2. Nr. 15441. Brasilien. Drei junge Stücke.

Fig. 159. $5 \quad--25,0 \times(14,7) 18,2-15,8 \times 9,6$. " $160.5-23,6 \times(14,0) 16,9-14,6 \times 9,2$. $5^{1 / 3}-26,8 \times(15,0) 18,1-15,8 \times 9,3$.

3. Das SENCKenbergsche Museum besitzt folgende, den vorstehenden genau entsprechende Stücke, die leider alle jung sind.

a) Etikette O. pulchellus, Brasilien. Ein Stïck.

b) Etikette Bul. rugicollis, Neu-Granada. Ein Stïck.

c) Etikette O. undatus juv., Veneznela. Zwei Stücke.

4. Unter dem mehrfach erwähnten UMLAUFFschen Vaterial von Trinidad befanden sich auch sieben Stïcke, die, alle vom gleichen Typus, den sub 1. und 2. verzeichneten Stücken entsprechen. Die Verschleppung kaun vom Amazonenstrom oder vom Orinoco, nach den Fundorten des Frankfurter Museums auch von Venezuela oder Columbien aus stattgefunden haben, wenn die Art nicht schon vor der Abtrennung der Insel vom Festlande dort vertreten war.

$$
\begin{aligned}
\text { Fig. } 157 . & 5 \frac{1}{2}-40,8 \times(21,8) 27,2-25,6 \times 15,1 . \\
" 152 . & 5^{1 / 8}-31,7 \times(17,2) 21,8-19,1 \times 11,7 . \\
" 153 . & 4 \frac{3}{4}-21,7 \times(13,2) 16,3-13,7 \times 8,6 .
\end{aligned}
$$

\section{Gruppe Z. mars.}

\section{Z. mars PFR.}

Taf. XI, Figg. 168/173, 175.

Pfeiffer, Monogr. Helic. VI, p. 202. Proceed. Z. S., London, 1861, p. 25, Taf. 2, Fig. 8. P., p. 143, Taf. 53, Fig. 42.

O. ponderosus. SP., p. 35, Taf. VII, Figg. 1, 5-8. M. ${ }^{2}$, p. 181, 190, Taf. 11, Figg. 10, 10 a. O. decolor PIlsbry nec Strebel. P., p. 131, Taf. 54, Figg. 43-47.

O. decolor, Form C. SP., p. 3S, Taf. I, Fig. 5 .

O. melanochilus von MaRTens partim. nec VALENC. M. ${ }^{2}$, p. 190, Taf. 11, Figg. 7 , 7 a.

Mit Bezug auf das Terhältnis dieser Art zu den von mir in SP. aufgestellten 0 . ponderosus und decolor habe ich mich in der Einleitung ansgesprochen. Die in SP. gegebene Beschreibung für O. ponderosus kann danach für $Z$. mars bestehen bleiben, nur wäre noch folgendes linzuzufügen. Die Art zeichnet sich durch kräftige Schale aus, es treten in der Form zwei Typen auf, wie sie durch die Figg. 168, 175 gekenn- 
zeirhnet werden, nïnlich cine hreitere, gleichübiger narh unten zmohmende

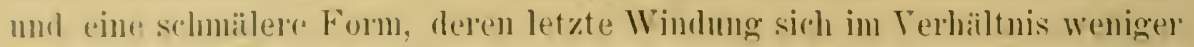

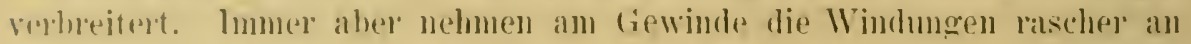

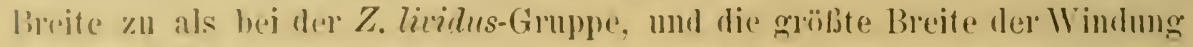
ist meln nach oben geriickt. Eine scharfe Tremmmg der heiden oben anterenteten Typen der Form lïbt sich aber nirbt durchfïhren. Die

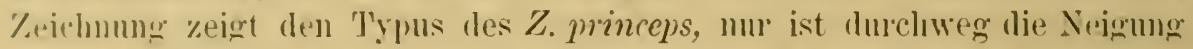
ronhandur, daf die Zeichnme anf der letzten Windung sich dahin verindert, dals die Streifen das Zickzackartige oder Gewellte rerlieren mo vinfach werden, weitläufiger stehen uder ganz aufhüren. Die Bänder ftlegen anf den ldzten Windungen dentlicher hervorzutreten, die dumkle Färbung des IVirbels erstreckt sich ron $1 \frac{1}{2}-21 \% 2$ Windungen, und iiber Varixstreifen. Mundrand und (allus ist das Nähere in sP. gesagt. Die Spindel steht hald greraler, bald schnäger zur Achse, anch ist sie meh" weniger verdickt, und zwal besonders in der mteren Hälfte, wodurh sie mehr wernger dentlich in der Mitte durch eine schräge Furche geteilt erscheint, ein Lmstand, der PFenfFer veranlaht lat, die Alt in die Gattung Conona zu strllen, in die sie aber nicht hineingehört. Dic Spindel ist meistens unten dunkelbraun gefäbt, sie kann aber auch weiter hinanf an ihrer Aufenscite dunkel gefäbl sein, so dab nur imen ein schmaler weißer Rand b]eibt. 1)as Innere ist immer rein weif, mit meln weniger dentlich durchscheinenden Varixstreifen. Die Skulptur ist die des Z. princeps, nur ins Grobe iibertragen. l)ie letzte Windmg erscheint meist etwas weitlänfig gerieft mo an der Naht scharf und dichter gefaltet, anch ist die Nalit meistens mit "inel schmalen helleren \%one berandet. Die Art hat anch ihre heterom. melunochitus mit Übergängen zu der typischen Form.

1. Koll.SoHst, von Mazatlan, drei Stïcke rom 'Tyums der Figg.172, 169.

2. Koll. O.SEMPER, von Manzanillo, H. Jürgessex leg. Ein defelites Stiick vom Typus der Fig. 17:2.

3. Rolle vend. C'olima. 15 Stïcke vom Typus del Figg. 169, 172, von denen ich nur der Vollständigkeit laalber ein jumges Stück abbilde. Fir. 170. $\quad 5^{3 / 1}-49,0 \times(27,3) 32,2-28,2 \times 16,3$.

4. Berl. Musemm. O. ponderusus, Dos Arroyos, 25 miles NE. of Acapulco. H. H. Suтrн. Zwei Stïcke, die zusammen mit acht Stiicken des Z. miles mili liegen.

$$
\text { Fig. 172. } \left.\quad 6^{1 / 2}-62,9\right)(32,7) 39,0-33,2 \times 17,5 .
$$

5. ex kinll. Gonefrioy, Ni. 14765. O. mars PFr., Mexiko. Eim stiirk, das sioh fast mit dem PFEIfFerschen 'Jypus deckt mod mur etwas

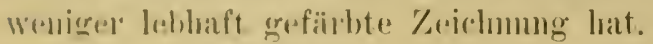

Fïig. li!!. $7-7: 9,0 \times(31,9) 41,4-36,1 \times 19,9$.

6. Lerl. Musemm. Konll. PAETLE. Mexiko. O. ponderosus. Zwei typische Stiicke, seln ihnlich dem vorangehenden Stiick. 
7. Tier Stïcke von englischen Händlern als O. mars erbalten, von denen ich die beiden abgebildeten an Herrn EDG. A. SmITH in London zum Vergleich mit dem Typus schickte.

$$
\begin{aligned}
\text { Fig. 175. } & 63 / 4-76,2 \times(39,0) 48,7-41,6 \times 23,1 . \\
\Rightarrow 168 . & 6 \frac{5}{8}-69,0 \times(32,0) 38,5-34,8 \times 17,9 . \\
& 6 \% / 8-75,2 \times(33,7) 40,5-37,2 \times 18,8 . \\
& 6 \frac{1}{2}-59,1 \times(30,3) 36,4-32,0 \times 16,1 .
\end{aligned}
$$

8. Koll. Scholvien. O. mars PFR., Peru. Drei Stïcke im Typus der Figg. 175, 168.

9. Berl. Museum. Das in M.², p. 190, erwähnte, von DoHRN erhaltene Stiick von Juraty, M. Amazonas. Es ist nicht ausgewachsen, entsplicht aber durchans dem Typus von Fig. 172.

Fig. 173. Fast $6-56,3 \times(27,0) 34,0-28,0 \times 16,1$.

Es sind noch viele Stücke ohne Fundort vorhanden, die aber keine besondere Abweichungen zeigen. Ich will nur anführen, daf sich darmuter auch die beiden $O$. ponderosus befinden, die in SP. beschrieben und auf Taf. VII, Figg. 7 und 8, abgebildet sind. Sie haben folgende Maße:

$$
\begin{aligned}
& 61 / 4-53,4 \times(26,3) 32,2-29,3 \times 15,5 . \\
& 65 / 8-64,6 \times(31,8) 38,8-33,6 \times 18,0 .
\end{aligned}
$$

Das erstere Stïck scheint eine Zwergform zu sein.

10. Aus der ScHOLVIENschen Sammlung liegt ein merkwürdig schmales Stück vor, das aber in der Zeichnung und Färbung typisch ist. Die Windungen sind etwas weniger gewölbt als sonst. Es ist O. obductus, Tampico, bezeichnet. $\mathrm{Ob}$ die Etikette vertanscht ist oder ob nur eine falsche Bestimmung vorliegt? Auffallend ist der Fundort, da von der Ostkïste Mexikos bis jetzt keine solche Formen bekannt sind. Vielleicht liegt ein Schreibfehler vor, und es soll Tepic heißen.

Fig. 171. $\quad 6 \frac{1}{4}-58,5 \times(29,1) 35,0-31,4 \times 16,9$.

\section{Z. mars, heterom. melanochilus.}

Taf. X, Figg. 163/166; Taf. XI, Figg. 174, 176.

1. Ein Stïck aus meiner ehemaligen Sammling, von La Paz, UnterCalifornien, das in SP. als O. decolor, Form C, p. 38, beschrieben und auf Taf. I, Fig. 5, abgebildet ist. Nach dem jetzt vorliegenden Material erweist es sich als hierher gehörig, aber als Übergangsform, denn es zeigt noch schwache Zeichnung.

Fig. 176. $\quad 6 \frac{1}{8}-55,6 \times(29,2) 34,8-30,7 \times 16,2$.

2. ROLlE vend. Colima. Fünf Stïcke, darunter zwei echte heterom. melanochilus, wie sie in M. ${ }^{2}$ als melanochilus VALENC., Fig. 7, 7 a, abgebildet sind. Ich bilde das Stück mit schwachen Bändern 2-5 ab, das andere hat keine ausgeprägte Bänder. 


$$
\text { Fig. 166. } \begin{array}{r}
6 \%-57,5-(29,8) 37,3-31,2-18,3 . \\
61 / 4-57,0 \cdots(29,7) 37,1-30,6 \times 17,0 .
\end{array}
$$

l)ie anderen drea stiicke sind ̈̈bergangsormen, die noch Reste ron \%ejelmumg anfweisell.

$$
\begin{aligned}
& \text { Fin. l64. } 6 \%-57,9 \times(30,7) 3(6,1-3), 1 \times 17,8 \text {. } \\
& \text {, 165. } 51 / 2-391,0-(2,2,9) 27,8-24,0-14,3 \text {. } \\
& \text { " 163. } 6 \% \text { - } 63 \%, 5)(31,0) 38.2-33,0-19,0 \text {. }
\end{aligned}
$$

$\therefore$ Rolde rend. (). melenochilus var., Eonador. Ein Stïck, das bis

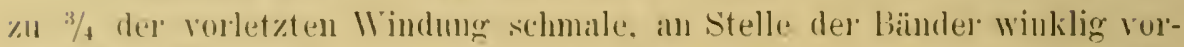

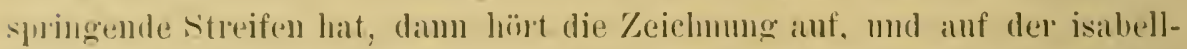
farbigen, ins Zimtlarbige übergehenden firundfube sind die Bänder 2, 3, 4 schwath angedentet. Man kam das siürk anch als eine val. den typuschen Formen anreilen, denen ess in allen übrigen Charakteren gleicht; in dew Form entejuricht es der Fig. 172.

$$
61 \% 2-65,9 \times(33,2) 39.8-33,5 \times 18,7 .
$$

4. I)as in SP., 1. 36, als ponderosus, Form B, anfqueülnte, rtwas almorme stiuck ist anch eine Ühergangsform, das der Fig. 163 ihnlich ist und nu ein kïl\%eres Gewinde hat.

Fig. 174. $59,1 \times(30,3): 37,3-33,8 \times 17,1$.

\section{Z. mars, Folm alecolom. STREBEL.}

'Taf. XI, Fig. 167.

SI', p. 37, Taf. VII, Figg. $2-4$.

Ich muf diese Form rolläufig abgesondert halten, die walnscheinlich

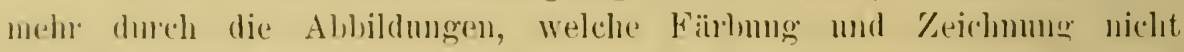
chankteristisch wientergegeben haben, von PILSBIT rerkannt ist, so dald a. mntre diesem Nannen, wie schon in der Einleitung aluserefiihnt wurle,

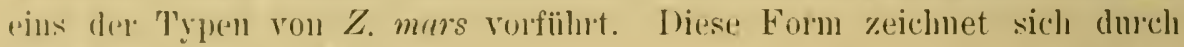
das follen hreiter Streifen und die falle, bräunlichgrane Fiabung ded

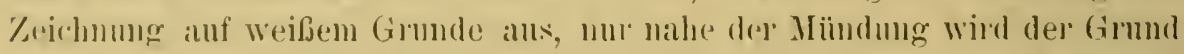
lacht braimlich. Irh hale unter dem mir vorliegenden groben Material des typischen Z. mars keine ähnlich abweichende stïcke gefunten. Leider ist die Herkunft selı msirher.

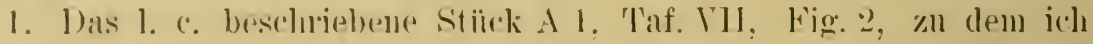

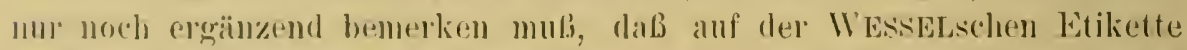
m:priunglich Bul. unduhs, Costa Rical, stand, dam ist mit Bleistift mars dazngeschricben.

2. Dies 1. c. Inter A2 erwilnte stiick hat leider keinen Fundort. lis weidht vost dem voranguhenden mur dureh die Gröbe al).

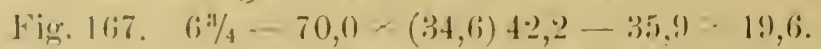

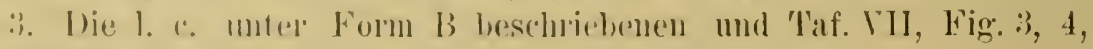

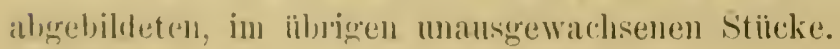




\section{Z. uhdermus VON MARTENS.}

Táf. X, Figg. 158, 161/162.

VON MARTENS liat in M. ${ }^{2}$, p. 189, diese Form als Varietät dem vermeintlichen $Z$. livens angegliedert, wohl weil ich das betreffende Strick in SP., p. 32, für diese Art gehalten, beschrieben und anf Taf. XI, Fig. 19, abgebildet liabe. Er hat die Abweichnng von $Z$. livens SHUTTLEworTH wohl erkannt, aber nach meiner Anffassmg gehört sie elıer in die Z. marsGruppe, denn sie lat die älnliche Art des Aufbans und anch das System der Färbung und Zeichnnng, nur ins Kleine übertragen. PILsBRY reiht sie als var. dem $O$. longus an, worin ich ihm nicht zustimmen kamn, wenigstens nicht nach meiner auf PFEIFFERs 'Typus gegrïndeten Auffassung dieser Art. Ich lasse deshalb diese Form als Art für sich bestehen. Leider sind die Mehrzahl der wenigen mir vorliegenden Stïcke in schlechtem Zustande, doch zeigen sie iibereinstimmend die Charaktere des typischen sub 1. aufgeführten Stïckes.

Die Form ist, wie gesagt, die des $Z$. mars, insoferlu anch die größere Wölbung etwas oberhalb der Naht der letzten Windung liegt; nur ist das Gewinde höher im Verhältnis znr letzten Windung. Das System der Zeichnung ist sehr ähnlich, auch hier verschwinden die Streifen im letzten Drittel der letzten Windnng, in welchem damn die Bänder 2, 3, 4 teils gegliedert, teils durchgefïhrt hervortreten. Auf der vorletzten und den ersten $2 / 3$ der letzten Windung treten die Bänder gegliedert anf, indem sie in den winkligen Verbreiternngen der Streifen stark betont sind. Am Wirbel ist nur die erste Windnng dunkelbramn abschattiert. Die Varixstreifen sind schmal schwärzlich, nach hinten mit einer ziemlich breiten blangrauen Zone besäumt, ganz wie bei $Z$. mars. Der Mundsamm innen, das Imnere, der Callus mnd die Spindel verhalten sich ganz wie bei $Z$. mars.

1. Berl. Musemm. UHdE. Michoacan. SP., Taf. XI, Fig. 19. Das Stück ist, wie dort erwähnt, abgekocht, und die Spindel ist ansgebrochen.

$$
6 \% 4-54,1 \times(25,7) 29,3-25,0 \times \text { ? }
$$

2. Ein gleiches Stïck ans unserer Sammlung, leider ohne Etikette.

Fig. $158 . \quad 7-54,7 \times(26,7) 30,5-25,7 \times 14,8$.

3. Koll. O. Semper. Acapulco. HelLwege, November 1878. Ein großes, leider verwittertes Stiick, das nur kaum noch die Zeichmung erkennen lüßt, aber unstreitig lierher gehört.

Figg. 161/162. $\quad 7 \frac{1}{4}-65,6 \times(29,0) 33,7-28,7 \times 16,0$.

\section{Z. grucheri n. $s p$.}

Taf. XVI, Figg. 252/253.

II.', p. 32, Taf. 1, Fig. 7. O. maraeaibensis ,PFR.

VON MARTENS 1. c. spricht sich selbst über die Abweichmigen von o. maracaibensis aus, meint aber, daf dies Stiick ein abnormes sei und 
mit seinem O. formssnci \%nsammenfalle, mud \%wall besonders wegen der kiim\%eren Mïndung gegeniber der llühe des Gewindes. Die Abbildmng

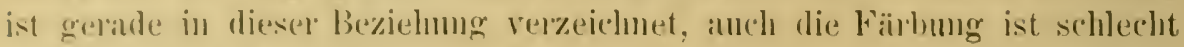
getroffen, grall anstalt bram. Bei dem Vergleich mit O. undahes ist, wie anch besomlers ans sejnel Zasammenstellung in Malak. 131. 1865, Vol. 1:2, 1. 4. hervorgeht, offenbar an die var. jumuicensis, nicht an den echten U. mulatus (nach P'ItsBril) gedilcht.

Bei dem vorliegrenden stiick, das ich noch mal in der Vordel- mo Riackenansicht korreliter ahbilde, handelt es sich mo keine der horangroogenen Formen, demn wem das Stïck anch auf der 4. Windumg eine beschädigung zeigt und dadmeln vielleicht etwas im Anfban becintlubt ist, so passen doch die sonstigen ('haraktere nicht zm Gruple Z. undatus mol näluern sich meln dem $Z$ : uhdeunus durch kïrzere Mïmlung, Z. princepsskulptur. braunschwar\% abschattierten Wirbel und breiten pupurschwarzen immeren Mundsium und ebenso gefäbten Callus. Anch die grane Zone hinter den Varixstreifen mod das Fehlen der durchscheinenden Bänder in weiben Inuern sowie die rerdickte, etwas gewumdene und ziemlich senkiecht stehende spindel sprechen für die Terwandtschaft mit Z. uhdeanus.

Die Gromdfarhe ist weif, nahe der Mündmug gelblich. Die Streifen sind bram, die breiteren derselben graburam; sie sind nur an Ende der vorletzten Windung lneit mol nach oben gegabelt, sonst sind sie meist schnnal und an Stelle der Bänder 2, 3, 4 winklig rorgezogen. Anf der letztern Haifte der letzten Windung treten noch mal schwache breitere strufen anf, aber lifer werden die Streifen iiberhanpt schwädrer in der Farbe. Von Bändern sind rom Ende der vorletzten Windung an 2, :3 und 4 durch stärkele Betommg in den Streifen erkembar, mod zwar :2 und \& nu schwach, 3 etwas dentlicher, mu nahe der Mündnug münden alle drei Bïnder als schwache, nicht minterlochene streifen ans.

$$
\text { Fast } 6 \%
$$

Jas Stiick stamme aus der ALBERsschen Sammlung mul ist rou GRUNER in Danacibo gefunden. Ls ist eine von den Fonmen, die gerade

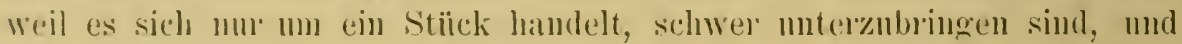
dir man trotzdem für sich halten mulj, his weiteres Matejial eine butscheidung bringt inwieweit dabej etwas Anormales in frage kommt.

\section{2. miles $11 . .51 \%$.}

'I'af. XII, Figg. 18:3/184, 186/189.

Gehaimse fostschlaligr, oval-konisch his oval-spindelfürmig. Am ziemlich

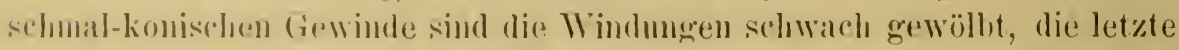
ist nach- moten otwas satckartig erweitert, besonders dentlich bei den grö̈ljeren Stïcken. Her Wirbe] ist ziemlich spitz, anf $1-1 \frac{1}{2}$ Windmogen 
schwarzbramn abschattiert. Die ersten Windungen sind hornfarbig, dann tritt eine weißliche Grundfarbe auf, die auf der vorletzten und letzten Windung zunehmend gelbbraun mit zuweilen grauem Anfluge wird. Die Zeichnung ist auf den oberen Windungen die des $Z$. princeps, d. h. es sind breitere, nach oben gegabelte Streifen vorhanden, die noch einigermaßen lebhaft braun gefärbt sind; später wird diese Zeichnung, welche die Streifen auf der letzten Windung auch nach unten gegabelt zeigt, sehr verschwommen, doch erkennt man noch eine Konturierung der Streifen mit Rotbraun. Bald auf der ganzen, bald nur auf einem Teil der letzten Windung hören die Streifen ganz auf, und anstatt ihrer treten die Bänder 2, 3, 4 mehr weniger deutlich hervor, Band 5 erkennt man als dunklere Zone um das Spindelende herum. Die Varixstreifen sind schmal, schwärzlich, nach rüickwärts nicht mit der blangranen Zone besäumt wie bei $Z$. mars. Der Mundrand ist innen sehr breit purpurschwarz ausfließend besäumt, und eine gleiche Farbe hat der Callus. Das Innere ist bläulich weiß mit lebhaft durchscheinenden breiten, ausfließenden Streifen. Die Spindel verhält sich ähnlich wie bei $Z$. mars, doch ist sie meistens nicht so stark verdickt. Die Skulptur ist dieselbe.

VON MARTENS fülurt diese Art in M. ${ }^{2}$ unter $O$. ponderosus auf, und Taf. 11, Fig. 9, soll ein Stiick von dem unten verzeichneten Fundorte darstellen, das, wenn es nicht verzeichnet ist, sich nicht unter den mir vorliegenden acht Stücken befindet.

Die Art nnterscheidet sich im Aufban der Windungen und in der Zeichnung leicht von Z. mars. Sie gehört wohl in die Gruppe, doch steht sie etwa in der Mitte $z$ wischen $Z$. mars und meiner $Z$. sphinx-Gruppe, von der sie sich aber auch im Aufbau und in der Zeichnung unterscheidet. Auch in dieser Art tritt neben dem schmalen ein etwas breiterer Typus wie bei $Z$. mars und auch eine Zwergform auf (Fig. 188).

Fig. 188. $\quad 6^{3} / 8-46,9 \times(23,7) 27,1-23,9 \times 13,4$.

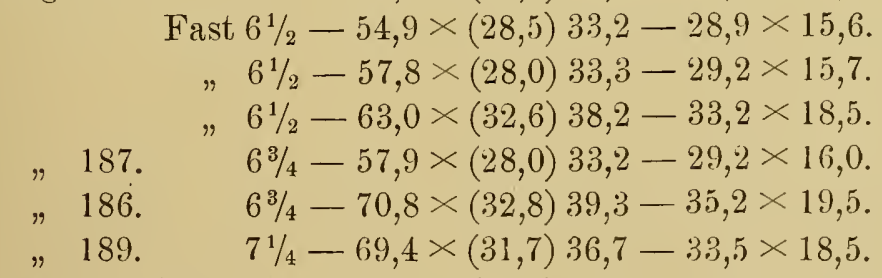

Figg. 183/184. $6^{5} / 8-62,5 \times(31,3) 37,7-31,4 \times 17,8$.

Fundort: Dos Arroyos, 25 miles NE. of Acapulco. H. H. SMITH leg.

\section{Gruppe Z. mas's-lividus.}

Hierunter fasse ich eine Formenreihe zusammen, die durch Termittlung des $Z$. hackeri mihi und $Z$. miles die $Z$. mars-Gruppe mit der 
7. lividus-Gruppe ineinmoler ïherführen. I)ie Form des ruamses ist mehr die znsinmengerulte der ersteren (rruples, hezw. der Mïndungs-

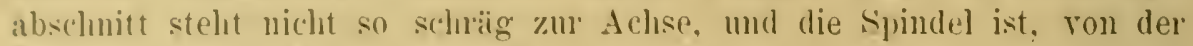
Saite gesehen, nicht so eingebogen wie die der Z. lividus-Gruple. Eins der hierher gehörigen stitcke habe ich in SP., p. 31, mit O. lividus-princeps bezeichnet, da in der 'Tat die Zeichnung anch an Z. princeps erimnert. aber das gleiche gilt auch ron Z. mars, und dieser Gruppe steht sie doch durch die Zuichmung des $Z$. miles näher. Die Skulptur ist dieselbe vergroüherte des $Z$. mars, die ja aber in ilnem $Z$. princeps-System für alle bisher behandelten Gruppen dieselbe ist. Die scharfe Faltung an der Naht ist ja anch ein allgemeines Merkmal, das ebenso wie die feinere Spiralskulptur immer nur mehr weniger dentlich ansgeprägt ist. Die Formen gehören eben zu denjenigen, die man nicht recht nnterzubingen weiß, und stellen doch im Grunde rerschiedene Typen dar.

\section{2. sphinx 21. sp.}

Taf. XII, Figg. 181, 185.

SP., O. lirilus-princeps, p. 31, Taf. I, Fig. 6.

Gehäuse festschalig. oval-konisch, ziemlich glanzlos. Glundfarbe oben weif.lich, dann gelblicher werdend, erste Windmg bramschwarz abschattiert. Die Zeichmmg besteht ans bramen, vielfach rot konturierten Streifen. die auf del letzten Windung melı in Dunkelbramngan übergehen. Sie sind meistens nach oben und unten gegabelt, und meistens an Stelle der Bänder winklig vorspringend, streckenweise zwischen Band 2 und :3 stark verbreitert, aber auch zwischendurch wieder schmäler. Nahe der Mïndung und $m$ m die Basis hören die Streifen anf, und es treten dort dann die Bänder 2, 3, 4 meln weniger dentlich hervor, die nach rïckwäts sich nur al) mol zu und sehr undeutlich durch stärkere Betonmng in den Vorsprimgen der Streifen kenntlich machen, und zwar meist nur Band 3. Brannschwal\%, schmale Varixstreifen treten rereinzelt auf, der Mundrand dagegen ist immen lreit purpurschwar\%, bram ansfließend berandet; dieselbe dmkle Fürbmg lat der Callus. Das Tmmere ist weif mit dentlichen breiten. Inamen, gran ansflefenden Varixstreifen. Die Sprndel ist weif mit brammon unteren Ende; sie stelit senkirecht oder etwas schüg zur Achse und ist, W'an verdickt wie bei dem sub 1. verzeichneten Stiick, wie die ron Z. mars beschalf(un, sonst muten nicht so dentlich abgestutzt.

1. Berl. Mnsemm. O. ponderosus var., 'Tepic. Richardson. Ein Stïck. Figg. 181, 18. . $\quad\left(3^{3} / x-(i 2,0 \times(31,7) 37,7-32,7 \times 18,8\right.$.

2. Nr. 150:3:, das in SI'. als lividus-princeps angefïhrte mol auf Taf. J.

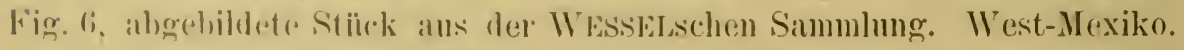

$$
\left(3^{5} \cdot 8-(i 1,2=(32,2) 40,7-34,6 \times 19,7 .\right.
$$


3. Koll. Scholvien. Ohne Etikette. Ein Stück, durchaus dem sub 1. verzeichneten Stïck entsprechend, nur ist die Spindel nicht so stark verdickt.

$$
61 / 2-61,5 \times(30,3) 37,4-33,3 \times 18,5 .
$$

4. RoLLE vend. Colima, als ponderosus. Eine kleinere Form, weicht in dem scharf Geriefelten der letzten Windung ab.

$$
61 / 4-54,5 \times(28,3) 34,7-29,7 \times 16,5 \text {. }
$$

5. ex Koll. ScholvieN. Ohne Etikette. Ein Stiick mit höherem Gewinde, das aber eine starke Beschädigung am Anfang der letzten Windung zeigt, so daß hierin anch die Ursache dieser Abweichung, wenigstens zum Teil, zu suchen ist.

$$
7-63,0 \times(29,0) 35,0-30,7 \times 16,7
$$

\section{Z. sphinx, Form latestriata n. $f$. Taf. XII, Figg. 177/178.}

Ein Stïck ans der SoHSTschen Sammlung, das zusammen mit Z. mars von Mazatlan lag, das aber dem ganzen Aufbau, der Färbung und dem Typns der Zeichnung nach hierher gehört, wenu die Streifen auch durchweg breit und lebhafter braun sind. Die Spindel ist wenig verdickt und steht ziemlich schräg zur Achse.

$$
6^{3} / 8-62,5 \times(31,1) 36,6-33,2 \times 19,1 .
$$

\section{Z. sphinx, Form «onata n. $f$.}

Taf. XII, Figg. 179, 182.

Diese kleinere aber hierher gehörige Form ist in der zonenartigen Zeichnung dem $Z$. delphinus, Form vividus, ähnlich, indem auf $2 / 3$ der letzten Windung die zwischen Band 2 und 3 breiten Streifen nach oben und unten schmal gegabelt sind; nahe der Mündung hören die Streifen wieder auf, und die Bänder 2, 3, 4 treten, wenn auch schwach, wie beim Typus hervor. Die Färbung der Streifen ist anch lebhafter brann, mit stellenweise rötlicher Konturierung. Die Varixstreifen sind schmal braumschwarz, der Mundrand dagegen innen breit purpurbraun ausfließend gesäumt, auch der Callus ist purpurbraun. Das Innere ist weiß mit breiten purpurbraungrau ansfließenden Streifen. Die Spindel steht wenig schräg zur Achse, ist mäßig verdickt und unten braun gefärbt.

1. Nr. 15710. WESSEL vend. ans meiner ehemaligen Sammlnng. O. zebra, Brasilien. Ein Stück, das ich s. Z. mnter O. princeps, Form E, p. 16, einbegriffen habe.

Figg. 179, 182. $6-55,3 \times(27,0) 34,3-29,7 \times 17,0$.

2. Berl. Museum. Bul. undatus Brug. Koll. Dunker. Puerto 


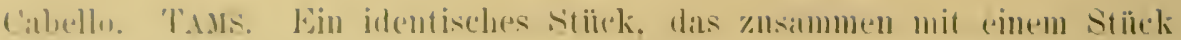
\%. obluctuss lang.

$$
.3 / 4-49.5 \times(25,3) 30,0-28,0 \times 15,4 .
$$

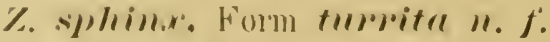

'Taf. XII, Jị. 180.

llies stiuk zrigt demselbun Typus in der allgememen Form. in der \%edelnumg und in der Mïndungspartie, es ist nur viel schmäler im Verhailtnis \%m Hïhe.

B»l. Museum. O. longus? T'Tes Marias. ForRer. (Insel gegeniiber sim bils. 11 --Mexiko.)

$$
\left(i^{5} / 6-5 f .9-(2.5 .5) 30.5-26.4 \times 14,4\right. \text {. }
$$

lliese Form nähert sich dem Z. longus, ist aber sowohl in der Formu

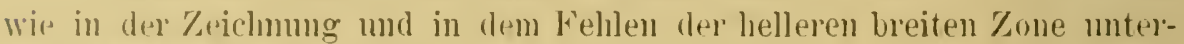
hall, der Naht rel'sehieden.

I)je folgenden Formen näher'n sich einerseits der Z. mars-Gruppe, andererseits aber lijetet jede derselben Eigentïmliehkeiten, die vin $/ / n$ simmenfassen untunlich erscheinen lassen. Ich ziehe es daher vor, sie nach dem Nimen der Hamptypen gesondert zu lassen.

\section{Iong/1s PFR.}

'Taf. XIIJ, Figg. $190 / 192$.

$\therefore$ P., p. 43, Furm A, 1, 2, Taf. VI, Figg. 1 h, c. 2 I. $^{2}$, p. 181, 189. P., p. 126 partim, 'Tif. 21 , Fig. 34.

Inh habe der 1. ‘. gegebenten Beschreibung nur noch hinzuzufiigen, dilf alle drei mir jetzt vorliegenden stïcke mur ganz vereinze]t noch simen der fuineren \%. minceps-Spiralskulptur zeigen, trotzdem sie gut

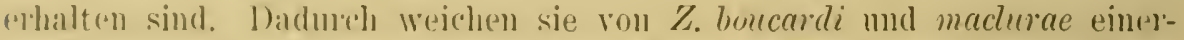
soits, sowie ron Z. mars und uhdenn andererseits erhehlich ab. Die

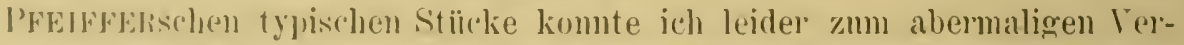
gleich nimt mhaltrn. aber die mir vorliegenden stïcke, von denen das Berliner stïck ja schon danals als identisch anferefülnt wurde, erweisen

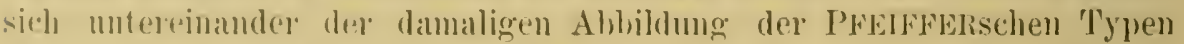
gleich. Die dumkelbramme reste Windme, das Band'2 anf der 3. und 4. Windung mod Simmen von liand I, ferner die auf dem Gewinde nach

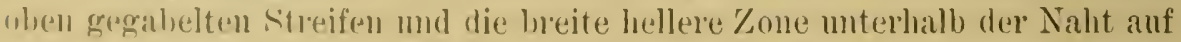

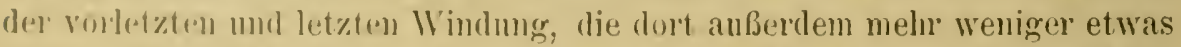
limbla oder doch alogeplattut ist, das alles sind charakteristische Merkmale, dir bei don Folmen, die PIssBkY als $Z$. longus anffïhrt, wie er 
selbst sagt, abweichen. Das gleiche gilt von dem zur PILsBRYschen Form gehörigen Form Z. longus in FC., p. 450, pl. 18, Fig. 4, trotzdem dort gesagt ist, daß PFEIFFER das ilm davon ïbersandte Stiick für $Z$. longus erklärt habe. Die Form allein mag ihn dazu bewogen haben, denn bei genanem Vergleich hätte er zum mindesten eine Absonderung als Varietät anempfehlen mïssen. Außerdem ist aber zu bedenken, daß die vielen Formen von der Westküiste Mexikos, die eine genaute Unterscheidung notwendig machen, PFEIFFER noch nicht bekannt waren.

1. Berl. Musenm. Uhde. Michoacan. SP., p. 43, Form A, 2.

$$
65 / 8-55,4 \times(26,0) 31,0-26,3 \times 15,8 \text {. }
$$

2. Ein Stück unseres Museums, ohne Fundort, identisch mit dem vorangehenden.

Figg. 191/192. $\quad 61 / 2-50,0 \times(24,3) 29,6-24,1 \times 14,2$.

3. Frankfurter Museum. Ein Stück von RoLLE mit der doppelt falschen Etikette O. zoniferus, Veracruz, Mexiko, erhalten. Es weicht nur von den vorangehenden durch ein verhältnismäßig nicht so hohes Gewinde ab, sonst ist es in jeder Beziehung identisch.

Fig. 190. $63 / 8-57,1 \times(27,0) 32,4-28,0 \times 16,3$.

Den PILsBRYschen O. longus stelle ich in die Nähe von $Z$. boucardi.

\section{Z. machurcue VON MARTENS.}

Taf. XIII, Figg. 193/203, 206/207.

O. maclurae von Martens. II. ${ }^{2}$, p. 1SS, Taf. 11, Figg. 1-3. P., p. 125, Taf. 21, Figg. 40-42. FC., O. melanochilus, p. $4 \check{8}$, Taf. 18, Figg. 5, 5 a.

Von dieser von VON MARTENS aufgestellten Art liegen mir mehrere Stiicke einer zum Teil größeren und auch etwas mehr ins Breite gehenden Form vor, die alle von der Westküste Mexikos bis linunter nach Tehtantepec stammen, während der Typus von der Fonseca-Bay in Nicaragua kommt. Von den dazwischen liegenden Gebieten fehlen bisher Funde. Eigentlich mïßte man die größere und etwas breitere Form, die ich in SP. als O. ponderosus-boucardi beschrieben habe, als die typische ansehen und den vON.MARTENSschen Namen einziehen, aber der damals gegebene Doppelname ist in diesem Falle nicht ganz zutreffend. Solche Doppelnamen sind ja in der Nomenklatur nicht gebränchlich, ich würde sie trotzdem anch ferner anwenden, wenn sie tatsächlich dije Eigenart beider dazu benutzten Artnamen dentlich aufweisen. Im vorliegenden Falle mag aber der VONMARTENSsche Name bestehen bleiben. Die Artdiagnose bedarf aber selbst für den VON MARTENSschen Typus noch einiger Ergänzungen. Das Gehäuse ist festschalig, seine Form zeigt anch den schmäleren und breiteren Typus wie bei $Z$. mars, wie denn überhaupt Färbung und Zeichnung melhr dieser Gruppe entsprechen. Aber neben der hell berandeten Naht macht sich 


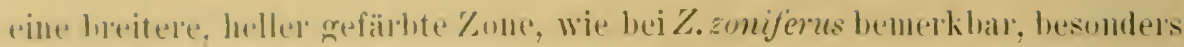
deutlich bei den dumkler gefiubten Stitcken, aber anch bei der heterom. melanochilus. L'un die Basis herum befindet sich ebenfalls eine lelle bis weibe Zone. 1)ie Bäindel 1-4 sind meist dentlich mod zusammenhängend durchgefiilnt, selten muterbrothen, doch kommt es rereinzelt vor, dalj sie anf del gan\%en orler anf einem 'Teil der letzten Windung verschwinden. Thas weibe lnuele zoigt die anben rorhandenen Bänder in schwächerer Färbung. I) je lanstreifen mud die skulptur verhalten sich ganz wie bei $Z$. mars.

Ilie Art stelıt dem Z. mars näler als dem Z. longus.

1. II. ‥ 181. 188, 'T'af. 11, Figg. 1-3. P., p. 125, T'af. 21, Fig.g. 40-41. $7 / m$ Vergleich lilde ich die Fig. 1 in M. ${ }^{2}$ hier nochmals ab. Nicaragna. Figg. 193, 198. $5 \%$

2. ROLLE rend, als O.ferussaci und $v a r$. trivinchus, Colima. Drei Stiicke. Fig. 194. $\quad 5 \frac{3}{4}-45,8 \times(24,7) 29,(j-25,3 \times 14,6$.

Figo. 206/207.6-54,8×(28,5) $35,0-29,3 \times 17,7$.

l)as größere Stiick zeigt eine seltene Abweichung. Erstens ist anf den mittleren Windungen mur Band 2 vorhanden, anf der vorletzten und letzten Windnng fehlen die Bänder überlaupt, und zweitens verhalten sich am Ende der rorletzten bis gegen Nitte der letzten Windung die streifen abweichend ron ihrem sonstigen Habitus, indem sie selı schmal und eng gereiht stehen, wem sie anch in sich etwas gewellt sind.

3. ROLLE rend. Ein Stïck der heterom. melanochitus, an dem. mu' am Anfang der 5. Windung die Bänder 2, 3, 4 sichthar sind, die später franz rerschwinden. Die gelbe Fïrbung der letzten Windung mit der Irellen breiten \%one muter der Naht und an der Basis sind anch lier vorlanden, ebenso wie die dunklen, nach hinten ansfließenden Varixstreifen.

$$
61 / 4-5) 2,5 \times(27,0) 33,2-28,7 \times 16,6 \text {. }
$$

Die Etikette besagt: O. princeps var. unicolor. Insel Tres Marias, Staat Jalisco. ForRER.

4. Nr.15042. Vergl. SP., p. 39, Taf. I, Figg. 4 a, h. 1)rei Stïcke ron T'elnantepec, von denen ich nu das kleinste abbilde.

$$
5: 3,7 \times(27,8) 34,1-28,2 \times 16,6 .
$$

Fig. 195. $47 / 8-25,0 \times(16,0) 19,8-16,8 \times 10,0$.

5. Koll. O.semen. Böndnamaus leg. T'ehmantepec. Sechs Stücke, datunter drej typische und drei heterom. melunorlitus.

$\begin{array}{ll}\text { Fig. 196. } & (; 1 / 4-53,7 \times(26,5) 33,2-29,0 \times 16,1 . \\ \text { Figg. } 197,202 . & 53 / 4-46,8 \times(25,5) 29,6-26,0 \times 15,0 . \\ \text { Fig. } 20(1) & 5)^{7} / 8-50,0 \times(25,8): 31,4-27,9 \times 15,8 .\end{array}$

"19!. Fast $5-26,3 \times(16,5) 19,8-16,3 \times 10,0$.

.201. Resichlich $5 \% \frac{34}{4} 48,0<(25,4) 30,7-27,0 \times 15,2$.

Jas let\%tere stiick lildet einen Übergang zur heterom. albinus, insofern nur anf de+ let\%ten W'indung die Bänder :3, 1 cine Strecke weit sichtbar sind. 
Die gelbliche Färbung dieser letzten Windung läßt die breite helle Zone unter der Naht dentlich erkennen. Die Tarixstreifen sind heller, und Mundrand und Callus sind unr violettbraum gefürbt, nicht purpurschwarz. Das Stück Fig. 200 entspricht dem O. melanochilus in FC., Figg. 5, 5 a.

6. ex Koll. Scholvien. Ohne Fundort. Drei Stïcke, von denen ich eins abbilde, dem auf der letzten Windung die Bänder ganz fehlen. Fig. 203. $\quad 6^{3} / 8-54,4 \times(29,0) 35,1-29,4 \times 18,0$.

7. Zwei Stuicke heterom. albinus. Es sind das reine Albino-Formen, mit granen Varixstreifen und farblosem Wirbel, Mundsaum und Callus.

Reichlich $6-52,7 \times(27,0) 32,4-28,8 \times 16,7$.

$$
61 / 4-50,3 \times(27,0) 33,2-27,0 \times 17,4 \text {. }
$$

8. UnLaUfF ded. Insel Trinidad. Ein mansgewachsenes, durchans typisches Stück.

$$
51 / 2-37,5 \times(21,8) 26,0-22,5 \times 12,4 .
$$

Auffallend ist vorläufig noch dieser Fundort, da von Suidamerika diese Art bisher noch nicht verzeichnet ist.

\section{Z. maclurce, Form turrita.}

Taf. XIII, Figg. 204/205.

Mir liegen drei Stücke einer getïrmten Form vor, die nach den beiden darunter befindlichen melanochilus-Formen wegen der scharf ansgeprägten Bänder $1-4$ (wenigstens am Gewinde) und den sonstigen Charakteren hierher gehören, und nur durch das löhere Gewinde abweichen. Das dritte Stück ist eine heterom. albinus. Ob es sich hier um heteromorphe Formen einer besonderen Lokalform oder nur um individnelle Abweichungen handelt, läßt sich nicht entscheiden.

1. Berl. Museum. RoLLE. O. melanochilus. Es ist das in M.. ${ }^{2}$, Taf. 11, Fig. 6, abgebildete Stück ohne Fundort.

$$
6^{5} / 8-56,2 \times(27,6) 32,8-29,0 \times 16,9 .
$$

2. Koll. ScHOLVIEN. Ohne Fundort.

$$
\text { Fig. 205. } \quad 6^{3} / 8-57,9 \times(26,6) 33,5-30,5 \times 17,2 \text {. }
$$

Das Stiick ist dem vorigen Stïck gleich, nur etwas entfärbt.

3. Koll. O. SEMPER. Tehuantepec. BöDdINGHAUs leg. Das Stück ist eine reine heterom. albinus und lag bei den sub 4 . verzeichneten Stïcken $Z$. machurae.

Fig. 204. $6^{5} / 8-59,0 \times(29,5) 35,1-30,5 \times 18,0$.

\section{Z. pseudo-longus n. sp.}

Taf. XIV, Figg. 208/209.

? O. longus Pil.SBry nec PFr. P., p. 126, Taf. 21, Fig. 33 ; Taf. 22, Figg. 1, 2, 6. FC., p. 450, Taf. 18, Fig. 4.

Ich erwähnte schon bei $Z$. longus PFR., daß PILSBRYs O. longus nicht mit dem PFEIFFERschen Typus ïbereinstimmt und wesentliche 


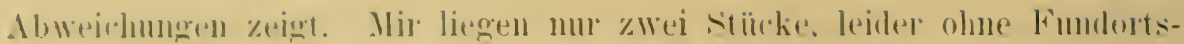

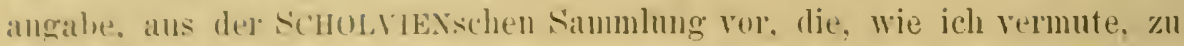

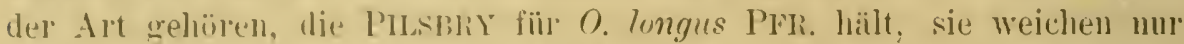
darin ab, dals sowohl der imnere Mundrand wie der Callns mogefärbt sind.

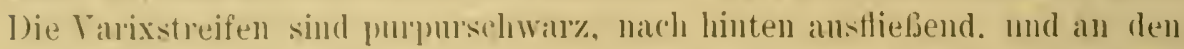
breiteren Stücken dam noch in eine grane anstlefente /one iibergehend. Die spindul steht seln schräg zur Achse, ist in sich etwas gewunden und ziemlich kräftig. I)as Junere ist gläinzend weib nit schwach durchscheinenden lauixstreifen. T)ie Skulptur ist die des Z. mars.

Fig. 209. 6\% - 58,2 - (27,4) $32,8-29,4 \times 16,4$.

"208. $\quad 6 \%-60,0 \times(30,0): 37,1-31,2<18,7$.

Diese mir vorliegende form, ol, sie mum mit dem Z. longus PILsBbir ihbereinstimmt oder nicht, muß jedenfalls einen nenen Namen haben.

\section{Gimple 2. boucrinti.}

\section{Z. boucardi PFR.}

'Taf. XIV, Figg. 210,216, 219/22:3.

O. boucardi P'Fk. P.Z.S., London 1860, p. 13\$, Taf. 51, Hig. 7. In Monogr. Helic., Vol. S, p. 263. FC., p. 451 , Taf. 18 , Figg. 3,3 a, b. SP., p. 40, Taf. I. Fig. 1 a-c, 2 a--d, f, g, nec Fig. 2 e. II. ${ }^{2}$, p. 15 7 , Taf. 11, Figg. 4, 5, 11. P., p. 12s, Taf. 20, Figg. 20-22, $24-26$.

PFenfFer lat in Monogr. Helic., Tol. 8, p. 20(3), an Stelle seiner ursprïnglichen Diagnose, die von Fischer und CROsse anf@efülnt. Fr meint mit diesen Autoren, daßsein urspringlich abgebildetes Stïck so wie FC., Fig. 3, junge Stücke, wiihrend FC., Figg. 3̇ a, b, ansgewachsene seien. Das ist nun wohl ein Irrtum, dem die brämnlichgelblich gefäıbten Stuicke kommen ebenso gut ausgewachsen ror, wie die mit rein weiljer Grumdfarbe. Auch der ron Fischen und CRosse erwilmte stmmpe hiel ist keineswegs immer vorhanden. Eine andere frage ist, ob solche verschiedene Typen zusammen vorkommen, order ob sie örtlich getrenut anftreten, wortiber nuch gemane Daterl ansistelen.

Der in SP. gegehenen beschreibung der Art wibte ich nichts hinzızufiigent.

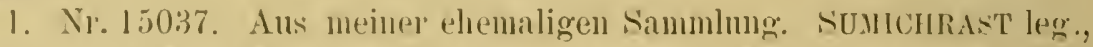

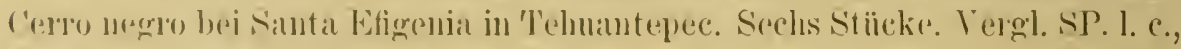
Form A, 1, Taf. 1, Figrg. 2a-d.

2. Nr. 15047. Ans meiner ehemaligen Simmlung. Ohne Fundort,

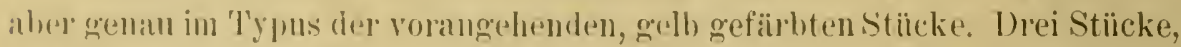
datron ain junges. Hire sind die bejden verschiedenen Formen vertreten.

Figg. 210, 211. Reichlich 53/4-49,6- $(26,8): 31,5-28,5 \times 15,6$.

Fig. 213. $6-48,6 \times(26,0) 31,5-25,7 \times 15,4$.

Dis letztverzrichnete stiick entspricht SP', Form B, 3, 'T'af. I, Fig. 2 f. 
3. Koll. O. SEMPER. BÖDdINGHAUs leg. Tehuantepec. O. undatus. Ein Stïck mit gelber Färbung.

$$
\text { Figg. 220/221. } 6-50,7 \times(27,8) 33,1-27,8 \times 16,7 \text {. }
$$

4. Berl. Museum. Oajaca. HöGE leg. Ein besonders großes und schönes Stïck mit weißer Grundfarbe, das die braunschwarzen Streifen anf den mittleren Windungen nach rïckwärts rötlich konturiert zeigt. Auf der letzten Windung sind granschwarze mit kastanienbraunen Streifen untermischt, die Streifen, sind schmal und zum Teil wellig. Auf der 4. und 5. Windung ist Band 3 über der Naht dentlich ausgeprägt.

Fig. 212. $63 / 8-55,9 \times(28,2) 34,9-29,5 \times 17,1$.

5. Nr. 15043. Zwei Stïcke, angeblich Orizaba. Vergl. SP., Form B, 2. Taf. I, Fig. 1 a.

6. Berl. Museum. Ohne Fundort. Ein merkwürdig gekieltes Stück, das am Anfang der 6. Windung oberhalb der Naht eine Bruchstelle zeigt, vou wo ab die Kielung auftritt. Abweichend vom gewöhnlichen Habitus ist der Wirbel dunkel gefärbt, und auf der 3. und 4. Windung sind Band 2, 3 unterbrochen vorhanden.

Figg. 214/215. $\quad 6^{1 / 8}-52,8 \times(28,2) 34,7-28,3 \times 17,8$.

7. Koll. O. SEMPER. Mexiko. Cumng, boncardi PFR. Ein kleines weißgrundiges, dentlich gekieltes Stïck mit wenig Zeichnung und vielen schwarzen, grau ausfließenden Varixstreifen.

Fig. 219. $6-44,6 \times(23,3) 28,1-22,8 \times 14,0$.

8. UnLaUfF ded. Insel Trinidad. Ein nicht ansgewachsenes Stïck. Es ist in jeder Beziehung typisch, nur ist auf dem letzten Drittel der 5. Windung an Stelle von Band 3 ein Doppelstreifen vorhanden, der sich dann noch sehr abgeschwächt eine Strecke fortsetzt. Der innere Mundrand ist schmal schwarz berandet, der Callus dagegen farblos.

Fig. 216. $5 \frac{3}{4}-41,2 \times(23,2) 28,3-23,2 \times 14,1$.

9. Koll. SchoLvien. Ohne Fundort. Sechs Stïcke einer eigenartigen Form, die offenbar von einem anderen Fundort als die bisher verzeichneten Stücke stammt. Die vier Stïcke darunter mit typischer Zeichnung sind auch nach unten zu gelblichbräunlich, aber auf den letzten Windungen werden die auf den oberen Windungen braunschwarzen Streifen mehr kastanienbraun, etwas ausfließend und zum Teil durch etwas hellere Bänder unterbrochen, auch ist an ein paar Stücken eine breitere hellere Zone unterhalb der Naht bemerkbar. Der Mundrand ist inuen schmal schwarzbram berandet, der (allus dagegen ist farblos.

Fig. 222. $\quad 61 / 4-53,0 \times(28,3) 33,5-28,3 \times 17,2$.

"223. $61 / 4-50,7 \times(25,9) 30,3-27,4 \times 15,3$.

$6 \frac{1}{4}-53,0 \times(28,2) 33,2-28,4 \times 17,3$.

$6-4.3,7 \times(24,1) 28,8-24,5 \times 14,3$.

Die anderen beiden stiicke folgen. 


\section{\%. bencrneli-heterom. melnnochilus.}

'l'af. XIJ. Figg. $217 / 218$.

1. Die beiden zu den vorangehenden gehörigen Stïcke, ron denen das rrste der Mafjliste oben noch \%eichmme in lellbramer Farbe zeigt. Die larixstreifen sind fast orangefarlyg, der Mundrand ist imnen schmal rotbram anstliefernd. und der (allus ist farblos. Das kleinere Stuick hat anf der letzten Ẅindung anfangs deutlich, spaiter verschwommen die Bänder 1-4. 1) Mundrand ist imnen zimnoberrot, der llirbel ist braun und der ('allus lellbram anstliefend. Es kimm bei diesem letzten stïck fraglich sem, ob es nicht zи $Z$. machume gehört, denn die Form ist ovaler.

Fig. 218. $6-47.1 \div(25,8) 31,0-26,3 \times 15,5$.

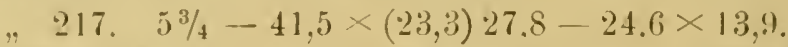

2. Nr. 150:26. Ans meiner ehemaligen Simmlung. SumcHRASt leg. ('ero negro bei Santa Efigenia, Tehmantepec. Finf Stïcke, zusammen mit $Z$. boucurdi, die sub 1. verzeichnet sind. Vergl. SP., p. 42, Form C, 'T'af. I, Figg. 1 b, c.

$$
\begin{aligned}
& 61 / 2-62,3 \times(32,1) 39,0-32,5 \times 19,2 . \\
& 61 / 4-57,5 \times(30,1): 35,7-30,5 \times 17,6 . \\
& 6-49,0 \times(25,9): 31,3-27,0 \times 15,5 . \\
& 5^{3 / 8}-37,3 \times(21,7) 25,9-22,2 \times 13,3 . \\
& 5^{3 / 8}-34,7 \times(19,7) 24,3-21,2 \times 12,2 .
\end{aligned}
$$

I)as erste und letzte Stiick entsprechen den Fignren in SP., 'T'af. I, Fig. $1 \mathrm{~b}, \mathrm{c}$.

\section{Z. boucarli heterom. xunthus.}

Koll. Scholviex. Olne Fundort. Ein Stïck mit nach muten zu hellırämulicher Färbung. Einzelne Streifen auf der vorletzten Windung, wo der Grund noch heller ist, sind hellbram, und die Varixstreifen sind hell granbram. An Stelle von Band 2 und 3 treten Anfang der letzten W'indung lıelle schnnale Bänder' auf, und auf dem größeren 'Teil der letzten I"indung befindet sich muterhalb der Naht eine hellere breite Zone. Der Mundrand ist lellbräunlich, der Callus ist farblos.

$$
6-52,2 \times(27,8) 34,5-28,0 \times 17,0 .
$$

\section{L. boucurdi heterom. rlbimus.}

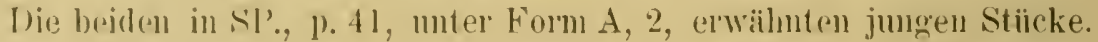

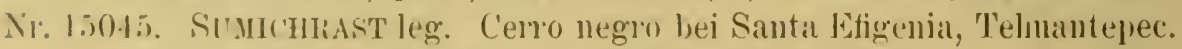

$$
51 / 4-31,9=(18,7) 22,6-18,4 \times 71,5 .
$$

\section{2. bourerredi, Form adustus.}

'T'af. XIV, Fim. ․․ㄹ.

Aus dou Berline Museum, leidel olme Fundort, liegt ein merkwiurdiges stück vor. 1) Wirbel ist wie bei $\%$. boucurdi, anch die ersten 
$4 \frac{1}{2}$ Windungen haben noch eine entsprechende fleckige und streifige schwarzbraune Zeichnung auf weißlichem Grunde, dann wird aber die Grundfarbe zunehmend gelb bis braun mit etwas granem Anflug, auf der anfangs schwarze, nach vorn hellgelblich konturierte, etwas gewellte Streifen stehen, die dann auf der letzten Hälfte der letzten Windung immer schwächer werden, und sich wenig von der Grundfarbe abheben. Die Varixstreifen sind schmal, scliwarzbraun, der imnere Mundrand ist dagegen ziemlich breit purpurschwarz gesäumt, und von gleicher Färbung ist der Callus. Das Innere ist weißlich mit violettem Anflug und den durchscheinenden, dunklen, hier weiß berandeten, unregelmäßigen Streifen. Die Spindel ist nicht verdickt, in sich von vorn gesehen gerade, aber schräg zur Achse stehend. Die Skulptur ist die übliche des Z. boucardi. Ich bemerke noch, daß die Naht nicht kreidigweiß wie bei $Z$. bouccurdi, sondern nur schmal ausfließend hell berandet ist.

$$
61 / 4-55,7 \times(27,3) 33,0-29,7 \times 17,5 .
$$

\section{Z. boucardi, Form zebriola.}

Taf. XIV, Figg. 229/230.

O. boucardi-ponderosus mihi. SP., p. 39, 1, Taf. I, Figg. 3 a, b. Leider ohne Fundort.

Ich gebe hier zu der 1. c. gegebenen Beschreibung nochmals eine Abbildung und die Maße. Nr. 15050.

$$
6^{3 / 8}-52,7 \times(26,3) 31,2 \times 28,8 \times 15,8 .
$$

Die nur weißlich berandete Naht wie auch die Zeichnung im ganzen entsprechen dem $Z$. boucardi, aber die ovalere Form des Gehäuses und der farblose Callus weichen ab. Der Mundrand ist graubraun ausfließend, aber schmal berandet.

\section{Z. boucardi, Form zoniferus.}

Taf. XIV, Figg. 224/225.

Zusammen mit dem Stücke der Koll. O. SEMPER, von T'eluantepec, BöDdINGHAUs leg., das unter $Z$. boucardi Nr. 3 verzeichnet ist, liegt dies eigenartige Stück, das man auf den ersten Blick für $Z$. zoniferus mihi halten könnte; aber es ist weniger schräg aufgerollt, hat die gelblichen ersten Windungen und die kreideweiß berandete Naht des $Z$. boucardi, und die Streifen sind auf den mittleren Windungen breiter. Auf der letzten Windung bemerkt man eine breite, etwas hellere Zone nnterhalb der Naht, aber diese Zone wird hier nicht so deutlich wie bei Z. zoniferus durch die Zeichnung hervorgehoben, denn die Streifen sind im allgemeinen breiter und stehen weitläufiger. Auf einem Teil der letzten Windung werden diese Streifen treppenartig in der helleren Zone, sonst verlaufen sie nur 


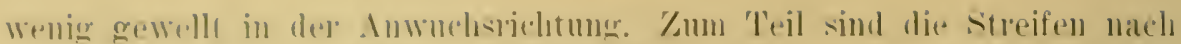

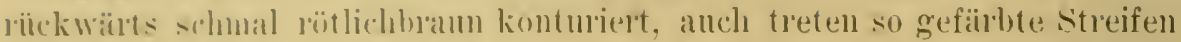
\%wisclen den eraubramen sowie auch einzelne rötlichbranne Wolken anf der let\%ten IV indung auf. Die Varixstreifen sind bramselwaw\% mo selmal, nalch linten zum 'T'eil schmal gran ansfliefjend. D) Mundsamm ist imen selmal bramgram berandet, der ('allus ist furblos, und das Imere ist weib mit durcholemenden streifen. Dic sknlptur ist die typische.

$$
6^{1 / 4}-5 s, 7=(30,2) 37,7-31,7 \times 18.9 \text {. }
$$

\section{Z. bourarali, Form strebeli PILSBRY.}

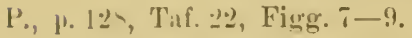

Ähnliche stücke wié die l. c. beschriebenen liegen mir nicht ror, die weder eine reine heterom. melanochilus, noch albinus sind. PILsBRY strllt sie als liuretait zu seiner O. longa, die ich in Z. pseudo-longus untaufe, da, wie ich anseinandel'setzte, ler echte $Z$. longus PFr. etwas anderes ist. Ich meine, sie paßt besser hierher.

\section{Gimpe Z. obriuctus.}

\section{と. obrluctu: SHUTTLEWORTH.}

'Taf. XT, Figg. 232-236.

SHITtLil, Not. Ialak., p. 61, Taf. III, Figg. 1-3. JI.', p. 33. SP., p. 33, Taf. III, Figg. 7a, b?, c. II. ${ }^{2}$ p. 187. P., p. 134, Taf. 25, Figg. 31-32?, 33-36.

Es kijmnte mach den SIUTTLEWURTHschen Abbildungen fraglich erscheinen, ob alle spaiteren Antoren die richtige Art mit diesen Namen belegt laben, denn sie geben weder die Form noch die /eichnumg so wieder, wie man sie an den allgemein für $Z$. obchotus gelaaltenen Stiicken sielat. I)ie Abbildumgen Figr. 3:3-36 im PILsBRY sind sogal noch weniger lichtig getorffell, weml. Was nicht anzmnehmen ist, ilmu nicht etwas ganz anderes vorlag. Die Buschreibmgen passen dagegen gut, besonders die

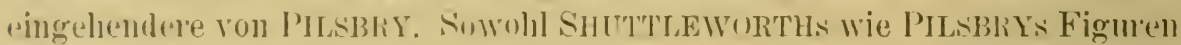

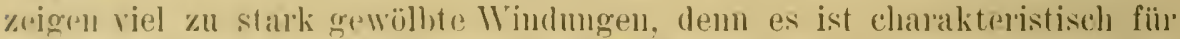
dir Art, dals das Gewinde, wie anch PIssblil in der Diagnose sagt, einen durch die Wölbung d(p' Windungen mur sehr wenig gestïrten Kegel mit

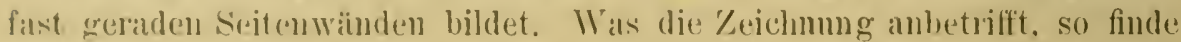
ich mutı den mir vorliegenden über j() stücken kein emzines, das so

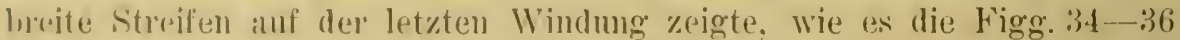
in P. \%rigen, die allerdings von Callatas stammen, und die anch gröfer sind, wie Phankr bencrkt, als die von Puerto Cabello. Von Caracas liegt mil kein Material ror. Nach dem mir vorliegenden* Material ist der 'I'ypus dar Zoichmung folgonder. Am Gewinde her'scht die Z. princeps- 
Zeiclmung vor, damn werden die Streifen aber stärker belegt, d. h. graner und nach der Mündıng zu zunehmend schmäler, so daß sie früher oder später fast ganz verschwinden. An Stelle der Bänder 2, 3, 4 treten anfangs noch fleckenartige Verbreiterungen auf, die nach vor'n ab und zu noch hell berandet sind, die aber auch rasch schmäler werden, so daß hierdurch die Bänder teils undentlich gegliedert werden oder doch ans dicht aneinander gereihten, stärker betonten Winkeln bestehen. Ab und zu sind besonders Band 3 und 4 durchgehend neben jener Zeichnung dunkler gefärbt. Die Varixstreifen sind meist nach vorn hell berandet. Im Innerı, das weißlich mit bläulichgrauem Anfluge gefärbt ist, markieren sich die Bänder nur schwach, die Tarixstreifen deutlicher. Die Spindel steht immer mehr weniger schräg zur Achse, ist in sich wenig gewunden oder, von der Seite gesehen, etwas ausgehöhlt. Die Skulptur ist auf der vorletzten Windung noch meistens selır deutlich die des Z. princeps, anf der letzten Windung wird sie undentlicher, so daß man meistens nur stellenweise Spiralstreifen erkennt. Die Naht ist immer scharf gefaltet.

Ich habe zu den Abbildungen die Figg. 234/235 für die charakteristische Form ausgewählt, die anch zugleich die am meisten vertretene Zeichmung wiedergibt, bei der die breiteren Streifen schon mit der letzten Windung aufhören, während in der Fig. 236 die Verbreiterung noch im ersten Drittel fortgesetzt wird und hier eine Annäherung mit den PILsBRYschen Figg. 34, 36 bietet. Ich muß aber dazu bemerken, daß die sowohl bei $O$. obductus als auch bei 0 . princeps var. deceptor von PILSBRY angedentete Ähnlichkeit beider Formen mir nicht einleuchtet, denn sowohl die Form des Gehäuses wie auch die Färbung und Zeichnung sind meiner Ansicht nach nicht miteinander zu verwechseln. Ich muß auch ferner bemerken, daß die mir vom Rio Chagres-Gebiet und von Coban vorliegenden, allerdings jüngeren Stïcke sich in nichts von Stïcken gleicher Größe von Columbien und Venezuela unterscheiden, so daß die in SP. unter Form A aufgeführten Stïcke alle zn Z. obductus gehören. Die Form B ist Z. crossei, und die Form C wird allerdings wohl zu Z. fischeri = deceptor PILSBRY gehören. In den Figg. 232-233 A habe ich jüngere Stadien der Art dargestellt.

Z. obductus ist als Art, wie auch PILSBRY bemerkt, durchaus charakteristisch und leicht von anderen Arten der Gattung durch Form und dunkle Färbung des Gehäuses zu unterscheiden. Er steht gewissermaßen in der Mitte zwischen $Z$. princeps und Z. maracaibensis einerseits, bezw. dem echten $Z$. undatus andererseits, und besonders ist es die Form gracilis, welche die Vermittlung mit Z. maracaibensis bezw. ferussaci übernimmt, wie es besonders in dem jüngeren Stiick dieser Form, Fig. 231, zutage tritt.

1. Berl. Museum. Koll. DunkER. Bul. undatus. Puerto Cabello. G. TAMS leg. Drei Stïicke. 
Fic. $236 . \quad 63^{3}+62.0=(30.9) 39,0-36,33<19.7$. $\left(i^{3}{ }^{3}-60,1-(31,4) 38,9-39,4<19,9\right.$.

2. Nr. 1562!. G. S'HAeIden vend. Venezuela. Vergl. SP., p. 33, For'm A, ‥ T'af. III. Figg. 7 a, b. Sechs Stïcke.

$$
\begin{aligned}
& 6^{3}, 5-59,0 \times(30,3) 38.4-35,0 \times 19,0 . \\
& 6^{1 /} 8-57,4 \times(29,7) 37,9-34,1 \times 19,6 .
\end{aligned}
$$

Fig. $233.5 .57 / 8-45,8 \times(24,4) 30,2-28,0 \times 15,2$.

. 233 A. $6 \%$ - $53,0<(28,3) 35,0-31,2 \times 18,3$.

3. Nr. 1562:3, 15625. Ans meiner ehemaligen Sammlung. WEssed rend. Putrto Cabello. Fünf Stiicke. Tergl. SP.. p), 33:3, Form A, 1.

4. Koll. 0. Sedrper. Rio Tapia, zwischen Dibull und Rio Hacha, 6-8 Neilen landeinwïrts. H. TETExs leg. Fin Strick.

$$
61 / 8-56,8 \times(29,2): 36,1-32,7 \times 18,2 .
$$

5. Koll. O. Semper. San Estevam, Puerto Cabello. JoH. T'Ans leg. Zwei stïcke, durchans typiscl.

6. Koll. Scholvien. Puerto Cabello. Tier Stiicke, zusammen mit der Form gracitis.

7. Koll. SoHst. Ohne Fundort und mit der Notiz: „lebt auf Blanholz." "Zwei stïcke, durchaus typisch.

8. Nr. 15624. Ans meiner ehemaligen Sammlung, ohne Fundort. Zwei stiicke.

Figg. $234 \cdot 235 . \quad 6 \%-61,1 \times(32,2) 40,3-35,1 \times 20,7$.

!. Koll. (). SEmper. Am Rio Cliagres, im Innem, Staat Panamá. \%wei mansgewachsene Stiicke.

$$
\begin{aligned}
& 5^{5 / 8}-39,7 \times(21,9) 27,1-23,8 \times 13,4 . \\
& 51 / 4-31,2 \times(17,9) 22,2-18,9 \times 11,2 .
\end{aligned}
$$

Diese Stïcke entsprechen durchaus der Fig. 232, sie wurden zusammen mit, O. delphimus, Form rividus, geschickt.

10. Frankfurter Museum. Zwei Stücke O. ferussari. Schnsiner rend. SARG leg. Coban, Verapaz, Ginatemala.

Fig. $232 . \quad 5^{5} / 8-41,7 \times(22,7) 28,0-25,4 \times 14,6$.

11. Umiauff ded. Insel Trinidad. Zwei durclians typische Stiicke.

Auferdem befindet sich in miserer Sammlmig noch eine ganze Reihe Stiicke ohme Fundort, die deshalls nicht weites aufgefiilnt werden. zumal sie keinerlei Alweichmgen darbieten.

\section{Z. obductus, Form gracilis n. $f$.}

Taf. XV, Figg. 226/2:31.

1)jese form ist kleiner und etwas sclmäler, bietet aber sonst keine Ahweichungen, пur dißs sie im ganzen etwas heller gefirbt erscheint.

1. Koll. Scmultax. P’uerto ('abello. Yier Stäke, ron denen ich zwei abbilde. 
Figg. 226/227. $6-49,7 \times(24,9) 31,3-27,5 \times 16,3$.

Fig. 231. $\quad 5 \% 4-42,3 \times(22,3) 28,1-24,7 \times 14,7$.

2. Koll. O. SenPER. La Guayra. Kapt. KöLCH leg. Ein Stück, durchaus den vorigen entsprechend.

Reichlich $5 \%$-- $43,3 \times(22,3) 27,4-24,0 \times 15,0$.

\section{Gruppe Z. undatus-maracribensis.}

Wie schon in der Einleitung bemerkt wurde, fasse ich unter diesem Namen die Formen zusammen, welche PILSBRY als 0 . undata mit den Varietäten jamaicensis, reses und floridensis für sich behandelt, dazu Z. maracaibensis mit der Varietät ferussaci VON MARTENS und anderen Zwischenformen. Leider liegt mir von Westindien ein weit geringeres Material als vom Festlande vor, aber für diese ganze Gruppe wiurde wahrscheinlich eine genauere und mit Sachkenntnis unternommene Durchforschung der betreffenden Gebiete noch manche Unklarheit schwinden machen, die zurzeit eine überzengende Anordnung aller der betreffenden Formen erschwert. Es ist verhältnismäßig leicht, die einzelnen typischen Formen herauszunehmen und zu charakterisieren, aber die individuellen Abweichungen innerhalb einer Art oder Varietät gehen in einzelnen Fällen so weit, daß die mühsam vorgenommene Sortierung der Formen wieder in Frage gestellt wird. Besonders ist dies bei Z.maracaibensis und den Varietäten ferussaci und pseudoobductus der Fall. Aber auch die kleinen in Jamaica vorkonımenden Formen, die PILSBRY (Figg. 19, 22) zur var. jamaicensis zieht, nähern sich bedenklich der var. ferussaci. Anordnung wie Zusammenfassung dieser Gruppe müssen daher mehr als sonst wohl als eine künstliche angesehen werden, die nur der praktischen Notwendigkeit entspringt, die verschiedenen Formen auseinanderzulialten.

Eine Charakterisierung der Gruppe würde für die meisten Komponenten der Schalencharaktere zu weit auseinanderliegende Grenzen ergeben und hat daher keinen Sinn. Nur ein paar gemeinsame Charaktere mögen hier erörtert werden. Die Skulptur, und zwar die feinere, in der Spiralrichtung liegende, ist im Grunde die schon in der Einleitung zur Gattung geschilderte, wie sie am feinsten bei $Z$. princeps und am deutlichsten, weil am gröbsten, bei $Z$. mars zutage tritt. Aber in der vorliegenden Gruppe ist sie immer bald mehr, bald weniger stark abgeschwächt, so daß man im giunstigsten Falle nur stellenweise und besonders an der unteren Hälfte der letzten Windıng oder an der vorletzten Windung noch ihren Charakter erkennen kann, meistens aber bemerkt man nur noch strichweise die Spiralstreifung; und ganze Teile erscheinen fast ganz skulpturlos; besonders gilt dies für die var. jamaicensis und auch für $Z$. maracaibensis, wenn auch nicht so stark ausgeprägt. Individuell treten diese Skulpturcharaktere aber selbst bei 
einer Alt mol ron einem Fundort selu verscheden anf. Bei Z. maracribensis bemellit man dagegen häıtigar als bei den anderen Formen die gohämmerte

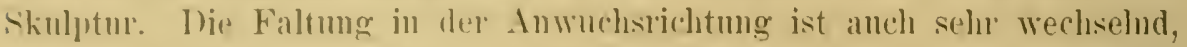

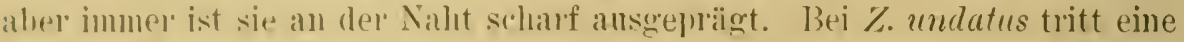

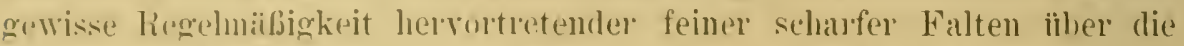
gamze lotztellindung anf, die lem (irhäuse ein leicht gorieftes Ansphen geben.

In der \%edohmmg ist konstant das Anftreten der Bänder :2 bis 4, von denen das letztere das breiteste ist. Die Bänder sind teilwoise unterbroclen und gegen die Mündmg zu zusammenlängender, aber was im Gremsat\% zu anderen Arten der Gattung am charakteristischsten ist, sie erscheinen immer im Inmern der Mïndmng, je nach dem änßeren Verhalten. mehr weniger dantlich mol mehr weniger znsimmenhängend.

Es kommen in dem mir vorliegenden Material rom Festlande auffalland viele heteromorphe Formen wie melanochitus, albinus und xanthus vor, dir letztere seltener und zunächst nur der Form ferussaci entsprechend. Es ist dem ganzen Terhalten der in der Gruppe vorkommenden, nit \%eichumg verselsenen Formen nach sehr schwierig, im einzelnen Falle zn entscheiden, welcher dieser Formen die heteromorphen Formen anzmeihen sind. da bei diesen mu die Gestalt des Gehäuses bezw. dessen (iriibe Anlaltspunkte zum Vergleich bietet, Merkmale, die bei der rorliegenden Gruple recht schwankend sind. So weit als tmnlich kamn der gleiche Fundort auslielfen. PIISBRY hat unter der dem $/$. maracribensis angegliederten var. imitutor zusammengefundene Fürbungen auf 'T'at'. :30 alggebildet, von denen die Figg. 49 (albino), 50, 51, 52, bei Maracaibo, die Fig.a. 5.3, 54 bei Barançnillo gefunden sind. Mir liegt ein gleiches Material vor, das ich anch dem 7 . maracaibensis anreihen kam, aber darmer befinden sich klemere Stïcke, von denen es sehr fraglich ist, ob sie nicht zur Form ferussaci gehören, mnd die den PILsBrischen Abhildungen 'l'af. 30, Figg. 55), 57, entsprechen, und doch nicht von Rio Hacha stammen, von wo allerdings anch solche kleine Formen vorliegen.

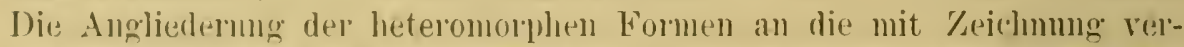
sehenen ist daher anch mu in gewissen Grenzen durehfïhbar. Zu wiederloblen ist in diesem Zusammenhange noch, daß die Pusbrssche var. floridensis sich in nichts von melnnochihus-Fonmen des Festlandes. die ich \%ı \%. muraraibensis stelle, unterseleidet.

\section{\%. Mmalluts BRUG.}

'Taf. XY'1, Figor. $237 / 239,241 / 242,245 / 248,250 / 251$;

'T'af. XVIJ, figg. $260263,26 \%, 270 / 271$.

P., p. Jof, Taf. 27 , Figg. 16-1s.

Wie schom in dor Einleitnmg hei Respurechumg dor kribischen Arten

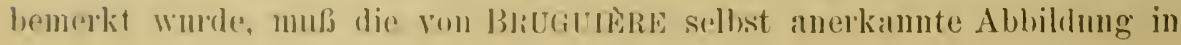


MaRTini und Chemn., Vol. IX, Figg. 1015, 1016 mit in den Formenkreis dieser Art, wie ich sie auffasse, gezogen werden, zumal ich glaube, in meinen Figg. 248, 250 von Trinidad die CHEnnitzsche Form wiederzuerkennen, wozu auch die in SP., Taf. II, Fig. 10, abgebildete Form gehören wird, die PILSBRY zu $Z$. undatus zieht.

PILSBRYs Diagnose liegen Formen zı Grunde, bei denen die Streifen nicht bis an die Basis gehen sollen, so daß daselbst eine helle Zone bleibt. Das ist bei einigen mir vorliegenden Formen zutreffend, bei anderen dagegen nicht. Die Grundfarbe ist oben weiß und wird dann mehr gelblich, die Zeichnung erscheint verhältnismäßig lebhaft, trotzdem die schwarzbraune Zeichnung auf der letzten Windung etwas belegt ist und daher einen grauen Schimmer annimmt. Das Lebhafte wird zumeist durch die rötlichbraune Konturierung der Streifen und einzelne für sich auftretende rotbraune schmale Streifen bewirkt. Diese Einzelheiten entbehre ich in der sonst zutreffenden Schilderung PILSBRYs. Alle mir vorliegenden Stiicke zeigen außerdem besonders anf der letzten Windung eine in ziemlich gleichen Zwischenräumen hervortretende feine scharfe Faltung, die dem sonst mattglänzenden Gehäuse ein gerieftes Ansehen geben; außerdem erscheint die Faltung an der Naht schärfer ausgeprägt.

Ich erwähnte schon, daß die weniger bauchigen Formen, als deren Typus die CHEMnitzschen Abbildungen gelten mögen, bezw. meine Figg. 248, 250, in den kleineren Stücken sich bis auf die Färbung sehr der Formferussaci nähern; bei ihnen gehen die Streifen dann auch häufig bis an die Basis.

Die schmäleren Formen, wie sie besonders unter $\mathrm{Nr} .5$ verzeichnet sind, dürften wohl den von PILSBRY zu O. maracaibensis gerechneten Formen, Taf. 29, Figg. 44/45, entsprechen, die wohl nur des Fundortes halber dorthin gebracht sind. Die Form allein kann eine Trennung nicht rechtfertigen, denı es sind Übergänge da; die Festigkeit der Schale, das Geriefte, die Färbung und Zeichmung dïrften entscheidend sein.

1. Koll. O. SEMPER. O. princeps. Altas Amazonas. Ein Stïck, das besonders an der Basis der letzten Windung noch verhältnismäßig dentlich die feinere $Z$. princeps-Skulptur erkennen läßt. Es ist die typische bauchige Form mit streifenloser Basalzone.

Figg. 241/245. $5 \frac{3}{4}-49,3 \times(25,7) 31,7-28,4 \times 16,2$.

2. Nr.15841. Aus meiner elemaligen Sammlung. GUST. ScHNEIDER vend. O. ferussaci. Dr. REISS leg. Juan da Costa (?), Ecuador. Zwei Stiicke. Vergl. O.ferussaci, Form C, p. 23, Taf. II, Fig. 8. Es ist eine kleinere Form mit stumpfkantiger letzter Windung, in der Gestalt der Form ferussaci gleich, aber nach Färbung und Zeichnung hierher gehörig; es hat auch die streifenlose Basalzone und die geriefte Skulptur.

Fig. 247. $5 \%$ - 39,7 $\times(21,0) 25,5-22,5 \times 12,7$.

"251. $6-44,0 \times(23,1) 28,0-25,0 \times 14,0$. 
7nsammen damit vier Stïcke heterom. melunochilus Nr. 15842, 15845, In der Form und dem gerieften Äubern durehans den rorangehenden entsprechend; lïgen sie allein, würde ich sie der Form halber nubedingt zur ferussuri-F(n)m rechnen.

$$
\begin{aligned}
\text { Fig. } 271 . & 5 \% 4-38,4 \times(20,3) 24,4-21,7 \times 12,0 . \\
, . \quad 270 . & 51 / 2-34,9 \times(19,7) 23,6-20,7 \times 11,9 .
\end{aligned}
$$

Fig. 271. Vergl. ferussuci, Form B, 1 e.

3. Koll. Sinotriex. O. pulchellus, Brasilien. Vier Stïcke. Durchans typisch, mit streifenloser Basalzone wie das sub 1. verzeichnete Stück. 1)anach wiire dor Fundort bei angenommener Verscheppung nicht unwalıscheinlich. wemn au'h der falsche Name den Verdacht nahe legt, dafs del Fundort himzugeselnieben sei.

$$
\begin{aligned}
& \text { Fig. 237. Fist' } 6-46,4 \times(25,1) 29,5-26,8 \times 15,2 \text {. } \\
& \text { 246. } 6-45,0 \times(23,3) 27,6-24,2 \times 13,6 \text {. }
\end{aligned}
$$

4. Frankfurter Museum. (). maracaibensis, Santa Marta, Columbien. Eiu sitïck, durchaus typisch.

Figg. 238/239. $\quad 6^{1 / 8}-50,7 \times(26,2) 31,1-28,3 \times 16,4$.

5. Koll. O. SEMPER. Santa Marta. GRosskopf leg. Drei Stiicke. Vergl. SP., ferussaci, A 3, Taf. II, Figg. 4 a, b, 5a. In derselben Reihenfolge entsprechen ihnen die folgenden Mabe.

$$
\begin{aligned}
& 6-45,6 \times(22,9) 27,2-24,9 \times 14,1 . \\
& 6-47,7 \times(26,4) 32,7-28,2 \times 16,9 .
\end{aligned}
$$

Figg. $260 / 261$. $6-47,8 \times(25,6) 30,8-27,8 \times 15,9$.

Fin weiteres Stiick

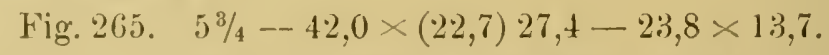

Bei diesen vier Stiicken gehen die Streifen bis an die Basis. Es kann fraglich sein, on man dieselhen als eine besondere Varietät anfzufassen hat, die entschieden zu der dem Z. mrracaibensis angegliederten Fornu psendo-obductus hiniuberneigt, wem anch die leblafte Färbung für lie Fimreihmg bei Z. undatus sprechen.

ls sind nocl, sechs junge Stïcke dabei, von denen zwei in SP., Taf. II, Fig. ba, d, abgebildet sind. J)er letzteren Figm entspricht hier die Fig. 262.

Fig. $26 \% 2.53 / x-34,8 \times(20,2) 25,3-21,3 \times 13,3$.

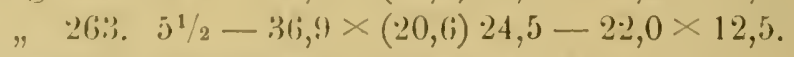

(i. Aus meiner chemaligen Sammhung $\mathrm{Nr}$. 15702. O. ferussaci. ()hue Fundort. Zwwei stïcke wie die rorangehenden $\mathrm{Nr} .5$.

7. Loll. Finßy. Olne Fundort, wie Nr. 5.

8. RoldLE vend. Win Stïck lacr bei Colima-Material, ist aber offenbar aแc Verselın dahin gekommen. Fs ist ein typisches Stiick mit streifenloser Basal\%one. nu etwas schlanker als die sub 1. - 3. verzeichneten.

$$
631 / 4-48,0-(24,1) 2 ! 9,1-26,1 \times 15,3 .
$$

4. Von der Expedition lï̌kextrat, md Hartanyer. Trinidad. 
Ein Stück, der CHEMNITZschen Abbildıng am meisten entsprechend, wenn diese anch nicht die gelbliche Grundfarbe zeigt. Es hat die streifenlose Basalzone, aber das hohe Gewinde und die verhältnismäBig flachen Windungen bieten einen Übergang zur Form ferussaci.

Figg. 248/250. 61/2-54,6 $\times(27,3) 33,3-29,6 \times 17,8$.

10. Ex Nr. 16747. Das Stück lag bei $O$. unclatus, von englischen Häıdlern unter Z. princeps verzeichnet. Thinidad. Es ist kleiner als das vorangehende, mit stumpfkantiger letzter Windung und streifenloser Basalzone. Vergl. SP., O.princeps, Form F, p. 17, das nicht abgebildete Stück.

Fig. 242. Fast $6-42,5 \times(22,8) 27,7-23,3 \times 14,5$.

11. UmuaUfF ded. Trinidad. Zwei junge Stïcke, etwas verwittert, aber offenbar hierher gehörend.

12. Koll. Scholdien. Ein Stück von Jamaica, zusammen mit der var. jamaicensis. Das Stïck ist unansgewachsen, aber sonst wie das vorangehende, nur gehen die Streifen noch (?) bis an die Basis.

13. Berl. Museum. N1. 40508. O. undatus. New Providence, Bahama. EGGERT. Ein junges Stiick, genau wie Fig. 242, aber kleiner.

$$
5^{1 / 2}-36,6 \times(20,0) 24,0-21,9 \times 12,3 \text {. }
$$

\section{Fragliche Form.}

Berl. Museum. O. undata. Florida. WAllenberg. Vier Stïcke. Das große Stiick hat die durchaus typische Form, aber eine weiße Grundfarbe und hell granbranne Zeichnung; auch die geriefte Skulptur ist vorhanden und man erkennt auch an ein paar Stellen dentlich die feinere $Z$. princeps-Skulptur. Der stellenweise ausgebrochene Mundrand ist schmal kastanienbraun besäumt, ebenso sind die Tarixstreifen gefärbt, der Callus dagegen ist dünnstreifig und hellbraun. Die Streifen gehen nicht ganz bis an die Basis, aber der freie Raum ist schmäler als beim typischen Z. undatus. Weder Zeichnung noch Färbung passen zur var. reses. Die drei jüngeren Stücke entsprechen in der Färbung melhr dem typischen Material, wenn sie anch nicht ganz so dunkel, aber dunkler als beim großen Stück ist.

Figg. 243/244. Reichlich $6-47,0 \times(25,7) 31,3-27,6 \times 16,4$.

Fig. 249.

"240.

$$
\begin{aligned}
& 5^{1 / 4}-34,6 \times(18,9) 23,8-20,3 \times 12,3 . \\
& 5^{1 / 8}-31,1 \times(17,8) 21,7-19,1 \times 11,4 .
\end{aligned}
$$

Z. undatus, Form reses (SAY) PILSBRY. Taf. XVII, Figg. 272/273.

P., p. 109, Taf. 27, Figg. 24-26.

Zu dieser Form glaube ich zwei Stïcke rechnen zu müssen, die ans den alten Beständen des Museums stammen (Nr. 5684) und Bul. Zebra MÜLLER ohne Fundortsangabe bezeichnet sind. Es ist der Z. undatus 


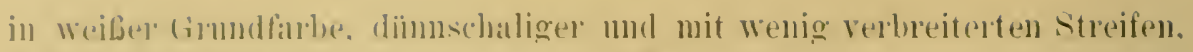

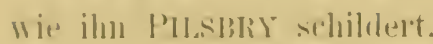

$$
53-46,7>(24.8) 31,0-27,7<15,9 .
$$

\section{Z. reses heterom. melamochilus.}

'J'if. XY]I, Fig. 267.

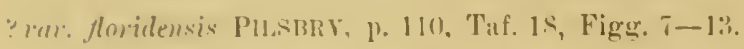

Talı fïge diese Form hier ein. Weil die drei vorlandenen Stücke von Rulde erworlyn, ans der Koll. Toldis, von Florida stammen sollen, mud and in dur Form des Geläuses durchans mit den voranstehenden stïrken ïhereinstimmen. Anferdem aber bemerke ich, dab identische Stiicke von santa Malta. Columbien, volliegen, wie ja anch PILsBR sellist anf die Chnlichlieit mit Festlandformen hinweist.

Fic. 267. Reichlich $6-47,2 \times(24,5) 30,6-26,3 \times 16,1$.

$$
\begin{aligned}
& 6-46,2<(24,7) 29,4-25,8 \times 15,1 . \\
& 5 \% 3-36,2 \div(20,4) 24,3-20,6 \times 12,3 .
\end{aligned}
$$

Mit der Folm reses kommt man schon nahe an $Z$. muracaibensis huran, insof(en die Höhe der Mündung in Verhältnis zum Gewinde zmmimmt.

\section{Z. mararaibensis PFR.}

'Taf. XYlII. Figg. 274 28!); 'Talf. XIX, Figg. 306/309.

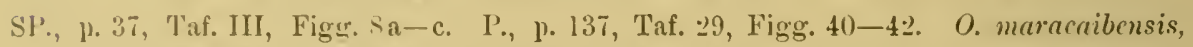
Forn initatm: P., 1. 140 Taf. :io, Figg. 49-54. Var. Fig. 5S.

J)er in Malak., Bl. IIJ. 1856, p. 186, beschrielene Typus ist in SP., Fig. 8c. md hier in Fig. 287 wiedergegeben. In den Monogr. Helic., Vul. VIII, 1). 261, fühnt dam PFEIFFER wohl als einzige ihm zur Velfïgung stehende Abbildung die in M. ${ }^{1}$. Taf. I, Fig. 7, von voN MARTENS grenebene an, die alher nicht hierher gehört (vergl. Z. gruneri mihi). Außel-

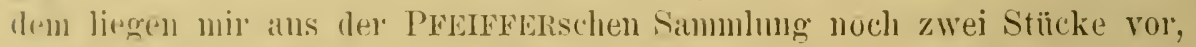
deren cines ich in Fig. 288 abbilde, das dritte Stitck entspucht dem in ST., Fig. Sb, abgebildeten, wälnend das vierte Stïck. das in SP., Fig. \&a, abgrebildet worde, mir jetzt nicht vorliegt. Ich habe diesmal die Vorderseite dop damaligen Fig. \& abgebildet, mm die breite Flammenzeidhmung zu zeigron; dir Rückseifo der Fig. 288 ist in der gerieften Oberfliche und den shlunalen. verschwommenen Streifen sehr ablulich der damaligen Fig. 8b,

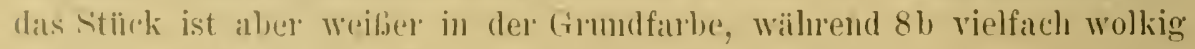
maimnlich bedeckt ist. Im ïhrigen leziche ich mich anf die damalige

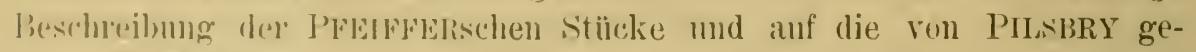

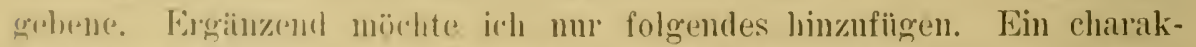
teristisches Markmal der Alt lietet neben der Gröbe und der matten Förbung die Form des Gehäises, bei der die letzte Windumg im Ver-

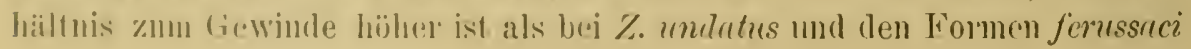


und jamaicensis, anch sind die Windungen etwas gewölbter. Die etwas sclıräge Aufrollıng der letzten Windmng und die stark erweiterte Mündung erimern an die Formen von $Z$. lividus und zoniferus.

Ich ziehe es vor, bei dieser Art ebenso wie bei der Form ferussuci die heteromorphen Formen den einzelnen Fundorten anzugliedern, damit der Überblick des Zusammengefundenen nicht verloren gehe.

1. Die drei Stücke aus PFEIFEERs Sammlnng.

Fig. 287. $\quad 6 \frac{1}{2}-67,8 \times(31,0) 41,5-36,2 \times 20,5$.

"288. Fast $6 \frac{1}{2}-60,2 \times(29,4) 36,4-33,6 \times 18,7$.

Das dritte, der Fig. $8 \mathrm{~b}$ in SP. entsprechende Stiick mißt:

$$
61 / 2-57,3 \times(29,5) 35,3-32,1 \times 18,1 \text {. }
$$

2. Nr. 15701. WaLLIS leg. (Nen-Granada) Colnmbien. Fïnf Stücke, in Größe und Zeichnung der Fig. 286 entsprechend.

3. Nr. 15909. SCHNEIDER vend., REISS leg., Nen-Granada. Ein Stiick.

Fig. 286. $\quad 61 / 4-49,2 \times(24,3) 31,0-26,0 \times 15,6$.

4. ex. Koll. O. SEMPER. O. zebra, Sombrana bei Baranquilla, an der Mündung des Magdalenenstromes. Ein Stïck.

Fig. 289. $\quad 61 / 4-58,7 \times(28,3) 36,1-33,7 \times 18,7$.

5. Nr. 15704. WALLIS leg. Am Magdalenenstrom. Ein junges Stiick, heterom. melanochitus, von gelblicher Färbung. Inneres der Nündung bräunlich. Vergl. SP., ferussaci, Form B, 1 d.

6. ex Koll. O. SEMPER. WALLIS leg. Mündung des Magdalenenstromes. Zwei typische Stïcke.

Fig. 283. $6-49,6 \times(24,7) 30,0-30,0 \times 16,0$.

Drei unausgewachsene Stiicke, heterom. melanochilus.

Zwei Stïcke, heterom. albinus, die wie fast alle albino-Formen einen stumpfen Stiel in der Nahthöhe der letzten Windung zeigen.

Fig. 285. $\quad 6 \frac{1}{4}-50,5 \times(25,6) 32,0-28,2 \times 16,8$.

7. Nr.15705. WALLISleg. Baranquilla. Ein Stïck, heterom. melanochilus.

Fig. 282. $\quad 6-50,2 \times(25,3) 30,0-29,6 \times 16,5$.

8. Koll. O. SEMPER. WALLIS leg. Baranquilla. An Bammstämmen klebend, in der Wintermhe. Acht Stïcke, heterom. melanochilus.

Fig. 284. $\quad 5^{7 / 8}-46,6 \times(25,5) 31,2-27,6 \times 15,8$.

Zwei Stücke, heterom. albinus, wie Fig. 285.

9. Koll. Scholvien. Ocaña, Neu-Granada. Fünf Stïcke, heterom. albinus, wie Fig. 285.

10. Koll. ScHoLviEN. Manta, Westkïste von Süd-Amerika. Zwei Stïcke, heterom. melanochilus, wie Fig. 282, zusammen mit zivei Stücken, Form ferussaci heterom. melanochitus.

$$
6 \frac{1}{2}-52,9 \times(26,4) 31,2-28,8 \times 15,7 \text {. }
$$

11. SALMIN vend., wahrsclieinlich von der ersten Reise GROSSKOPFs nachNeu-Granada stammend. Yergl. SP., p. 22. O. ferussaci, Form B, I b. Zu 


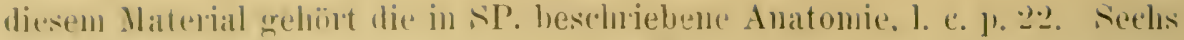
Stücke, heterom. melunorhitus, gelblich mit brämlichem Jnmern, wie Fig. 279.

12. (tAGZO ] S. Inni 1905). Sabanilla (Columbien). 13 typisclie Stïcke versthiedener Alterstufen. zum 'Teil mit 'Tier in Spiritus, zum T'eil trocken. Ith bilde drei ab, von denen das zureite der Mabliste einen mogefarbtrul Wirbel hat. Es ist außel der rar. jumaicensis das einzige Stiick unter dem groljen Material, sowohl ron Z. muracaibensis als ron der Form ferussaci, mit Ausnalıme natiulich der heterom. albinus.

\begin{tabular}{|c|c|}
\hline & \\
\hline ge. 275 & $(28,1) 34$ \\
\hline & $48.7 \times(26,7) 32,1-28,3$ \\
\hline & $5^{7}$ \\
\hline & 5 \\
\hline & f \\
\hline
\end{tabular}

Vier Stïcke, heterom. melanochitus. gelblich mit bräunlichem Innern. Fig. 279. $6-52.0 \times(-27.0) 32.5-30,9 \times 16,6$.

13. Koll. O. Swiper. Santa Marta. GRossKopf leg. Seln viele Stiicke heterom. melanochitus. Merkwïrdigerweise liegt von diesem Fundort kein typischer $\%$. maracribensis vor, nur die Form ferussaci und die For'm psendo-obductus. Tergl. SP., 1. 21, ferussaci, Form B, 1 a, 'Taf. II, Fig. 2c. Die Stiicke sind gelblich bis brämlich in der Außenfürbung, im Imel'n bald weißlich bräunlich, violett angehaucht, bald leller oder dunkler kastanienbraum. Mehr weniger deutlich verlüuft bei den meisten Stiicken unterhalb Band 3, an dieses angrenzend, eine gleich breite helle Zone, zuweilen oberhalb derselben eine etwas dunklere, stellenweise unterbrochene \%one, was an dem abgebildeten jüngeren Stïck zutage tritt. sie liegen zusammen mit Form ferussaci heterom. melanochitus.

Fig. 307. $5 \% \frac{3}{4}-38,8 \times(20.6) 25,5-23,2 \times 13,3$.

$$
" \text { 306. } \quad 61 / 8-52,5 \times(26,1) 31,7-29,9 \times 17,0 .
$$

14. Koll. Scholviris. Puerto Cabello. Zwei Stïcke. Das grofe heterom. melunochilus ent.jpricht den vorangehenden. Das schlankere Stïck, Fig. 308, ist selu dickschalig, halluwegs albino, insofern die Varixstreifen granviolett sind; der imnere Mundrand ist hell graubram, schmal, der Callus fast farblos, ıu' oben, nahe dem Mumd'ande, auf einem beschränkten Fleck hell gelbbraun.

$$
\begin{array}{rr}
\text { Fig. 309. } \quad 6 \frac{1}{2}-61,8 \times(31,5) 39,8-34,4 \times 20,5 . \\
\Rightarrow 308 . & \text { ca. } 6 \frac{1}{2}-53,3 \times(26,4) 32,0-2 !, 4 \times 16,8 .
\end{array}
$$

15. Berl. Museum. Y'uerto ('abello. ApIUN. '/wei Stiicke heterom. albimus, deren cines abnorm ist. I)as nol'nale Stïck ist selı dickschalig, mit ziemlich schräge stehender Spindel. Am Gewinde erkemnt man noch Andentungen von \%ejchmmg in der iiblichen gramen, etwas durchsichtigen Fïrbuug. Das Stïck mißt:

$$
\text { cat. } 6 \text { - cal. } 62,5>(28,6) 34,3-35,0 \times 27,0 \text {. }
$$


16. Wir besitzen noch eine Menge, zum großen Teil unausgewachsener Stiicke, die tot und olme Tierreste in Astlöchern von Pockholz saßen, welches hier angeblich von Puerto Cabello importiert wurde. Das Material besteht zum größten Teil aus heterom. melanochilus und albinus, nur ein paar junge mit Zeichnung versehene Stücke, sind darunter, von denen sich nicht sagen läßt, zu welcher Form sie gehören.

\section{Z. maracaibensis, Form fermsaci VON MARTENS.}

Taf. XIX, Figg. 290/305.

SP., p. 1S, partim. O. maracaibensis var. P., p. 140, Taf. 30, Figg. 55/57.

Diese Unterform unterscheidet sich in ihren typischen Stiicken durch folgendes von der Hauptform. Das Gehäuse ist kleiner, die Windungen am Gewinde sind weniger gewölbt, wodurch sich dieses reiner kegelförmig von der letzten Windung abhebt, die auch verhältnismäßig nicht so groß bezw. nicht so erweitert ist. Die Färbung des Grundes ist mehr weißlich, die der Zeichnung bei dem einen Typus reiner braun, bei dem andern mehr dunkel graubraun bis schwärzlich braun. Aber es ist nicht zu verkennen, daß bei einzelnen Stïcken die Abgrenzung besonders nach der Form pseudoobductus schwer wird, eine Mittelform, die ich absondere. Die Skulptur in der Anwuchsrichtung ist eine sehr unregelmäßige. Man könnte diese Form auch als eine Zwergform von Z. maracaibensis anselien.

1. Berl. Museum, das von DEPPE in Teliuantepec gesammelte Stiick. Vergl. M. ${ }^{2}$, Taf. 10, Fig. 9. Ihm kommen in der Färbung nur die unter Z. undatus sub Nr. 2 verzeichneten Stïcke am nächsten, bei denen aber die Streifen breiter und doch auch lebhafter gefärbt sind.

Fig. $291 / 292 . \quad 51 / 2-39,6 \times(20,9) 25,6-22,4 \times 13,1$.

Es ist mir anf meine Anfragen nach dem Verbleib der übrigen DEPPEschen Stïcke noch ein mit Fragezeichen versehenes Stiick zugeschickt, das sich ohne Fundort in der Sammlung befindet, und das sehr wohl dazu gehören kann. Es ist ausgewachsener als das typische Stück, die hellbraunen, etwas belegten Streifen werden auf der letzten Windung etwas breiter, während am Gewinde die Zeichnung identisch mit dem typischen Stiick ist. Auch dies Stück ist nicht mit den oben erwähnten Stïcken $Z$. undatus Nr. 2 zu verwechseln.

Fig. 290. $6-45,0 \times(23,7) 28,9-25,6 \times 14,1$.

2. Berl. Museum. Caracas. LANsBERG. Der zweite Typus der Art. Vergl. M. ${ }^{1}$, Taf. 1, Fig. 6. Liegt zusammen mit einem abgeblaßten Stïck von $Z$. obductus.

Fig. 293. $6-43,5 \times(22,1) 27,1-23,8 \times 13,5$.

3. C. GAGZo leg. 22. Dezember 1905. Cartagena, Columbien. Zwei Stiicke in Form und Zeichnung wie das sub 1. verzeichnete Stiick.

Fig. 298. $\quad 5 \frac{1}{2}-36,5 \times(19,8) 24,1-20,5 \times 12,6$. 
1. Kull. Sinumilil An Magilalentenstrom. Fin stiick, heterom. ubims, wie s'l'.. 'T'at,. II. Figg. 1 b.

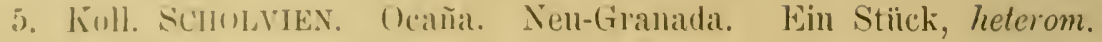
sunthus, wie Figg. :3(1)! 30:!.

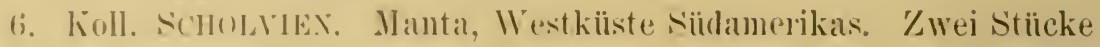
heterem. melanochilus.

$$
\begin{aligned}
\text { Fir. } 304 . & 53 / 4-40,2-(21,4) 25,6-22,0 \times 13,2 . \\
\text {. } 305 . & 53 / 4-37,7 \times(19,0) 22,5-21,0 \times 11,2 .
\end{aligned}
$$

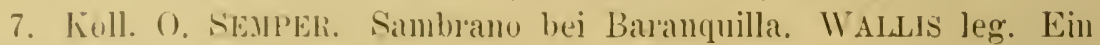
typisclies stïlek.

ふ. Koll. O. SEmper. Santa Marta. GRosskopt leg. Tergl. SP., Form A. \& a, 'L'if. Jl, Fig. !) a, b. Füinf Stiicke.

Fig. 294. Fast $6-42,3 \times(2,2,2) 26,6-24,0) 13,5$.

"297. $6 \quad-43,0 \times(2 \cdot 2,0) 25,8-24,2 \times 12,8$.

.295 . 5 $1 / 4-31,2 \times(17,4) 20,8-18,3 \times 10,1$.

Ein stiick. heterom. xanthus.

Fig. 296. Fist $6-43.7 \times(22,6) \cdot 27,8-24,0 \times 14,4$.

1:3 Stürke, heterom. melanochilus. Vergl. SP., Form B, ¿a, 'I'af. II, Fig. :ir. Diese Stïcke zeidmen sich vor denen bei $Z$. maracaibensis verzuichneten durch etwas kleinere Form und viele schwarze Varixstreifen aus. Die meisten Stücke sind allerding's größer, als es del Form ferussaci zuknmmt, so daf ihre Einordnumg hier fraglich bleibt.

1. Kull. O. Semper. Küste zwischen Puerto Dibullo und Rio Hacha, 'I'ETExs leg. Sechs tote stïcke, zum 'Teil zerbrochen.

10. Nr. 15911. Wessel vend. Rio Hacha. Vergl. SP., Form A, 4b, 'Taf. Il, Fig. 7. Ein stïck.

$$
\text { Fig. 299. } 63^{1 / 4}-45,9 \times(2 \cdot, 8) 27,4-23,2 \times 13,5 .
$$

Nr. 1.906. Ebendaller. Ein Stiick. Verg]. SP., Form B, :3b, Taf. II, Fig. 1 a; mit mämulich Heischfabigem Mundand.

$$
(; 1 / 4-47,7 \quad(24.1) 29,1-26,2 \times 14,6 .
$$

Nr. 15:1\%. Wbemaliel. '/wei Stiicke, heterom, albinus. Velgl. SP., $13: 3$ c, 'T'af. 11, Figg. 1 b, c.

$$
\begin{gathered}
61 / 4-47,0-(22,8) 28,0-25,0 \times 13,8 . \\
?-43,0-(20,1) \div 5,2-23,3 \times 12,6 .
\end{gathered}
$$

$\mathrm{Nr}, 1591 \%$ Ebendaher. Fin Stiick, heterom. molanochilus. Vergl. SP., 13 4. 'Tilf. II, Figr. $1 \mathrm{~d}$.

$$
(31 / 4-47,5 \times(23,1) 27,9-25,0 \times 14,3 .
$$

$\mathrm{Ni}, 15 ! 107$. Ehendaher. Mrei stiicke, heterom. melunochilus. Vergel. SP., B 3 a, 'T'itf. II, Fig. $1 \mathrm{e.}$

$$
(; 1 / .4-43,6=(21,2) 26,6 ;-23,5 \times 13,4 \text {. }
$$

11. Wlisser, vend. N1. 15910. Ohne Fundort. Drei unatusewachsene,

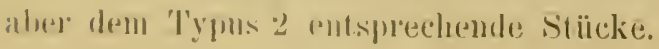


12. Nr. 15914. WESSEL vend. Ohne Fundort. Vier Stïcke der heterom. xanthus. Vergl: SP., A 5.

Fig. 301. $6-39,3 \times(21,0) 25,3-22,6 \times 13,4$.

"302. $6-38,0 \times(19,1) 23,0-20,9 \times 12,0$.

Zeichnung und Mundrand sind hellbramn, bezw. rotbraun. Der Callus ist an zwei Stïcken hell kastanienbraun, dünn und streifig, diese haben einen braunen Nucleus, an den anderen ist er farblos.

13. Koll. Scholvien. O. longus PFR. Mexiko. Zwei Stïcke der heterom. melanochilus. Sie sind normal, typisch in der Form fernssaci. Das abgebildete Stiick zeigt nach einer Beschädigung eine schrägere Aufrollung und ist offenbar über das normale Maß linausgewachsen, wodurch man ihm wohl die falsche Etikette verdankt.

Fig. 303. $\quad 63 / 8-50,1 \times(23,0) 28,3-25,0 \times 14,2$.

$$
6-41,3 \times(21,2) 25,2-22,0 \times 12,1 .
$$

14. Koll. ScHOLVIEN. Ein Stïck. Caracas. Ein typisches Stiick, ganz ähnlich der Fig. 2:34.

$$
6-44,1 \times(23,0) 28,3-24,8 \times 14,3 \text {. }
$$

15. UMLAUEF ded. Trinidad. Vier typische Stiicke.

Fig. 300. $5^{7 / 8}-44,8 \times(23,4) 28,4-24,5 \times 14,6$.

\section{Z. maracaibensis, Form pseudo-obductus.}

Taf. XVII, Figg. 256/259, 264, 266, 268/269.

Dies ist eine Form, die sich unter dem iibrigen Material verteilt vorfand, und die ich in SP. unter O. ferussaci, Form A 1, p. 18, für die normale, mit Cnticula versehene Form ansah. Das Gehäuse ist ziemlich dünnschalig, und steht in seiner Form zwischen $Z$. undatus und maracaibensis. Die Grundfarbe geht vom hornfarbigen der ersten Windungen durch Weiß in einen gelblich bräunlichen Ton ïber, das Gehäuse bekommt aber durch die zum Teil verwaschene und ziemlich dicht gedrängte Zeichnung ein düsteres Ansehen, wenn auch nicht so bräunlich wie bei Z. obductus. Die erste Windung ist braun abschattiert, damn beginnt die der Gruppe entsprechende typische Zeichmung, nämlich unterhalb Band 2 breit werdende Streifen, die sich nach oben gabeln. Die Streifen werden damn bald olivschwarz, schmäler und an der Stelle der Bänder 2, 3, 4 zu breiteren Torsprüngen ausbiegend, die nach vorn gelblich berandet sind. Nach der Mündung zu werden die Streifen immer schmäler, auch schwächer in der Färbung, und nur ab und zu treten noch in kurzen Strecken die hellen Umsäumungen hervor. Hier treten dann die Bänder, teils unterbrochen, teils durchgeführt, mehr hervor, die anch in der Mündung mehr weniger deutlich markiert sind. In der Zeichnung macht sich auch stellenweise eine rötliche Konturierung benerkbar, stellenweise auch 
Wolkig erscheinend. Die Varixstreifen sind selten, dmuel kastanienbraun und nach roln hell besiumt. Das Immere ist brämlich mit violettem Anflug und stark durchscheinender Zeichnung, in der aher die helle l'msäumung der streifen rein weif hervortritt. Der Mundsaum ist innen schmal schwaryham herandet, der Callus ist nicht selu dick und heller oder dumkler kistanienbram. Die Spindel ist diimu, weiß, in sich ziemlich rerade mo steht etwas schräg zur Achse. Die Skulptur zeigt die uibliche Faltumg, die anf der letzten Windung oft das Gehäuse gerieft erscheinen läßt; die feinere Skulptur ist im ganzen etwas dentlicher, besonders als bei Z. maracuibensis, fermssaci und jamaicensis.

1. Lioll. O. Sesuer. Santa Marta. Grosskopf leg. Acht Stïcke. Figg. 256;257. $6-48,7 \times(26,1) 31.3-28,0 \times 16,0$.

Fig. 258. $\quad 5 \% \frac{3 / 4}{5}-44,2 \times(23,8) 29,2-25,7 \times 15,5$.

$\because \quad 259 . \quad 5 \% \frac{8}{4}-43,7 \times(24,0) 30,4-26,3 \times 15,7$.

Von ebendaher weitere nem Stiicke, bei denen die Streifen meh" granbraum als olivschwarz sind, sonst ist das Verhalten dasselbe.

Figg. 268/269. $\quad 61 / 4-54,0 \times(26,7) 33,0-30,2 \times 17,3$.

Fig. 264. $6-47,7 \times(26,1): 32,4-28,2 \times 17,0$.

2. RK. 1843. SALMIN vend. Zusammen mit dem bei $Z$. maracaibensis verzeichneten Material. Drei Stïcke.

3. UnuAUFF ded. 'Trinidad. Zwei Stïcke. Sehr ähnlich in der Färbung den sub 1. verzeichmeten nem Stiicken.

Fig. 266. $5 \% 4-47,5 \times(26,3) 31,5-27,4 \times 16,3$.

\section{2. maracaibensis, Form jamaicensis.}

'l'af. XX, Figg. 314/315, 319/320, 322/326.

SP., p. 26. O. undatus. Taf. II, Fig. 11. P., p. 107, Taf. 누, Figg. 19/23.

Die charakteristischen Merkmale der typischen Form, wie sie anch PILsBRY bescheibt, sind: 1, die glanzlose Oberfläche, sofern die Stücke nicht kiunstlich anfgefrischt sind, 2 . die sehr undentliche feinere Skulptur in der Spiralrichtung, 3. die matte Farbe der Zeichnung, 4, der farblose Nucleus, 5. die mehr weniger schräg zu Achse stehende Spindel, und 6. der nur stellenweise vorhandene, hell gefärbte Callus. Ich habe s. Z. in SP. diese Form für den echten $Z$. undatus gehalten. Eine kleinere, anch auf Jamaica vorkommende Form (Fig. 32:3) ist in der Form des (iehäuses mehr der Form fernssnci entsprechend, anch die Zeichnmg ist dunkler und etwas lebhafter gefarht, nur der farblose Nicleus weicht ab, was eine Eigentiumlichkeit der anf Jamaicia lebenden Formen zu sein scheint. Prinzipiell wiurde ich diese Formen nicht von den Festlandformen tremuen; ra aber iiberhanpt in der ganzen $Z$. undatus-Grupue der Über- 
gänge viele vorkommen, so mag diese Form hier mit der größeren Form zusamnenbleiben, wie ja auch PILSBRY zwei verschiedene Formen abbildet.

1. Berl. Mnsenm. Nr. 21848. O. undatus, angeblich Costarica, vaN PATTEN. Ein Stïck lag zusammen mit Z. delphinus, Form intermedius. Ob hier eine Vertauschung vorliegt, muß ich dahingestellt sein lassen, denn das Stïck ist eine echte Form jamaicensis.

Fig. 324. $\quad 61 / 2-59,8 \times(28,3) 33,5-32,0 \times 17,0$.

2. Berl. Museum. O. undata. Kingston. HoPPE. Drei Stïcke.

Fig. 319. $\quad 6^{1 / 4}-54,9 \times(27,6) 32,8-29,9 \times 16,6$.

" 320 . $6 \frac{1}{8}-52,7 \times(25,7) 30,5-28,3 \times 15,2$.

$61 / 8-53,5 \times(25,4) 30,7-29,2 \times 15,8$.

3. Berl. Museum. Koll. AlBERS. Jamaica. Ein Stïck.

Fig. 322. $\quad 6 \frac{1}{2}-65,8 \times(29,8) 36,7-35,3 \times 20,3$.

4. Frankfurter Museum. Etikette Deutsche Malak. Ges. O. zebra. Jamaica. GLOYNE. Mehrere Stiicke. Fig. 325 ist eine mittlere Form, anch mit dunklerer Zeichnung, aber in der Form des Gehänses mehr dem Z. maracaibensis entsprechend. Die Fig. 323 entspricht der oben erwähnten, der Form ferussaci sich nähernden Form. Die Fig. 326 ist typisch.

Fig. 326. $\quad 63 / 4-64,8 \times(27,9) 34,3-32,7 \times 18,1$.

"325. $\quad 6 \frac{1}{8}-48,0 \times(23,8) 28,1-26,2 \times 14,8$.

"323. $6-41,7 \times(21,1) 24,4-23,0 \times 12,1$.

5. Frankfurter Museum. O. zebra MüLL. Jamaica. Drei Stuicke. Davon ist ein zerbrochenes Stïck typisch, ein zweites ist klein, der Form ferussaci entsprechend (Fig. 315). Das dritte Stïck ist ein Z. princeps, ganz verwittert und tot, daher wohl angeschwemmt.

Fig. 315. $6-41,5 \times(21,8) 25,5-23,2 \times 12,9$.

6. Rolle vend. O. undatus. Jamaica. Vier junge Stücke.

Fig. 314. $5-24,5 \times(14,0)-16,8-14,1 \times 8,6$.

7. D. Heitz leg. Jamaica, Jan. 1904. Ein Stück mittlerer Form, nngefähr der Fig. 325 entsprechend.

$$
6-47,4 \times(23,9) 28,5-26,6 \times 15,0 .
$$

8. Nr. 9111 . Koll. Forsmann. Ohme Fundort. Ein typisches Stiick.

$$
6 \frac{1}{2}-57,8 \times(27,0) 34,1-31,4 \times 18,5 \text {. }
$$

\section{Z. varius VON MARTENS.}

Taf. XX, Figg. 312/313, 316.

M. ${ }^{1}$, p. 190, Taf. 1, Figg. 4 a, b. Shuttleworth, 1. c. p. 65, Taf. 4, Figg. 1, 2. P., p. 144, Taf. 32, Figg. 69-7T.

VON MARTENS hat l. c. keine genaue Diagnose gegeben, el führt phlogerus PFR. nec ORBIGNy, PFEIFFER, Monogr. II, p. 145, an, der auch eine unvollständige Beschreibung und eine schlechte Abbildıng gibt. El vergleicht 


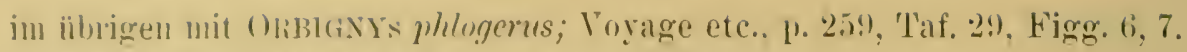

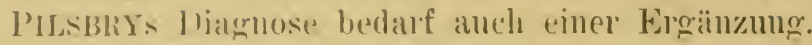

D) frolm des (iehänses mol die sehr verinderliche Zeichumg sind duch die Abhildungen in l’. l. c. genïgend charakterisiert. I)as Gelä̈se hat einen etwas fettigen Glanz, zeigt aber an einzelnen der mir vorliegenden Stïcke genau dieselbe Skulptur wie \%. bensoni, d. l. feine, zuWrilen etwas weitläufig stehende, aber im ganzen gedraingt erscheinende sipalleisten, die durch die umegelnäbige, wenn anch im ganzen feine Faltumg einen etwas welligen oder mmegelmäßigen Verlauf nelımen; dalei entstehen ab und zu kleine Vertiefmngen. wie Hämmerung, so dab im grußen ganzen eine Ähnlichkeit mit der Z. minceps-Skulptur vorhanden ist. aber die spiralfaltung tritt doch dentlicher hervor, sie ist gröber und zeigt weder den zuweilen stufenfürmigen noch den zuweilen netzartig sich kleuzenden Verlauf der feinen Spiralleisten. Trie schon gesagt, es gibt manche stiicke des Z. varius, an denen man an ganzen Strecken der Oberfläche katum eine Spiralskulptur entdecken kam, höchstens in der Vilutnälie und an der Basis, bei anderen ist sie wieder selı dentlich ausge\}ı̈ägt. Zu der Zeichmmg möchte ich noch bemerken, daß, wenn auch selten, doch bei einigen Stiicken besonder's das Band 2 dentlich dmnkellnam und weiß gegliedert ist. An dem hellgrundigen, von mix in Figg. 312/31:3 abgebildeten Stïck, und ebenso bei dem in P., Fig. 75, al)gebildeten Stück, ist sogar Bind :3 ebenso dentlich dunkel und weifo gegliedert; dies Band ist auch breiter als Band 2. Es tanclit dabei besonders die Vermutung auf, ob nicht doch $Z$. varius nur eine Tarietait von O. phlogerus ORB. sei, besonders wem man bedenkt, daß, wie PILSBRY richtic bemerlit, D'ORBIGrys Besclmeibung nicht mit seiner Abbildung ïbereinstimmt, soweit die Zeichnung in Betracht kommt. Da D'ORIBIGNY mu' die Höhe und Breite $(55 \times 24)$ angibt, die übrigen Maße nicht, so ist man auf die Richtigkeit der Albbildung angewiesen, die allerdings eine mehr spindelförmige Gestalt als die des z. varius zeigt, welchel letztere gedrungener ist und eine größere Breite im Verhältnis zur Höhe hat.

PILSBRy hat in Tol. XIV, p. I65, 'Taf. 2(;, Figg. 48/4!, eine Folm von O. phlogems beschieben und abgebildet, die el von 1)r. V. InERING rhalten und die von Araguary, Minas, stammt (Siidgrenze von Franz.(Guyana). Jie Fiolmug ist in der Abbildung wohl etwas dunkel geraten gecrenither der in der Beschreihung angegebenen. Eigentlich stimmt nur

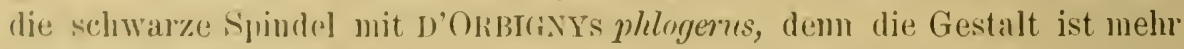
die des \%. varins, \%u dem ich das Stück elıel rechnen würde.

1. Berl. Musemm. Koll. Albers. Angostura. Zwei Stïcke. Das in M. ${ }^{1}$, Fig. 4 a, alogebildete stiick mißt:

$$
61 / 2-41,8-(19,2) 23,4-20,2 \times 10,3 .
$$

2. Frankfurter Musenu. U. phlogerns. Angostura. \%wei stïcke. 
Ein sehr großes typisches, ein kleineres gelbbramn mit Band 2 und 3 dunkel und heller gegliedert, sonst nur gewellte Streifen, keine dunkle Binden oder wolkige Flecke. Das große Stitck mißt:

$$
7-51,1 \times(22,3) 26,9-25,0 \times 12,6 .
$$

3. Koll. Scholvien. O. phlogerus. Angostura. Ein Stiick mit gelbbraunem Grund, sonst mit der typischen Zeichnung.

4. ex Koll. ScHOLVIEN. O. varius. Venezuela. Ein Stïck mit brännlich fleischfarbigem Grund und typischer Zeichnung.

5. ex Koll. Scholvien. O. phlogerus. Neu-Granada. Ein typisches Stiick, sehr ähnlich M.', Fig. 4 a.

6. ex Koll. Scholvien. Bensoni ReEve. Pernambuco. Zwei Stücke, typisch.

Fig. 316. $\quad 6^{3 / 4}-46,4 \times(21,4) 24,8-23,2 \times 11,8$.

7. Koll. SoHst. B. phlogerus, Guayana. Ein typisches Stück.

8. Aus meiner ehemaligen Sammlung. B. phlogerus, Orinoco. Ein typisches Stïck.

9. Nr. 5682. O. phllogerus, Olme Fundort. Ein jüngeres Stïck, ähnlich P., Fig. 76.

10. Drei typische Stïcke ohne Etikette.

11. O. phlogerus. Sïd-Amerika. Ein Stïck, hellgran, mit gegliederten Bändern 2, 3 in Dunkelbraun nind Weiß und mit schwarzbraunen Varixstreifen. Nur am Gewinde erkennt man hellbranne, feine gewellte Streifen bis zum Band 2. Callus hellbraun, Mundrand dunkelbram besäumt.

Figg. 312/313. $63 / 4-47,8 \times(22,0) 26,2-24,6 \times 12,8$.

\section{Z. bensoni REEVE.}

Taf. XX, Figg. 310/311, 317/18, 321.

P., p. 147, Taf. 31, Fig. $62-65$.

Zu der Beschreibung PILSBRYs möchte ich nach dem mir vorliegenden Material noch folgendes hinzufïgen. Die Skulptur habe ich schon bei $Z$. varius beschrieben, sie ist an den mir vorliegenden Stiicken durchweg deutlich ausgeprägt. Das Embryonalgewinde ist vom Gewinde insofern etwas abgesetzt, als sich an demselben die Windungen weniger rasch erweitern als die dann folgenden; der Nucleus ist etwas eingesenkt. Die Spindel ist an dem größten meiner Stiicke (Fig. 321) stark gewunden, an den kleineren gerade, sie bildet immer mit dem Basalrand einen Winkel.

Das Stïck .von HIDALGO, P., Fig. 65, scheint mir entschieden zu Corona regina oder regalis zu gelıören.

Leider sind die besten mir vorliegenden Stïcke mit falschem Fundort versehen.

1. RoLLE vend., als $O$. elegans? von Colima, das zweite kleinere 
Stiick ist $O$. nobilis, Colima, hestimmt. Hier ist RoLLE offenhar das Material seiner Vorrite durcheinander gekommen, dem es ist doch nicht anzunehmen, daf diese Art auch an der Westliiste Mexikos vorkommt. Beide Stiicke sind durchaus typisch.

$$
\begin{aligned}
\text { Fig. } 321 . & 7^{1 / 2}-01,8 \times(27,8) 32,7-28,3 \times 15,8 . \\
" 317 . & 7^{1 / 2}-57,0 \times(24,7) 29,2-25,0 \times 14.3 .
\end{aligned}
$$

2. O. bensoni. Ohne Fundort, von englischen Händlern erworben. Ein Stück selır dümnschalig, mit geradel Spindel, sonst typisch.

Figg. $310311.71 / 4-47,3 \times(23,1) 27,0-24,2 \times 13,4$.

3. Koll. Schodvics. Cayenne. Drei Stiicke, davon zwei junge, typisch.

$$
7^{1 / 8}-50,7 \times(24,1) 29,2-23,9 \times 14,9 .
$$

Fig. 318. $\quad 6^{3} / 8-37,7 \times(19,7) 22,9-18,8 \times 11,4$.

Z. phlogerus, varins und bensoni bilden jedenfalls eine kleine Gruple für sich.

Z. pfeifferi Hidalgo, den PILsBRY zu Oxystyla rechnet, stelle ich zur Gattung Corona, weil er der Form der Embryonalwindungen nach dorthin gehört. Bei Corona ist der Nuclens eingesenkt, damn erhebt sich die Windung etwas ïber das Nivean der stumpfen Kante, welche die ersten $1 \frac{1}{2}$ Windungen im weiteren Verlanf oben zeigen. Außerdem ist der Wirbel breiter und erscheint daher viel stumpfer als bei Z. bensoni, der auch eine ganz andere Skulptur hat.

7. macandrewi (SOW.), den PILSBRY anch zu Oxystyla rechnet, ist mil nicht bekannt, PILSBRY fülırt anch nur SOWERBYs Beschreibung und Ablildungr an.

7. Teucochilus CF., vergl. P., p. 129, Taf. 21, Figg. 37/39, ist eine allino-Form, die von Dr. BERENDT bei Orizaba gefunden sein soll und ans d↔ Sammlung ron W. G. BINNEY stammt. Ob sie Zu Z. boucardi gehört?

\%. Vifulguratus ReEvE. P., 1). 143, Taf. 31, Figg. 59/61, ist eine Form, die ich nicht kenne, die aber wohl jedenfalls in die Gruppe Z. princeps gehöjt.

Hiermit sind alle in P. unter Oxystyla aufgefülnten Arten und Varietäten besprochen, es erübrigt noch, einen Überblick ïber die geographische Verbreitung der einzelnen Formen nach dem mir vorliegenden Material zu geben. I)ie angefïgten Zahlen entsprechen der Nummer des Materials in der Auffiilnrmng des spezialteiles.

1 \%. minceps. Mexiko, Staat Veracruz (1-16), Stat Sinaloa (18), Stal Yucatan (17). Guatemala (19, 20). Panamá (21). 'Tlinidal (24, 25). Jamaica?? (22, 23). 
Ab Z. pilsbryi. Costarica (1). Columbien (2,3). Oberes Peru (4). Trinidad (6).

A a $\left\{\begin{array}{l}\text { Z. crossei. Guatemala (3). Costarica? (1). } \\ Z \text { crosei-fischeri. Guatemala. }\end{array}\right.$

Z. fischeri (deceptor PILSBRY, isabellina vON MARTENs). Guatemala (2, 4). Peru (6). Pernambuco (5).

Ae Z. maculiferus. Costarica.

(Z. delphinus, F. nebulosus. Mexik0, Staat Sinaloa (1, 2), Colima (3), Staat Veracruz, tot (9), Staat Oaxaca (4). Costarica (10). Am Amazonenstrom? (6). Columbien $(4,5)$.

Ac

Z. delphinus, F. vividus. Panamá(1). Columbien (2). Venezuela (3). Am Amazonenstrom? (4). Trinidad (2).

Z. delphinus, F. intermedius. Costarica.

Z. richardsoni. Mexiko, Tepic.

Z. selectus. Guatemala (2). Trinidad (1).

Z. elegans, Mexiko, Colima.

Z. nobilis. Mexiko, Colima.

Z. nobitis, F. pallida. M exik 0, Colima.

Z. quagga. Mexiko, Colima.

Ad

Z. quagga, F. turrita. Mexik0, Colima.

Z. livens. Guatemala.

Z. livens, F. aberrans. Mexiko, Colima (1). Trinidad (2).

Z. tepicensis. "Mexiko, Tepic.

Z. tepicensis, F. rollei. Mexik 0, Colima.

Z. lividus. Mexiko, Staat Michoacan (1). Columbien (4).

Z. hackeri. Mexiko, Tepic, Acapulco.

Z. zoniferus. Mexiko, Staat Guerrero.

$\boldsymbol{B}\{Z$. zoniferus, F. major. Mexiko, Staat Guerrero.

Z. zoniferus, F. euchrous. Mexik0, Staat Oaxaca.

Z. zoniferus, F. naesiotes. Tenezuela, tot. Trinidad. Barbados.

$\boldsymbol{B \boldsymbol { C }} Z$. vexans. Trinidad.

C Z. pulchellus. Brasilien. Trinidad.

Ca Z. pulchellus, F. prototypus. Colnmbien (3). Venezuela (3). Brasilien (1, 2). Trinidad (4).

D Z. mars. Mexiko, Nieder-Californien, Staat Sinaloa, Colima, Staat Guerrero (1-4). Peru? (8). Ecuador (3). Mittleres Amazonas (9).

Da Z. mars, F. decolor. Costarica?

Db Z. uhdeanus. Mexiko, Staaten Michoacan und Guerrero.

Dc Z. gruneri. Venezuela.

Dd Z. miles. Mexiko, Staat Gnerrero. 


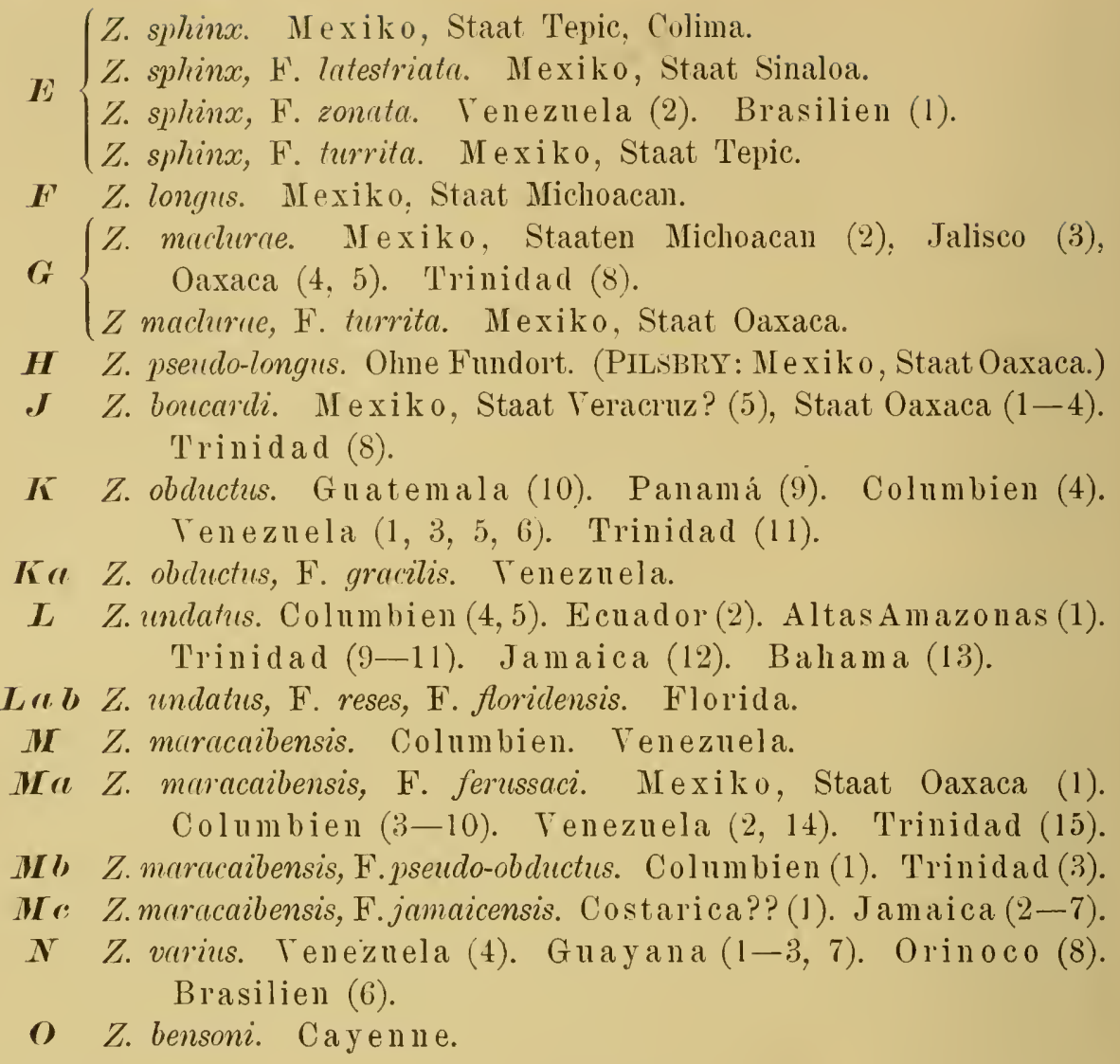

Die den Artnamen vorgesetzten Buchstaben beziehen sich auf die anschließende schematische Darstellung der Beziehungen der Arten zueinander nach den Schalencharakteren. Es sind nm die Namen der Haupttypen eingetragen, die Namen der Nebenformen möge man aus dem vorangehenden Terzeichnis ergänzen. 


\section{Ergänzunge॥ und Berichtigungen.}

p. 22. Zeile 11 von oben lies Fig. 25 anstatt Fig. 5 b.

p. 22. Zeile 6 von unten lies: Fig. 10 anstatt 18 .

p. 27 . Zeile 17 von unten lies: Figg 4,17 anstatt 17 .

p. 27. Zeile 4 von unten ist hinzuzufïgen: ? O. fernssaci PILSB. von Costarica. P., Taf. 17, Figg. 14/15.

p. 32. Zeile 3 von unten anfügeu: P., p. 141, Taf. 29, Figg. 47/48.

p. 34. Zwischen Zeile 11 und 12 einfügen: ? MI. ${ }^{2}$, p. 183, Form von Chacoj, Guatemala, Taf. X, Fig. 5. P., Taf. 16, Figg. 5, 7.

p. 41. Zeile 5 von unten lies: Fig. 94. Die Fig. 96 entspricht der folgenden letzten IIaßreihe.

p. 46. Zeile $S$ von unten lies: Z. princeps, F. pilsbryi n. $f$.

p. 55. Zeile 1 von unten lies: Fig. $13 S$ anstatt 136.

p. 59. Zeile 17 von oben lies: fünf Stiicke anstatt sieben.

p. 63. Zwischen Zeile 2 und 3 von oben als Synonyn einfügen: O. longa PILSB. var. uhdeana. P., p. 1:29, Taf. 22, Figg. 3/5; Taf. 23, Fig. 18.

p. 69. Zeile 18 von unten anfügen: SP., O. ponterosus-boucardi, p. 39, Taf. I, Figg. 4 a, b.

p. 72. Zeile 19 von oben, vor P., p. 12\&, einfügen: O. longa var. boucardi, und an das Ende: ? O. longa var. strebeli, P., p. 128, Taf. 32, Figg. $7 / 9$.

p. 78 . Zeile 5 von unten lies: Figg. 226/227, 231 anstatt $226 / 231$.

p. 81. Zeile 9 von unten lies: Figg. 241,245 anstatt $241 / 245$.

p. 83 . Zeile 5 von oben lies: Figg. 248,250 anstatt $248 / 250$.

p. S4. Zeile 20 von unten anfügen: ? O. undatus rav: floridensis PILSB. P., p. 110, Taf. 15, Figg. $7 / 13$.

p. S7. Zeile 9 von oben anfügen: O. fcrussaci PILSB. von Shkolak, Yucatan, P., p. 120, Taf. 17, Fig. 13 (gehört wohl zu heterom. xanthus).

p. 94. Zeile 7 von oben. Das sub Nr. 2 verzeichnete Stïck ist irrtiimlich hierler geraten anstatt bei Z.varius, Nr.11, p. 93, mit dem zusammen es durch die lielle Färbung und die braun und weiß gegliederten Bänder eine Varietät bildet, die schon p. 92 erwähnt ist.

p. 94. Als Ergänzung zu den in dieser Arbeit nicht beschriebenen und abgebildeteu Arten ist anzufügen: O. maracaibensis var. subulchclla PILsB. P., p. 141, Taf. 28, Figg. 38/39. Diese Form von Union Island (Grenadines) hat Ähnlichkeit mit Z. zoniferus, Form naesiotes. aber Form des Gehäuses, Zeichnung und zwei bis drei schwarze Varixstreifen sprechen mehr für die Zugehörigkeit zu Z. maracaibcnsis, Form ferussaci. Mir liegen sich deckende Stïcke nicht vor. Z. plilogerus ORB. P., p. 145, Taf. 37 , Figg. $67 / 68$.

Ich möchte hier am Schlnf nochmals anf die in der Einleitung nur kurz besprochene Heteromorphose oder Sprumgvariation zurïckkommen, 
eine Erscheinung, die ja von LANG für Helix nemoralis und hortensis eingehend bearbeitet ist. Es kamn auch noch auf die T'atsache hingewiesen werden, daß beispielsweise unser Eichhörnchen in der roten und dunklen Form, und ebenso die schwarze und graue Krähe in manchen Gegenden zusammen, in anderen wieder getrennt vorkommen, und daß beide Formen sogar in ein und demselben Genist bezw. Gelege nachgewiesen sind. Danach kann also eine Heteromorphose sowohl gemischt mit der typischen Art auftreten, wo man sie als Farbenvarietät auffassen kann, aber anch lokalisiert, wo man sie als Lokalform bezeichnen würde.

Eine sichere Entscheidung ïber die Erscheinung an sich, läßt sich freilich nur durch Züchtungsversuche feststellen, wie LANG sie durchgefïhrt hat. Andererseits ist die oft ungenane Bezeichnung der Fundorte bezw. die fehlende Sicherheit, ob selbst zusammenliegendes Material wirklich an ein und demselben Fundort gelunden wurde, schon an sich ein Hindernis, um zn entscheiden, ob es sich um Varietäten oder Lokalformen handelt. Endlich kommt man bei einer Durchführung der Bezeichnung heterom. albus, melanochilus, xanthus leicht in Konflikt mit der Prioritätsfrage für die Nomenklatur, wenn solche heteromorphe Form, oder was ich dafür halte, schon mit einem eigenen Namen belegt wurde, wie es z. B. bei den melanochilus-Formen von $Z$. undatus, maracaibensis, delphinus, Form nebulosus der Fall ist. Trotz solcher Einwände glaube ich, daß die Berechtigung der Znweisung solcher heteromorpher Formen zn einer bestimmten Art, wie ich es bei der Gattung Zebra getan habe, von der Beschaffenheit des Materials und dem Grad der Übereinstimnung abhängen muß. Bei der folgenden Abteilung sïdamerikanischer Arten tritt z. B. häufig eine bräunliche Farbenvarietät auf, von der es fraglich sein kann, ob sie als heterom. xanthus aufzufassen ist. Ich werde daher solchen Formen lieber einen eigenen Namen geben, neben dem Hinweis, daß es sich dabei wohl um heterom. xanthus liandelt.

Zu den Abbildungen möchte ich noch ergänzend zur ersten Einleitung bemerken, daß ich, an ein bestimmtes Format gebunden, des besseren Überblicks über nahe verwandte Formen halber, meistens Doppeltafeln gewählt habe. Ich habe in der folgenden Abteilung einige Tafeln selbst zeichnen können, die, mit meiner Unterschrift versehen, sich von den übrigen von Hern HEJIPEL gezeichneten unterscheiden. 
Die nachfolgenden Formen der Subfamilie Orthalicinae werden von PILsBRy wie folgt gruppiert:

1. Genus Porphyrobaphe;

2. Genus Liguus mit den Untergattungen Liguus, Corona und Hemibulimus;

3. Genus Orthalicus s. str. mit den Untergattungen Orthalicus und Metorthalicus.

Gattungen und Untergattungen werden damn nach beigegebenem Schlïssel in Gruppen geordnet, die nach der dafür charakteristischen Art. benannt werden.

Für viele der hierhergehörigen Formen ist die anatomische Untersuchung noch ausstehend, so daß der anatomische Befund zurzeit noch keine gute Unterlage für die systematische Gruppierung hergibt, der aber auch wahrscheinlich nu Unterscheidungsmerkmale für größere Terbände bietet, besonder's wemn el sich auf die bisher immerhin noch etwas einseitigen Untersuchungen des Tierkörper's beschränkt.

Wir haben es hier also ausschließlich mit den vom Gehäuse gebotenen Merkmalen zu tun. Meiner Auffassung derselben nach, kamn ich mich der PILsBRYschen Gruppierung, die ja im wesentlichen auch darauf begründet ist, nur zum Teil anschließen.

Zunächst stelle ich die Gattung Liguus im engeren Simne an das Ende, wemn sie anch der Gattung Corona am nächsten steht, eimmal, weil ihr Typus doch ein ganz eigenartiger ist, damn, weil sie autochthon für Westindien ist und in Südamerika nicht vorkommt, während alle anderen hier zu behandelnden Formen nach den bisherigen Funden ausschließlich in Sïdamerika leben. Der Tollständigkeit halber konnte ich diese Gattung aber nicht ganz ausschließen.

Bei der Gattung Zebra lag eine große Übereinstimmung in den Hauptschalencharakteren vor, so daß eine Einteilung in Artgruppen genïgte. Wenn dabei oft Absonderungen vorgenommen wurden, die eine schärfere Tremnung erscheinen lassen, als sie in Wirklichkeit besteht, so geschah es aus praktischen Grïnden. Bei der nummehr zu behandelnden geographischen Grupue der Unterfamilie der Orthalicinen war das Aufstellen von Artgruplen nur bei einer U'ntergattung möglich, da die vorliegenden Formen 
größere Unterschiede in den Hauptschalencharakteren zeigen, so daß neben den Gattungen das Aufstellen von mehr Untergattungen, als es PILSBRY getan hat, notwendig erschien. Es mag auf den ersten Blick befremden, daß diese Untergattungen oft nur eine oder wenige Arten enthalten; bei genaurer Prïfung wird man aber die vorgenommenen Trennungen berechtigt halten, soweit eben Schalencharaktere als Unterlage dienen. Die Systematik ist schließlich immer nur ein Hilfsmittel, mit dem man einer Gruppierung, welche der natürlichen Entstelıung und Entwicklung bezw. Umwandlung der Arten entspricht, näher zn kommen versncht. Thre Nomenklatur und die sich daran knüpfenden Begriffe können aber der Vielseitigkeit der Mittel, mit denen die Natur operiert, nie entsprechen, und es muß daher der Begriff eines Namens, z. B. Gattung, nicht für eine Gruppe von Formen dasselbe bedeuten wie für eine andere, bezw. die Methode der Gruppierung kamn und muß je nach den Formen, die uns entgegentreten, deren jede doch im Grunde ihre eigne Entwicklungsgeschichte hat, eine verschiedene sein.

Für Einteilungen in größere Verbände halte ich das Embryonalgewinde unter den Schalencharakteren für den geeignetsten, und zwar aus folgenden Gründen. Es bietet Merkmale im Aufban und in der Skulptur, die in ihrem allgemeinen Typus ziemlich beständig in Gruppen von Arten sind, die in ihren sonstigen Charakteren größere Verschiedenheiten anfweisen. Ferner zeigen sich an ihnen Merkmale, besonders in der Skulptur, aber auch zum T'eil in der Färbung, die nur an ihm auftreten, und die bei der TVeiterentwicklung des Gehäuses verschwinden. Das sind Erscheinungen, die doch wahrscheinlich auf ältere Typen in der Entwicklungsgeschichte der Arten hinweisen.

Ich wähle den Ausdruck Embryonalgewinde und nicht Embryonalgehäuse, weil das letztere nur ganz ausnahmsweise zur Verfügung steht, und man sich dalıer daranf beschränken muß, die Untersuchungen an möglichst jungen und gut erhaltenen Stücken vorzunehmen. Je ausgewachsener das Gehäuse ist, um so mehr hat man mit Abnutzung bezw. gewissen Teränderungen des Embryonalgewindes zu rechnen, so daß man nnter Umständen nur noch bei starker Vergrößerıng die maßgebenden Charaktere erkennen kann. Ich bemerke auch noch, daß, wie sich im Spezialteile erweisen wird, in ein paar Fällen sich selbst an jungen Stücken individuelle Abweichungen zeigen.

Nach dem Charakter des Embryonalgewindes erhalte ich nun folgende vier große Gruppen :

1. Genus Porphyrobaphe SHUTTLEW. mit glattem oder nur schwach gestreiftem Embryonalgewinde, dessen Windungen gewölbt sind. Typus $P$. iostoma SOWBY.

2. Gattung Corona ALB. mit ziemlich glattem und schwach gestreiftem Embryonalgewinde, das meist an der Naht eine feine, etwas weit- 
läufige Faltung zeigt, das aber, was besonders charakteristisch ist, etwas riemenförmig aufgerollte, $d$. h. seitlich flache Windungen hat, die daher oben stumpfkantig sind. Typus $C$. regina.

3. Gemus Tholus nov. gen. Das Embryonalgewinde hat eine breit kuppelförmige Gestalt und zeigt feine, gewellte, oft sich verzweigende scharfe Fältchen. Die Windungen sind wenig gewölbt. Typus Th. buckleyi HiGGINs.

4. Gemus Orthaticus BECK. Embryonalgewinde mit regelmäßig oder unregelmäßig sich mehr weniger schräg krenzenden Reihen von Grübchen, deren etwas wulstige Umrandmng als ein regelmäßiges odermuregelmäßiges Netzwerk erscheinen kann. Die Windungen sind gewölbt. Typns O. sultana.

Die besonderen Abweichmgen innerhalb dieser allgemeinen Charakterisierung sowie die sonstigen Schalencharaktere dienen dann zur Charakterisierung der Untergattungen. Es ist dadurch allerdings bedingt, daß sich für die Gattung anßer der kmzen Charakterisierung des Embryonalgewindes keine eingehende Diagnose geben läßt.

Ich habe auf Tafel 21, 22 die typischen Formen des Embryonalgewindes sowohl für die Gattnngen wie Untergattumgen in dreifacher Tergrößerung gezeichnet, und zwar in der Ansicht, die das Embryonalgewinde gibt, wemn man das Gehäuse so stellt, daß, von oben gesehen, der Nnclens wie in der Fig. 327 a liegt, während für die Zählung der Windungen die Lage in der Fig. $327 \mathrm{c}$ gegeben ist.

Bei der Diagnose der Untergattungen habe ich nur ansnahmsweise Färbung und Zeichnnng erwähnt, weil sie in ilıren vielen Einzelheiten und in ihren Terschiedenheiten besser der Artbeschreibumg znfallen. In dieser werden damn anch nur die etwaigen Besonderheiten, die inmerhalb des Ralımens der in der Diagnose der Untergattung aufgeführten Schalencharaktere liegen, angegeben.

Ich gebe nachstehend eine Übersicht meiner Gruppiermng:

I. Genns Porphyrobaphe SHUTTLEW.

A. Subgenus Porphyrobaphe s. str. Typus $P$. iostoma SowBy.

B. Subgenus Hemibutimus von MarTexs. Typns $H$. excisus VON MARTENS.

C. Subgenus Myiorthalicus n. subgen. Typus M. dennisoni REEvE.

D. Subgenus Oxyorthalicus $n$. subgen. Typus O. irroratus REEvE.

II. Genns Corona Alb. Typus regina FÉR.

III. Genus Tholus n. gen.

A. Subgenus Tholus s. str. Typus Th. buckleyi Higains.

B. Subgenns Pachytholus n. subgen. Typus P. pseudoiostoma n. spec.

IV. Genus Orthaticus BECK.

A. Subgenns Orthalicus s. str. Typus O. sultana DILLiryx.

B. Subgenus Clathrorthalicus n. subgen. Typus C. wallisi n. spec. 
C. Subgenus Trachyorthaticus $n$. subgen. Typus T. fraseri PFR.

D. Subgenus Metorthalicus PILSB. ${ }^{1}$ ) mit folgenden Artgruppen:

a) M. maranhonensis ALB., eine Art.

b) M. shuttleworthi ALB., eine Art.

c) $M$. kelletti ReEve, eine Art.

d) M. yatesi PFR. Typus M. yatesi.

E. Subgenus Melaniorthalicus n.subgen. Typus M. atramentarius PFR.

F. Subgenus Laeiorthalicus n. subgen. Typus L. reginaeformis n. spec. V. Gattung Liguus MIONTFORT. Typus L. virgineus L.

\section{Genus Porphyrobaphe SHUTTLEW.}

A. Subgenus Porphyrobaphe SHUTTLEW. s. str. Shuttlew., Notit. Malacol., p. 70 partim. SP., V, p. 3. P., p. 149 partim.

Gehäuse eiförmig-konisch, starkschalig, kaum glänzend, mit $5 \frac{1}{2}-6$ ziemlich gewölbten Windungen, deren letzte ungefähr gleich hoch wie das Gewinde und unten etwas zusammengedrückt ist. Mündung annähernd verkehrt ohrförmig, mit mehr weniger stark verdicktem Mundrand und einer gerade bis schräg zur Achse stehenden, gewundenen, verdickten und oben mit einer Falte versehenen Spindel. Embryonalgewinde mit $2 \frac{1}{2}$ Windungen (Fig. 327b), an jungen Stücken glänzend hornfarbig, später mehr weißlich oder bräunlich und nicht mehr durchsichtig, schwach gestreift, zuweilen mit einzelnen Fältchen an der Naht. Die erste steigt etwas an und ist oben stumpfkantig; sie liegt in einer etwas anderen Ebene als die folgenden Windungen ${ }^{2}$ ). Die Skulptur besteht ans schmalen Falten, deren 2-4 in gröbere Falten zusammengefaßt sind, was in der Nahtnähe besonders kräftig zum Ausdruck kommt, und hier geradezu eine Zone bildet. Sie werden von mehr weniger deutlichen, dicht stehenden, gewellten, feinen Spiralstreifen durchschnitten, die stellenweise, wenn Zwischenräume vorhanden sind, sich deutlich als solche erkennen lassen. Es treten auch einzelne gröbere Furchen auf, die dann stellenweise eine Stäbchenskulptur bewirken.

$\left.{ }^{1}\right)$ Ich habe für diesen Subgenus den PILSBRYschen Namen gewählt, trotzdem ich einige der darin aufgeführten Artelı anderweitig unterbringen mußte. PILSBRY charakterisiert diese Untergattung nur durch folgendes: „Artell mit Grïbchen am Embryonalgewinde wie beim typischen Orthalicus, aber verschieden durch die weniger bauchige Form und das entwickelte Peristom." Ein Typus wird nicht angeführt, was ja auch bei der großen Verschiedenheit der Arten natürlich war. Wenn auch die zuerst dabei aufgefïhrte Artgruppe die des $M$. fraseri ist, der er die ganz abwejchenden $M$. buckleyi und galactostoma anschließt, und $M$. fraser $i$ an sich von der Hehrzahl der ïbrigen Artgruppen bezw. Arten als eigenartig abzusondern war, so glaubte ich den Namen Metorthalicus besser eben dieser Mehrzahl der anfgeführten Arten geben zu sollen.

$\left.{ }^{2}\right)$ Da diese Eigentümlichkeit des Aufbaus, die übrigens auch bei der Gattung Zebra vorkommt, ein allgemeiner Charakter ist, so erwähne ich sie später nur dann, wenn sie besonders stark entwickelt ist. 


\section{P. iostoma SOWERBY.}

Taf. XXI, Figg. 327, $327 \mathrm{a}-\mathrm{b}$; Taf. XXIII, Figg. 358-360. P., p. 150, Taf. 49, Figg. $17-22$; Taf. 50, Figg. 26, 27.

Ich gebe in der Fig. 327 die Abbildung eines jungen Stïckes aus Guayaquil, um nicht nur die frïhen Bestandteile der Form, sondern auch den Typus der bramen Zeichnung zu zeigen, der später mehr und mehr den Zusammenhang verliert, und sich in einzelne Striche oder winklige Figuren anflösen kam, wenn er nicht wie bei der albino- und melanochitusForm ganz verschwindet. An ausgewachsenen Stïcken wird die anfangs typisch bräunlich fleischfarbene Grundfarbe mehr weißlich oder hellbräunlich mit zuweilen violettem Anfluge. Zuweilen tritt an Stelle von Band 2 ein helles Band auf, an dem die Zeichnung mehr weniger verschwindet. Das Innere der Mündung ist weiß, der immer stark, oft in mehrfachen Schichten verdickte Mundrand ist bei normalen Stïcken mehr weniger lebhaft violett, selten rosa, bei der albino-Form rein weiß, ebenso oder mehr dunkel purpmrviolett ist der die Mundränder verbindende Callus gefärbt, während an der violetten Spindel die obere Falte weiß ist. Varixstreifen sind nur ganz ausnahmsweise zu erkennen und sind dann schmal bram gefürbt. Ebenso tritt seltener in der Nähe der Mündung ein abschließender, erhabener Mundrandstreifen auf, demn die typische Terdickung des Mundrandes scheint in der Regel erst mit Abschluß des Wachstums zu erfolgen. Der Mundrand ist umgeschlagen, und die oft in mehrfachen Schichten auftretende Terdickung tritt daher nach rückwärts gerichtet auf. Meinem Material nach ist die besonders starke Verdickmng an keine besondere Lokalität gebunden, und da sich auch die nach PILSBRY damit verknüpft sein sollende obsoletere Spiralskulptur meinem Material nach nicht bestätigt, so kann ich eine Berechtigung seiner var. bilabratus nicht zugestehen.

Das Embryonalgewinde (Fig. 327 b) und die Skulptur entsprechen der Gattungsdiagnose, nur treten hier zuweilen noch kurze Runzeln auf, und besonders auf der letzten Windung geben die gröberen Falten dem Gehäuse oft ein gerieftes Ansehen.

Ich wähle hier wie auch in der Folge fiur die Abbildungen nur Stïcke aus, die PILSBRYs Abbildungen ergänzen, unter denen die Figg. 19, 20 den normalsten Aufbau zeigen.

1. Kapt. PAEssLer leg. 1902, 1907. Machalilla, Ecuador. Mehrere Stïcke in Spiritus mit Tier, von normalem Terhalten. Ferner ein am Strande aufgelesenes Stïck.

2. Waluis leg. Santa Rosa, Ecuador. Zwei normale Stïcke, das kleinere Stiick mit mäßig vermehrfachtem, das größere Stück mit schwach vermehrfachtem Mundrand. Das letztere Stïck erscheint auf der letzten Windung sehr weitläufig gerieft; es mißt:

$$
5 \% \text {. } \quad 81,7 \times(40,0) 52,0-46,0 \times 23,2 .
$$


Vier Stücke heterom. albinus. Das ganze Gehäuse ist rein weiß, alle Stücke haben einen mehr weniger stark vermehrfachten Mundrand. Das größte Stück mit dem am stärksten vermehrfachten Mundrand ist abgebildet, weil es zugleich die extremest vorkommende derartige Bildung zeigt.

Fig. 358. $\quad 61 / 4-73,5 \times(34,4) 45,7-37,0 \times 22,0$.

Fast 6. $\quad 61,6 \times(27,4) 35,2-33,7 \times 18,2$.

3. WALLIS leg. Ecuador. 1876. Drei typische Stïcke mit mäßig. vermehrfachtem Mundrand.

4. Ton Guayaquil.

a) W. F. H. Rosenberg vend. Zwei tote Stïcke, normal, mit nicht vermehrfachtem Mundrand.

b) F. V. Buchwald ded. Drei Stücke, deren zwei dunkle Färbung und helle Binde wie P., Fig. 19, zeigen. Der Mundrand ist nur an einem der Stücke etwas vermehrfacht.

c) L. URBAN ded. Ein Stück wie die vorstehenden dunkleren.

d) Dr. OHaus ded. 1. Januar 1907. Das junge abgebildete Stïck. Fig. 327. $\quad 4 \frac{3 / 4}{4}-33,7 \times(19,2) 25,4-22,7 \times 13,4$.

5. Rosenberg vend. Chongon, Ecuador. Zwei Stiicke, tot, mit mäßig erweitertem Mundrand und normaler Färbung.

6. Rosenberg vend. Puna, Ecuador. Ein sehr schmales, großes Stück mit normaler Färbung und ziemlich stark vermehrfachtem Mundrande. Die Spitze ist abgebrochen, so daß die Anzahl der Windungen und die Höhe nur abgeschätzt sind.

$$
\text { ca. } 6-81,0 \times(34,2) 45,7-43,9 \times 22,0 \text {. }
$$

7. Ecuador. ScHLÜTER, Halle, vend. Drei schöne, sehr breite Stücke, sehr dunkel gefärbt, mit sehr scharf sich abhebender heller Binde. Zwei Stücke mit mäßig, ein mit stark vermehrfachtem Mundrand; das letztere mißt:

$$
5 \frac{3}{4}-77,4 \times(38,0) 50,8-42,6 \times 23,9 .
$$

8. Koll. Scholvien. Ein Stück heterom. melanorhilus. Das Stiick ist verhältnismäßig dünnschalig, rein weiß mit nur schwach entwickelter Faltung. Es sind diclit nebeneinander am Anfang der letzten Windung zwei purpurbraune, schmale Varixstreifen vorhanden, der Mundrand ist einfach umgeschlagen, schmutzigviolett, der Callus ist purpurbraun.

Fig. 359. $\quad 53 / 4-64,7 \times(31,4) 40,3-35,0 \times 21,0$.

9. Koll. O. Seniper. Panamá. LandaUer vend. Ein typisches Stück mit mäßig vermehrfachtem Mundrande. Ob der Fundort richtig ist, muß ich nach dẹm bisher bekannten Vorkommen der Art bezweifeln.

10. Ecuador. Zwei Stïcke, typisch, mit schwach vermehrfachtem Mundrande und bald dahinter ein hervorstehender Tarixstreifen (siehe oben).

11. Ecuador. Drei typische Stiicke, davon eins unansgewachsen.

12. Nr. 15849. Peru. Zwei typische Stücke. 

Zeichnung.

13. Koll. SoHST. Von ebendaher ein typisches Stiick mit wenig Oline Fundort.

14. Tiele Stricke ex Koll. ScHoLvien, die nach erhaltener Auskunft aus einem bei UyLAUFF vorhandenen Faß ansgesucht sein sollen. Ich labe aus diesem sonst typischen Material nur das kleinste Stiick zur Abbildung ausgewällt. Der Fundort war niclıt melır festzustellen.

Fig. 360. $5^{3} / 8-55,0 \times(25,2) 34,4-29,0 \times 17,9$.

Das größte Stiick mißt:

$$
6^{1 / 8}-86,2 \times(39,2) 52,1-46,8 \times 25,2
$$

und hat nur einen einfach verdickten Mundrand.

15. Nr. 568s, alte Sammlung. Ein junges Stiick heterom. melanochilus wie das sub 8. verzeichnete. Das Stïck ist wie alle jungen Stücke auf der Mittelhöhe der letzten Windung kantig.

$$
5-40,6 \times(23,3) 28,4-25,2 \times 13,7 \text {. }
$$

16. Koll. Scholvier. Ein Stiick, außen etwas verwittert, scheinbar mit wenig Zeichnming und schwach entwickelter Faltung. Mundrand und dick aufliegender Callus sind rosafarbig, das Innere ist etwas gelblich, der Mundrand ist stark vermelnfacht. Die Mündungspartie ist frisch, nicht verwittert.

$$
\text { Fast } 5 \% \text { - } 70,0 \times(33,0) 44,8-37,3 \times 21,4 .
$$

\section{P. satumus PFR.}

Taf. XXIII, Figg. 367-369.

P., p. 153, Taf. 50, Figg. 23-25.

Der guten PILsBRYschen Beschreibung möchte ich nur noch folgendes hinzufiigen. Das Embryonalgewinde ist wie bei P. iostoma. Die Skulptur zeigt feinere, bezw. dichter gedrängte Falten als bei $P$. iostoma. Die Spiralskulptur ist aber ganz ähnlich und hängt nicht, wie aus der DoHRNschen Bemerkung im Jahrb. d. Malak. Ges., Tol, 9, p. 111, hervorgehen könute, mit dem Torhandensein der Cuticula zusammen, sondern ist auch ohne diese rorhanden, wemn das Stïck nicht abgerollt ist. Was die Zeichmung anbelangt, so liegen mir Stiicke vor (Nr. 1), die durchaus dem PfErffenschen Typus entsprechen. Die ziemlich breiten, gewellten Streifen auf der vorletzten und einem Teil der letzten Windung sind nach rorn weiblich gesäumt; diese helleren schmalen Streifen treten übrigens, wenn anch nur bruchstïckweise, zuweilen an Stücken auf, wo die dunkleren Streifen meist schmäler und matter in der Farbe sind. Die Varixstreifen sind wie der Callus und der Mundsanm bramschwarz, aber meistens vorn und hinten hell berandet. Die Spindel ist zuweilen stärker gewunden, als es die Figuren in P. zeigen (Nr. 2). 
1. Koll. Scholvien. Zwei Stïcke von englischen Händlem. Ecuador. Fast ganz dem PFEIFFERschen Typus entsprechend.

Fig. 368. $\quad 61 / 4-70,0 \times(30,3) 38,0-38,0 \times 18,1$.

2. Nr. 15846. R. GEALE vend. Malacates, Ecuador. Fünf Stücke, davon drei mit Cuticula, die daher olivgelb erscheinen; sie entsprechen in Form und Zeichnung P., Fig. 24.

Fig. 367. $\quad 61 / 4-72,0 \times(32,5) 42,5-39,8 \times 21,2$.

$6 \frac{1}{2}-76,4 \times(31,7) 44,1-38,5 \times 18,8$.

$61 / 4-71,5 \times(34,0) 41,4-40,0 \times 19,3$.

3. Ecuador. RoLLE vend. Ein Stück einer kleinen Form.

Fig. 369. $6-63,7 \times(28,0) 35,0-33,3 \times 16,3$.

4. Koll. SoHsT. Ein Stück mit französischer Etikette. Neu-Granada. Mit Cuticula, ganz wie die sub 2. verzeichneten.

\section{B. Subgenus Hemibulimus VON MARTENS, emend. STREBEL.}

von Martens, Conchol., Mitth. II, p. 175, und nachträgliche Bemerkung am Ende. P., p.1S4.

Gehäuse festschalig, spindelförmig oder eiförmig-konisch (H. iris), etwas fettglänzend bis fast glanzlos, mit $5 \frac{1}{2}-7$ mäßig gewölbten Windnngen, deren letzte an der Basis stark znsammengedrückt ist oder oberhalb derselben in Form eines Wulstes, der zwischen Basal- und Außemrand in eine Rinne ausmündet $(H$. iris). Die letzte Windung ist entweder ziemlich gleich hoch oder höher als das Gewinde (H. iris). Die Mündung ist entweder oval, beiderseits zugespitzt oder verkehrt-olırförmig (H. ivis). Der Mundrand ist nach unten etwas erweitert und entweder stmpf oder schmal umgeschlagen. Die Spindel ist stark eingebogen oder etwas schräg zur Aclise stehend und etwas gewunden (H. iris). Das Embryonalgewinde (Figg. 330, 331. 333, 334) hat 2\% Windungen, die glänzend und fein gestreift sind; zuweilen treten gegen Ende schon einzelne Spiralfurchen auf $(H$. iris). Es ist oft oben dunkel gefärbt und auch mit dunkleren und helleren Flecken an der Naht besetzt; ersteres findet bei heller Grundfarbe meistens nicht statt. Die Skulptur besteht ans schmalen Falten, deren zwei oder mehr in stärkere Falten zusammengefaßt sind. Die feinere Spiralsknlptur ist nur stellenweise zu erkennen, und zwar als feine Reifen, dagegen treten in unregelmäßigen Zwischemräumen und zuweilen nur strichweise, gröbere seichte Spiralfurchen anf, die eine Stäbchenskulptur bewirken; anch hammerschlagartige Eindrücke, Runzeln und wulstige Erhebungen kommen vor.

Ich habe diese Untergattung mit dem ursprünglichen Typus, $H$. excisus VON MARTENS, hierher gebraclit, weil VON MARTENS bei Beschreibung des Embryonalgewindes, das er l. c. fein gerunzelt nennt, sich durch eine Beschädigung der Oberfläche hat irre führen lassen, die durch einen mechanischen oder chemischen Torgang entstanden ist. Ich habe 
ferner den Bul. iris Pfr., den PILSBRY zu Porphyrobaphe bringt, hier eingefiigt, weil ich die wulstige Erhebung oberhalb der Basis für homolog mit der kanalförmigen Zusammenpressung der Basis bei $H$. excisus und den verwandten Arten halte, ferner auch, weil der Skulpturtypus derselbe ist. Die einzelnen Abweichungen bei $H$. iris sind oben in der Diagnose durch Hinweis gekennzeichnet.

von ILARTENs fügt Hemibulimus als Untergattung der Gattung Liguus an, worin ihm EDG. A. SuIth (Proceed. Malac. Soc. London, Vol. 7, p. 313) und ursprünglich anch PILSBRY folgen. Später hat der letztere in dem jüngst erschienenen Part 78 seines Mannal, p. 115, diese Ansicht berichtigt, indem er sagt: "The relation of Hemibulimus to Liguus is not very close and $I$ now donbt the propriety of including them in one genus. Except in the structure of the columella, Hemibulimus is very similar to Porphyrobaphe." Ich kann ihm, wie man aus meiner Anordnung sieht, darin nur beistimmen.

\section{H. excisus VON MARTENS.}

Taf. XXI, Fig. 333; Taf. XXIII, Figg. 361, 363.

yon Martens, 1. c. p. 173, 200, Taf. 35, Figg. 1, 2, 4, 5. P., p. 185, Taf. 36 a, Figg. $31 / 34$.

Ich habe der guten Beschreibung von von MARTENS mur weniges linznzufügen. Das Gehäuse ist wenig glänzend, der Mundrand ist nach außen schmal und schwach verdickt, der Callus ist purpurschwarz, nach imnen weis, die Spindel ist bald mehr, bald weniger eingebogen. Die Färbung ist dunkler bräunlich-olivenfarbig als die Abbildung l. c. sie zeigt.

von MaRTens l. c. erklärt in einer nachträglichen Bemerkmng, daß, nach einem Vergleich mit Stücken von $H$. magnificus (anf die ich weiter unten zurückkomme), der Name excisus zu streichen und durch magnificus zu ersetzen sei. Da mir beide Formen ans dem Berliner Museum vorliegen, so kann ich bestimmt sagen, daß VON MARTENS hierin sich geirrt hat, und daß seine Art rorlänfig bestehen bleiben muß. Es kann sich höchstens darmm handeln, ob $H$. excisus eine abweichende Lokalform von $H$. magnificus, wie ich ihn auffasse, ist, worüber aber weiteres Material entscheiden muß.

1. Berl. Yusenm. STÜBEL leg. Columbien, Hacienda de Sotara bei Popayan, $2400 \mathrm{~m}$. Der rox MarTenssche Typus, von dem ich nur zum Tergleich die Seitenansicht der letzten Windung abbilde. Das Stiick ist etwas fettglänzend.

$$
\text { Fig. 363. } \quad 5 \frac{1}{2}-43,0 \times(18,3) 23,5-23,8 \times 13,4 .
$$

2. Rolle vend. Yon Maccas, Ecuador. Ein Stück. Es ist etwas spindelförmiger als der Typus, etwas gröber skulpiert, ziemlich glanzlos und lat eine etwas weniger stark eingebogene Spindel. Außerdem tritt hier am Anfang der letzten Windung eine Strecke weit das schmale, gelbe Band 4 auf. Fig. $361 . \quad 5 \frac{1}{2}-43,6 \times(17,5) 21,5-24,2 \times 11,7$. 
H. magnificus PFR. emend. STREBEL.

Taf. XXI, Fig. 3.34; Taf. XXIII, Figg. 362, 364.

Achatina magnifica PFR. Monogr. Hel. II, p. 255, und III, p. 487, hier mit Hinweis auf Reeves Achatina magnifica Pfr., Fig. 33. P., p. 185, Taf. 36 a, Fig. 30. Kopie nach REEVE.

Hemibulimus magnificus PFR. EDGAR A. SMTTH in Proceed. Mal. Soc. London, Vol. VII, p. 313. P. in Manual of Conch., neuestes Heft, part is, p. 117.

Mir liegen aus dem Berliner Museum drei nicht ausgewachsene Stücke vor, die Hopke in Cuembi, Nen-Granada, gesammelt hat, die 1898 katalogisiert und von VON MARTENS $H$. magnificus PFR. bestimmt sind. Es sind dieselben Stïcke, welche VON MARTENs zum Vergleich mit seinem $H$. excisus vorgelegen haben.

EDGAR A. SMITH hat nun 1. c. die PFEIFFERsche Art zusammen mit Hemibulimus (Achatina) dennisoni REEvE 1. c. besprochen. Er spricht die Ansicht aus, daß PFEIFFER sich geirrt hat, wenn er bei seiner A. magnifica, die 1847 beschrieben ist, später anf REEvEs Figur 33 (1849 veröffentlicht) hinweist; denn der aus der CuMINGschen Sammlung stammende Typus, jetzt im British Mnsem liegend, sei etwas anderes, wälsrend die Fig. 33, die REEvE für A. magnifica PFR. gehalten hat, da sie anch vom selben Fundort stammt wie PFEIFFERs Typus, ein junges Stiick von der Achatina dennisoni REEve, Fig. 32, von Bogota sei, was aus dem ilım vorliegenden Material erhelle, das von PAINE und BRINKLEY in Quilachao, Cauca-Tal, Columbien, gesammelt und später von SowERBY und FULTON in den Handel gebracht wurde. SuITH sagt vom CuMINGschen Stiick nur, es sei ,thin, smooth, with very different coloration", während doch eine eingehende Beschreibung um so mehr am Platz gewesen wäre, als die beigegebene Abbildung sehr verwischt und undentlich ist. Ich gebe nun zunächst die Beschreibung jener drei Stiicke.

Das Gehäuse ist dünuschaliger, etwas breiter oval-konisch, und die letzte Windung ist etwas höher im Terhältnis zum Gewinde als bei $H$. excisus. Die Färbumg ist von Anfang an heller, die ersten Windungen sind hell hornfarbig, nicht dunkel abschattiert und ohne den rötlichen Nuclens. Später wird die Grundfarbe mehr bräunlichgelb bis gelblicholivenfarbig. Anf die $2 \frac{1}{2}$ einfarbigen Embryonalwindungen folgt, immer dentlicher und breiter werdend, ein aus braunen und gelblichen Flecken gebildetes Band an der schmal hell berandeten Nalıt. Die bramen Flecke lösen sich naclı unten in sclımale braune, z. T. etwas gewellte und unterhalb Band 2 verstiarkte, winklig vorspringende Streifen auf, zuweilen untermischt mit breiteren Streifen. Nach der Mündung zu verlieren sich mehr und mehr die schmalen Streifen, je größer die Stücke werden, und es bleiben nur unregelmäßig verteilte, vorn meist gelblich berandete Streifen uibrig. Anch das Fleckenband an der Naht verliert sich frïher 
oder später. Yom Ende der Embryonalwindmngen an tritt Band 2 schmal und gelblich auf, dem sich unten unmittelbar die winklig rorspringenden verstärkten Streifen als srhmales, gegliedertes Band anschließen. Dieses Doppelband kann fast bis zur Mündung gehen, aber anch schon früher aufhören, zuweilen bleibt nur das helle schmale Band nach. Ein älnnliches Doppelband 3 verläuft bei den beiden kleinsten Stücken oberlıalb der Naht, hört aber auf der letzten Windung anf. Dem größten Stïck fehlt es, statt seiner sind aber auf der letzten Windung die Bänder 3 und 4 als schmale gelbe Streifen vorhanden (das Band :3 undentlicher als Band 4). Inı blänlichweif belegten Innern, in dem die Zeichnung melı weniger durchscheint, erkennt man anch bei den kleineren Stücken, wenn auch undentlich, die Bänder 3 und 4, wo bei dem großen Stïck Band 2 und 4 selı dentlich weif hervortreten. Die Miundung ist oval, oben und unten zugespitzt und von gleichmäßigerer Form als bei $H$. excisus, bei dem die Spindelseite duch die eingebogenere Spindel sich weiter auswölbt als bei H. magnificus. Bei dem kleinsten Stiick ist der Mund'and etwas verdickt wie bei $H$. excisus, weil das Stïck gerade bei einem Wachstumsabschluß gefunden wurde; er ist auch nach innen schmal braun ausfließend berandet. Die Spindel ist mehr weniger eingebogen, weißlich, unten rötlich. Der Callus ist dunkel purpurbraun, nach imen weißlich werdend.

Die Skulptur ist dieselbe wie bei $H$. excisus.

Fig. 362. $\quad 5 \% 3-49,5 \times(21,1) 27,6-29,2 \times 15,2$.

$51 / 4-46,0 \times(20,5) 24,7-27,1 \times 13,0$.

"364. $5 \frac{1}{4}-41,0 \times(17,3) 22,8-23,1 \times 12,3$.

Vergleicht man die vorangehende Beschreibung mit PFEIFFERs kurzer Diagnose, so fällt an meisten auf, daß das Fleckenband an der Naht in letzterer fehlt, da er nur von einem gelb und bram gegliederten Band oberhalb der Mitte spricht, womit das Band 2 gemeint ist. Aber SumTHs Figur, bezw. der Cumingsche Typus der Art läßt das Fleckenband an der Naht dentlicls erkennen, besonders an den mittleren Windungen. Daa die Bänder eigentlich schmal gelb sind, und daß von ihnen anch Band 3 und 4 auftreten kömmen, scheint aus der SyrTHschen Figur nicht hervorzllgehen. Ich bemerke dazu aber, daß, wie oben erwähnt, diese Bänder mur an dem größten der drei Stïcke deutlich ansgeprägt, bei den anderen nur im Innel'n mdentlich angedeutet sind. Wenn PFEIFFER die Spindel "recta, verticalis" nennt, so ist das nach der SuITHschen Figur nicht richtig, wo sie auclı etwas eingebogen ist, ebenso wie das jüngste der oben angeführten drei Stïcke (Fig. 364). Die Skuptur ist durch "leviter striatuld, haud nitens" sehr oberflächlich geschildert, aber schon die Bezeichnung kaum glänzend spricht für eine verhältnismäßig gut ausgeprägte Skulptur, wälıend SuITHs Bemerkung "smooth" nicht lichtig sein kann, denn dann wiirde die Art nicht in die Gattung oder Untergattung Hemibulimus passen. 
Die Maßverhältnisse betreffend, so ist $z$ wischen den von PFEIFFER angegebenen und denen, welche sich ans der SurtHschen Abbildung ergeben, keine rechte Übereinstimmung.

$$
\begin{aligned}
& \text { PFEIFFER }=47,0 \times 21-27 \times 13 . \\
& \text { SHITH }=45,5 \times(19,7) 23,0-24,0 \times 12,1 .
\end{aligned}
$$

Sieht man von der Anzahl der Windungen und dem Breitenverhältnis ab, wobei die Verschiedenheit individueller Methoden in Frage kommt, so deckt sich das mittlere der vorliegenden drei Stiicke gut mit der SyITHschen Abbildung, nur ist die letzte Windung etwas höher und stimmt, wie auch die Breite der Mündung; besser mit PFEIfFers Maßen.

Ich glaube, daß nach der eingehenden Beschreibung und den daran geknüpften Erörterungen man mir zustimmen wird, wenn ich die drei Stiicke des Berliner Museums mit dem PfEtfFerschen Namen belege und danach die Beschreibung PfEIfFers ergänze und berichtige. Es erübrigt nur noch, die Beziehungen zur ReEveschen Figur 33 zu erörtern. Nach den jungen Stücken, die mir von der Quilachao-Form von $H$. dennisoni vorliegen, hat SuITH allerdings recht, wenn er sie für verschieden von H. magnificus hält, aber wie er schon bemerkt, hat PFEIFFER sich wohl durch den gleichen Fundort Qnito und die entschiedene allgemeine Ähnlichkeit verleiten lassen, jene Figur 33 bei seinem $H$. magnificus anzuführen. Hat doch auch REEve, dem doch der Typus aus der Cunivgschen Sammlung bekannt gewesen sein muß, da er ihn aúsdrücklich erwähnt, die Gleichheit beider Formen vertreten. Weiteres Material aus jenem Hochlande, von dem $H$. dennisoni mit der var. cara, H. magnificus und H. excisus stammen, mag darüber entscheiden, ob sich die Beziehungen dieser drei Arten zu einander noch enger heransstellen als es vorläufig den Anschein hat.

PILSBRY folgt in dem schon oben angeführten nenen Heft 78 seines Mannal den SyitHschen Ausfïhrungen.

\section{H. Aenmisoni REEVE.}

Achatina dennisoni ReEve, Conch. Icon., Fig. 32. SiIth, 1. c. p. 313. P., 1. c. part 7 , p. 115.

Der REEvesche Typus ans Bogota muß wohl vorläufig abgesondert bleiben, demn weder unter dem mir vorliegenden noch dem von SuITH angeführten und von PILSBRY eingehend beschriebenen Material von Quilachao befindet sich ein sich damit deckendes Stïck. Die hellfarbigen Stücke haben keine hellen Bänder, nicht mal alle dunkelfarbigen, und der Callus ist bei allen dunkel purpurbraun. Wenn REEve von „a pale obscure band" spricht, so stimmt das nicht mit seiner Abbildung, die helle Bänder 2 und 3 zeigt. 


\section{Aemisoni ReEVE, Form curus PILSBRY.}

Taf. XXI, Fig. 331; Taf. XXIII, Figg. 365 a, b, 366.

SмITH, l. c. p. 313 . P., l. c. p. 116.

SIITH verweist allerdings anf die Abweichungen vom REEvEschen Typus, gibt aber dieser von SOwERBY und FutToN als Hemibulimus dennisoni und var. magnifica REEVE non PFEIFFER in den Handel gebrachten Form keinen eigenen Namen. PILsBry hat dem 1. c. abgeholfen und beschreibt die verschiedenen Farben und Zeichnmoen, die bei dem ihm rorliegenden Material vertreten waren. Mir kam erst bei der Korrektur der Drucklegung meines Manuskriptes jenes Heft 78 zu Händen. Ich hatte diese Form cauccensis genannt, was nun einzuziehen ist; dagegen lasse ich meine Beschreibung stehen, die der PILsBRYschen als Ergänzung und zum Tergleich dienen mag.

Die Form ist größer als $H$. magnificus, starkschaliger, mit rascher zunehmenden $6-6 \frac{1}{4}$ Windungen und einem schmäler ausgezogenen Gewinde; die letzte Windming ist bei den großen Stricken meist oben etwas kantig. Die Spindel ist an jüngeren Stïcken gerade bis etwas eingebogen, bei ansgewachsenen Stïcken stärker, wenn anch verschieden stark, eingebogen. Die oberen Windungen sind entweder hell oder bei zwei jungen Stïcken der dunkleren Färbung oben dunkelbram abschattiert, aber der Nucleus ist auch hier nicht rötlich wie bei $H$. excisus. Sonst zeigen die oberen :3-4 Windingen dieselbe Zeichnung wie bei $H$. magnifica, mur verschwindet das Fleckenband an der Naht anf den letzten 2-3 Windungen ganz, und Band 2 zeigt nur an einem der jungen dunkeln Stïcke an einer kurzen Stelle die Kombination mit dem Fleckenband, sonst sind die Bänder 2, 3, 4 schmal und gelb, aber zumehmend etwas breiter werdend. Bei den fast einfarbigen Stücken fehlen sie anf den letzten Windungen ganz. Die Skuptur weicht dadurch von $H$. excisus wie $H$. magnificus ab, daß sie weit gröber ist. Die schmalen Falten gehen meist bis an die Naht, und sind dort meistens in gröbere Falten zusammengefaßt, was ja anch bei den anderen beiden Formen der Fall ist, aber sie sind schärfer ansgeprägt, und durch die gröberen Spiralfurchen wird rorwiegend eine Stäbchenskulptur bewirkt. Die feineren Spiralfurchen sind nur in Spuren erkennbar, wälnend sie bei den anderen beiden Formen noch meist dentlich als feine Reifen erkembar sind, die oft weitläufig und mregelmäßig verlanfen, anch muterbrochen sind. Bei den größeren Stücken kommen auf den letzten Windungen vereinzelt hammerschlagartige Eindrïcke und kurze anfgetriebene Stellen in der Spiralrichtmo vor. Ihre Skuhptur nähert sich mehr der des $H$. iris. Der Mundrand ist wie die Spindelbasis bei ausgewachsenen Stücken mennigrot oder orange, dahinter tritt zuweilen ein purpurbramer ausfließender Streifen anf, und dieselbe Farbe lat nach an@en hin der Callus, doch ist der bläulichweife Teil 
schmäler als bei den beiden anderen Formen, und zwar zunehmend bei jüngeren Stücken. Das Innere ist bläulichweiß, hell blangran oder rein weiß mit rötlichem Anflug.

Die mir vorliegenden Stïcke zeigen folgende Farbenvarietäten anf.

1. In Färbung und Zeichmung wie ReEves A. magnifica, Fig. 33. Drei Stiicke, davon zwei mit hellen, ein mit dunkel abschattierten letzten Windungen, sonst ganz ïbereinstimmend. Ich bilde das größte und kleinste Stïck ab.

$$
\begin{aligned}
& \text { Fig. } 365 \text { a. } \quad 61 / 4-68,2 \times(27,6) 34,6-36,2 \times 19,3 \text {. } \\
& 5 \frac{1}{2}-52,2 \times(22,5) 26,8-29,4 \times 14,3 . \\
& \text { "365b. } 5-41,0 \times(18,1) 20,2-23,2 \times 11,9 \text {. }
\end{aligned}
$$

Ein noch jüngeres, aber defektes Stïck hat eine gerade, etwas schräg zur Achse stehende Spindel.

2. Ein dunkel olivbraunes Stück, nach oben rötlichbraun werdend. Das Fleckenband an der Naht und Band 2 sind noch bis auf die 4. Windung schwach erkennbar, sonst fehlt jede Zeichnung, nur einzelne dunkle, nach vorn gelblich berandete Tarixstreifen sind vorhanden. Mundrand, Inneres und Callus sind wie bei dem vorgehenden Stïck gefärbt.

$$
6-72,2 \times(27,8) 37,3-39,6 \times 20,8 .
$$

3. Ein Stiick, schmutzighell strohgelb. Auch hier fehlen Zeichnung und Bänder auf den letzten Windungen wie bei dem vorangehenden Stïck; die Tarixstreifen sind nur hell olivfarbig. Der Mundrand und das Spindelende sind orangefarbig; der dunkle Streifen hinter dem Mundrande fehlt. Der Callus ist purpurbraum.

Fig. 366. $\quad 61 / 8-77,9 \times(29,4) 38,5-40,2 \times 21,3$.

4. Ein Stück, rötlich orangefarbig, sonst wie das vorangehende. Die Varixstreifen sind rotbraun, der Mundrand ist nach unten zu erweitert, memnigrot, breit ausfließend und ohne dunklen Strich dahinter. Der Callus ist purpurbraun, das Spindelende mennigrot.

$$
6-72,5 \times(28,5) 39,0-40,0 \times 22,0 .
$$

Die beiden letzten Stücke sind vielleicht auch als heterom. xanthus aufzufassen.

\section{II. ivis PFR.}

Taf. XXI, Fig. 330; Taf. XXIT, Fig. 373.

Bul. iris Pfr. ILART. und Chenn., 2. Aufl., p. 244, Taf.65, Figg.4, 5. Bull.vallisiamus Ilouss. MIalak., BI. 21, 1879, p. 9. Novit. Conch. IV, p. 135, Taf. 130, Figg. 7/S. P., p. 157, Taf. 51, Figg. $2 S-32$.

Außer den l. c. gegebenen Beschreibungen und Abbildungen hat anch H. DOHRN in Jahrb. d. d. Malak. Ges. II, 1875, eine eingehende Besprechung der Art gegeben, und ich habe in der Diagnose der Untergattung ihre besonderen Merkmale hervorgehoben, so daß hier nur noch einige Ergänzungen zu folgen branchen. 
In der Grundfarbe tritt ein brämmliches Strohgelb und eine brämnliche Olivenfärbung anf, die im ersteren Fall nach oben heller, znweilen etwas violett-fleischfarbig, im letzteren Falle nach oben dunkler, schwärzlichviolett wird, wobei sich an der Naht zuerst eine schwarze Zone hinzieht, die später mit leicht weißlichen Flecken gegliedert wird (s. Fig. 330). Das gegliederte Band an der Naht, das sich meist bis an die 4. Windung hinanzieht, kamn ganz oder fast ganz fehlen, und zwar ansschließlich bei der helleren Grundfarbe, oder es ist bei beiden Grundfärbungen mehr weniger dentlich ansgeprägt. Dies Merkmal vermisse ich in den Beschreibungen, ebenso daß das Innere bei der dunklen Grundfarbe hell blangran und nur bei der helleren Grundfarbe rein weiß ist. Bei jumgen Stücken ist das Immere immer mehr weniger dunkelbram oder violettbram. Es treten anch bei jungen und alten Stïcken, bei heller nnd dmkler Grundfarbe in der Mïndung zuweilen dentliche, nach unten zu breiter verdende drei breite dunkle Zonen anf (bezw. die schmalen Zwischenräume entsprechen ungefähr den Bändern 2, 3, 4), die man außen nicht oder nur sehr undeutlich erkennt. Der an Stelle von Band 4 verlaufende Wulst ist innen immer lein weif, was besonder's an jungen Stiicken seln: deutlich hervortritt.

Junge Stücke der dunkleren Färbung bieten im allgemeinen äußeren Anssehen, bis auf die Form und die abweichende Basal- bezw. Spindelpartie Ähnlichkeit mit $H$. excisus.

1. Wallis leg. Sonson, Prov. Antioquia, Neu-Granada. Aus O. SEMPERs und meiner ehemaligen Sammlung. Tiele Stiicke, von denen ich nur einige Maße anführe.

$$
\begin{aligned}
\text { Fast } 6-85,2 \times(34,8) 46,8-49,0 \times 24,6 . \\
" \quad 51 / 2-81,8 \times(33,7) 47,1-48,0 \times 24,0 . \\
5 \%-65,7 \times(30,1) 41,4-39,3 \times 21,3 . \\
51 / 4-65,0 \times(30,4) 42,4-40,3 \times 22,6 . \\
51 / 4-67,6 \times(31,2) 41,0-40,9 \times 20,3 .
\end{aligned}
$$

Fig. 373. $5-47,9 \times(22,9) 29,3-29,5 \times 16,0$.

$$
5-54,4 \times(24,8) 33,9-34,4 \times 18,2 .
$$

Man sieht, wie verschieden die Terhältnisse zwischen Anzahl der Windungen und den Maßen an den verschiedenen Stïcken sind.

2. GUST. SchneIDER vend. Frontino, Nen-Granada. Ein junges Stück.

3. Gust. SCHNEIDER vend. Ocaña, Neu-Granada. Ein junges Stück.

Diverse andere Stïcke ohne genanen Fundort.

Die ron DOHRN 1. c. und von PILSBRy gegebenen Maßje rervollständigen die Veränderliclıeit der Form.

\section{Subgenus Myiorthaticus 1. subgen.}

Gehäuse fest- aber nicht dickschalig, glanzlos, oval-konisch, mit. 6 schwachgewölbten Windıngen, die sich rasch erweitern, und deren 
letzte bei großen Stïcken bedeutend größer als das Gewinde sein kann; bei jungen Stücken weniger. Die Mündung ist oval, oben zugespitzt, zuweilen, und besonders bei jüngeren Stïcken, bildet die Spindel mit der Mündungswand einen stumpfen Winkel. Der Mundrand ist stumpf, nach rückwärts schmal verdickt, nach mnten bei großen Stïcken etwas erweitert. Die Spindel steht senkrecht oder etwas schräg zur Achse; sie ist in sich zuweilen fast gerade, meistens aber eingebogen, oben zurïckweichend, selten etwas gewunden, ganz weiß oder nach unten etwas bräunlich werdend; ihr Ende bildet mit dem Basalrand einen etwas abgerundeten Winkel. Der Callus ist dünn, weißlich, nach außen immer mehr weniger dick und mehr weniger schmal, dunkelbram berandet, bei der var. pallida, die ich für eine heterom. xanthus halte, nicht.

Das Embryonalgewinde mit $21 / 2$ Windungen (Fig. 328) ist glänzend, fein gestreift, oben ab und zu scharf und kurz gefaltet, an einem großen Stïck anch am Unterteil der Windung in entgegengesetzter Richtung scharf und kurz gefaltet, andererseits kommen auch jüngere Stïcke vor, an denen selbst die oberen Fältchen fehlen. Gegen das Ende treten rhombische braune, mit gelblichen abwechselnde Flecke an der Naht auf, welche Zone auch auf den späteren Windungen oft noch lange erhalten bleibt.

Die Skulptur besteht aus fadenförmigen Falten, die selbständig bis an die Naht reichen, so daß keine Zone stärkerer Falten an der Naht auftritt. Sie werden von gleich starken feinen Spiralreifen durchkreuzt, so daß die Falten in Körner zerschnitten werden. Mit dem Fortschreiten des Wachstums werden die Zwischenräume zwischen den Falten und den Spiralreifen gleichmäßig größer, so daß dann eine regelrecht gegitterte Skulptur entsteht, bei der die Kreuzungsstellen verdickt erscheinen. Die Skulptur, ohne Lupe betrachtet, hat den Anschein eines groben Gewebes.

Der Name ist nach den fliegenschmutzartigen Flecken mit Fliege in Verbindung gebracht.

\section{M. demnisoni REEVE und var. pallida STREBEL.}

Taf. XXI, Fig. 328; Taf. XXIT, Figg. 376/37!.

P., p. 158, Taf. 48, Figg. 13/16. SP., V, pag. 1.

Die Untergattung hat nur diesen Tertreter, den PILSBRY unter Porphyrobaphe stellt, so daß ihre Diagnose anch für die Art gilt; es bleiben nur Färbung und Zeichmung zu beschreiben.

Die Grundfarbe ist hell gelbbram bis zimtfarbig mit helleren, zuweilen sogar stellenweise weißlichen schmalen Bändern 2, 3, 4, 5, von denen Band 2 meistens sich kaum von der hellen Grundfarbe abhebt. Band 3 und 4 sind meistens dentlich, Band 5 fehlt meistens bei der typischen Form und immer bei der var. pallida. An der Basis, unterhalb Band 5, tritt bei der typischen Form häufig eine kastanienbraune Zone 
als Abschluß auf. Bei der typischen Form treten sehr ımregelmäßige, fast schwarze Streifen auf, die oft unterbrochen sind, sich auch stellenweise verbreitern und nach vorn zackig und hell oder selbst weiß berandet sind, was häufig mit den hellen Bändern zusammenfällt, wodurch diese dam stellenweise gegliedert erscheinen. Über das Ganze sind dann sehr viele schwarze Flecke von verschiedener Größe verstreut, die meistens nach vorn hell berandet sind. Bei der var.pallida sind die Streifen meist braun anstatt schwarz und weit spärlicher; das gleiche gilt von den Flecken.

Der stumpfe Nundrand ist bram, meistens nach immen breit ausfließend. Das Innere ist weiß mit mehr weniger deutlich durchscheinender Zeichnung. Der Callus ist ziemlich dümn, weißlich, mit schwarzbramem äußerem, etwas verdicktem, schmalen Rand, der bei der var. pallida fehlt.

Nach dem mir vorliegenden Material aus der O. SENPERschen und meiner alten Sammlung, das wir beide s. Z. von SCHMLLTZ, der den Tertrieb des WaLLISschen Naterials hatte, erwarben, ist die var. pallida mit der Etikette Frontino, Nen-Granada, versehen, während die typische Form von Sonson, Nen-Granada, stammt. Andererseits liegen in der SCHOLviENschen Sammlumg Stïcke beider Formen von Frontino. Danach kämen beide Formen zusammen vor. In der O. SEMPERschen Sammlung. liegen damn noch zwei Stuicke von Sonson, Nell-Granada, die der Beschreibung nach zn MoUssons var. obscurata passen, auch in der Form und dem fehlenden immeren bramen Mundsaum mit der Abbildung in den Novitat., Taf. 127, Fig. 12, 13 ïbereinstimmen, die in der Farbengebung ganz verfehlt ist, mehr noch in der Kopie in PILSBRY. Ich kam diese Tarietät nicht recht anerkemnen, denn das Fehlen des inneren bramen Mundrandes kommt auch sonst vereinzelt vor', und die Form wie das Detail der Zeichnung sind überhaupt bei dieser Art sehr wechselnd. Die von PILSBRY aufgeführte var. marmatensis, die BLAND in Marmato, Columbien, gefunden lıat, scheint mir der Abbildung nach (Fig. 14) dasselbe zu sein, was ich var. pallida nemne (vergl. SP., T, pag. 2). Die Frage spitzt sich also nur dahin zu, ob diese Tarietät eine Lokalform oder nur eine Farbenvarietät ist, die zusammen, mit der typischen Form vorkommt.

1. Ton SchuÜtrer in Halle gekauft, aus dem Material von STAUdrager stammend. Canca-Tal, Columbien. Drei große schöne, typische Stücke, ganz ähnlich der REETEschen Figur 166, nur daß die Spindel eingebogen ist.

$$
6-83,3 \times(35,0) 50,8-50,7 \times 27,3 .
$$

2. Fioll. O. SEMrER. WALlis leg. Frontino, 6-8000'. Fünf Stïcke var. pallida.

$$
\begin{array}{ll} 
& 6-69,2 \times(29,8) 41,7-41,0 \times 22,2 . \\
\text { Figg. 378/379. } & 5^{7} / 8-65,5 \times(30,1) 39,7-38,0 \times 20,7 . \\
& 51 / 2-47,8 \times(22,5) 29,2-26,6 \times 14,7 . \\
\text { Fig. 376. } & 5-34,5 \times(16,8) 21,9-21,0 \times 11,4 .
\end{array}
$$


3. Nr. 15800. WaLlis leg. Frontino, 6-8000'. Zwei Stïcke wie die vorstehenden.

4. Koll. SCHOLVIEN. Frontino. Ein Stïck wie vorstehend und drei typische Stiicke, von denen das größte folgende Maße hat:

$$
\text { Fast } 6-65,2 \times(30,6) 41,2-38,5 \times 21,1 \text {. }
$$

5. Koll. O. SEMPER. WALLIS leg. Sonson. Zwei Stïcke, von denen das frischeste eine zwischen hell zimtfarbig und granviolett abwechselnde Grundfarbe und vor den Streifen viele rein weiße Flecke und Streifen zeigt, so daß bei den hellen Tönen der Zeichnung der typischen Form hier das Weiß vorwiegt. Der Mundrand ist innen nicht braun besäumt, auch der Callus nicht. ? var. obscurata Mouss.

$$
5^{3 / 4}-66,8 \times(29,8) 40,0-37,3 \times 21,0 .
$$

6. Außerdem noch mehrere Stücke ohne anderen Fundort als NeuGranada und zwei Stücke aus der FuLBYschen Sammlung ohne Fundort, von denen ich das eine wegen seiner reichen Zeichnung abbilde, da hier die Bänder deutlich aus hellen und dunklen Flecken bestehen; nur Band 4 ist hellfarbig durchgehend.

Fig. 377. Fast $5 \frac{1}{2}-51,5 \times(24,6) 32,2-30,6 \times 16,0$.

\section{Subgenus Oxyorthalicus n. subgen.}

Gehäuse fest-, aber nicht sehr dickschalig, oval-konisch, kaum oder matt glänzend, mit 6 wenig gewölbten, sich ziemlich rasch erweiternden Windungen, deren letzte etwas höher als das Gewinde ist. Mündung melır weniger verkehrt-ohrförmig; Mundrand mehr weniger breit und flach ungeschlagen, nach unten etwas erweitert, farbig oder weib (grevillei). Der Basalrand geht im Bogen in die Spindel ïber, welche senkrecht oder schräg zur Achse steht, gewunden und oft etwas eingebogen ist und oben zurïckweicht. Der Callus ist weiß, mäßig dick.

Das Embryonalgewinde (Fig. 329) mit 23/4 Windungen ist glänzend, fein gestreift, dunkelbraun oder hell hornfarbig. Die erste Windung steigt plötzlich und stark empor, so daß der Wirbel spitz erscheint, der Nucleus ist bei den dunkelgefärbten Stïcken weiß.

Die Skulptur besteht aus schmalen Falten, die vereinzelt bis an die Naht durchgehen, meistens aber in der Nahtnähe in gröbere Falten zusammengefaßt sind, so daß hier wie bei Porphyrobaphe sich eine Zone grober Falten absondert. Die feinere Spiralskulptur ist meist nur schwach und nur stellenweise ausgeprägt; wenn deutlicher, so erkennt man feine gewellte Spiralreifen. Dagegen treten dentlicher auf den letzten Windungell in unregelmäßig weiten Zwischemräumen seichte, grobe Furchen auf, welche die Falten in Stäbchen zerlegen.

Auf das Embryonalgewinde folgend, tritt an der Naht meistens eine Zone dunkelbrauner und weißlicher Flecke auf, die sich aber auf den 
letzten Windungen nicht fortsetzt oder in die Streifen- oder Zickzackzeichnung übergeht. Charakteristisch für diese Untergattung sind die dunkelbramen Flecke, die nach vorn in kurze oder lange helle Streifen in der Spiralrichtung auslaufen.

Ich liabe diese, nur durch $O$. irroratus und die Form grevillei vertretene Untergattung von $\boldsymbol{M}$. dennisoni abgetremnt, weil die Form des Embryonalgewindes und die Skulptur sich ganz anders verhalten.

\section{O. irrorretus REEVE.}

Taf. XXI, Fig. 329; Taf. XXIV, Figg. 37.2, 374.

P., p. 155, Taf. 52, Figg. 33/37, von denen Figg. 36/37 den ReEvEschen Typus. Fig. 33 die var. elongata IILLER, Fig. 35 die var. minor MILLLER kopieren.

Die Art zeigt entweder eine bräunlich strohgelbe oder zimtfarbige bis brame Grundfarbe. Im ersteren Falle hebt sich die Zeichmug durch unregelmäßige, oft wie zusammengeschobene Zickzackstreifen erscheinende Streifen lebhafter ab. Dementsprechend sind auch die oberen Windungen heller oder dunkler gefärbt. Der Mundrand ist orangegelb oder hell mennigrot. Stiicke mit so breiter Falte an der Spindel wie der REEvEsche Typus sie zeigt, liegen mir nicht vor. Bei den mir vorliegenden Stïcken ist die Spindel vielleicht ansnalımsweise oben durchweg dïnn und wird nach unten etwas dicker; sie geht zuweilen aber durch einen nach außen liegenden Absatz in den breiteren Basalrand über (Fig. 37\%), was alles anch für die Form grevillei gilt. Ferner sind alle die mir vorliegenden Stiicke in der Form insofern vom REEveschen Typus ab)weichend, als die Windungen an Gewinde nur sehr schwach gewölbt sind. Das Innere ist blanweiß und bei dem dunkelsten Stïck grauviolett.

1. Koll. O. SemPER. Ohne Fundort. Ein Stïck fast typisch in der Form, aber ron einer ziemlich dunklen Färbung, auf der der helle Teil der Flecke auf der letzten Windung nur sehr schwach ausgebildet ist. Der Inndsaum ist hell orangegelb, das Immere schmutzig blangran mit durchscheinender Zeichmung. Der Callus ist nach dem Außenrande zu verdickt, gelblich weif, nach innen diunner werdend. Ich bilde nur die Miindungspartie al.

Fig. 374. ca. $6-70,0 \times(30,0) 41,8-41,0 \sim 22,2$.

2. Koll. SCHoLvien. Quito. Ein sehr dunkles, oben schwarzbrames Stiick. Der hellere Teil der Flecke ist nur am Anfang der letzten Windung erkemubar. Der Mundsam ist wenig verdickt, hell orangegelb. Die Spindel ist sehr dumn und steht senkrecht zur Achse, sie ist im Innenkontur etwas ausgeliöhlt.

$$
6^{1 / 4}-67,5 \times(30,0) 40,0-38,7 \times 22,3 .
$$

3. Koll. Scholtien. Echador (Sotrerbi und Fulton vend.). Es ist ein in der Zeichnumg etwas abweichendes Stïck. Die Fleckenzone an der Nalıt geht bis an den Anfang der vorletzten Windung, sie gelıt 
anfangs in eine unregelmäßig sich verschiebende braune Flammenzeichnung über, dann anf der letzten Windnng in breite branne Streifen, die aus unregelmäßig langen und sich in der senkrechten Richtung verschiebende Striche zusammensetzen, wobei sich oft pfeilspitzenfürmige Vorsprünge bilden. Der orangegelbe Mundsaum ist verdickt und geht in gleicher Stärke in den Basalrand ïber, der Callus ist weiblich, nach innen zu sehr schwach werdend, das Imere ist blänlichgrau mit durchscheinender Zeichmung, und die Spindel ist etwas dicker als beim vorangehenden Stiick, sonst gleich.

Fig. 372. $6-69,0 \times(31,0) 41,4-41,2 \times 22,8$.

O. irroratus, Form grevillei SOWERBY.

Taf. XXIV, Figg. 370, 371, 375.

P., p. 156, Taf. 53, Figg. 3\$/41.

MILLER sowohl wie PILSBRY halten diese Art nur für eine Tarietät von 0 . irroratus. Mir liegt zu wenig Naterial vor, und vor allen Dingen kann ich keinen sicheren Anhaltspunkt dafïr finden, ob diese Form zusammen mit der typischen Form vorkommt oder nur lokalisiert. Meiner Ansicht nach handelt es sich dabei um eine Art von heterom. xanthus.

Nach dem mir vorliegenden Material unterscheidet sich diese Form vom Typus uur durch die grünlich- oder bräunlichgelbe Färbung, hellen Wirbel und den weifen, znweilen etwas breiter umgeschlagenen Mundrand. Der normal sein sollende Knoten auf der Innenseite des Mundrandes an seiner oberen Einfïgung ist nur an einem meiner Stïcke schwach vertreten, und auch PILSBRY bemerkt, daß er nicht konstant zu sein scheint.

Nach meiner vorstehend geschilderten Anffassung der Unterschiede von $O$. irroratus gehört num das unten folgende erste Stiick hierher, trotzdem es keine Spur von der knotenförmigen Terdickung des Mundrandes oben, sondern nur unterhalb ein kleines Knötchen zeigt, das ich für eine zufällige Ablagerung halte, ebenso wie die Terdicknng in der Mitte des Mnndrandes. Ton den beiden folgenden Stücken hat das erste (Nr. 2) deutlich die Verdickung am Ifundrande oben, aber eine weit schmälere Form als der typische 0 . grevillei sie haben soll, und ihm gleicht das dritte Stïck, das keinen Knoten, sondern nur eine Rinne zwischen Mundrand und Callus zeigt, von der PILSBRY anch spricht.

1. Koll. Scholvien. Ecuador. Bul. irroratus bestimmt. Es zeigt nur auf der rorletzten und letzten Windung, wenn auch nur schwach, die charakteristische Zeichnming von 0 . irroratus, ist aber bräunlich-strohgelb gefärbt. Der Mnndrand ist weiß mit einem leichten gelblichen Anflug, ebenso die Spindel. Das Imnere ist granviolett, der Callus diumn und blaugrau. In der Form und Färbung entspricht es gut dem 0 . grevillei.

Fig. 371. $6-63,7 \times(30,0) 40,0-36,9 \times 21,7$. 
2. Ohne Etikette. Ein Stïck wie das vorstehende, aber weit schmäler, mit breiterem, rein weißem Mundrand, weißem Callus und violettgranem, aber hellerem Innern als das sub 1. verzeichnete Stïck es zeigt. Die Verdickung oben am Mundrande ist dentlich, aber die Form des Gehänses schmäler als der Typus.

Fig. 370. $6-58,5 \times(25,3) 35,5-34,0 \times 19,0$.

3. BoucARD vend. B. grevillei. Ecuador. Das Stiick entspricht dem vorangehenden, es ist nur kleiner, und der weiße Mundrand hat nach aufen einen gelblichen Anflng. Die Spindel steht schräg zur Achse. Ich bilde nur die Mïndungspartie ab.

$$
\text { Fig. 375. } 5 \frac{1}{2}-54,2 \times(23,0) 31,6-32,8 \times 16,8 \text {. }
$$

\section{o. subirroratus DA COSTA. = irroratus var.}

Diese in P., vol. 14, y. 163, Taf. 24, Fig. 11, aufgeführte Form liegt mir nicht vor. Die Skulpturbeschreibung bezw. das Fehlen der erhabenen Streifen scheint mir für die Untergattung unwahrscheinlich.

\section{Genus Coroma ALB.}

Gehäuse starkschalig; oval-konisch, häufig links gewunden, melır weniger mattglänzend, mit bis 8 wenig gewölbten Windungen, deren letzte niedriger ist als das Gewinde. Die Mïndung ist verkehrt-ohrförmig, der Mundrand geradeaus, mehr weniger stumpf, bei großen Stïcken nach unten erweitert. Die Spindel steht senkrecht oder meist etwas schräge zur Achse, sie ist mehr weniger stark gewunden und meist auf der Innenseite mit einer oft mregehmäßigen und höckerigen Verdickung belegt, die sich bis zu einer plattenartigen Erhebung steigern kann, und die im Gegensatz zu Liguns immer oben am stärksten entwickelt ist.

Das Embryonalgewinde (Fig. 339) hat 23/4 Windungen, die glänzend und fein gestreift sind, oben und unten treten oft sehr feine Fältchen, in der Mitte eine sehr feine Stäbchenskulptur auf, was aber 'nur unter starker Lupe sichtbar ist. Sie sind etwas riemenförmig anfgerollt, d. h. seitlich platt und oben stumpfkantig, meist rosa oder violett gefärbt, und zwar nach oben heller werdend, und gegen das Ende pflegen bräunliche Streifen aufzutreten.

Die Skulptur bestelıt aus feinen, umregelmäßig starken, wenig scharfen Falten, die sich hänfig auf den letzten Windungen paarweise vereinigen und gröbere, ziemlich regelmäßig gereihte Falten bilden, die dem Gehäuse ein gerieftes Ansehen verleihen. Die Vereinigung der Falten ist meist nur stellenweise unter der Lupe erkennbar. Die Spiralskulptur besteht aus feinen Furchen, die aber nur selten und dann auch uur stellenweise dentlich zu erkennen sind, was individuell sehr verschieden ist; zuweilen verrät sie sich stellenweise nur durch auftretende schwache Stäbchenskulptur, welche ja nur durch das Durchschmeiden der Falten entstelıt. 


\section{Gruppe C. vegina FÉR.}

Wie schon PILSBRY p. 176 bemerkt, ist es oft schwer, die Gruppe von Formen, die sich um C. regina FÉR. gruppieren, auseinander zu halten, da sie alle in den am meisten charakteristischen Merkmalen des Gehäuses übereinstimmen und nur in Fürbung und Zeichnung Verschiedenheiten zeigen, die aber anch oft ineinander ïbergehen. Die Trennung in Lokalformen ist deshalb schwer, weil man nur selten größeres, zusammen gefundenes Naterial von bestimmten Fundorten zur Verfügmng hat, da es meistens, wie es den Händlern hänfig zur Verfüg'nng stehen mag, auseinandergerissen und mit mehr weniger guter Bestimmung verschickt wird. Meistens fehlen die Fundorte überhaupt, oder sie sind so allgemein gehalten, daß nichts damit anzufangen ist. In einem Falle konnte ich bei dem DoHRNschen Material vom Rio Machado feststellen, daß sich darunter die Hauptarten dieser Gattung vertreten fanden, also doch wahrscheinlich zusammen gefunden sind, wenn sie sich auch leicht voneinander unterscheiden ließen.

PILSBRY gibt num auf p. 177 einen Schlïssel zum Auseinanderhalten der verschieden benannten Arten, der aber, wie er selbst vorher sagt, anch nur ein Notbehelf ist, und der die vorkommenden Abweichungen und Übergänge nicht berücksichtigen kann. Seine Einzelbeschreibungen und seine Abbildungen ergänzen diesen Schlüssel, soweit es bei der Teränderlichkeit in dieser Gruppe möglich ist. Ich kann mich nach PILSBRYs guter Torarbeit in der Charakterisierung der einzelnen Formen oder sogenannten Arten kurz fassen und werde hauptsächlich die einzelnen fraglichen Formen des mir vorliegenden Materials genaner erörtern und, soweit es nötig ist, abbilden. Jedenfalls stimme ich mit PILSBRY ïberein, daß es vorläufig geraten ist, die Formen oder Arten, wie sie mal gegeben sind, soweit es möglich ist, anseinander zn halten, bis rationell gesammeltes Naterial weiter entscheidet. Ich muß iibrigens noch bemerken, daß in dieser Gruppe, wie schon erwähnt, feine Spiralstreifen vorkommen, was PILsBRy leugnet.

\section{C. vegince HÉR.}

Taf. XXY, Figg. 381/384, 388; Taf. XXYI, Figg. 389, 390. FÉrussac, Hist., Taf. 119, Figg. 3/5. P., p. 17i, Taf. 33, Figg. 1, 2, 4, 5.

1. W. SCHLÜtTER vend. Ton StAudingers Material stammend. Unterer Amazonas (?). Ein Stiick, zusammen mit vielen Stücken der C. regalis, das sịch genau mit FÉRUSSACs Fig. 5 deckt, Färbung wie P., Fig. 1; die Rückseite, Fig. 2, zeigt eine dunkle Cuticula, die bei dem vorliegenden Stïck nur olivenfarbig und nur in Streifen vorhanden ist. Wirbel rosa.

$$
8^{1 / 8}-85,6 \times(34,7) 40,8-42,4 \times 19,4 .
$$


2. Koll. Dr. H. DoHRx. Tom Rio Machado, einem Nebenfluß des Rio Madeira (oberes Amazonas-Gebiet). Drei typische Stïcke zusammen mit einem Stiick $C$. percersa und zwei Stïcken $C$. incisa und einem fraglichen Stïck $C$. regalis.

a) Fig. $388 . \quad 8^{3} / 8-101,4 \times(35,5) 41,4-43,6 \times 20,9$.

Dies Prachtstiick ist der Cuticula entkleidet, wemn es anch durchans frisch ist. Es ist daher anf der letzten Windung rein weiß, während es am Gewinde gran mit riolettem Anfluge ist. Der Wirbel ist weißlich. Es treten mu stellenweise am Gewinde schmale, etwas dunklere, winklig gebrochene mud einige ron der Stelle des Band 2 ab plötzlich breiter werdende dunkel violettgrane Streifen auf. Anf der letzten Windung sind zwei schmale, pmrpurschwarze Tarixstreifen und das schwarzbrame Band 3 vorhanden, das sich aber nur auf das erste Drittel der Windung erstreckt, dam aufhört; eine weiße beiderseitige Umrandung läßt sich trotz der weißlichen, freilich etwas gelblich angehauchten Grundfarbe noch schwach erkemnen. Mundrand außen und innen schmal schwarzbraun berandet, Callus braunschwarz. Die Spindel ist verhältnismäßig stark verdickt und brämlichweif, die Terdickung ist in der Mitte durch eine schräge Furche getremnt; der obere 'Teil ist stärker verdickt als der untere.

b) Fig. 384. Fast $8-87,8 \times(36,4) 43,0-41,7 \times 20,0$.

Dies Stïck ist fast identisch mit dem sub 1. aufgefühnten, nur zeigen die 3 . bis 5 . Windming auf violettgramem Untergrumde schmale, an Stelle von Band 2 winklig gebrochene bräunliche Streifen. Die letzte Windung ist mit einer in Streifen aufgelösten, dunkel olivenfarbigen Cuticula bedeckt und mit dem beiderseits hell berandeten schwarzbramen Band 3 fast durchgehend geziert. Ich bilde davon nur den minteren Teil ab.

c) Fig. 383. $77 / 8-78,5 \times(30,9) 35,6-36,2 \times 17,8$.

Dies Stiick ist nicht ginz ansgewachsen. Die oberen Windungen mit weißlichem Wirbel werden allnählich violettgrau und zeigen die schmalen, winklig gebrochenen und nur selten breiteren, vorn weif berandeten Streifen, daneben anf der 4 . bis 7 . Windung oberhalb der Naht ein dunkelbraun und weif gegliedertes Band, das sich noch bis über das erste Tiertel der letzten Windung hinzieht, damn aber bis zu Ende schwarzbram, beiderseits schmal hell berandet wird. Die letzte Windung ist hell olivenfarbig mit dunkleren streifen. Mundrand und Callus sind jurpurschwarz. Die Spindel ist in sich fast gerade, nur wenig, und zwar nach innen und oben, faltenartig verdickt.

3. RoLLE vend. Anden, Pern. Unter anderen $C$. regina bestimmten, zu C. regulis gehörenden Stücken mit typischer Spindelbildnng befand sich dies eine Stïck, welches keine Ablagerung anf der Spindel zeigt, um oben eine schwach rorstehende Falte, die nur auf ihrer änßersten Er- 
hebung etwas weißlich ist. Dies Stïck hat auf der vorletzten und letzten Windung Band 2 und 3 klar abgegrenzt und gegliedert, und die letzte Windung ist nur von Band 2 bis zu dem schwach dunkler angedeuteten Band 4 etwas dunkler, d. h. hell kastanienbraun gefärbt, wälırend oberhalb und auf dem Gewinde die Färbung mehr bräunlich fleischfarbig ist, die aber nach oben mehr rötlichviolett wird und in einem purpurschwarzen Virbel endet. Der Mundrand ist außen und innen schmal purpurschwarz berandet, und ebenso sind Callus und Spindel gefärbt.

Figg. 381/382. $8-88,8 \times(35,8) 41,0-42,0 \times 19,5$.

4. RoLLE vend. Amazonenstrom. SCHAUfuss-Material. Unter zwei linksgewundenen Stiicken $C$. regalis befand sich ebenfalls ein Stück, das den vorangehenden gleich ist, nur ist die Grundfarbe der unteren Windungen mehr ins Olivenfarbige spielend, und es treten schmale, ziemlich gleichmäßig gereihte, an Stelle von Band 2 winklig vorspringende, etwas dunklere Streifen auf. Wirbel und Mundrand wie bei dem vorangehenden Stück, die Spindelfalte ist oben etwas stärker verdickt.

Fig. 389. $\quad 81 / 4-88,2 \times(35,5) 40,8-41,6 \times 18,5$.

5. RoLlE vend. Ohne Etikette. Ein merkwürdig breites und fast einfarbig zimtfarbiges, nach oben rötlich werdendes Stïck mit dunklem Wirbel, von dem es fraglich ist, ob es hierher oder zu C. regalis gehört. Bis zur 5. Windung sieht man noch über der Naht das schmale gegliederte Band 2 wie bei den beiden vorangehenden Stiicken, das damn verschwindet. Es treten an dem ganzen Stück nur ein paar dunklere Striemen auf, die von der Mitte der letzten Windung ab etwas schwärzlich werden und zweimal in Band 2 in voln zugespitzte schwärzliche Striche ausmünden. Außerdem heben sich von der vorletzten Windung an die beiden dunkleren Zonen $\mathrm{z}$ wischen Band 2 und 3 und 3 und 4 sehr scharf abgegrenzt und deutlich ab, wie sie bei den beiden vorangehenden Stïcken auch rolhanden sind, während Band 2 und 3 sich nur durch etwas hellere Färbung: abheben. Unterhalb der unteren breiteren Zone wird die Färbung heller und rotbraum. Mundrand und Callus sind auch purpurschwarz, und die Spindel ist genau wie bei $\mathrm{Nr} .2$.

Fig. 390. $85,7 \times(38,5) 45,0-42,5 \times 22,3$.

6. Rolle rend. Amazonas-Gebiet, ex Kioll. L. IV. ScHaufuss. Ein junges Stiick, das dieselbe Färbung wie das vorangehende zeigt, nur tritt von der 3. Windung an das schmale gegliederte Band 3 oberhalb der Naht auf, das sich damn noch eine Strecke weit auf der letzten Windung fortsetzt. Außerdem tritt vom Ende der vorletzten Windung an bis zuletzt das gegliederte Band 2 anf, und es sind im ganzen mehr dunklere, rorm hell berandete, breitere Streifen vorhanden. Der Mundrand ist außen und immen purpurschwarz berandet, und von gleicher Farbe ist der Callus. 
Die Spindel ist gewunden, hellbram und wenig verdickt. Bei diesem Stiick wird es noch fraglicher, ob es hierher gehört.

$$
\begin{gathered}
7-56,0 \times(24,8) 27,6-27,2 \times 13,3 . \\
\text { C. regulis HUPÉ. }
\end{gathered}
$$

Taf. XXI, Figg. 339 a, b; 'Taf. XXVI, Figg. 391/396, 399;

Taf. XXYIT, Fig. 402.

Hupé in Castelixad, Exped. dans l'Amerique du Sud. MIoll., p. 34, Taf. 10, Fig. 3. P., p. 180, Taf. 33, Figg. 3, 6; Taf. 34, Figg. 9/12; Taf. 35, Figg. 13, 14, 19; Taf. 36 a, Figg. 26/29.

Die große Terschiedenheit in der Färbung und Zeichnung ist zum Teil durch PILsBRYs Abbildungen gezeigt; ich gebe dazu noch einige Ergänzungen. Zu der PILSBRYschen Beschreibung der Zeichnung könnte noch hinzugefügt werden, daß die dunklen Streifen am Gewinde schmal, regelmäfsig und ziemlich dicht gereiht auftreten können, ähnlich wie es bei dem Stïck, das ich mer Nr. 4 bei C. regina anführe, der Fall ist. Sie können auch breit werden und mit zackigen Torsprïngen versehen sein, auch als ziemlich weit ausholende, mehr weniger zusammengeschobene Zickzackstreifen auftreten, oder endlich sich in Streifen oder Flecke auflösen. Die breiteren Streifen sind in der Regel nach vorn hell berandet. Der Wirbel ist bei keinem meiner Stiicke schwarzbraun, sondern höchstens bräunlich, oft ungefärbt. Der Mundrand ist, wie schon bei C. regina bemerkt, ausnahmsweise inmen ziemlich breit ausfließend purpurschwarz gesäumt; allerdings sind die betreffenden Stïcke nicht ganz ausgewachsen und haben leider keinen Fundort. Es kommt auch eine kleine Form ror.

1. Berl. Museum. Koll. ALBERs. Meobamba, Peru. Als regina bestimmt. Ein rechtsgewundenes und ein linksgewundenes Stïck, ganz ähnlich in Färbung und Zeichnung wie P., Figg. 11/12.

2. Berl. Musemm. STAUdinger. Oberer Amazonenstrom. Tier Stiicke, davon drei ähnlich wie die vorangehenden sind, und eins fast einfarbig wie P., Fig. 10, nur etwas mehr gelblichbraun, nicht so schokoladebram ist.

3. Berl. Mnsemm. Iherixg. Rio Juma (?). Ein rechtsgewundenes Stïck, ähnlich wie P., Figg. 11/12.

4. Berl. Museum. BARTLETT. Nauta, Ost-Peru. Zwei typische unausgewachsene Stïcke.

5. Berl. Museum 35516. STÜBEL. Tarapoto. Zwei unausgewachsene Stïcke.

6. RoLle vend. Schaufuss-Material. Amazonenstrom. Zwei Stïcke, zusammen mit $C$. regina Nr. 4, ähnlich wie P., Fig. 12.

7. W. SCHLÜTER vend. STAUDINGER-Material. Unterer Amazonas (?). Zusammen mit C. regina Nr. 1. Drei Stiicke, davon eins rechtsgewunden, 
das in Färbung und Zeichmung ähnlich P., Fig. 11, 12, ist, aber eine stark verdickte Spindel hat.

$$
8-83,8 \times(31,6) 38,3-40,0 \times 15,4 .
$$

Von den linksgewundenen ist das eine dem HuPÉschen Typus in der blangranen, violett angehanchten Färbung des Gewindes und der olivgrünen Farbe der letzten Windung ähnlich, die auch durch weiße Streifen unterbrochen wird; das Stück ist nur größer und hat eine stark verdickte Spindel.

$$
71 / 2-82,2 \times(32,3) 38,8-39,5 \times 15,8 .
$$

Das zweite Stïck ist am Gewinde weißlich mit breiten blangranen Streifen, und auf der letzten Windung treten viele weiße längliche Flecke auf, ein Torgang, der an die var. loroisianus erinnert. Der Wirbel ist abgebrochen und vom Tier geschlossen, die Spindel ist wenig verdickt.

Fig. 395 . ca. $71 / 2-79,0 \times(33,2) 38,7-39,3 \times 20,0$.

8. Koll. O. SEMPER. E. BARTLETT leg. Ymimaguas am HanllagaFluß. Östl. Peru. Drei Stïcke, davon zwei rechtsgewunden, von denen eins unausgewachsen ist. Das ansgewachsene ist am Gewinde bräunlich fleischfarbig, mit kaum erkennbaren Streifen und mit dem schmalen gegliederten Band 2. Die letzte Windung von gleicher, oft ins Weiße spielender Grundfarbe, zeigt zum Teil lange, breite Striche in der Spiralrichtung, die vorn in Weiß ausmünden, und die die weißlichen Streifen zerlegen.

Fig. 391. Fast $8-87,6 \times(36,0) 41,4-43,2 \times 18,5$.

Ich bilde hiervon nur den charakteristischen unteren Teil ab.

Das linksgewundene Stiick hat anch eine eigentümliche Zeichnung. Während der obere Teil eine grünlichgelbe Grundfarbe hat mit einzelnen violettbraunen, nach vorn weiß besïnnten bréiten Strichen und Flecken, ist der untere Teil sehr lebhaft dunkel olivengrün gefärbt mit schwarzen Anwuchsstreifen und bräunlichweißen breiten Zickzackstreifen und Flecken.

Fig. 392. $\quad 73 / 4-78,0(32,3) 37,7-38,4 \times 18,5$.

Das gegliederte Band 2 fehlt, nur Band 3 ist über der Naht auf der vorletzten Windung zu sehen. Die brämmlichweißen Flecke auf der letzten Windung spielen wieder nach der var. loroisianus hinüber.

9. Koll. Scholdien. Amazonas. Ein großes rechtsgewundenes und vier junge, davon zwei rechts- und zwei linksgewundene Stïcke. Das große Stück entspricht ungefähr dem Hupéschen Typus in Färbung und Zeichnung. Yon den jungen Stïcken bilde ich zwei ab, die unter dem Kiel die Bänder 3, 4, 5 zeigen. Die Zone zwischen Band 3, 4 ist etwas dunkler, Band 5 ist noch dunkler und nimmt die ganze Basis ein.

Fig. 394. $\quad 5 \% 3-31,5 \times(17,4) 20,5-17,2 \times 10,0$.

$$
\text { 393. } 4 \frac{3}{4}-21,2 \times(12,0) 14,4-11,2 \times 6,7 \text {. }
$$

10. Koll. Scholtien. Anden von Peru. Zwei Stücke, davon ein rechtsgewundenes, das typisch ist; das linksgewundene ist fast einfarbig 
hell olivenfarbig, mit wenigen dunkleren Streifen und Flecken; die gegliederten Bänder 2 und 3 sind nur auf den oberen Windungen sichtbar.

11. Koll. Scholviex. Brasilien. Ein linksgewundenes Stück, mansgewachsen, ohne besondere Merkmale.

12. Koll. Filbr. Brasilien. Drei typische Stïcke, das größte mißt:

$$
\text { Fast } 8-94,0 \times(37,6) 45,1-47,0 \times 20,0 \text {. }
$$

13. Koll. SoHsT. Amazonenstrom. Ein Stïck, nicht ausgewachsen, mit $6 \frac{1}{2}$ Windungen, brämlichgrau mit lebhaft grïner letzter Windung, auf der sich nur ein breiter weißer Anwuchsstreifen zeigt. Die Zeichnung ist nur spärlich.

14. Koll. DoHRx. Rio Machado. Ein Stiick ganz ähnlich in der Färbung wie die sub 5., 6. bei C. regina verzeichneten Stücke, mit nur wenigen schwärzlichgranen breiteren Streifen. Auf der 3. bis 5. Windung tritt das sclmale gegliederte Band 3 wie bei C. regina $\mathrm{Nr}^{2} .6$ auf, das sich auf der letzten Windung nur als lielles Band fortsetzt, während von der 4. Windmmg an Band 2 anfangs schwach gegliedert, dann auch nur lıellgefärbt sich bis zuletzt fortsetzt. Die letzte Windung wird gegen das Ende olivenfarbig, dunkler gestreift, doch sind anch hier noch die helleren Bändel 2, 3 erkemubar. Der Mundrand ist anßen und innen weiß, der Callus und ein T'eil der stark verdickten Spindel sind purpurschwarz. Fig. 399. $\quad 7 \frac{1}{2}-62,5 \times(27,0) 30,6-30,0 \times 13,3$.

Dies besonders starkschalige Stïck habe ich nur deshalb nicht an C. regina $\mathrm{Nr}$. 5, 6 angeschlossen, weil es einen weißen Mundrand hat. Es bildet mit ihmen eine der Übergangsformen zul C. regalis.

15. UuLAufF ded. Trinidad. Drei unausgewachsene typische Stiicke; wenigstens soweit man es nach jungen Stïcken beurteilen kann, rechtsgewunden, das größte mit sieben Windungen. Sie sind offenbar angeschwemmt und frisch, das eine hat noch Tierreste in sich.

\section{Ohne Fundort.}

16. Vier Stiicke, darmuter ein rechtsgewundenes, das ausgeprägt die zusammengeschobenen, weit ausgreifenden blaugranen Zickzackstreifen zeigt; die letzte Hälfte der letzten Windung ist mit der bräunlich olivenfarbigen Cuticula bedeckt, die nur einige von Cuticula entblößte Streifen und einige dunklere Zonen in der Spiralrichtung zeigt. Der Mundrand ist innen hellrosa ausfließend gesäumt.

$$
\text { Fig. 396. } \quad 71 / 2-88,8 \times(37,9) 4: 3,8-42,4 \times 20,7 \text {. }
$$

17. Ein linksgewundenes Stück, gelbbraun, mit wenigen braunen, nach rïckwärts weißlich berandeten Streifen und Flecken und den üblichen schmalen gegliederten Bändern 2, 3 auf den oberen Windungen. Der Mundrand ist anfen breit, innen schmäler purpurschwarz berandet. Das Stiick hat nur sieben Windungen, ist also nicht ganz ansgewachsen. 
18. Zwei Stücke wie das vorige, aber mit mehr olivenfarbigem Grunde. Die Stücke sind noch weniger ausgewachsen $\left(6^{1 / 8}-61 / 2\right.$ Windungen) und zeigen nur innen einen ziemlich breit purpursclıwarz gesäumten Mundrand.

\section{Zweifelhafte Formen.}

1. Berl. Museum. DoHRy ded. Nr. 34303. Juraty am mittleren Amazonas. Ein Stïck von verhältnismäßig kleiner Gestalt. Die oberen Windungen sind fleischfarbig mit violettgrauen, unregelmäßigen, winklig ausbiegenden oder geraden Streifen. Das anfangs undentlich gegliederte, später durchgehende Band 2 ist auf der 4 . bis Ende der vorletzten Windung vorhanden. Auch von Band 3 sieht man einen Teil auf der 4. und 5. Windung: Die letzte Windung ist mit einer olivengrünen, gegen Ende lebhaft grünen und zum Teil in Streifen aufgelösten Cuticula bekleidet. Da wo die Cuticula fehlt, erkennt man noch eine Zickzackzeichnung. Nur Band 3 ist hell durchgefïhrt.

$$
71 / 2-53,2 \times(24,0) 27,0-25,0 \times 1 \cdot 2,0 .
$$

Es scheint mir nach diesem von DoHrs dem Berliner Museum geschenkten Stïck, daß es sich bei dieser kleinen Form um die Form handelt, die DoHRN für Orthalicus loroisianus HUPÉ hält (vergl. Jahrb. d. Mal. Ges. 9, p. 109), und die auch von Juraty stammt. Er führt die Anzahl der Windungen nicht an, erwähnt anch in der Beschreibung nicht die für diese Tarietät charakteristisch sein sollenden hellen Flecke auf der letzten Windung. Er sagt von ihr nur: "nit einer mehr weniger abgeriebenen olivenfarbigen Epidermis ledeckt", womit doch offenbar nur die von Cuticula entblößten weißen streifen in der Anwuchsrichtung zu verstehen sind. Die weißlichen oder orange Striche und Flecke in der Spiralrichtung, wie sie dem Typus von C. loroisianus eigen sind, müssen wohl als der Grundfarbe entsprechend angesehen werden, über die sich eine dunkle, vielfach unterbrochene, und in ihren Unterbrechungen verschobene, aus Zonen verschiedener Breite in der Spiralrichtung verlaufende Zeichnung hinzieht. Ich muß die Frage, wohin diese Form gehört, offen lassen, bis weiteres Material mit genauen Fundortsangaben entscheidet. Bei der groben Form von $C$. regalis habe ich schon auf ähnliche Fleckenzeichnung hingewiesen.

2. Koll.SCHOLvIEN, SCHLÜTER vend. Amazonas-Gebiet. Zwei Stücke Bul. loroisianus bestimmt, die sich dem vorigen anschließen, bei dem ich zu bemerken vergaß, daß die Spindel stark und etwas höckerig verdickt, und daß der Callus purpurschwarz bei weißem Mundrande ist. Alles das ist auch bei diesen Stücken vorhanden. Die Färbung der letzten Windung ist bei dem einen Stück hell, bei dem anderen dunkel olivenfarbig, doch ist an den weißen Streifen keine Zickzackzeichnung zu erkennen, nur das helle Band 3 ist vorhanden. Die violettgrauen Streifen sind weniger unregel- 
mäßig, und bei dem abgebildeten Stïck treten anf der 4. Windung oben und unten kurze, breite violettgraue Streifen anf, wie sie häufiger bei C. perversa als bei $C$. regalis auftreten.

$$
\text { Fig. 402. } \begin{aligned}
& 71 / 2-57,0 \times(24,8) 29,4-26,2 \times 12,3 . \\
& 73 / 4-56,3 \times(24,1) 28,3-25,8 \times 12,3 .
\end{aligned}
$$

\section{C. regalis, Form loroisiana HuPÉ.}

Taf. XXYII, Figg. 404/407, 409, 410.

Hupe, 1. c. Taf. 10, Fig. 1. P., p. 183, Taf. 34, Figg. 7, 8 (Kopie von Hupés Figuren).

Es hängt bei dieser Fol'm von der Grundfarbe der letzten Windung und der Farbe der Zeichnmmg auf ihr ab, wie weit die Abweichmogen vom Typus gehen. So kastanienbrann, wie die Hupésche Abbildnng erscheint, liegt mir kein Stïck vor. Nach dem mir rorliegenden Material sind die oberen Windmngen wie in der ganzen Gruppe fleischfarbig gran bis rosa oder auch violett angehaucht, die mittleren Windmgen werden heller, mehr ins Weibliche übergehend. welche Färbung entweder bis zuletzt bleibt, oder es tritt, anf der vorletzten Windung oder später beginnend, eine gelbliche bis orangefarbige Färbung anf, die sich dann von der braun-olivenfarbigen bis in lebhaftes Dunkelgrün hinïberspielenden Zeichmung abhebt, eine Zeichnmng, über deren Komponenten ich mich schon weiter oben aussprach. Die Kleinheit der Form gegenüber C. regalis bleibt jedenfalls ein sicheres Charakteristikum, vielleicht anch, daß anf dem Gewinde nur wenige und schwach gefärbte Streifen vorkommen, so daß das gegliederte Band 2 sich dentlicher abhebt als sonst wohl. Aber bei der sehr wechsehnden Zeichnung und Färbung innerhalb der engeren Gruppe C.regalis-loroisiamus sind alle daranf beruhenden Merkmale trügerisch.

Es ist noch zu bemerken, daß anch bei dieser angeblichen Tarietät rechtsgewundene Stiicke vorkommen, und ferner, daß das beim Typus in der Torderansicht als Fortsetzung der Naht der letzten Vindung anftretende schmale schwarze Band 3, das sich nach der Rückenansicht dort nicht fortsetzt, nicht immer vorhanden ist. Andererseits tritt an zwei Stïcken des Berliner Museums anßerdem noch Band $t$ in derselben beschränkten Ausdehmung auf.

Nach einem jungen Stïcke, das den Stïcken dieser Tarietät ron Ucayali (Berliner Museum) beiliegt, ist die Basis, von dem dicht unter dem Kiel liegenden, schmalen, dunkelbramen Band 3 an, kastanienbram. Es heben sich dann noch davon Band 4 und 5 in dunklerer Färbung deutlich ab. Ob dies ein Merkmal dieser Tarietät ist, mub ich dahingestellt sein lassen. Ich bringe aber deshalb einige junge Stücke unter Nr. 8 hierher, die dieses Merkmal zeigen, und die sich unter den jungen Stïcken der Kóll. SCHOLtren rom Amazonas befanden, welche ich sub 9. bei $C$. regalis unterbrachte. Danach kamn die kastanienbrame Färbung: 
bei dem größten Stück (vergl. Fig. 405) erst von Band 4 an beginnen. Bei noch mehr im Wachstum vorgeschrittenen Stïcken, die ihrem sonstigen Verhalten nach hierher gehören, wird die Färbung der Basis schon heller und es fehlen die Bänder (vergl. Fig. 406), oder sie verschwindet ganz. Bei der annähernden Gleichheit in der Färbung und Zeichnung der vier bis fünf oberen Windungen ist es sebr schwer zu bestimmen, zu welcher Form junge Stïcke gehören, wemn sie nicht zusammen mit ausgewachsenen gefunden sind. Nüir bei $C$. incisus und $C$. perversus ist es möglich.

1. Berl. Museum Nr. 37644. Ucayali, von STAudinger (? Hucayali, Peru). Drei Stiicke rechtsgewunden, dabei das oben besprochene junge Stiick, und das ebenfalls oben erwähnte nicht ganz ausgewachsene Stück mit Band 3, 4 am Anfang der letzten Windung, das hier eine rötlichgelbe Grundfarbe bekommt und das ich abbilde, während sie bei dem größten Stiick weiß ist.

$$
61 / 4-61,1 \times(28,2) 33,4-31,8 \times 16,1 .
$$

Fig. 407. $6 \frac{1 / 4}{4} 54,5 \times(25,5) 28,6-27,0 \times 13,3$.

$$
\text { "404. } \quad 5 \% / 8-29,2 \times(15,3) 17,6-14,8 \times 13,0 .
$$

2. Berl. Museum. Tarapoto. STÜBEL leg. Ein Stiick. Gewinde etwas verwittert und ohne Zeichnung, Band 2 ist ein durchgehender heller Streifen. Am Anfang der letzten Windung treten wiederum Band 3 und 4 auf.

$$
7-64,4 \times(28,7) 32,0-32,8 \times 15,4 .
$$

3. Berl. Museum. Koll. ALBERS. Meobamba. Ein typisches Stück, nicht ganz ausgewachsen, mit gelblicher letzter Windung, ganz ähnlich wie Fig. 407, aber olme Band 3, 4.

4. Rolle vend., ex Schaufuss-Material. Pert. Ein typisches Stïck, genau wie das vorangehende.

5. Nr. 15444. Amazonas. Ein nicht ganz ansgewachsenes Stück mit vielen Streifen in der Spiralrichtung; die sich mit denen in der Anwuchsrichtung kreuzen; aber es sind nur Spuren von Flecken vorhanden. In der Yorderansicht, wo die dunkelgrüne Fürbung mehr abgerieben ist, tritt anfang der letzten Windung Band 3 auf. Es ist dies ein Stïck, von dem es fraglich erscheinen kann, ob es hierher zu rechnen ist oder ob es zu den Formen sub 1., 2. bei den hinter C. regalis beschriebenen fraglichen Formen gehört.

6. Koll. Scholvien. Olme Fundort. Drei Stiicke, teils mit weißer, teils mit orange Grundfarbe. Während die beiden ersten Stücke der Maßliste durchaus typisch in der Fleckenzeichnung sind (das Band 3 am. Anfang der letzten Windung fehlt allen dreien), zeigt das dritte Stiick anf weißem Grunde in Grün mehr die Zickzackzeichnung der Figg. 392 und 405.

$$
\begin{aligned}
\text { Fast } 8-74,5 \times(29,6) 34,7-35,2 \times 17,0 . \\
71 / 2-66,0 \times(26,7) 31,7-31,4 \times 15,3 .
\end{aligned}
$$

Fig. 409. $\quad 7 \frac{1}{2}-64,7 \times(28,3) 32,2-31,9 \times 15,4$. 
7. Koll. ScHoLviEN. Ohne Fundort. Zwei unausgewachsene Stïcke. Das abgebildete Stiick ist das oben erwähnte, an dem unterhalb des Kieles die Färbung nu noch hell kastanienbraun ist.

$$
\text { Fig. } 406 . \quad \begin{aligned}
& 7-50,0 \times(24,8) 26,6-25,0 \times 12,8 . \\
& 71 / 8-48,5 \times(23,0) 25,5-24,6 \times 11,4 .
\end{aligned}
$$

Das letzte Stiick hat an der Basis dieselbe weißliche Färbung wie oben, zeigt anch keine Flecke wie das erste Stuick, sondern nu viele Streifen in der Spiralrichtimg.

8. Koll. Scholviex. Amazonas. Drei jumge Stïcke, zusammen mit den sub 9. bei $C$. regalis verzeichneten (siehe oben).

Fig. 410. $5 \frac{3 / 4}{3}-31,7 \times(17,4) 21,0-16,7 \times 9,7$.

$$
" \quad 405 . \quad 6 \frac{1}{4}-39,7 \times(20,7) 23,6-19,6 \times 10,6 \text {. }
$$

Das letzte Stïck zeigt zuletzt die Zickzackzeichmung auf olivenfarbigem Giunde.

9. Berl. Museum. Koll. PAETEL. Bolivien, zusammen mit C. incisus. Ein junges Stïck wie die oben abgebildeten.

\section{C. incisa HUPÉ.}

Taf. XXYII, Fig. 411.

Hupé 1. c., Taf. 9, Fig. 1. P., p. 179, Taf. 35, Figg. 15/17. SHUtTleworth Not., C. melanostoma, p. 67 .

Die Beschreibungen Hupés und die bessere von SHUTTLEWORTH bedïrfen noch einer Ergänzmng, die für diese Art charakteristisch ist. Auf der 3. Windung begimnen bei allen mir vorliegenden typischen Stïcken schmale braune, ziemlich regelmäßige Streifen, die an der Stelle von Band 2 spitzwinklig ausbiegen. Allmählich schwächen sich die verbindenden Streifen ab, wobei gleichzeitig die spitzen Winkel stärker getont sind, die dann allmählich in das gegliederte Band übergehen, wobei aber doch ab und zu sich noch wieder in den dumklen Flecken die spitzwinklige Form erkemen läbt. Das artikulierte Band verschwindet meist auf der letzten Windung, kann aber auch noch undentlich bestehen bleiben. Es begrenzt dort und schon früher die Zone der breiten dunklen Streifen, die sich nie ganz bis an die Naht ziehen. Auf dem rötlich bramnen Teil der Windımgen unterhalb von Band 2, das in der Anwuchsrichtung mmegelmäßig gestreift ist, treten dann zuweilen noch, wenn anch undeutlich und stellenweise, Band 3,4 und 5 auf.

Bei allen mir vorliegenden Stïcken ist das Innere melı weniger dunkel granviolett, doch bleibt am purpurbram gesäunten Mundrande ein weißer Streifen, der ron der Stelle von Band 2 sich breiter werdend bis Band 5 himmer zieht und nnterhalb desselben sich ins Innere zieht. Das abgebildete Stiick zeigt die beiden von mir hervorgehobenen Merk- 
male, welche in den Beschreibungen nicht genügend hervorgehoben sind. Die Spindel steht senkrecht oder etwas schräg zur Achse und ist nur wenig verdickt.

1. Berl. Museum. Koll. ALbers. Demerara. ED. MÜLler. Vier Stïcke.

$$
77 / 8-76,0 \times(30,3) 33,8-36,6 \times 17,3 .
$$

Fig. 411. $\quad 71 / 8-62,5 \times(26,0) 30,3-29,2 \times 14,1$.

Die Windungen an dem abgebildeten Stück sind ausnahmsweise stärker gewölbt, was sonst nicht der Fall ist. Auch die Spindel ist sonst oben etwas stärker verdickt. Das Stïck ist nicht ganz ausgewachsen, das Spindelende geht deshalb noch schärfer winklig in den Basalrand über, der bei dem größeren Stück mehr im Bogen absetzt.

2. Berl. Mnseum. Koll. PaEtel. Bolivien. Ein Stüçk.

3. Wessel vend. Nr. 5683. Bolivien. Ein Stiick.

\section{C. incisa, Form machadoensis n. var.}

Taf. XXVII, Fig. 412/413.

Aus der Koll. DOHRN befinden sich unter den sieben schon mehrfach erwähnten Stücken vom Rio Machado, die alle als C. regina bestimmt sind, zwei sehr interessante Stïcke, die ich nur der dunklen Färbung des Innern und der wenig verdickten Spindel halber hierher bringe.

Das Gehäuse ist größer als der Typus, hat bis acht gewölbtere Windungen, deren letztere niedriger als das Gewinde ist. Die Färbung ist gelblichgrau mit zum Teil violettem Anfluge, der Wirbel ist heller mit braun abschattierter erster Windung. Die bei dem Typus geschilderte Zeichnung der oberen bis mittleren Windungen ist hier nur ganz im Anfang vorhanden, sehr rasch treten schmale und breitere Streifen anf, welch letztere nach rückwärts weißlich berandet sind. Schon von der dritten Windung an bis zur vorletzten des ausgewachsenen Stïckes ist das aus dunkelbraunen pfeilförmigen Flecken auf weißem Grunde gegliederte schmale Band 2 scharf ansgeprägt. Ebenso tritt Band 3 mehr weniger deutlich aus der Naht hervor. Schon von der vorletzten Windung an oder früher tritt zwischen Band 2 und 3 und von Band 3 bis zur Basis an dem jüngeren, bis zu Band 4 bei dem ansgewachsenen Stück eine gelblich olivenfarbige, sich von der Grundfarbe abhebende Färbung auf. Bei dem größten Stïck ist Band 3 auf der letzten Windung nur durch die hellere Färbung angedentet. Es fehlt also bei dieser Form die ans stärker betonten Streifen gebildete Zone zwischen der Naht und Band 2. Das Innere ist bei dem unausgewaclisenen Stück braunviolett, bei dem ansgewachsenen lebhaft violett, dann folgt ein weißer Streifen und endlich am Mundrande ein breiter ansfließender Streifen, der beim unausgewachsenen Stïck weniger rein als beim ausgewachsenen, schmutzig 
blangrün ist. Der Rand selbst ist hellbrämulich anßen und innen. Der Callus und die nicht verdickte ziemlich senkrecht stehende Spindel sind purpurbraun, letztere ist 1 ganz oben etwas weißlich.

Fig. 413. $8 \quad-81,5 \times(33,5) 42,1-36,7 \times 19,5$.

$" \quad 412 . \quad 7 \frac{1}{2}-66,3 \times(29,0) 34,0-31,6 \times 16,3$.

\section{C. perversa SWATNSON.}

Taf. XXVII, Figg. 400, 403, 408.

P., p. 17S, Taf. 36, Figg. 2023.

Zu der in PILsBRy gegebenen guten Beschreibung möchte ich nur noch hinzufïgen, daß, wenn auch undentlich, wie ans seiner Fig. 21 hervorgeht, zwischen Band 2 und 3 und 3 und 4 sich auf der letzten Windung dunklere, hellbrämliche Zonen befinden, die durch das breite weiße Band 3, anf der das schmälere durchgelıende oder gegliederte Band hinläuft, getrennt werden; Band 4 ist nicht vorhanden. Junge Stiicke (vergl. Fig. 408) lassen sich leicht von den anderen Arten durch die charakteristische Färbung und Zeichnung unterscheiden. Der Mundrand ist keineswegs immer schwarz berandet, wie PILsBRy es verlangt.

1. Berl. Museum. Nr.51468. Surinam. MICHAELIs, als C. regina bestimmt. Drei Stiicke, alle mit durchgehendem Band 3 und den erwähnten bräunlichen Zonen zwischen Band 2 und 4. Die Spindel ist mit einer sehr starken Lamelle belegt, und Band 3 ist eine kurze Strecke auch im Imnern schwarz markiert.

$$
\begin{aligned}
& 8-74,8 \times(33,5) 38,5-33,7 \times 16,7 . \\
& 71 / 2-61,9 \times(28,6) 32,2-29,3 \times 14,8 .
\end{aligned}
$$

Fig. 403. $7 \frac{1}{2}-67,5 \times(30,0): 3: 3,7-31,2 \times 14,4$.

2. Berl. Museum. Koll. AlBERs. Ein Cumngsches Stück. Brasilien. Auf der ALBERsschen Etikette stelit „Orth. victorialis ALB.", VON MARTENS hat es damu C. regina genannt. Das große Stïck lat die starke Terdickung der Spindel ganz nach der nicht ron vor'n sichtbaren Imenseite gerichtet; es ist schlanker als die vorangehenden.

$$
71 / 2-71,2 \div(28,1) 32,7-31,3 \times 15.1 \text {. }
$$

Fig. 408. $\quad 61 / 4-37,7 \times(21,0) 23,9-18,9 \times 10,7$.

3. Berl. Musemm. Koll. Dunker. O. regina HarTvig. Olme Fundort. Ein Stück mit weifem Mundrand.

4. Nr. 15445. O. regina. Brasilien. Ein jumges Stïck, sehr ähmlich dem abgebildeten.

5. IV. SCHLÜtER vend. STAUDINGER-Material. Lnterer Amazonas. Zwei Stïcke, anf der letzten Windung im Anfange fast schwarz, an dem einem Stück bis an die Nalit, an dem anderen nur bis zur Grenze der bräunlichen Zone oberhalb von Band 3. Im Innern ist auch Band 3 
anfangs als schwarzer Fleck, später nur durchscheinend sichtbar, der Mundrand ist weiß.

6. Rolle vend. Schaufuss-Material. Ober Surinam. Ein normales Stïck, das aber auch im Innern Band 3, wie oben geschildert, zeigt.

7. Koll. Scholvien. O. melanostomus SwaInson. Ohne Fundort. Ein normales Stiick wie das größere der abgebildeten.

8. Koll. DoHRis. Rio Machado. Ein Stück typisch, zuletzt mit einer etwas grünlichen Cuticula bekleidet, auf der das Band 3 aufhört schwarz zu sein und sich nur hell abhebt; der Mundrand ist außen nicht schwarz, innen schwarzgran ausfließend berandet.

Fig. 400. $8-70,6 \times(29,6) 33,6-31,5 \times 16,9$.

Man kann es begreifen, daß diese Art für $C$. regina FÉR. gehalten wird, besonders wenn man die in $\mathrm{P}$. abgebildeten rechtsgewundenen Stiicke, Figg. 2t, 25, ansieht, von denen mir keins vorliegt. Nach den von mir beschriebenen typischen Stiicken dieser Art besteht immerhin in der etwas verschiedenen Färbung und Zeichnung ein Unterschied.

\section{Fragliche Formen.}

'Taf. XXV, Fig. 385; Taf. XXVII, Fig. 401.

1. Koll. Scholvies. Ohne Fundort. Ein Stïck, linksgewunden, Grundfarbe weißlich, nach oben zu rosa werdend. Die Zeichnung ist älnnlich der von $C$. perversa, d. h. es sind breite violettgraue Streifen in der senkrechten und spiralen Richtung vorhanden, letztere oft zusammengeschoben zickzackförmig. Die letzte Windung ist mit einer gelbbraunen in Streifen aufgelösten Cuticula bedeckt, auf der sich Band 3 als heller Streifen markiept. Die gegliederten Bänder 2 und 3 sind am Gewinde streckenweise vorhanden. Es fehlen diesem Stïck das schwarze Band 3, welches so charakteristisch für $C$. perversa ist, sowie die liell rotbraunen Zonen von Band 2 ab auf der letzten Windung, von denen hier nur an einer Stelle auf der vorletzten Windung die obere angedentet ist; auf der letzten erkennt man nur auf den weißen Streifen eine schwache Andeutung der Färbung unterhalb Band 3. Andererseits sprechen die niedrige letzte Windung und die schlanke Form gegen $C$. regalis.

Fig. 401. $8-71,5 \times(28,0) 32,8-32,2 \times 13,9$.

2. Berl. Museum. Nr. 40681. v. D. STEINEN leg. Nakagua, mit der Bemerkung "Bündelweise zusammengebunden als Schmuck". V. MAR'TENS hat dies Stïck, das noch das Loch aus seiner Benutzungsweise zeigt, Bul. incisus HUP.́́ genannt, was aber meiner Ansicht nach nicht richtig ist, da die entsprechende Zeichnung und die Färbung des Innern fehlen. Das Stiick ist jeder Cuticula entkleidet, nur auf der letzten, jeder Zeichnung entbehrenden Windung erkennt man nahe der Mündung Reste einer hell olivenfarbigen Cuticula. Es erscheint durch scharfe Falten 
ziemlich gerieft, ist weißlich, nach oben etwas violett angehaucht, im Innern rein weiß. Es sind nur wenige dunkle Streifen und Andeutungen durch einzelne Flecke von Band 2 und 3 vorhanden. Nur auf der 4 . und 5. Windung ist das dentlich gegliederte Band 2 ausgeprägt.

Fig. 385. Fast $8-66,2 \times(25,5) 29,0-30,6 \times 13,5$.

Es ist dies ein Stück, das man der Größe und schlanken, getürmten Form nach nicht zu $C$. regalis rechnen kann.

\section{Nfeifferi Hidalgo.}

Orthalicus pfeifferi HID. ist anfangs von PILSBRY unter Oxystyla eingereiht (P., p. 146, Taf. 55, Figg. 48-50), später im Indexband zu Band 10-14, p. 64, unter. Corona. EDGAR A. SuITH hat gelegentlich der Beschreibung einer var. gracilis vom Rio Caqueta, S. O. Columbien, auf den Fehler der ursprünglichen Unterbringung aufmerksam gemacht (Proceed. Malac. Society, London, Bd. T, p. 170). Er meint dabei, daß die Art ihm näher dem Subgenus Metorthalicas, bezw. M. atramentarius und Adamsoni zu stehen scheine als der Gattung Liguns, wobei er die ganz verschiedene Form und Skulptur des Embryonalgewindes übersehen hat. Die Art gehört ohne Frage zum Genus Corona, der allerdings, wenn überhampt, in die Nähe von Lignus gehört.

Ton Stücken, wie die abgebildeten, die aus HIDALGns Tiage al Pacifico und aus dem Jomrn. d. Conchyl. 1870 kopiert sind, liegt mir nur ein Stiick aus dem Berl. Musenm vor', das aus Nen-Granada, Gebiet des Putumayo, stammt. Es ist nicht ganz ansgewachsen und nicht ganz frisch, zeigt aber dentlich, daß die Bezeichnung "gewellte Linien" in der Diagnose hier nicht ganz zutreffend ist. Die schmalen, gleichmäßig gereihten bramnen Limien sind nämlich besonders auf den letzten drei Windungen an Stelle von Band 2 und 3 deutlich winklig nach rïickwärts ausbiegend. Auberdem sind diese Bänder durch etwas hellere Grundfarbe, wenn anch undentlich, erkennbar. Das Stïck ist nicht ganz ansgewachsen, und wohl deshalb ist am Anfang der letzten Windung noch eine stumpfe Kante erkennbar, welche die Diagnose freilich anch aufführt. Die Spindel ist bis an den Callus weib, mur unten etwas bräunlich, die Abbildung des Typus zeigt sie ganz bram, und anch die Diagnose nennt sie "nigra intus callo albido". Freilich nemnt die Diagnose sie auch ,parum torta, subrecta", während sie an dem mir rorliegenden Stück stark, und in der typischen Abbildung, wenn anch weniger stark, doch deutlich gewunden ist. Die Art scheint auch veränderlich zu sein.

$$
7 \frac{1}{4}-52,6 \times(24,2) 27,4-25,4 \times 12,0 \text {. }
$$

Del. Typus stammt von Canelos, Ecuador, also sïdlicher als das Stiick des Berl. Museums. 


\section{C. pfeifferi, Form cincta n. $f$.}

\section{Taf. XXI, Fig. 337 ; Taf. XXII, Figg. 356, 357.}

In Memorias de la Real Acad. de Ciencias, Madrid, vol. 16, Obras Malacologicas de J. G. HIDALGO, parte 3, p. 56, gibt HIDALGO nochmals die Originaldiagnose der Art ans dem Journal de Conchyliologie, vol. 17 bezw. 18, nebst spanischer Übersetzung. HIDALGOS Werk, Viage al pacifico etc., liegt mir leider nicht vor, aber PILSBRY gibt ja auf Taf. 55, Figg. 48, 49, die Kopie der darans entnommenen Abbildungen des Typus der Art, sowie in Fig. 50 derjenigen ans dem Journal de Conchyliologie, vol. 18. HIDALGO sagt mur l. c. p. 58, daß im Museum eine von seinen Abbildungen abweichende Form liege, die eine größere Anzahl von bramen Linien als der Typus habe, und anßerdem eine weißliche Zone in der Mitte der letzten Windung, in der viele der braunen Linien unterbrochen sind; woher diese Form stammt, wird nicht angeführt. Ob dazu etwa die zweite Fundortsangabe in der Originaldiagnose ebendaselbst, „im Lanb an den Ründern des Flusses Napo (Cousin)“, gehört, muß ich dahingestellt sein lassen. Der Rio Napo fließt auch in Ecuador. Immerhin kann es sich dabei um eine Lokalform handeln. Es ist wohl ein Irrtum, wenn PILSBRY, p. 147, bei der Kopie der angefïhrten Notiz Hidalgos auf die Fig. 50 hinweist, die, wie gesagt, eine Kopie des Typus ans dem Journal de Conchyliologie ist, denn weder zeigt dies Stiick die weißliche Binde, noch gibt HIDALGO einen solchen Hinweis.

1. Mir liegt nun ein Stïck des Berliner Mruseums ans der PAETELschen Sammlung vor, bei dem nur Ecuador als Fundort angegeben ist, und das genan die beschriebene weiße Binde zeigt.

Dieses Stiickes und besonders des darauf folgenden halber, sondere ich diese sonst typische Form als Form cincta ab. Weiteres Material muß ergeben, ob es sich dabei um eine Varietät oder um eine Lokalform handelt.

Fig. 357. $\quad 7-55,2 \times(23,4) 25,0-26,4 \times 10,9$.

Das Stiick zeigt anch noch am Anfang der letzten Windung etwas wie einen stumpfen Kiel. Der Wirbel ist hell kastanienbraun. Der Callus ist außen kastanienbraun, nach innen schwarzbraun.

2. Koll. Scholvien. Ecuador. Ein Stiick. Der Wirbel ist anch hellbraun. Auf der weißlichen Grundfarbe treten anßer den breiten dunkel blangranen, nach rüickwärts abschattierten, nach vorı weiß berandeten Streifen noch hellere blangrane Wolken auf den letzten Windungen auf, die zum Teil biṣ Band 3 senkrecht himuntergehen, zum Teil aber an Stelle von Band 3 ihre Richtung verschieben, dann das Band 3 zum Teil in senkrechter, zum Teil in schräger Richtung nnterbrechen. An ein paar Stellen treten auch weiße Flecke an Stelle von Band 2 anf. Die schmalen Streifen sind rotbram und sind an Stelle von Band 2 nach 
rïckwärts winklig ausbiegend. Das gegliederte Band 3 tritt schon anf der 4. Windung oberhalb der Naht auf.

Der Callus ist an diesem Stiick abweichend vom Typus und ron dem vorangehenden Stiick, dïnn und weißlich mit durchscheinender Zeichnung. Das Innere zeigt die breiten Streifen und das weibe Band 3 deutlich durchscheinend. Der stumpfe Kiel ist nicht vorhanden. Der Mundrand ist außen ziemlich breit rotbraun berandet, worauf sich ein blangraner durchgehender Streifen anschließt. Die rotbrannen schmalen Streifen sind auch auf den dunklen Streifen noch erkennbar.

Figg. 337, 356. $7-54,9 \times\left(22\right.$, (i) $^{2} 25,3-25,7 \times 11,4$.

\section{C. pfeifferi var. gracilis E. A. SuITH.}

Diese in Proceed. Malac. S. London, vol. 5, p. 170, beschriebene und abgebildete Form vom Rio Caqueta, Sïdost-Columbien, liegt mir nicht vor. Sie scheint der Abbildung nach auf der letzten Windung auch das schwach heller gefärbte Band 3 zu haben, das aber nicht gegliedert erscheint. Die schmalen rotbraumen Streifen scheinen weitläufiger zu stehen und sollen weniger deutlich ausgeprägt sein. Die wolkigen Flecke, die ich bei dem vorangehenden Stïck erwähnte, scheinen auch hier vorhanden zu sein, bezw. die drei etwas verschobenen dunklen Streifen.

\section{C. rosenbergi n. sp.}

Taf. XXI, Fig. 336; Taf. XXII, Fig. 355.

Es liegt leider nur ein unansgewachsenes Stïck vor, das aber so charakteristische Merkmale zeigt, daf es leicht wieder zu erkennen und in ausgewachsenen Stiicken kaum wesentlich abweichen wird.

Gehäuse im Aufbau wie C. pfeifferi, der Anfang der letzten Windung zeigt noch eine deutliche stumpfe Kantung. Das Embryonalgewinde mit 21/2 Windungen (Fig. 336) zeigt die erste Windung braunschwarz, dann werden die Windungen oben weiß, nach unten hell rotviolett und nach $1 \frac{1}{2}$ Windungen treten rotbrame Streifen auf, die sich auf den auf das Embryonalgewinde folgenden Windungen zuerst in kurze, hakenförmige, schmale Streifen umwandeln, von denen dann nur ein schmales gegliedertes Band an der Nalit und das gegliederte Band 2 ïbrig bleibt. Diese Fürbung und Zeichnung setzt sich nur bis zu Anfang der 5. Windung fort, dann geht die Färbung mehr ins Graubrame über, und beide gegliederte Bänder verschwinden. Dafür treten sehr vereinzelt dınkle, fast schwarze, nach vorn lebhaft fleischfarbige Streifen als Wachstumsabschlïsse auf, nach denen man schließen kann, daß der Mundrand an ansgewachsenen Stïcken dunkel berandet sein muß. Die Spindel steht senkrecht zur Achse, weicht oben etwas zurïck, ist aber in sich noch (?) 
gerade und schwarzbraun wie der Callus, nur ganz oben etwas weißlich verdickt. Der vom Spindelende etwas winklig abbiegende Basalrand wird voranssichtlich, wemn. die Spindel stärker verdickt und stärker gewunden wird, ausgeglichener werden.

$$
6-43,5 \times(20,6) 23,2-20,9 \times 11,0 .
$$

\section{Genus Thotus n. gen.}

\section{A. Subgenus Tholus.}

Gehäuse festschalig, schmal oval-konisch, etwas fettglänzend, mit breit erscheinender Spitze und 6 nur mäßig gewölbten Windungen, deren letzte niedriger als das Gewinde ist. Mündung oval, oben zugespitzt. schräg zur Aclise stehend, innen farbig. Mundsaum weißlich, verdickt umgeschlagen, nach unten erweitert. Der Basalrand geht etwas abgerundet winklig in die Spindel über, die oben etwas zurückweicht, schräg zur Achse steht, in sich oben schwach oder nicht faltig und ganz schwach eingebogen ist. Der Callus ist dünn.

Das Embryonalgewinde (Fig. 341) mit $2 \frac{1}{2}$ bis $2^{5 / 3}$ Windungen hat eine hohe Kuppelform. Von Anfang an treten an der Naht kurze, schräge, nach vorn gerichtete rotbraune Streifen auf, die sich schon nach der ersten Windung zu schwächer gefärbten senkrechten Streifen verlängern, welche häufig an Stelle von Band 2 Einknickungen zeigen. Später verlieren sich diese Streifen in der dicken bräunlichgelben Cuticula. Sie sind mit feinen, etwas unregelmäßig gewellten, besonders nach dem Unterteil der Windung zu sich verzweigenden Fältchen bedeckt, die auch vielfach eingekerbt erscheinen. Diese Skulptur ist nur bei gut erhaltenen Stïcken erkennbar.

Die spätere Skulptur erscheint sehr grob, sie besteht ans schmalen, nur anfangs deutlich erkennbaren Falten, die sich später zu gröberẹn Falten zusammenschließen, welche die Naht sehr unregelmäßig gekerbt erscheinen lassen. Eine feinere Spiralskulptur ist nur ganz vereinzelt erkennbar, dagegen treten weitlünfiger stehende, gröbere Furchen anf, die aber meist nur in kurzen Strichen, selten auf längeren Strecken, auftreten. Jedenfalls ist $a b$ und zu eine schwache Stäbchenskulptur vorkanden, aber alles wird undentlich gemacht durch die vielen hammerschlagartigen Eindrïcke und die bald in der senkrechten, bald in der spiralen Richtung auftretenden kurzen Anschwellungen.

\section{Th. buckleyi HIGGINS.}

Taf. XXI, Fig. 341; Taf. XXIV, Figg. 380 a, b. P., p. 193, Taf. 41, Fig. 6.

Dies ist die einzige hierher gelörige Art. Zur Ergänzung der obenstehenden Diagnose diene folgendes. 
Das Gehäuse ist anf den unteren Windungen mit einer gelbbraunen Cuticnla belegt, ans der sich einige der goöberen Falten heller abheben, während die Zwischenräume dunkler sind; außerdem treten einzelne schmale dunkelbraune Tarixstreifen anf. Die oberen Windungen haben einen rötlichen Anflug. Das Innere ist schmutzig hell violettrosa, der Mundrand gelblichweif. Die Spindel ist rosa gefärbt, nach dem ziemlich dïmen Callus zu ins Weißliche iibergehend. Die beiden vorliegenden Stïcke weichen roneinander in der Spindelform etwas ab, anch ist der Basalrand bei dem größten Stïck besonders nach der Spindel zu mehr vorgezogen als bei dem anderen. Ich habe deshalb den unteren Teil beider Stiicke von der Seite gesehen abgebildet.

Koll. SchoLviEx. Ecuador. Zwei Stïcke.

Fig. 380b. $6-86,8 \times(30,0) 38,6-40,1 \times 20,3$.

"380a. $53 / 4-78,6 \times(27,9) 35,5-38,5 \times 19,0$.

Der 'Typus ist größer' und zeigt unten an der Spindel noch eine Verdicknng, die meine Stïcke nicht zeigen.

\section{B. Subgenns Parhytholus u. subg.}

Gehäuse mäßig starkschalig, fettglänzend, oval-konisch mit breit erscheinender Spitze. Die $6 \frac{1}{4}$ bis $6 \frac{3}{4}$ Windungen nehmen anfangs rascher an Breite zu als später, sie sind mäßig gewölbt und die letzte ist mehr weniger etwas kürzer als das Gewinde. Die Mündung ist verkehrt-ohrförmig, imen grauweißlich oder mit leicht violettem Anfluge und zuweilen mit durchscheinender Zeichmung. Der Mundrand ist weif, fast geradeaus, nur wenig rerdickt mo nach rïckwärts sehr kurz umgeschlagen. Die Spindel ist stark gewmuden und rerdickt, ilır Ende geht winklig in den Basalrand iiber. Der Callus ist düm nit mehr weniger durchscheinender Zeichnung.

Das Embryonalgewinde (Figg. 335, 338) hat $2 \frac{3}{4}$ Windungen mit breit kuppelförnigem Aufbau. Sie sind zuerst mit sehr feinen gewellten Fältchen besetzt, dann folgen gröbere Falten. Gegen das Ende treten braune Streifen auf.

Die allgemeine Skulptur besteht ans schmalen, etwas mregelmäßig. starken Falten, deren zwei bis drei sich in der Nahtnähe zu groben Falten vereinigen, so daf ähnlich wie bei Porphyrobaphe eine Zone von groben Falten an der Naht entsteht, die diese nmregelmäfig gekerbt macht. Es sind Spuren von feinen gewellten Spiralstreifen vorhanden, melı hervortretend sind dagegen die gröberen. weitläufiger gereihten Spiralfurchen, die nur kurz oder anf langen Strecken durchgeführt sind. Ab und zn erkemnt man eine mehr weniger dentliche Stäbchenskulptur. Hammerschlagartige Eindrïcke treten nur selten auf. 


\section{$\boldsymbol{P}$. flori Jousseaume.}

Taf. XXI, Figg. 335 a, b; Taf. XXY, Figg. 386, 387.

P., vol. 14, p. 164 .

Zu der gegebenen Diagnose habe ich ergänzend nur folgendes zu sagen.

Das Gehäuse erscheint verhältnismäßig glatt, da die oben geschilderte Skulptur im allgemeinen schwach ausgeprägt ist. Die hellund dunkel- bis schwarzbramnen Streifen anf weißem, zuletzt oft braunem oder graubraunem Untergrunde sind stellenweise violett angehaucht. Sie haben auf den oberen Windungen oft Zickzackform oder erscheinen an der Naht gegabelt, später sind sie gerade. Bei dem einen Stück ist die Zeichnung im ganzen dunkler als bei dem anderen, und anf ihm treten dentlich einzelne weißliche längliche Flecke in der Spiralrichtung anf, und an der Basis befindet sich eine ziemlich breite dunkelbraune Zone.

Bei dem hellen Stïck ist das Embryonalgewinde anormal, insofern dort oben und unten an den Windungen einige seichte Vertiefungen auftreten (Fig. 335 b). Der Mundrand ist kaum verdickt und nach rïckwärts kurz umgeschlagen, innen mit einem violettbrämnlichen schmalen ausfließenden Streifen belegt, welche Färbung sich auch noch auf den unteren Teil der dicken weißen Spindel erstreckt. Der Callus ist dïnn, innen weißlich, außen bramn berandet, mit durchscheinender Zeichnung.

1. SOWERBY und FuLTON vend. Ecuador. Das dunklere Stiick. Fig. 386/387. $\quad 63 / 4-85,8 \times(34,8) 42,3-43,0 \times 20,5$.

2. Koll. Scholvien. Bul. integer PFR. Ecuador. Jousseaume bemerkt, daß er seine Art zuweilen mit diesem Namen in den Sammlungen angetroffen habe. Was eigentlich $B u l$. integer ist, weiß auch PILSBRY nicht, da die Art nicht abgebildet wurde. P. flori ist freilich auch nicht abgebildet.

$$
61 / 2-78,8 \times(33,2) 41,1-42,7 \times 19,5 .
$$

Bei oberflächlicher Betrachtung kann man diese Art für Metorthalicus maranhonensis halten.

\section{P. psencloiostomus n. sp).}

Taf. XXI, Fig. 338; Taf. XXVI, Figg. 397/398.

Gehäuse von gedrungenerer Form als P. flori. Grundfarbe oben weißlich, unten hell violettbräunlich, mit dunkleren, nach vorn breit weiß berandeten T'arixstreifen. Auf der letzen Windung treten, wenn auch undeutlich, einige hellere Flecke anf. Das Innere ist schmutzigweiß mit violettem Anfluge, der schmal umgeschlagene, etwas verdickte Mundrand ist elfenbeinweiß, die stark gewundene, oben zurückweichende nnd verdickte Spindel ist bei einem Stïck etwas bräunlich. Der Callus ist dümm, glänzend, weißlich oder bräunlich, nach außen etwas dunkler 
berandet und nit durchscheinender Zeichnung. Die oben geschilderte Skulptur ist etwas stäker ausgeprägt als bei $P$. flori; wemn aber bei dieser Art noch Spuren der feineren Spiralstreifen rorhanden sind, kamn ich hier solche nicht entdecken.

1. H. Rolle vend. Schaufauss-Material. Chile. Ein Stïck, etwas beschädigt und ausgebessert, weshalb ich es nicht zur Abbildung wähle.

$$
61 / 8-67,7 \times(30,0) 38,5-35,2 \times 18,0 \text {. }
$$

2. Nr. 5252. Ohne Namen und Fundort. Ein Stïck.

Figg. 397/398. $6 \frac{1}{2}-73,0 \times(34,0) 40,5-38,3 \times 19,7$.

Diese Art verdient ihren Namen wohl mit Recht, dem man kömnte sie bei oberflächlicher Betrachtung für $P$. iostoma halten.

\section{IT. Gents Orthatirus BECK.}

\section{A. Subgenus Orthrolicuss s. str.}

P., 1. $1 \leqslant 6$.

Gehäuse aufgeblasen, mehr weniger dünnschalig, ziemlich glanzlos, mit sechs sehr rasch an Breite zmehmenden gewölbten Windmgen, deren letzte bedentend größer als das Gewinde ist. Mïndung breit oval, oben zngespitzt oder annälıernd verkehrt-ohrförmig, je nachdem der Spindelansatz mit der Windungswand einen mehr weniger dentlichen Winkel bildet. Mundrand geradeaus, scharf oder stumpf, zuweilen nach unten erweitert. Spindel dümn oder stärker, weiß oder bram, senkrecht oder schräg zur Achse stehend, gerade, eingebogen oder selbst gewunden.

Das Embryonalgewinde (Fig. 344) hat $2 \frac{1}{2}$ bis $23 \frac{4}{4}$ gewölbte Windungen, oben nicht stumpfkantig, mit sich regelmäßig schräg kreuzenden, verhältnismäßig großen Grübchen besetzt, an der Naht zuerst mit einer bramen Zone, die bis Band 2 reicht und dann in eine weißliche Zone mit bramen eingebogenen Streifen ïbergeht, welche nach miten in mehr senkrechter Richtung abbiegen und bei Band 3 winklig ansbiegen.

Die folgende Skulptur besteht aus schmalen, etwas umregehäßig starken Falten, die von feinen gewellten Spiralstreifen durchschnitten werden, die sich anf den unteren Windungen als dentliche Spiralreifen erkemnen lassen, welche bald dicht, bald weitlänfiger gereiht stehen. In mehr weniger unregehmäßigen weiteren Zwischenrümen treten seichte Furchen auf, in denen man unter der Lupe noch zwei bis drei der feinen Spiralreifen erkemnen kam, sie durchbrechen die Falten so, daf eine Stäbchenskulptur entsteht, wobei aber die Stäbchen durch die feineren Spiralfurchen bezw. -reifen in Körner anfgelöst werden.

Die Girundfarbe ist gelb, gelbbraun oder graubraum, mit vielen schmalen bramnen Streifen, die an den Bändern winklig ansbiegen, aber 
häufig auch streckenweise zu eintönigem Braun zusammenfließen, das sich zu dunklen, vorn meist hell berandeten Streifen verdichtet, die ebenfalls die winkligen Ausbiegungen an den Bändern zeigen. Es sind die Bänder 2, 3, 4 in hellerer Grundfarbe und mehr weniger weitlänfig durch die dunklen Streifen gegliedert vorhanden, das Band 5 ist meist schwächer ansgeprägt, oft mit einer dunkleren Zone um die Basis vereinigt. Ton Band 2 bis in die Nahtnähe erstrecken sich meist die dunklen, vorn hell berandeten Terbreiterungen der Streifen, und ferner treten zwischen Band 2 und $: 3$ und 3 und 4 noch Zwischenbänder auf, die entweder schmäler oder ebenso breit, auch breiter als die Hauptbänder sein kömnen, und entweder nur durch die winkligen Torsprünge der schmalen Streifen oder anch durch breitere Flecke wie die Hauptbänder gegliedert sein können; sie sind entweder deutlich ausgeprägt oder sie können auch verschwommene Zeichnung zeigen. Außer dieser typischen Zeichnung treten anch in geringer oder gröferer Anzahl kleine, runde helle Flecke von verschiedener Größe auf.

Das Imnere ist mit einer melr weniger dünnen weißen Schmelzschicht belegt, welche die äußere Zeichnung durchscheinen läßt. Der Mundrand ist innen schmal oder breiter ausfließend braun berandet.

Nach dem mir vorliegenden Material bin ich der Ansicht, daß es sich bei den drei, eigentlich nur zwei Arten dieser Untergattung nur um Lokalformen einer und derselben Art handelt, deren Typus ja nur nach der Anciennität aufgestellt wird; denn welche der verschiedenen Formen; die in der Entwicklungsgeschichte älteste ist, das läßt sich ja vorderhand nicht nachweisen, wemn ich auch glauben möchte, daß als solche der O. meobambensis bezw. trullisatus gelten kann. In den Einzelheiten, welche diese sogenannten Arten charakterisieren sollen, finde ich durch vorhandene Ausnahmen und Übergänge so viele Terschiedenheiten, daß es schwer hält, selbst diese Lokalformen auseinander zu halten.

Als älteste beschriebene und abgebildete Form muf man wohl den O. gallina-sultana, wie er in MaRTINI und ChemNITZ, XI, Taf. 210, Figg. 2070, 2071, abgebildet wird, ansehen, fiir den noch Nen-Seeland als Vaterland angegeben wird. Auch ReEves Fig. 198 von Bolivien entspricht diesem Typus, während SPIX (WAGNer), Taf. 9, Fig. 1, ohne Fundort, dieselbe Zeichnnug, aber eine etwas weniger eingebogene und breitere weiße Spindel zeigt. Ton diesem 'Typus des O. sultana, für den PILSBRY als Hauptverbreitungsgebiet Guayana annimmt, muß man wohl ausgehen. Es wird sich zeigen, daß auch in Guayana schon abweichende Formen auftreten. Zukünftiges, rationell gesammeltes Material muß Aufschluß bringen, welche Formen endgïltig als Lokalformen gelten können, und wie weit sich andererseits die Yariationsweite einer Form innerhalb eines Fundortes gestaltet. 


\section{O. sultrince DILLWYN.}

Taf. XXI, Fig. 344; Taf. XXX, Figg. 436, 438.

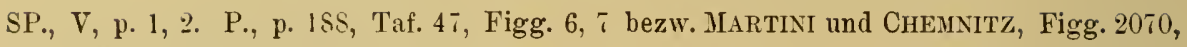
2071, und REEVE, Fig. 198.

Dieser Typus charakterisiert sich durch die dïme Schale, die schmalen, meist nur durch winklige Torsprünge der schmalen Streifen hervorgehobenen Zwischenbänder und durch die mehr weniger eingebogene, verhältnismäßig dïmne weiße Spindel. Hierbei tritt schon eine Verschiedenheit insofern anf, als bei großen Stiicken gegen das Ende die Bänder und Zwischenbänder gleichwertig an Breite werden können, daß fermer der Callus farblos oder kastanienbram sein kamn.

1. Berl. Musemm. Koll. ALBERS. Ein Cumingsches Stück von Cayenne (SchImPER), Demerara. Callus kastanienbraun. Mundrand breit ansfließend hellbram.

Fig. 438. $6-76,9 \times(42,0) 56,0-53,9 \times 31,2$.

2. Berl. Museum. Koll. Dunker. Guiana. LANDAUER. Zwei Stiicke, davon eins ganz jung. Wie das vorangehende, nur ist bei dem größten Stïck der Mundrand schmal hellbram berandet und der Callus hellbram.

$$
\begin{aligned}
& 5^{7} / 8-63,2 \times(33,7) 46,2-43,3 \times 27,1 . \\
& 5-33,0 \times(20,1) 26,2-21,3 \times 14,4 .
\end{aligned}
$$

3. Berl. Museum. Nr. 10379. Guiana, SCHOMBURGK. Zwei Stïcke, defekt, in Zeichnung wie die vorangehenden. An dem einen Stïck ist die Spindel eingebogen, an dem anderen gerade und schräg zur Achse stehend. An diesem Stück besteht auf der letzten Windung das Band zwischen Band 2 und 3 anch aus größeren Flecken, freilich nur streckenweise. Der Mundrand ist verlältnismäßig breit, schwarzbram berandet, der Callus scheint dagegen farblos; es mißt:

$$
5^{7} / \mathrm{s}-70,8 \times(38,5) 53,3-48,1 \times 29,8 .
$$

4. Berl. Musem. Koll. AlbERs. Guayana. Ein typisches Stïck, nicht ganz ausgewachsen, mit farblosem Callus.

5. Berl. Musemm. Surinam. KAPPLER. Ein typisches Stïck, mit farblosem Callus und MIundrand.

6. Nr. 5471. Alte Sammlung, olme Fundort. Zwei typische Stiicke, mit farblosem Callus. Das Stück hat etwa $1 \frac{1}{2} \mathrm{~cm}$ vor der Mündung: einen erhabenen rarixstreifen, und ron da ab treten bei sonst gleicher Färbung und Zeichmung viele helle Flecke auf, die also nicht auf die Form trullisatus bezw. meobambensis beschränkt sind.

Fig. 436. $\quad 5^{3 / 4}-62,2 \times(33,3) 45,8-42,3 \times 26,7$.

7. Koll. SoHst. Olme Fundort. Ein typisches Stiick.

8. Koll. Scholvies. Ohne Fundort. Zwei typische Stücke. 
9. Koll. O. Semper. Marquiere. Peru, Dep. Cuzco. Ein typisches Stiick, mit farblosem Callus und Mundrand.

$$
5^{3 / 4}-59,9 \times(34,4) 45,5-40,7 \times 27,6 .
$$

\section{Zwischenformen.}

Taf. XXVIII, Figg. 414/417, 421/422; Taf. XXX, Fig. 435.

A. Die Form ist weniger anfgeblasen, gestreckter, bezw. das Gewinde ist im Verhältnis höher und nähert sich dadurch mehr der Form meobambensis.

1. Koll. ScholviEN. O. moyobambensis. Bolivien. Ein Stück, von der hellen Farbe der typischen 0 . sultana, auch die Zeichnung ist dieselbe, aber die Spindel ist gerade, schräg zur Achse stehend, weiß. Der Mundrand ist hellbram, der Callus farblos.

$$
6-65,5 \times(35,0) 45,4-42,6 \times 24,1 .
$$

2. Nr. 15626. O. meobambensis. Peru. Ein jüngeres Stück, von etwas dunklerer, mehr ins Grane spielenden Grundfarbe. Zeichnung und Bänder wie beim typischen $O$. sultana, aber die Spindel ist gerade, schräg zur Achse stehend, und Mundrand und Callus sind nicht braun.

$$
5 \frac{1}{2}-55,7 \times(28,2) 36,1-33,8 \times 19,0 .
$$

3. Koll. Filby. O. gallina-sultana. Peru. Ein Stück wie das vorangehende.

$$
5^{5} / 8-61,5 \times(31,4) 41,7-37,6 \times 22,0 .
$$

4. Koll. Scholvien. O. gallina-sultana. Unterer Amazonenstrom. Ein Stïck, sehr gestreckt, sonst sind Färbung und Zeichnung annähernd typisch wie 0 . sultana. Die Spindel ist gerade, steht schräg zur Achse, der Mundrand ist noch nicht gefärbt, der Callus dünn, hellbraun.

Fig. 435. $\quad 6-69,9 \times(34,1) 45,1-44,8 \times 24,8$.

5. Koll. O. SEMPER. Ein CUMnNGsches Stück, Wessed vend. O. moyobambensis PER. Moyobamba. Es ist in allen seinen Charakteren fast dem $O$. sultana gleichkommend, nur werden die Bänder zuletzt gleichwertig an Breite, und die Gestalt ist nicht so bauchig.

\section{B. Form von Caceres.}

Koll. O. SeMrer. Fünf Stïcke. Grosskopf leg. Januar 1879. Caceres im Staate Antioquia.

Die Form ist ebenfalls nicht so anfgeblasen wie der typische 0 . sultana bezw. das Gewinde ist höher im Terhältnis. Die Grundfarbe ist dunkler, bei dem größten Stück (Fig. 422) zuletzt ins Olivenfarbige spielend, während sie bei dem jüngsten Stück (Fig. 415) noch melhr gelb ist. Die Zeichnung ist bei dem jüngsten Stïck noch typisch, bei den größeren ist die Zone breiter Flecke zwischen Band 2 und der Naht nur vereinzelt 
angedentet, und die Bänder sind auf den letzten Windungen bis auf Band 2 nur selten gegliedert. Die Zwischenbänder 2a und 3 a bestehen an zwei Stïcken und ganz besonders bei Fig. 422 aus dunkleren, nicht oder kaum winklig gebrochenen und dunkler gefärbten Strichen, und die Bänder 2, 3 selbst sind verhältnismäßig schmal, während bei einem anderen Stück besonders Band 3 wieder breiter ist. Die Spindel ist verhältnismäßig breit in der Mitte, weif, bei dem größten Stïck schwach eingebogen, bei den anderen gerade und etwas schräg zur Achse stehend. Der Mundrand ist bei dem größten Stück innen schmal hellbraun gesäumt und der Callus dünn und etwas weißlich. Das Innere ist nu mit einer dünnen weißlichen Schicht belegt, durch die die Zeichmmg hindurchscheint. An der Basis ist die ausmündende dunklere Zone des typischen O. meobambensis hellbraun. Bei den jüngeren Stïcken treten diese letztgenamnten Charaktere weit schwächer auf.

Fig. $\begin{aligned} 422 . & 5 \frac{7}{8}-77,5 \times(39,6) 55,5-51,0 \times 29,9 . \\ & 5 \frac{1}{1}-70,3 \times(36,(i) 50,1-45,7 \times 28,0 . \\ & 51 / 2-64,0 \times(34,6) 46,0-43,4 \times 25,6 . \\ & 51 / 2-61,1 \times(31,7) 42,6-40,2 \times 23,7 . \\ , \quad 415 . \quad & 51 / 8-47,7 \times(24,3) 33,7-31,5 \times 18,2 .\end{aligned}$

\section{Form vom IInrri-Tal.}

Koll. O. SEMPER und H. Strebel. G. WALLIS leg. Murri-Tal, zum Atrato-Gebiet gehörig. Zwei Stiicke von diisterer Färbung, weil die hellen Umränderungen der Streifen weniger hervortreten. Der Breitenunterschied zwischen den Bändern und Zwischenbändern ist sehr gering. Bei dem kleineren Stïck treten zuletzt melı Terbreiterungen der Streifen anf als bei dem größeren, bei diesem dagegen kommen auf der letzten Hälfte der Windung einzelne helle Flecke wie beim typischen $O$. neobambensis ror. Die Spindel ist bei beiden Stiicken weif nnd eingebogen, der Mundrand und der Callus sind nicht braun gefärbt. Die brame austretende Zone an der Basis ist nicht vorhanden, und das Innere ist nur dïm weiblich belegt mit durchscheinender Zeichnmng.

$$
\text { Fig. 421. } 6 \begin{aligned}
& 6-73,0 \times(37,3) 50,8-43,9 \times 29,3 . \\
& 53 / 4-62,0 \times(33,9) 45,6-38,7 \times 26,1 .
\end{aligned}
$$

\section{Form voul Maroni.}

Das Gehäuse ist etwas weniger rasch verbreitert, bezw. das Gewinde ist höher in Terhältnis zur letzten Windung; wodurch auch ein Übergang zul Form meobambensis geschaffen wird. Abweichend ist aber ron allen Formen die gewundene, nicht eingebogene Spindel. Nr.15628. G. SCHNEIDER rend. Am oberen Maroni, Surinam. Drei Stiicke, von denen das jüngste 
eine eingebogene, nicht gewundene Spindel hat. Bei allen drei Stücken treten einzelne helle Flecke auf, und der Callus ist besonders nach unten hin braun. Bei dem größten abgebildeten Stück, das sonst die typische Zeichnung hat, werden auf der letzten Hälfte der letzten Windung (Fig. 416) die Bänder 2, 3 und die Zwischenbänder 2a, 3 a gleich breit und fast durchgehend, nur teilweise unterbrochen. Das abgebildete Stiick hat unten im Innern die ausmündende Zone der Form meobambensis, die hier aber hellbram ist und die den beiden anderen Stücken fehlt.

Figg. 414, 416. $\begin{array}{ll}57 / 8-69,1 \times(36,7) 49,2-45,2 \times 26,0 . \\ 6-58,2 \times(30,7) 41,4-36,6 \times 24,2 .\end{array}$

Das letzte Stïck der Maßliste ist das kleinste Stück mit eingebogener, nicht gewundener Spindel, das schon etwas mehr Windungen hat als das größte Stïck.

\section{E. Form von Pará.}

Berl. Museum. HELLER leg. Der Sammler wohnt in Paramaribo. Bei diesem Stïck lag ein Zettel "Distrikt Pará“. Ein Stïck von etwas dunklerer Färbung als das vorangehende, besonders der Bänder und Streifen, die fast schwarz auf der letzten Windung sind. Anch die annähernd gleiche Breite der Bänder ist ähmlicher der Form meobambensis; die dunkle Zone an der Basis des Innern ist nur ganz undeutlich und hellbramn. Der Mnndrand ist noch (?) ungefärbt, der Callus sehr dünn, nur unten hellbraun. Die Spindel ist weiß, dünn und etwas weniger, aber doch dentlicher gewunden als bei dem großen der vorangehenden Form.

Fig. 417. Fast $6-66,4 \times(37,1) 49,0-43,6 \times 28,3$.

\section{O. sultana, Form meobambensis PFR.}

Taf. XXVIII, Figg. 418/420; Taf. XXIX, Figg. 426/427, 429/430;

Taf. XXX, Fig. 439.

O. trullisatus Shuttlew., Notit., p. 58, Taf. 5, Fig. 1. P., p. 191. PfeIfFER, Monogr. III,

p. 381, als gallina-sultana var. $\beta$; O. meobambensis, ibid. IV, p. 586 . P., p. 191 .

PFEIFFER bezeichnet den Unterschied mit O. sultana wie folgt: ,forma oblonga, textura solidiore, anfractibus convexioribus, columella stricta", und führt 0 . trullisatus SHUTTLEW. als Synonym auf. Ich hatte das in Fig. 429 abgebildete Stück an Herrn EDG. A. Sirth in London zum Tergleich mit dem Typus aus der CuMINGschen Sammlung geschickt, der mir darauf schrieb, daß es in jeder Beziehung übereinstimmend sei. Da dies Stück eine ganz bramne Spindel zeigt und PFEIFFER sie in seiner Beschreibung weiß nennt, so habe ich darüber nochmal angefragt und die Auskunft erhalten, daß die Spindel an den typischen Stïcken auf der unteren Hälfte braun, auf der oberen weiß sei. Ich fand das auch an einem zweiten, 
der Fig. 429 beiliegenden und in Fig. 427 abgebildeten Stiick bestätigt, wie denn dieses Merkmal wechselnd ist. Jedenfalls mub man wohl danach annehmelı, daß PFEIFFER mit Recht die Form trullisatus SHUTTLEW. als Synonym bezeichnet hat, dem in der Beschreibung stimmen beide ïberein bis anf die Farbe der Spindel und die hellen Flecke, welch letztere PFEIFFER offenbar ïbersehen hat, die aber, wie schon gezeigt, kein ausgesprochenes Merkmal gerade dieser Form sind, wenn sie auch bei ihr häufiger vorkommen.

Charakteristisch für die Form meobambensis ist die etwas gestrecktere Gestalt gegenüber dem typischen $O$. sultana, das etwas kiäftigere Gehäuse -sowie die gröbere Skulptur, die im Gegensatz zum typischen O. sultana durch die hänfigeren groben Furchen die Stäbchenskulptur mehr in den Vordergrund stellen, wobei freilich diese Stäbchen immer noch durch die feineren und engeren Furchen zerschmitten bleiben. Dieser Skulpturcharakter hat aber besonders bei den Zwischenformen seine individuellen Abweichmogen, die sich mehr dem O. sultana-Typus nälıern. Die Spindel ist der Form entsprechend etwas länger und weniger eingebogen, bezw. gerader, aber anch hierin kommen Abweichungen vor. Ebenso sind IIundrand und Callus purpurbram, aber zuweilen anch heller gefärbt, sofern man eben die Gestalt allein als typisch betrachtet, wofür die vorhin aufgefïlnten Zwischenformen auch schon Übergänge boten. Es ist eben, wie schon weiter oben gesagt wurde, kein einziges Merkmal durchans beständig. Fuir die Zeichnung künnte nlan, das will ich noch hinzufügen, sagen, dafo Bänder und Zwischenbänder im allgeneinen gleich breit zu sein pflegen, weshalb SHUTTLEWORTH auch fünf Bänder angibt, wobei er das eigentlich 5. Band, welches als breite dunkle Zone die Basis mmzieht, ansläßt. Diese Zone tritt im Immern am Spindelende in lebhafter Färbming heraus und in den Basalrand über, ein Torgang, der bei dem typischen $O$. sultana fehlt. Band 1 fellt ja in der ganzen Gruppe oder es wird duch die breiten und großen Flecke von Band ?, die sich luäufig bis an die Naht ziehen, verdeckt. Aber auch dies Merkmal der Zeichnung ist nicht beständig, wie sich aus den folgenden Aufführumgen zeigen wird.

Ich will hier zum Schluf noch benerkell, daf, wie PILsBRY amimmt, die von ORBIGNY angeführte, in Bolivien gefundene Tarietät wahrscheinlich O. meobambensis sei, und daß damit woll die von STC̈BEL am Rio Tocantins gefundene und von voN MARTENS anfgeführte Tarietät zusammenfalle. Ton der letzteren, die mir vorlieg't, kann ich sagen, daß sie anch zu der engeren Gruppe O. meobrmbensis gehört, wenn sie anch Abweichmoen zeigt.

Iclı werde die Besprechung des Materials mit dell mir als typisch bezeichmeten Stiicken beginnen, die zugleich dem O. trullisatus entsprechen, und dann die Abweichungen anschließen.

1. Koll. SCHolvien. O. meobambensis. Huagabamba, Peru. Zwei Stiiclie. 
Fig. 429. $6-85,8 \times(43,5) 61,0-54,9 \times 35,7$.

"427. $6-81,2 \times(38,0) 52,8-51,8 \times 29,3$.

Die Färbung spielt mehr ins Graubraune hinüber. Die Bänder zeigen nicht den Breitenunterschied gegenüber den Zwischenbändern wie beim typischen $O$. sultana. Es sind viele helle Flecke iiber die letzte Windung verstrent. Bei Fig. 429 ist der Mundrand innen schmal graubraun berandet, der Callus dunkel kastanienbraun, die Spindel hellbraun, ganz oben und nach innen etwas weißlich. Bei der Fig. 427, diesem auffallend schmalen Stïck, ist der Mundrand innen schmal kastanienbraun berandet, der Callus dünn hell kastanienbraun, nach innen sehr dünn werdend, und die Spindel ist weiß, nur unten etwas bräunlich. Die Zeichnung dieses Stückes ist insofern abweichend, als, von der vorletzten Windung beginnend, die ganze Partie zwischen Band 3 und der Naht aus breiten, vorn weiß berandeten Streifen mit winkligen Ausbuchtungen bestelit.

2. Koll. FıLBY. O. meobambensis, Moyobamba, Pert. Zwei Stïcke, ganz ähnlich wie die Fig. 429. Bei purpurbramem Mundrand nnd Callus ist die Spindel bei dem einen Stïck etwas eingebogen und braun, nur oben und innen etwas heller. Bei dem anderen Stück ist die Spindel wie bei dem vorangehenden Stïck gerade, und in der oberen Hälfte weißlich werdend.

3. Koll. ScHOLvIEN. Ohne Fundort, von VON MARTENS O. trullisatus bestimmt. Die Grundfarbe ist hell bräunlichgrau, sonst der Fig. 429 entsprechend. Der Mundrand ist breiter besäumt und wie der Callus purpurbraun. Die Spindel zeigt dieselbe Färbung, nur ganz oben und innen ist sie weiß, dazu schwach eingebogen.

$$
5^{7} / 8-74,3 \times(37,7) 53,8-48,6 \times 30,5 .
$$

4. Berl. Musem. STÜBEL leg. Rio Tocantins, in der Gegend von Baiao, $5 \mathrm{~m}$ über dem Meere, nordöstliches Brasilien (VON MARTENs, Conch. Mitth. II, p. 158). Ein Stück. Es ist sehr dunkel gefürbt, die letzte Windung grünlichgrau, sonst in der Zeichmung wie Fig. 429. Mundrand breit besäumt und purpurbraun wie der Callus. Die Spindel ist dentlich eingebogen, in der oberen Hälfte weiß. Der Wirbel ist ansgebrochen. Fig. 439. ? - 72,0 $\times(38,3) 51,4-48,4 \times 29,6$.

5. Berl. Museum. Mocoa, Nen-Granada. DeIBRICH leg. Nr. 50840. Zwei Stiicke. Die Grundfarbe ist mehr gelblich, die Bänder sind sclmal, die verbreiterten Streifen spärlicher. Dem grofen Stïck fehlen die hellen Flecke, das kleinere dag'egen hat sie. Bei dem großen, mehr entwickelten Stuick ist das Innere violettweiß mit durchscheinender Zeichnung, der Mundrand purpurbram und breit violett in das Innere ausfließend, der Calhus ist purpurbraun, an der Spindel etwas weißlich werdend, die Spindel ist gerade, weiß, nur ganz unten purpurbram.

Fig. 430. $6-78,1 \times(39,9) 56,3-51,9 \times 31,3$. 
6. Berl. Museum. Koll. PAETEL. O. meobambensis (Meobambo?), Noyobamba. Ein Stiick, sehr älnlich der Fig. 427, wemn anch nicht ganz so schlank; aber anch hier geht die breite Zeichnung ron Band 3 bis an die Nalıt. Der Mundrand und Callus sind purpurbram, die Spindel ist in der Nitte etwas eingeknickt und nur oben und innen weißlich.

7. Berl.Musemm. Koll. THIERMAxN. Nr.10375. O.moyobamliensis PFR., Ecuador, mit einem Zettel von VoN MARTENS: „gallina sultana CHEsn. var. gracitior, columella stricta." Zwei Stücke von einer kleineren Form. Grundfarbe anf der letzten Windung zum Teil weißlich, wo die gelbliche Cuticula abgerieben ist, sonst ist die Zeichnung etwas kleinlich, aber typisch. Der Mundrand ist an dem nicht abgebildeten Stïck breit purpurbram berandet, von gleicher Farbe ist bei beiden der Callus. Die Spindel ist der ganzen Länge nach bei beiden Stiicken innen schmal weif berandet, und bei dem abgebildeten Stück in der Mitte etwas eingekuickt, bei dem anderen gerader.

$$
\text { Fig. 426. } \begin{array}{ll} 
& 5^{3 / 4}-62,0 \times(34,0) 41,5-38,9 \times 23,2 . \\
& 51 / 2-59,9 \times(33,0) 42,2-38,9 \times 23,1 .
\end{array}
$$

8. Koll. SoHst. Ohne Fundort. Ein ganz ähnliches jüngeres Stück, in Färbung und Zeichnung wie die vorangehenden der Nr. 7. Der Mundrand ist schmal bram berandet, der Callus dunkelbraun, nach oben dümn werdend, die Spindel ist gerade, steht schräg zur Achse und ist hellbramn gefärbt. Die brame Basalzone in Innern ist schmal und hell.

Fig. $420 . \quad 5 \% / 8-51,2 \times(28,2) 35,1-32,7 \times 18,9$.

9. Koll. H. DoHrN. Tom Rio Ucayali in der Nähe vom Fundort des Pfeifferschen 'Typus. O. meobambensis. Tier Stïcke, die sehr verschieden sind.

a) Ein Stiick, typisch in der Skulptur, Färbung und Zeichmung, aber olne die hellen Flecke. Der Mundrand ist unfertig, daher woll farblos, der Callus ist dunkel kastanienbraun, nach innen zu dïmner und heller werdend. Die Spindel ist etwas eingebogen, weiß, in der Mitte breit und beiderseits schmäler werdend, das mntere Drittel ist bram. Das Imnere ist bläulichweiß nit schwach durchscheinender Zeichnung und an der Basis mit der purpurbraun ausmündenden Zone. Ich bilde nur die Spindelpartie al.

Fig. 418. $\quad 6 \frac{1}{4}-86,0 \times(44,0) 61,7-57,6 \times 36,0$.

b) Ein Stïck, ganz ähnlich, nur ist die Färbung heller, melı gelblich, nnd das Innere ist mit einer nur dïnnen, weißlichen Schmelzschicht belegt.

$$
6-72,0 \times(32,7) 49,7-45,5 \times 29,2 \text {. }
$$

c) Ein Stiick. In Färbumg und Zeichmung wie das erste Stïck, abel mit einzelnen hellen Flecken. Der Mundrand ist purpurbraun berandet, von gleicher Farbe ist der Callus und die ausniundende Basalzone. Die Spindel ist gerade, miten etwas eingeknickt mo purpurbram, oben nach 
innen zu weißlich. Das Innere ist mit einer dünneren weißen Schmelzschicht belegt, daher die Zeichnung durchscheinender.

$$
53 / 4-79,1 \times(42,2) 61,3-53,3 \times 34,5 \text {. }
$$

d) Dies Stiuck ist gestreckter in der Form, hell graubraun im Grundton mit nur wenigen verbreiterten Streifen oberhalb Band 2 im Anfang der letzten Windung, dann kommen schmale etwas dunklere Streifen als der Grundton, die an Stelle von Band 2a, 3, 3a winklig ausbiegen, Band 4 ist dentlicher gegliedert. Auf der letzten Hälfte der letzten Windung hören die schmalen Streifen ganz auf, bezw. sie fließen zusammen, dafïr treten Band 2a, 3, 3a, 4 deutlicher und nur wenig unterbrochen hervor. Mundrand, Callus und Inneres verhalten sich wie bei dem vorangehenden Stiick. Die Spindel ist in sich gerade und steht schräge zur Achse, sie ist unten dunkel, oben heller bis weiß gefärbt.

Fig. $419 . \quad 6^{1 / 3}-79,7 \times(38,4) 52,8-51,5 \times 29,1$.

10. UirlaufF ded. Insel Trinidad. Ein junges Stïck, offenbar angeschwemmt, ähnlich denen vom Murri-Tal in Färbung und Zeichnung, aber der Callus ist dün und braun und die Spindel ist weiß, gerade und stelit senkrecht zur Achse.

$$
5-43,3 \times(25,6) 34,2-30,5 \times 18,6 .
$$

\section{O. sultana, Form meobambensis var. carnea n. v.}

Taf. XXIX, Fig. 428.

Berl. Museum. Koll. AlBERs. Ein CuMirgsches Stïck. O. trullisatus SHUTTLEW. Meobamba. Im Innern liegt ein Zettel mit der Bemerkung "This shell cost me a guinea".

Dies sebr schmale Stiick hat einen fleischfarbigen, zuletzt melır ins Graue übergehenden hellen Grundton, von dem sich die dunkelbraun und weiß gegliederten Bänder 2, 3 sehr lebhaft abheben, zumal die Zeichnung fast ausschließlich aus schmalen Streifen besteht; nur dicht an der Naht erkennt man noch den Anfang einer Fleckenzone, die sich beim typischen O. sultana ja bis Band 2, aus immer breiter werdenden Flecken bestehend, herabzieht. Band 2a besteht ans etwas stärker betonten, aber nicht mit hell abwechselnden winkligen Flecken, Band 3a und das breitere Band 4 verhalten sich ebenso, Band 5 ist eine breitere Zone um die Basis, die aber nicht im Innern bemerkbar ist. Die letzte Windung, wo die schmalen Streifen zusammenfließen, ist mit hellen Flecken übersät. Das Innere ist weißlich mit durchscheinender Zeichnung, der Mundsaum ist außen und innen schmal hellbraun berandet, und ebenso ist der Callus gefärbt. Die Spindel ist ein wenig eingebogen und weiß. 


\section{B. Subgenus Clathrorthaticus n. suby.}

Gehäuse dümnschalig, oval-konisch, matt seidenglänzend, mit $4 \frac{3}{4}$ rasch an Höhe zunelımenden, wenig gewölbten Windungen, deren letzte bedeutend höher als das Gewinde ist. Mündung oval, oben zugespitzt, verhältnismäßig groß und hoch. Mundrand nach unten erweitert und zunelimend, aber nicht breit, flach umgeschlagen, der Basalrand geht etwas rechtwinklig gebogen in die dünne weiße, etwas eingebogene Spindel über. Das Embryonalgewinde (Fig. 348) hat $2 \frac{1}{2}$ einfarbige, hell rosa Windungen, die anfangs oben etwas kantig, dann wenig gewölbt sind. Sie sind mit äußerst feinen Griibchen bedeckt, die in schräge sich kreuzenden Reihen geordnet sind, was aber nur in gewisser, wechselnder Belichtung erkennbar ist, denn unter gewöhnlicher Lupe erscheinen sie eher in der senkrechten Richtung geordnet.

Die Skulptur besteht ans sehr feinen scharfen Falten, die allmählich kräftiger, wenn anch nie breit werden und die meistens bis an die Naht durchgehen. Die feinere Spiralskulptur ist mur ganz vereinzelt zu erkennen, dagegen treten, immer schärfer ansgeprägt werdend, gröbere Furchen in unregelmäßig breiten Zwischenräumen auf, welche die Falten in Stäbchen zerlegen.

\section{Hallisi n. sp.}

Taf. XXII, Figg. 348, 354.

Die obige Diagnose gilt zugleich für die einzige Art, der ich $u m$ so melı den Namen des verdienten Sammlers gebe, als der Bul. wallisi Mousson ja dem ersten Namen $B$. iris PFR. weichen mußte, welche Art außerdem zu Hemibulimus gehört.

Ergänzend zux Diagnose füge ich noch folgendes linzu. Die ersten $3 \frac{1}{2}$ Windungen erscheinen hell rosa gefärbt, dann tritt zunehmend die gelbe Cuticula und mit ihr zugleich die graubraune, in ziemlich gleichmäßigen Streifen geordnete Zeichnung anf, die mit schmalen Streifen der Grundfarbe abwechseln und von zwei Binden der Grundfarbe durclkreuzt werden, welche ungefähr den Bänder’n ¿2, 3 entsprechen dürften. Unterhalb Band :3 wird die gerade Linie der Streifen mehrfach miterbrochen, sie biegen entweder etwas winklig aus oder sie verschieben sich auch in der Richtung. An dem jüngeren Stiick treten stellenweise solche Ausbiegungen und Tersetzungen schon vou der Naht ab auf. Der Mundrand ist nach unten zu hell rosa angehaucht, das Innere ist nur mit einer schwachen weißen Schmelzschicht belegt, mit lebhaft durchscheinender Zeichnung, die hier aber aus bramen und weißen Streifen zusammengesetzt erscheint. Der Callus ist dunkelbraum, nach innen zu heller werdend. 
Fig. 354. $\quad 4 \frac{3}{4}-53,0 \times(22,9) 34,0-34,6 \times 19,0$.

$4 \frac{1}{2}-47,8 \times(20,4) 27,7-30,7 \times 16,3$.

WALLIS leg. Cordillera de las Juntas $10000^{\prime}$, westlich von Frontino. In Koll. O. SEMPER und H. STREBEL je ein Stïck.

Es scheint fast, als ob von dieser schönen Art nur diese zwei Stïcke bekannt geworden sind. Ton ihrer gegitterten Zeichnung habe ich den Namen der Untergattung abgeleitet.

Es ist walu'scheinlich, daß Bul. victor PFR., Novit. II, p. 169, Taf. 46, Figg. 1, 2, den PILsBRy als fraglich unter Porphyrobaphe, Gruppe dennisoni, aufführt, in diese Untergattung gehört. Der Typus in der CuMINGschen Sammlung stammt aus der Proviuz Antioquia, Neu-Granada. Die Skulptur mit den kaum unter der Lupe bemerklichen Spiralriefchen stimmt nicht, ebensowenig die Zeichnung zu meiner Art, aber die Form und Textur bietet große Ähnlichkeit. Weun ANCEY in Nautilus, Vol. 17, p. 90, sagt, P. victor PFR. sei gleich $P$. augusti Jouss., so irrt er; clenn diese Art gehört zu T. fraseri.

\section{Subgenus Trachyorthalicus n. subg.}

Gehäuse fest- aber nicht besonders dickschalig, matt seidenglänzend, oval-spindelförmig mit $5 \frac{1}{2}$ bis 6 wenig gewölbten Windungen, deren letzte höher ist als das Gewinde. Mündung oval, oben zugespitzt oder annähernd verkehrt ohrförmig, je nachdem der Spindelansatz mit der Windungswand einen mehr weniger deutlichen stumpfen Winkel bildet. Mundrand nach unten erweitert und mehr weniger breit umgeschlagen; der Basalrand geht fast rechtwinklig in das Spindelende über. Die Spindel ist oben etwas zurückweichend, etwas eingebogen und mehr weniger gewunden, in der typischen Form oben mit einer verdickten Falte und unten mit einer etwas knotigen Terdickung versehen.

Das Embryonalgewinde (Fig. 345) hat 21/2, zuerst oben schwach stumpfkantige, dlann wenig gewölbte Windungen, die mit feineren oder gröberen, schräge sich krenzenden Reihen von Grübchen bedeckt sind. Von der zweiten Windung an tritt an der Naht eine aus braunen und weißlichen rhombischen Flecken gegliederte Zone auf, die braimen Flecke gehen dann bald in die schmäleren oder breiteren Streifen der späteren Zeichnung über.

Die Skulptur besteht aus feinen, besonders anfangs scliarfen Falten, deren ab und zu etwa zwei sich zu gröberen Falten zusammenschließen, was in der Nahtnähe immer stattfindet und dort am schärfsten ausgeprägt ist. Zuweilen werden die Falten auf der letzten Windung obsoleter. Die feinere Spiralskulptur ist nur stellenweise schwach erkennbar, dagegen treten in umregelmäßigen aber weiteren Zwischenräumen gröbere Furchen auf, welche die Falten in Stäbchen zerlegen. 


\section{T. froseri PFR.}

Taf. XXII, Fig. 345; Taf. XXX, Figg. 431, 434.

P., 193, Taf. 46, Figg. 31/33.

Die mir vorliegenden wenigen typischen Stïcke dieser Art haben eine bräunlichgelbe Grumdfarbe, die bej einem der Stïcke zuletzt einen etwas olivenfarbigen Anflug bekommt. Die Zeichnung ist zuerst kastanienbraun, dann fast schwarz werdend, sie besteht anfangs ans schmalen Streifen, die an Stelle von Band 2, 2a, 3 (anch hier tritt ein Zwischenband auf) stärker getont winklig vorspringen. Bald treten dazwischen breitere, ebenfalls an Stelle der Bänder, winklig vorspringende Streifen auf, doch können diese breiteren Streifen auch fast ganz fehlen (Fig. 434). Auf der letzten Windung ist, wie anch aus den Abbildungen der Proceeding: und Novitates hervorgeht (die in PILSBRY nicht gut in der Färbung wiedergegeben sind), nur Band 2, 3, 4, 5, letztere beiden breiter als 2, 3 vorhanden, die hier an sich ein wenig heller als die Grundfarbe sind, so daß die nach vorn zugespitzten oder nur schräg verlaufenden Streifen (Band 5) vorn etwas heller gesäumt erscheinen. Am Gewinde sind die Bänder meist nur durch die winkligen Torsprïnge angedentet. (Bei Pfeiffers Typus in Proc. L. Z. S. Pl. 51, Fig. 5, sind am Gewinde die Bänder anch schon heller und anch die enger zusammengeschobene Pfeilspitzenzeichnung ist dentlicher.) Auf der letzten Windung treten sie dagegen deutlicher als Bänder anf, besonder's die Bänder 3, 4, 5, doch können sie auch ganz fehlen, und statt ihrer dunklere Zonen auftreten (Fig. 434), diese Varietät könnte man luteus nennen.

Die vorangehende Beschreibung der Färbung und Zeichnung entspricht nur den beiden einzigen mir vorliegenden Stïcken der typischen Form, soweit diese durclı die Form des Gehäuses charakterisiert ist, deren Gewinde gleich hoch oder nur sehr wenig niedriger als die letzte Windung ist (in der idealen Achse gemessen), während es bei der Form brevispisa entschieden niedriger ist, wobei zugleich die Windungen etwas rascher an 'Breite zunehmen. Die Zeichnung und die Fürbung des Mundrandes, des Tnner'n und der Spindel sowie die Form der letzteren sind aber bei den mir vorliegenden Stücken insofern von einander abweichend, als neben dem typischen Stück 1 a sich die oben erwähnte var. luteus befindet, die wohl als eine heterom. xanthus anfzufassen ist.

1. SOWERBY und Fulton vend. Ecuador. Buckley leg. Zwei Stiicke.

a) Ein Stück, annälıernd typisch in Färbung und Zeichmung sowie in der Form der lebhaft violetten Spindel, die oben mit einer weißlichen faltenartigen, unten mit einer etwas knotenartigen Terdickmng versehen ist. Das Innere ist weiß mit schwach durchschimmernder Zeichnnng, die am breit umgeschlagenen Mundsaum in deutlich hellviolette Spiralzonen 
ausmündet, die den Bändern 2, 3, 4, 5 entsprechen, aber besonders oben breiter sind als sie auf der Aubenseite erscheinen. Der Callus ist nicht sehr stark, violett, mit durchscheinender Zeichnung.

Fig. 431. $6-73,5 \times(31,6) 42,7-44,1 \times 20,7$.

b) Ein Stïck, var. luteus, das in jeder Beziehung sehr abweichend ist. $\mathrm{Ob}$ es in derselben Lokalität gefunden wurde wie das vorangehende, muß dahingestellt bleiben. Die Zeichnung der obersten Windungen ist die typische, die damn folgenden schmalen, braunen und an Stelle der Bänder 2, 2a, 3 etwas ausbiegenden Streifen, setzten sich bis zum ersten Viertel der letzten Windung fort, und nur an ein paar Stellen treten etwas breitere dunklere Streifen auf, dann werden die Streifen gerade im Verlauf und seltener, nur zuletzt mehren sie sich wieder. Schon gegen Ende der vorletzten Windung, besonders dentlich auf der letzten Windung; treten etwas dunklere Zonen als die Grundfarbe auf, die ungefähr den Bändern 2, 3, 4, 5 entsprechen. Die Basis ist mit einer schmalen dunkelbraunen Zone umsäumt. Das Innere ist weißlich mit schwacher Audeutung der äußeren Zonen in einer etwas schmutzig, violett angehauchten Färbung, während der Mindrand rein weiß und etwas schmäler umgeschlagen als beim vorangehenden Stück ist. Der Basalrand bildet mit dem Spindelende einen scharfen Winkel, der innere Kontur der rein weißen Spindel erscheint oberhalb der Mitte etwas eingeknickt, von da nach oben befindet sich die faltenartige Verdickung, die aber schwächer als beim vorangehenden Stück ist, die knotenartige Verdickung unten fehlt. Der Callus ist rein weiß und nicht sehr dick.

Fig. 434 . ca. $6-72,3 \times(28,1) 37,4-40,9 \times 19,1$.

2. Berl. Museum. Koll. PaETEL. Ecuador. P. fraseri. Ein ganz abgeriebenes Stïck, über dessen Zeichnung sich nicht mehr viel sagen läßt, nur sind die ersten Windungen (der Wirbel ist ausgebrochen) oben mit einer dunkelbraunen Zone reisehen. Mundrand, Inneres, Spindel und Callus sind rein weif, die Spindel hat oben die verdickte Falte, unten ist sie mur etwas angeschwollen, nicht knotenförmig verdickt.

$$
?-74,0 \times(30,4) 42,1-44,0 \times 21,3 \text {. }
$$

\section{T. fraseri, Form brevispira PILSB.}

Taf. XXIX, Figg. 423/425; Taf. XXX, Fig. 432.

\section{P., p. 194, Taf. 46, Figg. 34/35.}

Wenn ich nur die durch den Namen und die Abbildung bezeichnete Form des Gehäuses zugrunde lege, liegen mir mehrere Stïcke vor, die dann aber eine Abänderung der PLSBRYschen Beschreibung notwendig machen. Vor allen Dingen befindet sich darunter kein Stïck, welches auch unten die knotenförmige Verdickung der Spindel zeigt, wie sie bei 
der tỵischen Form und bei der var. brexispira P., Fig. 35, vorhanden ist. Außerdem ist die Spindel bei keinem meiner stiicke riolett, sondern ïbereinstimmend mit dem Mundrande entweder rein weif oder rosa. Die Färbung und Zeichnung sind im allgemeinen entsprechend, nicht nur der der Figg. 34/35, sondern auch der des Typus, doch zeigt sich bei mehreren stïcken besonders anf der letzten Windung, daß das am Gewinde noch isolierte, durch winklige Vorsprünge angedentete Band 2 a mit dem Band 3 zusammenfällt und vorn gewölbte oder in der Mitte etwas eingekerbte starke Terbreitermng der Streifen bildet, wobei zugleich gleiche Verbreiterungen sich von Band 2 bis fast an die Naht ziehen. In gleicher Weise sind dam Band 4 und 5 gekemzeichnet, so daß auf der letzten Windmog vier breite Zonen entstehen, die ans breiten, hinten graden, vorn ausgebogenen oder gekerbten Flecken bestehen, die vorn hell berandet sind, eine Zeichnmo. die oft an M. Relletti erinnert.

Andererseits tritt anch hier eine gleiche Varietät fast olme Zeichnmmg auf, wie sie bei der typischen Form unter $1 \mathrm{~b}$ geschildert wurde, die ich mit in: modestus bezeichne, die aber anch wie jene als heterom. xanthus aufzufassen sein dürfte. Die Sknlptur ist wohl etwas gröber als bei der Stammform.

1. Koll. Schouvien, Porphyrobapherictor bestimmt, olne Fundort. Ein Stiick mit der oben beschriebenen Art der Zeichnmng der vier breitfleckigen Zonen. Der nicht sehr breit umgeschlagene Mundrand, wie die spindel und der Callus sind rosa gefärbt. Die Spindel stelıt fast senkrecht zur Achse, weicht oben zurück und ist in sich gewunden, wenn anch ihr Innenkontur fast gerade erscheint.

Fig. $423 . \quad 5^{5} / 8-70,7 \times(29.2) 39,7-44.7 \times 21,9$.

2. Koll. Scholvtex. P. firaseri. Eeuador. Ein Stïck. Die Zeichnung nähert sich mehr der des typischen fraseri insofern, als Band 2 noch bis zuletzt aus pfeilförmigen, vorn hell berandeten schmalen Flecken besteht. Die verbreiterten Flecken von Band 3, 4, 5 treten seltener anf. Mundrand. Spindel und Callus sind rein weiß. Die Spindel ist wie bei dem vorangehenden Stïck gebildet, nur nach unten etwas an- mond abschwellend verdickt, was am dentlichsten in der Seitenansicht sichtbar wird.

Fig. 425. $\quad 5 \frac{1}{2}-62,0 \times(25,7) 36,2-38,0 \times 17,9$.

3. Koll. DoHrs. Drei Stücke. Loja, Ecuador. Davon entsprechen zwei durchans den vorangehenden beiden in Färbung und Zeichnung, nur zeigen beide Stücke das Innere mit einer dümneren Schmelzschicht belegt, so daßf die Zeichmmg lebhaft durchscheint, was nur bei dem sub 1 verzeichneten Stück der Fall ist. Andererseits zeigt das zweite Stiick, das dem sub 2 in der Zeichmmng gleich ist, auch den weißen Mundrand, dabei aber eine vom unteren 'Teil der Spindel bis ïber den Callus sich erstreckende rötlich violette Färbung. Auf der Spinde] 
zieht sich eine schräge schmale Falte bis auf die Mitte des unteren Teils der Spindel, weshalb ich nur diese Partie des Stückes abbilde.

$$
5 \%-66,7 \times(28,5) 39,1-42,8 \times 21,4 \text {. }
$$

Fig. 424. ca. $5 \frac{1}{2}-67,0 \times(27,8) 37,0-41,7 \times 18,1$.

Das dritte Stïck var. modestus gehört der Form nach hierher, zeigt aber Färbung und Zeichnung wie T. fraseri $\mathrm{Nr} .1 \mathrm{~b}$, mit dem es auch die Spindelbildung gemeinsam hat. Sie, wie Mundrand, Callus und Inneres sind rein weiß, letzteres nur anfangs, im Schlund blä̈ulichgrau werdend.

Fig. 432. $6-73,2 \times(31,0) 42,8-43,5 \times 21,0$.

\section{T. fraseri, Form perplexus n. $f$. \\ Tat. XXX, Fig. 433.}

Dieses merkwürdige Stück, welches zusammen mit den drei vorangehenden Stïcken der DoHRxschen Sammlung liegt, wird in der Zeichnımg dem M. kelletti noch ähnlicher. während es der Form und besonders der Form der Mündıng nach hierher gehört. Die erste Windung ist schmntzig weiß, oben mit einer schwarzbramen Zone versehen (vergl. T. fraseri Nr. 2), dann wird der untere Teil bis zum Ende des Embryonalgewindes hell rotbraun, und nach $1 \frac{3}{4}$ Windungen wird die dunkle Zone von weißlichen Flecken unterbrochen, die dann allmählich in die gelblichen Streifen ïbergehen, welche die dunklen Streifen nach vorn beranden. Die Zeichnung wird dann im Prinzip dieselbe wie beim typischen T. fraseri bezw. der Form brevispisa, nur treten schon bei $3 \%{ }_{4}$ Windungen am Gewinde die zwei, auf den letzten Windungen die vier breiten Zonen von unregelmäßigen braunschwarzen Verbreiterungen auf, welche durch schmale Streifen miteinander verbunden werden. Die Grundfarbe ist die typische bräunlichgelbe.

Die Form des Gehäuses ist klein und besonders schmal. Mundrand, Spindel und Callus sind rein weiß, das Innere nach innen zu etwas bläulichgrau. Die Spindel zeigt nur oben eine schmale, ziemlich scharfe Falte.

Fig. 433. $\quad 5^{1 / 4}-60,2 \times(23,7) 32,6-35,3 \times 15,8$.

Ich muf es dahingestellt sein lassen, ob dies Stück nur als eine Varietät oder etwa als eine lokalisierte Form anzusehen ist.

\section{T. cuegusti JOUSSEAUNE.}

P., p. 195, Taf. 44, Fig. 20.

Es scheint mir mit PILSBRY wahrscheinlich, daß diese Art hierher gehört, zumal wenn man die weiter vorn erörterte var. luteus berücksichtigt und die meist bei der Form brevispira auftretende Spindel. 


\section{Subgenus MLetorthaticus PILSB.}

Trie ich schon in der Einleitung zu dieser Abteilung südamerikanischer Arten bemerkte, ist die ron PILSBRT gegebene Diagnose dieser Untergattung nur sehr kurz, wie das anch nicht anders möglich ist, da sie sehr Terschiedenartiges mmfaßt. PILSBRY hilft sich damn damit, daß er diese Untergattung in rerschiedene Gruppen teilt, die ich zum Teil ihrer ausgesprochenen Verschiedenheit halber zu Untergattungen erhebe. Da, wie schon bemerkt, PILsBrr keinen Typus für diese Untergattung aufstellt, ihn auch nicht aufstellen konnte, so habe ich, da der Name an sich indifferent ist, ihn nur für einen Teil der Arten gewählt, die PILSBRI in diese Untergattung bringt, die dann aber wieder in verschiedene Gruppen gebracht sind, deren jede mit einer Diagnose versehen wird. Eine allgemeine Diagnose der Untergattung scheint mir keinen Zweck zu haben, da sie sich nm auf wenige allgemeine und nichtssagende Angaben beschränken müßte, mit denen für eine Klassifikation nichts anzufangen wäre.

\section{a) Gruppe M. maramhonensis.}

Gehänse ziemlich starkschalig, schwach fettglänzend, oval-konisch mit $6 \frac{1}{2}$ durch eine schmal berandete Naht getrennten, wenig gewölbten Windungen, deren letzte kürzer ist als das Gewinde. Nündung verkehrt ohrförmig, Mundrand nach unten erweitert und etwas flach umgeschlagen, der Basalrand geht in einem tiefen Bogen in die sehr kurze, schräg zur Achse stehende, gewminene und verdickte Spindel über, deren Ende nach außen einen stumpfen Winkel mit dem Basalrand bildet, was, nebenbei gesagt, in den Abbildungen der Novitates I, Taf. XI, Figg. 11/12, ebensowenig zum Ausdruck kommt, wie die Färbung und Zeichmung.

Das Embryonalgewinde (Fig. 340) hat $2 \frac{1}{2}$ wenig gewölbte Windungen, die mit schräg sich kreuzenden Reihen ron Grübchen bedeckt sind. Gegen das Fnde treten etwas unregelmäßige, weitläufig stehende braune Streifen auf.

Die Skulptur besteht ans schmalen feinen Falten, die, wie es scheint, zum Teil in einzelne gröbere zusammengefaßt sind, besonders am Gewinde, aber auf der letzten Windung scheinen sie mehr einzeln an die Naht zu gehen, wem auch ab und zu einige stärker ansgeprägt erscheinen; im ganzen sind hier aber die Falten wenig scharf ansgeprägt. Dagegen sind die überaus feinen, etwas voneinander getremnten Spirahreihen dentlicher, die einen etwas gewellten Terlauf nehmen.

\section{H. manahomensis ALBERS.}

Taf. XXI, Fig. 340; Taf. XXXI, Fig. 449.

P., p. 198, Taf. 41, Figg. 3/4. Kopie aus den Novitates.

Diese einzige hierher gehörige Art hat eine oberflächliche Ähnlichkeit mit Puchytholus flori, aber For'm und Skulptur des Embryonalgewindes sind rerschieden. 
Die Färbung ist oben weißlich, dann wird sie hellbrämnlich, zuletzt mehr ins Violettgrane iibergehend. Von der vorvorletzten Windung an ist der Teil von etwa der Stelle von Band 2 bis zur Naht heller gefärbt als der untere. Bänder sind nicht vorhanden, nur Streifen und etwas wolkige Flecke, dazu viele schwärzliche runde Flecke, die nach vorn einen weißlichen Wischer in der Spiralrichtung haben. Die Streifen zeigen auf den oberen Windungen Verbreiterungen und winklige Vorsprünge, zuletzt werden sie einfach. Diese Zeichnmmg und Färbung ist, trotzdem PFEIFFER classelbe Stïck ans der ALBERsschen Sammlung vorlag, in seiner Beschreibung und Abbildung schleclit wiedergegeben.

Das Innere ist bläulichgrau, der Mundrand ist leberfarbig, am Basalrand plötzlich weißlich, auch die Spindel wie das Innere des Callus sind bräunlich angehaucht, letzterer außen weißlich aber dünn verdickt.

Fig. $440 . \quad 6 \frac{1}{2}-74,0 \times(30,0) 39,3-35,2 \times 18,2$.

\section{b) Gruppe Mr. shuttleworthi ALB.}

Gehäuse ziemlich starkschalig, schwach fettglänzend, oval-konisch mit 6 schwach gewölbten und durch eine schmal berandete Naht getremnte Windungen, deren letzte etwas kürzer als das Gewinde ist. Mündung verkehrt ohrförmig, Mundrand breit flach, nach rückwärts auch verhältnismäßig breit umgeschlagen, der Basalrand setzt sich etwas winklig von der ziemlich senkrecht stehenden Spindel ab, die dick ist, oben eine Falte trägt und unten schwach angeschwollen ist.

Das Embryonalgewinde (Fig. 342) hat 21/2 wenig gewölbte Windungen, die mit selır feinen, nicht ganz regelmäßig gereihten Grübchen bedeckt sind; so daß deren wulstige Ränder besonders am oberen Teil der Windung unter starker Lupe etwas unregelmäßig maschenartig verlaufen.

Die Skulptur ist, was die Falten anbelangt, ähnlich wie bei der vorangeheuden Gruppe, aber zuletzt noch obsoleter, dazu kommen auf den beiden letzten Windungen hammerschlagartige Eindrïcke und kurze Auftreibungen in der Spiralrichtung. Ton feinerer Spiralskulptur sind kaum Andeutungen vorhanden, nur ab und zil treten auf den letzten Windungen kurze gröbere Furchen und stellenweise eine Stäbchenskulptur auf.

\section{H. shuttleworthi ALBERS.}

Taf. XXI, Fig. 342; Taf. XXX, Figg. 437, 440.

P., p. 201, Taf. 41, Figg. 1/2.

Die einzige sicher hierher gehörige Art, die schon etwas in die Gruppe M. yatesi hinüberspielt, ist oben weißlich, zuletzt mit einer schmutzig gelblichen Cuticula bekleidet. Zuerst treten rötlichbrame Streifen auf, 
die allmählich in die Zickzackform ïbergehen, wobei sie auf den beiden letzten Windungen in bräunlichgraner Färbung, zuerst weit ausholend, damı nach unten zu gestreckt, in sehr schräger Richtung nach vorn verlaufen. Das Innere ist weißlich, der Mundrand, die Spindel und der Callus sind schwach rötlich angehaucht.

1. Berl. Museum. Koll. ALBERs. Nr. 544. Columbien ad fluv. Maranhon. WARSEWICZ. Ein Stïck.

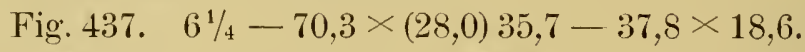

2. Berl. Musenm. Koll. PAETEL. Maranhon. Ein Stïck, ohme die gelbe Cuticula und etwas schmäler.

$$
\text { Fig. 440. ca. } 6-68,0 \times(26,2) 34,6-36,8 \times 17,8 \text {. }
$$

\section{Wresniousliii LUBOMIRSKI.}

P., p. 198, Taf. 42, Figg. 7/8.

PILSBRY stellt diese Art zwischen M. debughicie und maranhonensis. Ich kamm nach der ungenïgenden Beschreibung nicht bemteilen, wohin sie gehört, der Form und der Zeichnmo nach bringe ich sie hierher.

\section{c) Gruple M. lielletti ReEve.}

Gehäuse selten linksgewumden, zicmlich starkschalig, ziemlich glänzend, oval-konisch mit $5 \frac{1}{2}-5^{3 / 4}$ mäßig gewölbten Windungen, die durch eine schmal angepreßte, stellenweise auch wulstig berandete Naht getrennt werden, und deren letzte meistens etwas höher als das Gewinde ist. Die Nündung ist verkehrt ohrförmig, der Mundrand besonders nach unten zu erweitert, mehr weniger stark, oft schichtenweise verdickt und kur\% umgeschlagen. Der Basalıand geht mehr weniger deutlich winklig in die mehr weniger gewnulene, meist schräge, selten gerade zur Achse stehende spindel ïber. Charakteristisch ist, worauf schon DoHRN in Jahrbïcher, vol. 9, 1. 112/114, aufmerksam macht, dab sich an der Basis auben. hinter der Spindelschwicle, eine glanzlose Ablagermng von schalensubstanz befindet von meist halbmondförmiger Form, die in der Anwuchsrichtung geschichtet ist und sich damm meistens noch hinter dem umgeschlagenen Teil des Mundrandes schmal nach oben zieht.

Das Embryonalgewinde (Fig. 343) hat 2/4-21/2 wenig gewölbte Windungen, die mit sich schräg kreuzenden Reihen von Grïbchen bedeckt sind, und die gegen das Ende meistens schon schräge, etwas abgestufte braune Streifen zeigen. Ganz ausnahmsweise kommen sonst nicht abweichende Stịcke vor, an denen von Anfang an sich eine schwärzliche Zone an der Naht befindet, die gegen das Ende zwischen den bramen Streifen weifliche entsprechende streifen zeigt, ein Vorgang, der sich damn noch eine Strecke weit später fortsetzt. 
Die Skulptur besteht besonders deutlich auf den mittleren WVindungen aus feinen Falten, davon meist zwei zu gröberen Falten zusammengefaßt sind. Zuweilen bleiben 2--3 Falten dazwischen vereinzelt, wodurch dann das Gehäuse ein gereiftes Aussehen bekommt. Im allgemeinen sind die Falten auf der letzten Windung schwächer ausgeprägt. Die feinere Spiralskulptur ist nur ganz vereinzelt zu erkennen, stellenweise treten kurze gröbere Spiralfurchen auf, und mit ihnen eine undeutliche Stäbchenskulptur; auch hammerschlagartige Eindrücke kommen vor.

\section{Relletti REEVE.}

Taf. XXI, Fig. 343; Taf. XXXI, Figg. 441/442, 444/446, 448. DOHRN 1. c. P., p. 204, Taf. 45, Figg. 23/28. M. fungairinoi HID. als Varietät.

DOHRN hat die Veränderlichkeit dieser Art l. c. eingehend besprochen und auch nachgewiesen, daf M. fungaiminoi HIDALGO dazu gehört. Auch PILSBRY ergänzt die REEvEsche Beschreibung in ihrer wechselnden Färbung und Zeichnung; so daß ich nu wenig Ergänzendes hinzuzufügen habe.

Unter dem sehr reichhaltigen, mir vorliegenden Material befindet sich kein einziges Stück, das dieselbe gleichmäßige Breite der vier Bänder wie die ReEvesche Figur zeigt, immer ist das obere Band das schmälste, die anderen drei sind unter sich ungefähr gleich breit, doch sind häufig; wie schon DOHRN bemerkt, das 3. und 4. Band miteinander verschmolzen, wenn anch die Einbiegung der hellen Streifen der Grundfarbe die Tremung markiert. Es können aber auch alle Bänder fast ganz zusammenfließen, wie es Fig. 446 zeigt. Andererseits gebe ich in Fig. 442 ein Stiick wieder, das bis zmm Anfang der letzten Windung gar kein Band zeigt, damn ist das 2. Band sehr schmal, wie sonst das erste Band beschaffen ist, Band 3 ist breiter, aber anch schmal, und Band 4 nur sehr undentlich ausgeprägt. Auch ein gänzliches Fehlen der Bändler bezw. der typischen Zeichmung ist in der Fig. 450 dargestellt, eine Parallelerscheinung mit dem gleichen Vorkommen bei T.fraserivar.luteus und moclestus. Das einzige links gewundene, sonst durchaus typische Stück ist in Fig. 448 dargestellt. Im übrigen habe ich nur noch einige Abweichungen in der Form abgebildet, welche die zitierten Abbildungen ergänzen mögen, wie es andererseits durch die Maßlisten geschieht.

1. Koll. Strebel. GEale vend. Malacates, Ecuador. 13 Stïcke. alle mit fertigem bräunlichrosa Nundrand, der nach innen dunkler rotbraun, mehr weniger breit ausfliebt. Ich bilde in Fig. 441 ein anffallend schmales, großes, in Fig. 442 ein ebensolches kleineres Stïck ab, das ich seiner auffallenden Zeichnung halber oben schon erwälnte. Die ersten vier Windungen sind der Cuticnla entkleidet und fast olne Zeichnung, rosagrau gefärbt. In den anderen beiden Stücken der Maßliste, die 
typisch gefärbt und gezeichnet sind, verzeichne ich das größte und das kleinste Stïck.

$$
\begin{array}{cl}
\text { Fig. 441. } & 51 / 2-72,6 \times(26,7) 36,8-39,4 \times 17.5 . \\
.442 . & 5^{5} / 8-62,0 \times(23,2) 29,7-34,3 \times 15,1 . \\
& 51 / 2-75,8 \times(31,2) 41,7-43,3 \times 19,7 . \\
& 5^{1 / 4}-57.5 \times(22,1) 28,8-31,6 \times 15,5 .
\end{array}
$$

2. Rolle rend. Quito. Ein typisches Stück.

3. Koll. O. Semper. Wablis leg. Nabon bei Cuenca. Drei Stïcke, davon zwei trpisch und eins, das erste der Maßliste, das ron oben an zuerst blaß, dann intensiver hell olivenfarbig ist; die Bänder auf der letzten Windung sind nicht, wie ïblich, dunkelbraun oder schwärzlich, sondern ebenso gefärbt wie das übrige, nur etwas dunkler. Der Mundrand ist an diesem Stück verhältnismäßig wenig verdickt, nnd die Spindel ebenso und wenig gewunden.

$$
\begin{aligned}
& 5 \% \frac{1}{4}-66,4 \times(28,6) 37,2-37,2 \times 19,7 . \\
& 51 / 2-68,3 \times(27,4) 36,4-38,8 \times 18,3 . \\
& 51 / 2-59,2 \times(26,2) 33,2-33,7 \times 16.6 .
\end{aligned}
$$

4. Rolle rend. Ecuador. Drei Stücke. Das erste der Maßliste hat eine dem REEveschen Typus von kelletti ähnliche Färbung und Zeichnung, nur ist das obere Band schmäler als die anderen drei. Das zweite abgebildete Stück hat die helle blänlichgraue Färbung der Bänder und den helleren Grundton mit leicht violettem Anfluge. Hier fließen die Bänder zusammen, und nur Band 1 und 2 markieren sich schwach durch etwas dunklere Färbmug. Das dritte Stïck ist typisch.

$$
5 \frac{1}{2}-58,2 \times(24,1) 30,0-30,7 \times 15,5 .
$$

Fig. $446 . \quad 5^{5} / 8-58,1 \times(25,1) 32,5-30,6 \times 16,0$.

$$
5^{1 / 2}-58,8 \times(26,7) 32,8-34,3 \times 17,4 \text {. }
$$

5. Nr. 15855. Koll. STREBEL. Ecuador. Ein linksgewundenes, sonst typisches Stiick.

$$
\text { Fig. 448. } \quad 5 \frac{1}{2}-66,2 \times(29,6) 38,7-39,3 \times 20,1 \text {. }
$$

6. Koll. ScHoLviEx. Westküste Südamerika. Ein selı gedrungenes Stïck, typisch in Färbung und Zeichnung. Die Bänder fließen dunkler in den Mundsaum ans.

Fig. 445. $5 \frac{1}{4}-64,0 \times(28,4) 37,8-40,4 \times 20,2$.

7. Rolle vend. Ex Koll. Schatfuss. Ecuador. Ein Stïck in typischer Färbung, aber die ersten drei Windungen haben eine schwarzgrane Zone an der Naht, die ron der 2. Windung an mit weißlichen Flecken besetzt ist, welche den hellen Zwischemäumen der dunklen Zickzackzeichnmo entsprechen. Diese weiblichen Flecke werden allmählich mehr gelblich wie die sonstige Grundfarbe, sie werden aber schmäler, wie auch die Anfänge der dunklen Streifen, so dab eine breiter werdende Zone an der Naht von abwechselnd hellen und dunklen schmalen senk- 
rechten Streifen entsteht, die sich bis zu Anfang der letzten Windung erhält und Band 2 nach oben abgrenzt. Die Spindelstellung ist an diesem Stiick besonders schräg und gewunden.

Fig. 444. $6-71,6 \times(28,8) 37,3-41,7 \times 18,9$.

8. Plagemans Nachlaß ded. P. war früher in Chile ansässig. Ein Stz̈ick ohme Fundort wie das vorangehende.

$$
5^{5} / 8-79,3 \times(30,4) 40,5-43,7 \times 20,1 .
$$

9. Engl. Händler. Koll. ScholviEN. Ecuador. Nem Stïcke, von denen ich einige Maße gebe. Das letzte der Maßliste entspricht in der dumklen Zone an der Naht der oberen Windungen den beiden vorangehenden Stüicken.

$$
\begin{aligned}
& 5^{1 / 2}-69,2 \times(31,0) 39,9-42,7 \times 21,1 . \\
& 5^{1 / 2}-68,0 \times(27,9) 36,3-38,5 \times 19,8 . \\
& 5^{5} / 8-78,5 \times(31,7) 41,6-45,6 \times 22,0 . \\
& 5^{3 / 4}-77,7 \times(30,7) 38,7-40,5 \times 18,4 .
\end{aligned}
$$

10. Koll. Fubby. Ectrador. Ein Stïck, ähnlich in der olivenfarbigen Färbung der Bänder dem sub Nr. 3 beschriebenen, aber kleiner und mit sehr kuzem Gewinde.

$$
5^{1 / s}-56,0 \times(25,9) 33,3-34,8 \times 16,6 .
$$

11. Koll. SoHst. Ohne Fundort. Zwei Stücke, ähnlich in den hell olivenfarbigen und etwas undeutlichen Bändern dem vorangehenden Stïck, aber sonst typisch.

12. Koll. SoHsT. Ohne Fundort, mit Zettel Bul. victor. Ein Stück, typisch in der Form und Zeichmung, aber von einer ins Grame spielenden Grundfarbe mit braunschwarzen Bändern.

\section{Relletti, Form lojanus n. f.}

Taf. XXXI, Fig. 450.

Unter dem DoHRNschen Material von T. fraseri aus Loja, Ecuador, lag das nachfolgend beschriebene Stück, das wahrscheinlich seiner Ähnlichkeit mit T. fraseri, Form hrerispisa, urr. modestus, halber nicht abgesondert wurde, trotzdem es die fïr $M$. kelletti charakteristische Ablagerung an der Basis hinter der Spindel zeigt, wenn es anch sonst in Färbung und Zeichnmo, ja sogar in dem matteren Glanz von M. lielletti abweicht, so daf es fraglich ist, ob wir es hier mit einer Lokalform oder gar mit einer eigenen Art zu tun haben.

Die Form des Gehäuses steht der von T. firaseri, Form brevispisa, näher als der von M. Kelletti, auch die Skulptur steht etwa in der Mitte derjenigen beider Arten, insofern die Stäbchenskulptur etwas verbreiteter auftritt. Die Mündungspartie entspricht dagegen in allen ihren Komponenten und auch in der Färbung dem M. Felletti, nur sind Mundrand und Spindel 
weniger kräftig entwickelt. Die oberen Windmugen sind wie bei M. Relletti gezeichmet, damn treten bei zuerst etwas brämlich fleischfarbiger; zuletzt mehr schmntzig gelber Färbmig nur ab und zu etwas dunklere, schmale Streifen anf. Am Ende der vorletzten und im Anfang der letzten Trindung zeigen sich schmale, dichtstehende, zum Teil sich verzweigende und auch ab und zu winklig gebrochene, hellbrame Streifen, welche Zeichnmo dam aber wieder bis zur Nümdıng durch einzelne bräunliche Streifen ersetzt wird. In dem schmutzigrosa Inneren erkennt man wieder vier etwas dunklere Spiralbänder, wie sie dem M. lelletti entsprechen, die aber anf der Anßenseite kaum zu erkennen sind.

$$
5 \frac{1}{2}-74,3 \times(32,1) 42,6-44,4 \times 21,9 .
$$

\section{d) Gruppe $\boldsymbol{M}$. yatesi PFR.}

Gehänse starkschalig, mehr weniger fettglänzend, mit 6 bis $6 \%$ mäßig gewölbten Windungen, dic durch eine schmal angepreßte oder anch berandete, vereinzelt sogar wulstig berandete Naht getrennt sind, und deren letzte muten etwas zusammengedrückt und moefähr gleich hoch wie das Gewinde ist. Nündung verkehrt ohrförmig, mehr nach dem rhombischen neigend, da der Basalrand mit dem spindelende oft einen mehr weniger scharfen spitzen Winkel bildet. Der Mnndrand ist mehr weniger verdickt und mehr weniger breit mogeschlagen. nach miten oft erweitert, weiß oder farbig. Die Spindel steht mehr weniger senkrecht zur Achse, ist gewunden, verdickt und oben mit einer Falte oder anch löckerartigen Verdickmng versehen. mnten mehr weniger angeschwollen. Der Callus ist ziemlich stark, nach auben oft wulstig berandet und wie die spindel weib oder farbig.

Das Embryonalgewinde (Fig. 346 ) hat 3 bis $3 \frac{1}{2}$, znerst oben etwas kantige, damn mäBig gewölbte Windungen. Es ist mit Grübchen bedeckt. deren wulstige Umrandungen bei starker Vergrößerumg ein etwas mnregelmäßiges Netzwerk bilden, das besonders am oberen Teil der Windungen mehr längliche Maschen zeigt, während nach mten zn mehr sich schräg kreuzende Reihen von Grübchen anftreten. Nach $2 \frac{1}{2}$ Windungen tritt eine Binde an der Naht auf, die aus abwechselnd bramen und weiben Flecken besteht, die zuweilen ohne C̈bergang, zuweilen alhmählich in Band 2 ïbergchen, das freilich einigen Formen fehlt. Zuweilen ist anch von Anfang an eine braune oder schwärliche Abschatticrmg, damn eine gefleckte \%one vorhanden.

Die skulptur besteht ans einer mregchmäßig starken, aber an sich feinen mol schwach lrervortretenden Faltung. die besonders anf der letzten IVindumg seln unscheinbar wird. Es werden meist ein par der feineren Falten, besonder's in der Nahtnähe, in gröbere Falten zusammengefaßt, doch tritt auch dieser Vorgang nie scharf ausgeprägt auf. Die 
sehr feinen Spiralreifchen sind nur stellenweise und besonders am unteren Teil der letzten Windungen zu erkennen, mit Ausnahme von M. deburghiae, bei dem sie deutlich und gewellt auf den ganzen letzten Windungen sichtbar sind. Zuweilen treten stellenweise und schwach, gröbere Furchen auf, die dann auch eine schwache Stäbchenskulptur bewirken; auch hammerschlagartige Eindrüicke und kurze, schräge, seichte Furchen treten auf, mit Ausnahme von $M$. deburghice.

M. yatesi PFR.

Taf. XXII, Fig. 346; Taf. XXXI, Figg. 447, 451;

Taf. XXXII, Figg. 454, 457, 458, 460, 461.

O. yatesi PFR. P., p. 202, Taf. 43, Figg. 14, 17 (Typus), 15, 16.

Porphyrobaphe latevittata SHutTuEw. P., p. 203, Taf. 43, Figg. 12/13.

P. sublabeo Ancey. P. vicarius Fulton, unter diesem Namen von Sowerby und Fultox in den Handel gebracht. P., p. 203, und P., p. 200, Taf. 48, Fig. 12.

Bul. yatesi SHUTTLEW. HupÉ in Castelnau Voyage, p. 31, Taf. 8, Fig. 1a, b. Porphyrob. galactostoma ANCEY = yatesi var. albolabris DoHRN. P., p. 194.

PFEIFFERs Beschreibung und Abbildung sind scheinbar auf eine Form begründet, zu deren Mündungspartie keins der mir vorliegenden Stücke paßt, bei denen allen der Basalrand in einen mehr weniger spitzen Winkel in das Spindelende ïbergeht. PFEIFFer nennt in der Diagnose freilich die Form „basi attenuatus“, während er die Mündung ellipticooblonga, basi subangulata beschreibt, aber in der Originalabbildung in P. Z. S. 1855, Taf. 31, Fig. 5, erkennt man weder das eine noch das andere. Auch die Zeichnumg dieses Typus ist wohl nicht gut gelungen, selbst Stücke wie P., Fig. 16, die fraglich auf sublabeo ANCEY-DOHRN bezogen wird, und die wohl die Zeichnnng, wie sie beim Typus sein sollte, und auch die Forn des Gehäuses richtiger wiedergibt, kommen meinem Material nach verhältnismäßig selten vor. Andererseits ist die Abbildung in den Novitates I, p. 63, Taf. XVIII, Figg. 1/2, für die leider kein besonderer Fundort angegeben wird, in der gestreckten, schmalen Form und in der Zeichnung wieder sehr abweichend von PFEIFFERs erstem Typus, eine Form, die nur sehr vereinzelt vorkommt; ich komme darauf später noch zurück. IVenn PILSBRY meint, dilb diese Form zu der Rasse von SHuTtueworTHs P. lateritata gehört, wemn dieser Typus "sich als eine Rasse herausstellen sollte“, so stimmt das nicht mit dem mir vorliegenden Material, denn wemu SHLTTLEWORTHs Abbildung auch in der mnteren Zṇspitzung etwas übertrieben ist, so ist sie doch im ganzen typischer als PfEIfFERs Typus (vergl. meine Fig. 461); sie ist aber immer in der Mitte breiter als die schmale Form der Novitates, welche anch in dem etwas weniger Zusammengedıücktsein der Basalpartie dem mir vorliegenden Stïck (Fig.447) entspricht. PFEIFFER hat laterittrita SHUTTLEW. 
trotz der Abweichungen von seinem Typus schon mit Recht als Synonym angefïhrt.

HuPÉ beschreibt l. c. die Art und gibt eine sehr wenig charakteristische Abbildung derselben, welche ebenfalls den Ubergang des Basalrandes in die Spindel gewölbt zeigt, wie er denu auch in der Beschreibung. von der Spindel sagt: „elle s'mit an bord droit sans discontinuité, mais en formant un angle à peine indiqué." Es scheinen also anch solche Stücke rorzukommen, wie sie mir freilich, wie schon gesagt, nicht vorliegen. PILsBRTs Fig. 15 ist ebenso, aber er sagt von ihr wie von der Fig. 16. dab der Zeichner es übersehen habe, den Charakter, den er nur ,.subangular production of the aperture at the base of the columella" nennt. wiederzugeben.

Im grofen ganzen zeigt die Art und ihre Tarietäten eine grofe Gleichmäbigkeit in der rasch zur Mitte breiter werdenden, damn wieder sich zuspitzenden Form des Gehäuses bezw. in den Komponenten der Mündumgspartie. Dasselbe ist mit der Grundfärbung der Fall, die nur bald ins olivenfarbig - bald mehr ins bräunlich - Gelbliche hinïberspielt. Konstant ist auch die Fleckenzone an der Naht der oberen Windungen, doch kommt anch hier wie bei $M$. lielletti eine Abweichung. durch eine ron Anfang an brame bis schwärzlich abschattierte, damn mit weißlichen Flecken besetzte Zone vor.

Die spätere Zeichmung ist verändericher, besonder's mit Bezug anf die Zahl und Breite der gegliederten Bänder. Bald sind alle Bänder 2 bis 5 ansgeprägt, bald setzt ein Teil ron ihnen streckenweise ans, doch tritt damn an ihre Stelle meist ein einfach dunkles Band anf. Durch die Dicke der Schale sind die Bänder im weißen Innern nie sichtbar. Die hellen Streifen, welche die Bänder goliedern. sind anfangs immer pfeilförmig; später sind sie an Stelle der Bänder zuweilen anch vorgebogen oder, wenn die Bänder breit sind, auch zickzackartig. Wie bei T. firtseri und M. lielletti kommt aber anch lier eine Form ror, der anf den minteren Windungen die schwärzlichen Bänder und die hellen Streifen ganz feblen, und die bis anf die obersten Windungen fast einfarbig, nur mit wenigen schwachen, dumkleren Streifen besetzt ist, meist aber eine etwas dunklere Zonenbildung an stelle der Bänder zeigt. Nan kann diese Form auch als eine heterom. ranthus ansehen, die gleichzeitig den Übergang zu FuLToxs $P$. circrims bildet. Ich komme darauf noch zurück.

Der Mundrand ist hell oder dunkler leberbram bis violettbraun, und dieselbe Färbung zeigen Spindel und Callus. Die Spindel zeigt die obere Falte immer weif, und anch der Callus wird hänfig im Innern weiflich. Die Terdickungen an der Spindel sind im Prinzip immer die gleichen, sie sind aber veränderlich in der Stärke ilurer Ausbildung. Die Stellung der Sphindel kamn senkrecht, sie kamn aber auch schräg zur Achse stehend sein, 
und zwar, wenn auch nie stark, doch bald mit dem Ende nach rechts, bald nach links gerichtet.

Die Stücke mit weißem Mundrand, weißer Spindel und Callus hat ANCEY ursprünglich als $P$. galactostoma beschrieben, und zwar nach einem jungen Stiick. Später, im Nautilus, vol.17, p. 89, hat er die Art neu beschrieben und fügt als Synonym $P$. yatesi PFR., var. albolabris DOHRN in Cat. STAUdINGER hinzu, was PILsBRY bei Abfassung seiner Arbeit noch nicht bekannt war. Ich halte diese Form auch nur für eine Varietät, es kann aber auch eine Lokalform sein. ANCEY selbst fügt hinzu: "closely allied to $P$. sublabeo ANCEx, vicaria FuLT. and yatesi PFR., all from Peru." In der Tat nähert sich diese Form dem M. labeo.

Ich möchte noch auf ein Merkmal der Art hinweisen, das in den Beschreibungen nicht erwähnt wird, nämlich eine schmale, hell- oder dunkelbraune Zone an der Basis hinter der Spindel, die nicht etwa der Ablagerung bei $M$. kelletti entspricht, sondern nur eine Färbung ist; außerdem ist die Basis mehr weniger zusammengedrïckt.

1. IV. SCHLÜTER vend. Ex Koll. STAUdinger. P. yatesi var. sublabeo. Huajamba (soll wohl Huayabamba heißen), Peru. Acht Stücke, die ich gesondert beschreiben mul.

a) Ein nicht ganz ausgewachsenes Stïck, in Form und Zeiclunung wie P., Fig. 16, die PILSBRY auf die var. sublabeo ANCEY beziehen zu müssen glaubt. Es ist dies eine Form, die jedenfalls dem ersten Typus von PFEIFFER wohl am besten entspricht, und die nicht als Tarietät abgesondert werden kann, nur die Mündungspartie ist anders, was ich aber eher auf eine mangelhafte Zeichnung ihres Typus zurïckfïhre.

b) Zwei schlankere, ausgewachsene Stïcke, die ebenfalls als typisch anzusehen sind. Das abgebildete Stück hat auf der Rückseite der letzten Wrindung, die ich abbilde, die Bänder 2 und 3 etwas zusammengeflossen. Der Übergang des Basalrandes in das Spindelende ist nicht so scharf spitzwinklig wie bei dem zweiten Stïck der IIaßliste, das auch schmäler ist. Beide Stücke gehören in die Formenreihe, von denen P.latevittata SHUTTLEw. der'Typus ist.

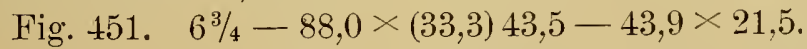

$$
6 \% \text { - } 82,3 \times(29,2) 41,2-38,5 \times 19,8 \text {. }
$$

c) Zwei Stïcke, die den vorangehenden entsprechen, nur verlieren sich Band 2, 4 und 5 auf den beiden letzten Windungen, sind aber bei dem zweiten Stück der Maßliste durch etwas dunklere Bänder angedentet. Das Band 2 ist sehr schmal. Ich habe das eine Stïck seiner gedrungenen Form halber abgebildet. Das zweite der Maßliste hat die obersten Wiudungen dunkel abschattiert.

Fig. $460 . \quad 6 \frac{1}{2}-80,1 \times(35,8) 44,7-41,9 \times 22,8$.

$$
71 / 4-91,8 \times(33,7) 45,9-45,0 \times 21,6 \text {. }
$$

d) Ein Stïck, das sehr gut zu dem Typus in den Novitates paßt. 
Es ist auben etwas abgerollt, d. h. die Cuticula ist mehr weniger defekt, innen aber frisch und zeigt oben die dunkle Zone an der Naht, von der ich weiter oben sprach.

Fig. 447. $7-77,8 \times(28,7) 37,2-36,4 \times 17,7$.

Zu der Kleinheit der Form, den dunklen Zonen oben an der Naht gesellt sich, da6 auf der letzten Hälfte der letzten Windung Band 2, 4, 5 mur durch leichtere dmklere Färbmg angedentet sind, und daß Band 3 äußerst schmal. aber durch weitlänfig stelıende, helle Flecke gegliedert ist. Der Mundrand und die Anfenseite der Spindel sind hell leberbram gefärbbt, das Innere ist bläulichgran und der Callus sehr dümn, geschichtet, nach innen etwas grauweil werdend.

e) Zwei Stücke. welche sich dem vicrins FuLTON sehr nähern. Bei dem abgebildeten stïck ist Band 3 noch in einem schmalen dmuklen, durch hellere schräge Streifen unterbrochenen Streifen angedentet, bei dem zweiten der Maßliste fehlt es ganz und sind die Bänder 2 bis 5 nur durch etwas dunklere Zonen angedentet. Der einzige Unterschied besteht in dem weniger stark entwickelten Mundrand und der Spindel, die 1 . virarius anszeichnen.

Da diese Stücke zusammen mit den vorangehenden liegen, für die nur ein Fundort angegeben ist, mufs man wohl mit Recht solche $A b-$ weichmgen als zur Tariationsweite der Art gehörig ansehen.

Fig. 454. $63 / 4-80,3 \times(33,5) 43,9-41,4 \times 22,6$. $6^{5} / 8-80,3 \times(33,8) 43,7-42,2 \times 21,9$.

Das letzte Stïck der Maßliste hat übrigens anch wieder die obersten Windungen dunkel abschattiert.

2. Koll. Dohrs. P. yatesi PFR. Moyobamba. Sechs Stïcke. rom Typus der rorangehend sub a, b, c beschriebenen Stücke, von denen ich einige Maße anführe. Ich will dazu nur noch folgendes bemerken. An einem Stïck markieren sich die Bünder durch einen etwas dunkleren Ton an Mundrande. Ferner zeigen zwei Stïcke im Mnndrande einige l'mde hellere Flecke, die nicht etwa vertieft liegen oder hervortreten, aber in scitlicher Belichtung irisierend erscheinen. Ob das der Anfang einer Bildung ist, wie sie für $M$. labeo charakteristisch ist? Tielleicht hat dies DOHRN zu der Bemerkmng auf dem beigelegten Zettel veranlaßt, "anch nur eine $v a r$. labeo". Ich bemerke denselben Vorgang übrigens anch bei einigen der sub 1 rerzeichneten Stïcke.

$$
\begin{aligned}
& 63 / 4-88,0 \times(36,3) 47,0-47,0 \times 24,2 . \\
& 65 / 8-84,6 \times(31,6) 41,6-41,9 \times 19,3 . \\
& 61 / 2-80.2 \times(35,9) 45,7-42,6 \times 23,2 . \\
& 6^{3 / 8}-71,7 \times(28,3) 37,7-37,2 \times 17, \overline{3}
\end{aligned}
$$

3. Koll. Scholviex. S. yatesi rar. sublabeo DoHRn. Peru. Ein Stück, wie die sub $1 \mathrm{a}, \mathrm{b}$ beschriebenen.

$$
6{ }^{1} / 2-80,6 \times(34,0) 44,3-42,8 \times 22,0 .
$$


4. Koll. SCHolvien. Ton englischem Händler, P. sublabeo ANCEY. Chacopoyas (?). Zwei Stücke. Das abgebildete Stück ist hell grünlichgelb, das zweite ist dunkel olivengrün, mit kamm erkennbaren Bändern anf der letzten Trindung, von denen das Band 3 noch Spuren der Unterbrechung durch helle Zickzackstreifen zeigt.

Fig. 461. $\quad 6 \frac{1}{4}-85,4 \times(33,8) 46,2-47,0 \times 22,5$.

$$
6 \% \text { - } 76,1 \times(31,5) 40,1-41,0 \times 20,1 \text {. }
$$

5. Rolle vend. Chanchomayo, Peru. Koll. Schunke 1907/1908. Zwei Stïcke einer Form, die sehr gut dem Typus von latevittata SHUTTLEW. in der Zeichnung und der scharf zusammengepreßten Basis entspricht, nur ist das Geivinde auffallend kurz, und während Mundrand, Basalrand und unteres Ende der Spindel bräunlich violett sind, sind Spindel und Callus wie das Innere rein weiß. Der Mundrand ist stark nach anßen gebogen. RoLLE bezeichnet diese Stïcke fälschlich als $P$. gloriosus PFR.

Fig. $458 . \quad 5^{3 / 4}-71,8 \times(30,4) 39,0-40,7 \times 18,5$.

$$
6-74,7 \times(30,6) 41,5-41,3 \times 20,6 \text {. }
$$

\section{M. yatesi, Form vicurius FULTON.}

Taf. XXXII, Fig. 457.

P., p. 200, Taf. 48, Fig. 12.

Fulton hat diese Form dem Bul. labeo var. Renve, Fig. 207, 1. c. gleichgestellt, was mir nach den von SOVERBY und FuLToN gekauften beiden Stücken insofern fraglich erscheint, als die REErEsche Form viel breiter ist. Da er aber diesen Typus vor sich gehabt hat, so muß man eben annehmen, daß die Form veränderlich ist. Jedenfalls möchte ich aus den schon weiter vorn angedeuteten Gründen diese Form nur als eine Lokalform von M.yatesi, nicht für eine eigene Art ansehen. (Vergl. auch das bei M.yatesi $1 \mathrm{e}$ Gesagte.) Ich komme auf die REEvEsche Form bei M. Tabeo noch zurïck.

Sowerby und FulTon rend. Loimabamba, Peru, 8000 feet.

Sie zeigen außer der mehr braungelben Färbung und dem fast purpurbramen Mundrand und der gleich gefärbten Spindel und Callus diese Partien stärker entwickelt als bei den unter 1 e verzeichneten Stïcken. Auf der 4. Windung treten schmale, ziemlich gedrängte braune Streifen auf, die an Stelle von Band 2 und 3 winklig ausbiegen, was sich damn aber bald verliert. Undeutliche dunklere Zonen erkennt man an Stelle der Bänder, wie sie auch bei $M$. yatesi vorkommen.

Fig. 457. $6^{5 / 8}-78,5 \times(31,6) 43,4-40,5 \times 21,7$. $6 \%$ - $78,2 \times(32,4) 42,4-39,7 \times 19,8$.

ir. yatesi, Form galactostomms ANCEY. Taf. XXXI, Fig. 443; Taf. XXXII, Fig. 459.

Außer dem reinen Weiß des Imneren, Mundsaums, Callus und der Spindel, unterscheidet sich diese Form vielleicht noch dadurch, daß 
die Bänder mehr dunkelgran-olivenfarbig als schwärzlich sind. Die oberen Windungen sind anch meln gelblichweif als hell gelbrot. wie sie der typische M. yatesi hat, nur die var. vicurius ist ihm darin ähnlich. Ferner bietet die Oberfläche des Mumdrandes eine mehr weniger mregelmäßige Oberfläche durch auftretende seichte Tertiefungen. wodurch eine schwache Annäherung an M. labeo erzielt wird. Der Vorgang ist Wahrscheinlich auf dieselben Ursachen zurückzuführen, nur daß sie bei M. labeo in verstärktem Maße auftreten.

1. Koll. DoHrx. Tier Stücke, die zusammen mit M. labeo lagen und ron denselben Fundorten stammen: Balsapuerto und Cachapoyas (anf den Karten Chachapoyas genannt). Beide Ortschaften licgen in NordPerı um ILyobamba herım. DoHRs lıält diese Form wohl mit Unrecht zu M. labeo gehörig, wenn man nicht die ganze hier verzeichnete Formenreihe dem M. labeo, als dem älteren Namen, als Varietäten oder Lokalformen anreihen will. Meiner Ansicht nach haben $M$. labeo ebenso wie M. deburghie durch Färbung und Zeichnung ihren eigenen Typus. Ich bilde ron diesen vier Stücken nur das junge ab, damit auch dieses Stadium vertreten sei.

$$
\text { Fig. 443. } \begin{aligned}
& 5^{1 / s}-56,1 \times(25,7) 31,0-32,5 \times 14,9 . \\
& 6-82,2 \times(31,4) 43,0-43,0 \times 20,1 . \\
& 6-71,8 \times(29,6) 38,8-38,4 \times 18,6 .
\end{aligned}
$$

2. Koll. Scholrien. P. yatesi var. albolabris DoHRx. La Pecá, Perll. Zwei Stïcke.

Fig. 459. $6-74,6 \times(30,1) 39,3-40,0 \times 19,6$. $5 \%$ - $71,2 \times(30,1) 39,8-39,7 \times 19,5$.

\section{I. yatesi, Form gromatis RoLLE.}

Taf. XXXIII, Fig. 476.

RoLle hat im Nachrichtsblatt d. M. G. 1902. 1. 211, eine Porphyiobayle grandis beschrieben, aber nicht abgebildet. Es ist mir gelungen, diesen Typus, von dem der Fundort nicht anzugeben war, zur Abbildmng zil erhalten. Das stïck ist scheinbar tot in einem durch Abbrennen gerodeten Busch oder Wald gefunden, und dadurch auf der Rückseite über alle rindungen fort ganz farblos geworden, wie denn anch die gelbliche Cuticula ganz fehlt, wodurch die Grundfarbe der drei unteren Windungen violettgrau crscheint, was den Gesamteindruck sehr abweichend vou dem sonst ïblichen gestaltet. Die vierte Windung, wo die Cuticula immer dïnner wird, ist hier melı bräunlich, während die drei oberen Windungen ganz farblos geworden sind. Dic Zeichnung ist dadurch etwas eigenartig, daß schmale, ziemlich dicht gedrängte Streifen rorwiegen, die nur an Stelle der Bänder zum T'eil etwas winklig ansbiegen, 
und die bis zur Mündung vorhanden sind, was sonst nur auf den oberen Windungen $a b$ und zu vorkommt. Es sind nur selten breitere, zwischen der Stelle von Band 2 und 3 eckig ausbiegende und vorn hell berandete Streifen vorhanden, wie aus der Abbildung ersichtlich ist. Band 3 tritt von der 4. Windung an dunkelbram und weiß gegliedert auf und setzt sich bis zur Mündming fort, nur daß das Dunkelbraun allmählich in Schwarz ïbergeht. Band 2 und $2 \mathrm{a}$ sind nur angedentet, und von Band 4 und 5 sind Spuren vorhanden. Auf den drei letzten Windungen erscheint die Naht schmal weiß berandet mit stärkerer Betonung der ausmündenden Streifen. An der Basis tritt, wie auch sonst wohl, eine schmale dunkle Zone auf.

Der Mundrand ist in der oberen Hälfte hell leberbraun wie auch der Callus, aber in der unteren Partie werden beide mehr gelblichweiß, was vielleicht auf die oben angeführte Beschädigung zurückzuführen ist. Der Wirbel ist ausgebrochen.

$$
\text { ca. } 7 \frac{1 / 4}{4}-100,5 \times(34,2) 43,3-46,7 \times 20,1 \text {. }
$$

Es unterliegt für mich keinem Zweifel, daß es sich hier um einen M. yatesi handelt, wobei es dahingestellt bleiben mub, ob es nur eine Varietät oder eine Lokalform ist. In meinen Figuren 447 und 461 sind, was die Zeichnung anbelangt, Amähermgen geboten, auch die Abbildung in den Novitates mag angeführt sein. Bei der großen Veränderlichkeit in der Zeichnung und Färbung des M. yatesi kann man die hier vorliegende Abweichung durch die vielen schmalen Streifen nicht allzu hoch einschätzen, jedenfalls nicht, um eine neue Art darauf zu begründen. Die Form des Gehäuses und alle Komponenten der Mündungspartie sind typisch, ebenso die Skulptur, wie ich sie für die Art beschrieben habe.

\section{M. labeo BRODERIP.}

Taf. XXXII, Fig. 462.

P., p. 199, Taf. 44, Figg. 21/22. ? Reeve, Taf. 71/72, Figg. 207 b, c.

Der Typus dieser schönen Art wurde von Leut. MAW in der Umgegend von Chachapoyas in mehreren Stücken gefunden. Die mir vorliegenden schönen Stücke aus der DoHRNschen Sammlung rom gleichen und einem naheliegenden Fundort gestatten eine Erweiterung der Diagnose. So schön frisch die Stïcke sonst sind, so ist doch an allen der obere Teil so abgeriebẹn, daß sich die Grübchenskulptur nicht mehr erkemnen läßt, nur an einer Stelle des dort besterhaltenen Stïckes glanbe ich noch unterm Mikroskop eine Spur davon zu erkemnen. Aber nach dem ganzen Habitus muß man doch annehmen, daß auch diese Art die Skulptur des Embryonalgewindes der Untergattmg, beziehungsweise 
dieser Gruppe d hat, zumal anch die Fleckenzone an der Naht rorlianden ist.

Die Form des Gehäuses ist insofern etwas verschieden von M. yatesi. als die Windungen etwas gewölbter sind und die letzte etwas mehr sackförmig nach unten erweitert ist. Ferner sind die oberen Windungen im Anfang etwas breiter angelegt. Die Färbung ist hell bis dunkel kastanienbraun. nach oben heller werdend. Die oberen Windnngen sind entweder an der Naht bram abschatticrt oder nicht, nit $2 \frac{1}{2}$ Windungen tritt aber immer die Fleckenzone an der Naht anf, die entweder bram oder purpurschwarz mit hellen Flecken sein kann, alles wie bei M.yatesi. Die schmale, angeprebte Zone an der Naht ist auch wie bei M.yatesi durch einen schmalen bramen Strich abgegrenzt, und auf der 4 . Windung kommen brame Zickzackstreifen bei der hellen Varietät vor.

Ton den drei Stücken sind zwei dunkelbram gefärbt, eins davon zeigt ron der 4. Windung an Band 3. das etwa $3 \mathrm{~mm}$ breit, braunschwarz und ab und zu dureh Bruchstïcke der sonst nicht sichtbaren schmalen hellen Zickzackstreifen unterbrochen ist. Darunter steht nicht unterbrochen Band 5, das ebenso breit, aber etwas weniger dunkel ist. Band 2 und 4 sind breiter und lassen sich nur als eine etwas dumklere Zone crkemen. Dies Stïck hat einen hell weiblichbramen. breiten. flach wulstigen Mundrand, der typisch mit Grübchen versehen ist. Die Spindel ist nach immen zu weiblich, nach auben wie der Callus purpurbram.

$$
6 \frac{1}{4}-77.4 \times(30,2)+1,5-44.0:<21,2 .
$$

Das 2. Stück, welches an den oberen Windungen nicht die dunkle Zone an der Naht hat, zeigt keinerlei Bänder, nicht eimmal die sie andeutenden dunkleren \%onen, nur ist die Partic ron der Stelle der Oberkante ron Band 2 bis an die Naht etwas heller gefärbt. Der IIundrand ist dunkelbraum, er wird nur in seinem nach rïickwärts umgeschlagenen Teil hell weißlichbraun. Dic vielen Querfurchen und Grübchen sind an diesem Stück in der Tiefe weißlich ansgefüllt.

$$
6^{3} / 8-77,1 \times(31,3) 42,7-42,8 \times 22.6 \text {. }
$$

Das 3. Stück ist eine iar. albolabris und rerhält sich daher zum Typus wie M. yatesi. Form galactostoma. zu seinem Typus. Es ist heller in der Grundfarbe, mehr gelblichbraur, und nur die Bänder bezw. die Zonen sind zum Teil etwas ins Olivenfarbige hinüberspielend. Die oberen Windungen laben die schwärzliche Zone an der Naht, und die 4. Windıng: zeigt schmale branne Zickzackstreifen, die in Band 3 in dunkelbranne, pfeilförmige Figuren ansmünden, und es gliedern. Die beiden letzten Windungen zeigen cin schmales, nur wenig dumkler getontes Band 2, ein breites Band 3, anf dem sich Spuren einer helleren Zickzackzeichnung erkennen lassen, das dam mten durch ein schmales schwarzbrames Band abgegrenzt wird, in das vereinzelt jene hellen Zickzackstreifen ansmünden, 
das hier aber weit schmäler ist als bei dem zuerst verzeichneten Stïck. Band 4 ist breit und nach unten dunkel abschattiert, so daß sich hier einzelne hellere winklige Streifen deutlicher erkennen lassen. Band 5 ist ebenso, mur etwas schmäler.

Callus, Spindel und Inneres sind rein weiß. Der Mundrand ist etwas schmäler als bei den beiden anderen Stïcken und schwach höckerig, aber ohne die Vertiefungen oder Löcher; er ist weiß, schwach rosa angehaucht. Der Basalrand zieht sich nicht so breit hinter der Spindel in die Höhe, wodurch das untere Ende der Spindel freier wird, das hier stark wulstig nach links umbiegt.

Fig. 462. $\quad 6 \frac{1}{4}-79,9 \times(32,7) 44,6-41,4 \times 22,7$.

Auberdem besitzen wir noch ein etwas defektes Stück aus der Koll. SCHOLVIEx, das dem zweiten der oben verzeichneten gleich ist, nur tritt noch ein schmaler schwarzbrauner Streifen als untere Grenze von Band 3 auf.

$$
6-69,4 \times(28,8) 39,1-39,7 \times 19,8 .
$$

Der Eindruck dieser vier mir vorliegenden Stücke ist der einer für sich bestehenden Forns, die natürlich mit den anderen Formen Gemeinsamkeiten zeigt, die aber durch die Gruppe begründet sind. Selbst das weißlippige Stiick, dem das charakteristische Merkmal der Tertiefungen bezw. Grübchen fehlt, läßt sich weder mit $M$. yatesi, Form galactostoma, noch die mit dunklem Mundrande mit dem M. yatesi, Form vicrivis, zusammenstellen. Die Furchen und Grübchen im Mundrande erweisen sich freilich durch das Stïck mit weißem Mundrande als nicht festes Merkmal für $M$. labeo, wie denn ja schon bei $M$. yatesi und der Form galactostoma sich am Nundrande Vorgänge zeigten, die die Anfänge solcher abnormen Bildung sein dürften. Ob diese Erscheinung auf einen Defekt im Organismus des Tieres, besonders des Mantelrandes, oder in einer mechanischen oder chemischen Störung zu suchen ist. muß ich dahingestellt sein lassen.

Was nun die fraglich oben herangezogene ReEvesche Tarietät von B. labeo, Taf. 71/72, Figg. 207 b, c, betrifft, welche von LOBB in Limabamba, demselben Distrikt, wo ذiaw den Typus fand, gefunden wurde, und die sich in Cummas Sammlung befindet,- so möchte ich dazn noch folgendes bemerken. Schon PILSBRY sagt bei P. vicarius FulTon, p. 201, daß seine Stücke schmäler sind als die REEvEsche Tarietät, auf die ja FULTON seine $P$. vicarius begründete, und die mir vorliegenden beiden durch SOwERBY, und FULTON in den Handel gebrachten Stïcke haben dieselbe Form wie das von PILsBRY auf Taf. 48, Fig. 12, abgebildete Stïck. Man muß annehmen, daß diese Stïcke von M. vicarius typisch sind, sie weichen aber nicht nur in der schmäleren Form von der REEVEschen Varietät ab, sondern das Gewinde ist anch im Verhältnis 
zur letzten Windung, in der idealen Achse gemessen, etwas höher. und das gleiche findet beim Tergleich mit den ron mir beschriebenen Stücken ron $\boldsymbol{M}$. labeo statt. Danach möchte ich doch glauben, daß REEvEs Abbildnng mehr zu labeo als zu yatesi. Form vicarins, gehört. Es muf die Entscheidung dieser Frage noch weiterem Material überlassen bleiben.

\section{M. deburghiae REEVE.}

Taf. XXII, Fig. 347; Taf. XXXII, Figg. 452, 456.

Bul. gloriosus PFr. $=$ Bul. deburghiae Reeve. P., p. 196, Taf. 39, Figg. 3, 5; Taf. 42, Figg. 9/11.

PFEIFFer hat in Monogr. Helic., vol. TIII, p. 22, seinen Bul. gloriosus und Bul. deburghice REETE noch gesondert aufgeführt, wirft aber doch bei ersterer Art die Frage auf. ob es nicht dieselbe wie $B$. deburghicte sei, zumal er ja dazn HIDALGOs ansführlichere Diagnose kopiert und die Abbildungen anführt, die schon die helle Zone unterhalb der Naht, in der auch die Zeichnung sehr abgeschwächt erscheint, angeben. Das ist aber der einzigè Unterschied, der den Abbildungen nach zwischen den beiden Arten besteht.

$\mathrm{Zu}$ den Beschreibung'en von HIDALGO und PILSBRY wäre nur weniges linzuzufïgen. Das in Fig. 347 abgebildete Embryonalgewinde mit drei Windungen bildet meist einen Kegel, der sich ron den folgenden, rascher an Breite zunehmenden Windungen eigentïnlich abhebt. Es hat aber nur selten gegen das Ende die der Gruppe charakteristische Fleckenzone, wie es die Abbildung zeigt. meist treten sofort Streifen auf, auch beginnt die in Färbung und Zeichnung blassere Zone an der Naht entweder schon gegen Ende oder erst mit dem Ende des Embryonalgewindes. Diese blassere Zone reicht ron der Naht bis zur Stelle ron Band 2.

Die Partie zwischen Band 2 und 4 ist durch einen olivenfarbigen Grundton ausgefüllt, der in vier gleich breite, meist etwas verschieden nïanzierte Binden zerfällt. Die interen Grenzen der 2. und 4. Binde werden durch die schmalen, schwarzen Bänder 3 und $t$ bezeichnet. Über diese ganze Partie ziehen sich schmale, ziemlich weitläufig g'ereihte. zickzackartige, hell- bis orangegelbe streifen hin, die ron der Naht an einen schräg nach vorn gerichteten Terlauf nehmen, und deren Abstufungen vielfach mit jenen vier Binden zusammenfallen. Dies System der Zeichmmg findet man ja anch bei 1 . yretesi und Relletti. Band 3 wird durch die hellen Streifen muterbrochen. Band $t$ nicht mehr. Unterhalb Band $t$ befindet sich eine orangefarbige Zone olne Zeichnung.

Charakteristisch ist für die Art die starke höckerige Verdickung oben an der Spindel, die zuweilen sogar zweiteilig ist. d. h. ans einem 
oberen stärksten und darunter schwächeren Höcker besteht. Der mehr weniger breit umgeschlagene Mnndrand zeigt anch an einzelnen Stïcken eine schwach höckerige Beschaffenheit, ganz wie bei der weißlippigen Form, die ich bei $M$. labeo beschrieben habe.

1. Koll. Scholvien. Engl. Händler. Ecuador. Tier Stücke.

Fig. 452. $6^{5} / 8-66,0 \times(27,3) 34,9-33,1 \times 17,4$.

? ca. $69,0 \times(31,0) 40,7-36,0 \times 18,2$.

Das letzte Stïck der Maßliste ist ein besonders breites.

2. ROSENBERG vend.

a) Mirador, Ecuador. Vier Stücke, alle tot gesammelt, ron denen ich nur eins wegen der abnormen Ablagerung auf dem Callus abbilde; es ist an sich wohl nicht ganz ansgewachsen. Das zweite Stück der Maßliste entspricht wohl der Form elongata MILLER.

Fig. 456. $\quad 6 \frac{1}{2}-59,1 \times(27,1) 33,3-28,8 \times 15,0$.

ca. $6 \frac{1}{2}-66,7 \times(25,8) 32,7-33,6 \times 15,4$.

$6^{3} / 8-64,0 \times(27,6) 35,3-32,8 \times 16,7$.

b) Porvenir, Ecnador. Ein tot gesammeltes Stïck, wie die rorangehenden, nur etwas kleiner und mit sehr verdickter Spindel.

$$
6^{3} / 8-60,8 \times(25,7) 32,0-30,8 \times 13,3 \text {. }
$$

\section{E. Subgenus Melaniorthalicus n. subg.}

Gehäuse mit Ausnahme ron II. deticosus starkschalig, mehr weniger fettglänzend, oval-konisch, mit 6 bis 7 wenig gewölbten Windungen, die durch eine schmal berandete Naht getrennt sind, oberhalb welcher zuweilen eine Rinne verläuft, wenn die vorangehende Windung etwas kantig überragt, was bei $M$. adamsoni und pouisianus oft rorkommt. Die letzte Windung ist mehr weniger niedriger und meistens viel dunkler gefärbt als das Gewinde. Die Mündung ist etwas rhombisch oder oval zugespitzt, Mundrand geradeaus, stumpf. nach unten mehr weniger erweitert. Der Basalrand bildet mit dem Spindelende einen Winkel. Die Spindel steht ziemlich senkrecht zur Achse, sie ist gerade oder eingebogen und der Länge nach mit Ausnahme von M. deliciosus mit einer unregelmäßigen, mehr weniger entwickelten Verdickung belegt, die oben stärker als unten ist. Das Embryonalgewinde (Figg. 349/352) hat $2^{1 / 2}$ bis 3 schwach gewölbte Windungen, deren erste meistens dentlich ansteigt und überragt. Sie sind mit feineren oder gröberen, oft sich schräge kreuzenden Reihen von Grïbchen bedeckt, die aber auch unregelmäßig angeordnet sein und stellenweise aussetzen können. Meistens sind die elsten Windungen abschattiert, und zwar nach unten dunkler werdend, außerdem ist die erste Windung zuweilen oben braun gefärbt (adramsoni, powisianus). Gegen das Ende treten an der Naht braune 
Flecke anf, die sich bald zu Streifen umbilden, anch Band 2 beginnt schon hier.

Die skulptur besteht ans unregelmäßig starken, aber im ganzen schmalen Falten, die meistens einzeln bis an die Naht gehen, aber vereinzelt sich anch in deren Nähe zu gröberen Falten zusammenfügen. Sie sind zuweilen nur sehr schwach ansgeprägt (M. powisiams, deliciosus). Die feinere spiralskulptur ist nur seln unscheinbar und nur stellenweise als Furchen zu erkennen (am deutlichsten bei M. adamsoni.) Es konmen auch schräge, kmre und seichte Furchen bezw. Rumzeln ror (M.poursiamus).

Der Name dieser Untergattung ist nach der vorwiegend veilchenblanen und schwarzen Färbung gewählt.

\section{Ml. atrumenturius PFR.}

Taf. XXII, Figg. 350 a. b; Taf. XXXIII, Figg. $470 / 471,474 / 475$.

SP. Y, p. 3. P., p. 209, Taf. 38, Figg. 35/40; Taf. 39, Fig. 7 .

Die eingehende Beschreibung PILsBrys, und dessen die Teränderlichkeit der Färbung und Zeichnung wiedergebenden Abbildungen bedürfen nur weniger Ergänzungen.

Das Embryonalgewinde (Figg. 350 a, b) liat $2 \frac{1}{2}$ bis $2 \frac{3}{4}$ Windungen, die selbst bei jungen frischen Stïcken, wie die für die Abbildnng ansgewählten, nur stellenweise (Fig. 350 b) die feine Grübchenskulptur und vorwiegend nur schräge Fältchen an der Naht neben einer feinen Streifung zeigen könmen.

Die Grundfarbe des Gelıäuses ist hell- bis dunkelgrau, gelblichgrau, violettgrau, bräunlichgelb oder stellenweise selbst orange. Die obersten ITindungen sind inmer rötlich. Die Streifen kömnen einfach sein, sie sind aber meist auf den oberen Wrindungen ron Band 2 ab breit, nach oben gegabelt und am Bande winklig vorspringend. Diese Zeichnmg verliert sich meistens abel bald, die Streifen werden schmäler, zum 'Teil nur noch an Stelle der Bändel winklig ausbiegend. Stellenweise verringert sich die Zahl der Streifen, dann wieder fließen sie zu breiten Streifen zusammen. Auf einem Teil oder der ganzen letzten Windung tritt vorwiegend eine schwäızliche Färbung anf, die nur durch einzelne helle streifen oder auch hellere, streifige spiralzonen unterbrochen wird. Selur häufig kommen auf dem Gehäuse dunkle kurze Striche in der Spiralrichtung oder anch Flecke vor, die vorn einen hellen Wischer haben, oder auch helle Wischer treten allein auf. Das Band 2 ist meist nur oben deutlich ausgeprägt und meist gegliedert. Schärfer und entweder durchgehend oder muterbrochen ist das schmale dunkle Band 3. Daneben aber kommen oft Streifen und dunklere Zonen in der Spiralrichtung vor. Die 
Stïcke haben an der Basis eine purpurbraune Zone, die nur selten bei ausgewachsenen Stïcken sichtbar wird, da hier die Färbung überhanpt dumkel ist. Bei jungen Stïcken dagegen ist sie immer vorhanden und mündet im Innern in den Basalrand aus.

Die Spindel ist in der Stärke der innen aufgelagerten Verdickung und in der Richtung, d. h. ob gerade oder eingebogen verlaufend, sehr verschieden ausgebildet. Sie ist immer gefärbt, wenn anch meist nach innen heller bis weißlich werdend.

1. Koll. O. SEmPER. Facatativa, Nen-Granada. PETERsen leg. Neun Stïcke.

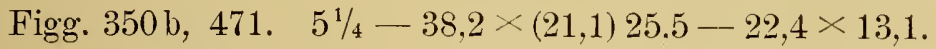

Fig. 350 a. $5^{1 / 4}-33,6 \times(19,0) 23,3-19,2 \times 11,9$.

" $475.7-73,8 \times(30,6) 36,0-36,0 \times 18,2$.

" 474. $\quad 6 \%$ - $70,2 \times(31,7) 36,9-35,0 \times 18,7$.

" $\quad 470.65-64,0 \times(31,1) 36,6-34,4 \times 18,7$.

$6 \frac{1 / 4}{4} 59,0 \times(28,8) 34,0-29,5 \times 17,8$.

2. Koll. SCHOLviEN. Socorro, Staat Santander, Columbien. Vier Stücke.

3. Zwischen Socorro und Sanjil, tierra templada, Staat Santander.

a) Koll. O. SEMPER. PETERsen leg. Zwei Stüicke.

b) Baron NoLCKE leg.

Nr. 15714. Vier Stïcke.

Nr. 5797. Zwei Stïcke.

4. Koll. FilbY. Ecuador. Ein Stück.

5. Ohne Fundort. Sechs Stïcke.

Da ich sub Nr. 1 sowohl besondere Färbungen und Zeichunngen für die Abbildungen ansgewählt und die rerschiedensten Гaße angegeben habe, war es überflüssig, bei den folgenden Nummern Maße und Abbildungen zu geben.

Im Lübecker Museum befindet sich die Art vom Fusagaruga-Gebirge, - Staat Cundinamara, Columbien.

\section{M. adamsomi GRAY.}

Taf. XXII, Fig. 349; Taf. XXXIII, Fig. 477.

P., p. 207, Taf. 39, Figg. 1/2; Taf. 40, Figg. $7 / 8$.

Das Embryonalgewinde (Fig. 349) hat $2 \frac{3}{4}$, meistens 3 Windungen, die Grübchen sind etwas gröber als bei $M$. atramentarins, die 1 . Windung ist auf der Innenseite braun gefärbt.

Für die Skulptur ist hervorzuheben, daß die schmalen, nicht besonders scharfen Falten besonders auf den letzten Windumgen hänfig regelmäßig gereiht sind und dem Gehäuse ein gerieftes Ansehen geben. Die Spiralskmlptur ist meist deutlich, besonders anf der mittleren und auf der 
unteren Hälfte der letzten Windung. Da wo sie deutlich ist, erkennt man stellenweise sogar, daf sie aus änferst feinen Spiralreifchen besteht.

Die Färbung und Zeichmung hat PILSBR eingehend geschildert und anch in den Abbildungen gezeigt. Ich bemerke dazu noch folgendes. Die gelb- bis rötlichbrame Färbung, die sich nach P., Figg. 1/2, meistens von der Basis bis zur Hälfte zwischen Band 3 und 2 hinaufzieht. hört an einem der mir vorliegenden Stïcke mit Band 3 anf. Die brannschwarzen Streifen können anf den zwei vorletzten Windungen auch mal breit und wolkig werden, wie es an Fig. 458 zn sehen ist, ein Stïck, das besonders schmal ist. Ton den Bändem ist Band 2 mterbrochen, meist anf den mittleren Windungen am deutlichsten, es kilnn sich aber auch bis zur Mündung, damm aus winkligen Figuren zusammengesetzt, fortsetzen. Band 3 ist breiter, entweder rein weis mit Brannschwarz abwechsehnd gegliedert. oder es ist unten auberdem noch mit einer schwarzen Linie abgegrenzt. Ton Band 4 sind zuweilen noch Andentumgen durch dunkle Flecke geboten. Anch bei dieser Art sieht man, soweit die Färbung es erlanbt, eine schwarzbraume Zone um die Basis. Die letzte Windmng kamn gegen die Mündung zn sehr dunkel gefärbt sein, wie es die Figuren 7'8 in P. zeigen. meistens aber ist nur nahe der Mündung hinter dem lell berandeten Mundsanm ein mehr weniger breit ansflicßender, schwärzlicher oder schwarzbramer Streifen rorhanden.

Die spindel verhält sich ganz ähnlich wie bei M. atramentarius.

1. Koll. O. SEmper. Facatativa, Nen-Granada. PETERSEN leg. Ein Stïck, ganz älmlich in Form und Zeichnung wie Fig. 458.

$$
6 \frac{1}{2}-73,0 \times(30,2) 37,0-35,8 \times 19,6 .
$$

2. Nr. 5798. Cundai. Staat Tolima, Columbien. Baron V. NoLCKE leg. 1876. Ein Stück, ganz ähnlich wie das vorangehende.

3. Koll. STrEBEL. Nen-Granada. Ein Stück, auch ganz ähnlich dem sub 1 . verzeichneten.

4. Koll. ScHoLviex. Nen-Gramada. Ein Stück, fast identisch mit P.. Fig. 7, aber die Rückseite ist nur mit einem schwarzen, ausfließenden Streifen hinter dem hell berandeten Inundsamm versehen.

$$
\text { т } 90,0 \times 137,6) 46,8-46.7 \times 24.9 \text {. }
$$

5. Koll. Scholviex. Columbien. Zwei Stïcke, ganz ähnlich wie das sub 1 relzeichnote Stiick.

6. RoLLE rend. Columbien. Zwei stïcke, ähnlich wie P., Figg. 7/8, nur weiflicher in der Grundfarbe und mit zum Teil größeren Fleckenstreifen. Gegen das Ende wird die letzte Windung rotbraun, und bei dem einen Stück, den zweiten der Mabliste, gelıt die gelbbrame Fürbung: nul bis Band 3 .

$$
\begin{aligned}
& 7-80.8 \times(35,7) 41,7-40,9 \times 20,7 . \\
& 6 \%-81,8 \times(34,5) 41,7-40,7 \times 21,0 .
\end{aligned}
$$


7. Koll. DoHRN. ? Columbien. Drei Stïcke.

Fig. 477. $61 / 4-73,4 \times(31,4) 38,3-37,7 \times 18,8$.

$6 \frac{1}{2}-75,2 \times(32,3) 41,0-38,4 \times 19,8$.

$63 / 4-84,0 \times(35,7) 42,4-40,5 \times 22,3$.

Während die ersten beiden Stïcke unter sich fast gleich sind, entspricht das letzte der Maßliste mehr P., Fig. 7, nur bleibt die letzte Hälfte der letzten Windung hell gefärbt, und nur nahe dem Mundrande befindet sich ein schwarzbramer, schmaler, ansfließender Streifen.

\section{II. powisianus PETTT.}

Taf. XXIII, Fig. 351; Taf. XXXII, Figg.472, 473, 478.

P., p. 206, Taf. 37, Figg. 28/34.

Ich habe der PILsBRYschen Beschreibung nur weniges hinzuzufügen.

Am Embryonalgewinde mit 23 bis 3 Windungen (Fig. 351) sind die Grübchen bald in regelmäßigen, bald in etwas mregelınäßigen Reihen angeordnet, im ganzen sind sie etwas kleiner als bei $M$. adamsoni.

Es kommt eine kleine Form vor (Fig. 459). Form und Zeichnung des Gehäuses sind verschieden, wie schon ans den Abbildungen PILSBRYs hervorgeht, die ich noch ergänze. Ein Stück, Fig. 470, hat am Gewinde keine Spur von Bändern, und auf der letzten Windung ist Band 3 weiß, und zeigt nur auf der letzten Hälfte in der Mitte noch einen schmalen braunen Streifen.

Anch bei dieser Art befindet sich an der Basis die dunkle schmale Zone, die beim jungen Stück im Innern in den Basalrand ausmündet.

Es kommen anf der letzten Windung vielfach breite schwache Rumzeln vor bezw. seichte grobe Furchen, die mehr weniger lang sind; auch hanmerschlagartige Eindrïcke traten auf.

1. Sonson, Prov. Antioquia. WALLIS leg.

a) Nr. 15712. Koll. STREBEL. Ein großes Stiuck, das auf den vorletzten Windungen undentliche grauviolette wolkige Streifen auf weißem Grunde zeigt. Unterhalb des schwarzbramen Bandes 3 tritt auf der letzten Windung eine hell bräunlichgelbe Färbumg anf, und anf dem letzten Drittel wird die Windung bis zum schwarz berandeten Mundsaum rotbraun.

Fig. 478. ? $7-81,7 \times(33,7) 41,2-39,8 \times 22,8$.

b) Koll. O. SEMPER. Zwei Stïcke, in Färbung und Zeichnung ganz ähnlich wie P., Fig. 28, aber mit der typischen Mündıngspartie bezw. der ausg'ehöhlten Spindel.

$$
7-71,0 \times(29,6) 36,1-33,6 \times 19,7 \text {. }
$$

2. Koll. DoHRN. Columbien. Sechs Stücke, von denen ich nur das junge und das Stück mit dem weißen Band 3 abbilde; die übrigen entsprechen den Abbildungen in P., Figg. 28, 33, 34. 
Fig. 472. $\quad 5^{3} / 8-35,2 \times(22,4) 24,8-19,0 \times 12,8$.

,. 473 . са. $6^{7 / 8}-66,0 \times(28,2) 32,8-31,1 \times 18,2$.

$7-70,6 \times(30,3) 35,6-34,3 \times 17,6$.

$63 / 8-50,7 \times(24,2) 27,3-23,4 \times 14,0$.

$61 / 4-51,0 \times(24,6) 29,0-24,9 \times 15,5$.

3. Nr. 15 713. Koll. Strebel. Nell-Granada. Ein typisches Stück. $63 / 4-67,0 \times(29,8) 36,0-33,4 \times 19,4$.

4. Koll. Scholvien. Neu-Granada. Zwei Stücke, die von kleiner Form sind und eine etwas gelblichgrane, nach oben zu violettgrane Färbung haben. Sie entsprechen in der Zeichnung der Fig. 28 in P. $63 / 8-54,4 \times(25,1) 28,2-25,5 \times 15,1$.

\section{M. apmoximatus FuLTON.}

Taf. XXXIII, Fig. 468.

P., p. 208, Taf. 40, Figg. 1/3.

Diese gut beschriebene Art steht in der Mitte zwischen Mr atramentarins und $M$. porisiamus, sie hat mit letzterer gemeinsam, daß die Mündung innen weiß und nicht violett wie bei erstgenamnter Art ist. Während die Form des Gehänses sich mehr der des M. povisianus nähert, entsprechen Färbung und Zeichnung mehr denen von Mr. atramentarius, wofür meine Fig. 475 dieser Art ein Beleg sein mag.

Das mir vorliegende, von SOWERBY und FuLToN gekanfte, also wohl typische Stïck, hat nicht wie PILSBRY sagt, die oberen Windungen der Cuticula entkleidet, diese wird nur nach oben dünner und ist dadurch die Färbung mehr grau mit leicht violettem Anflug. Das Embryonalgewinde mit $23 / 4$ Windungen ist mit nicht ganz regelmäßigen Reihen von verhältnismäßig großen Grübchen bedeckt. Das mir vorliegende Stïck zeigt außerdem die ersten $1 \frac{1}{2}$ Windungen an der Naht ziemlich grob gefaltet, ob das zufällig ist, muß ich dahingestellt sein lassen. Zuerst tritt eine helle Zone an der Naht auf, die dann in eine Zone mit braunen und weißen Flecken übergeht, welche aber bald in Streifen anslanfen, von denen die braunen an Stelle von Band 2 winklig vorspringen, doch hört das mit dem Embryonalgewinde auf. Im übrigen stimmt alles mit Beschreilung und Abbildungen in $\mathrm{P}$.

$$
6^{1 / 8}-59,0 \times(26,2) 31,5-29,7 \times 15,5 .
$$

\section{Aeliciosus n. sp.}

Taf. XXII. Figg. $352 \mathrm{a}-\mathrm{g}$.

Das Gehäuse ist festschalig, aber dümnschaliger als die übrigen Arten dieser Untergattung, schwach fettglänzend, in der Form dem M. adtamsoni entsprechend, aber bedentend kleiner, und die Spindel ist eingebngen, düm, weißlich bis granviolett und mit keiner verdickenden 
Auflagerung versehen. Die Windungen sind mäßig gewölbt und durch eine schmal berandete Naht getrennt.

Als den Typus der Färbung und Zeichnung muß man wohl die Figuren 352 c, f, g ansehen. Es ist eine isabell- bis ockergelbe Grundfarbe, die nach oben ins hell Hornfarbige übergeht. Auf die zuerst braunen Flecke, dann Streifen, des Embryonalgewindes folgen Streifen, die an Stelle von Band 2 winklig ausbiegen, und die damu allmählich dunkler werden, gedrängter und regelmäßig gereiht stehen, vereinzelt sich verzweigen oder, auch wellig werden. Dazu gesellen sich auf den letzten Windungen zuweilen wolkige, hell- oder dunkelgraue Streifen (Figg. 352f, g) und ein schwarzes, durchgehendes (Fig. 352 g) oder durch wechselnde Betomung stellenweise gegliedertes Band 3 (Fig. $352 \mathrm{c}$ ). Das Band 2 kennzeichnet sich immer nur durch winklige Ausbiegungen oder stärkere Betomung der schmalen Streifen; das Band 4 ist breiter und nur durch stärkere Betonung der Streifen markiert. An der Basis befindet sich damu eine verhältnismäßig breite, dunkel- bis schwarzbraune Zone, die im Innern in den Basalrand ausfließt.

Den Übergang zu einem zweiten Typus der Zeichnumg bietet Fig. $352 \mathrm{f}$, bei dem oberhalb des schwarzen Bandes 3 sich eine hellere Zone befindet, die durch unterbrochen auftretende Verbreiterung des Bandes nach oben, gegliedert erscheint. Den zweiten Typus bildet dann Figg. 352 d, e, bei dem von der 3. Windung an die Zone zwischen Band 2 und 3 weiß ist, mit breiten schwärzlichen Streifen besetzt, die von dem brannschwarzen Band 3 schräg nach rechts aufsteigen. In diesen schwärzlichen Streifen, wie auch in dem Weiß, zeigen sich ab und zu noch die durchgehenden schmalen braunen Streifen der typischen Zeichmung. Während bei diesem Typus die Zone oberhalb Band 2 einen mehr weißlichen Grundton zeigt, ist die Zone zwischen Band 3 und der schwarzbraunen Basalzone durchweg mehr ockergelb gefärbt. Eine dritte Abweichung ist in Fig. $352 \mathrm{~b}$ dargestellt, bei der die ganze Partie zwischen Band 3 und der Naht sich wie die vorangehend geschilderte Zone zwischen Band 3 und 2 verhält, doch können hier die graubraunen, in sich gestreiften breiten Streifen nicht nur senkrecht in der Auwuchsrichtung verlaufen, wie es die Fig.352b zeigt, sondern auch zickzack- oder treppenartig abgestuft.

Das Innere ist mit einer dünnen oder stärkeren, weißlichen, etwas violett angehauchten Schmelzschicht belegt, welche die änßere Zeichnung mehr weniger durchscheinen läßt. Der Mundrand ist außen und imnen schmal dunkel purpurbraun berandet, und ebenso ist der Callus gefärbt, der aber meist nach oben und innen dünner bezw. heller wird.

Die Skulptur ist verhältnismäßig schwach ansgeprägt, die Falten sind schmal und unscheinbar und die Spiralfurchen äußerst fein, dicht gedrängt und nur stellenweise und unter starker Lupe erkennbar. 
Es ist eigentïmlich, daf diese schöne Art, die W'ALLIS gesammelt hat, in O. SEMPERs und meiner Sammlung die langen Jahre ein merkanntes Dasein gefristet haben. Ich hatte sie als O. bensoni liegen, mnd zwar in sieben Stiicken von Baranquilla an der Mündung des MagdalenaStromes. Darunter die Typen:

Fig. 352 b. $\quad 6 \frac{1}{4}-54,0 \times(23,7) 28,7-28,0 \times 16,6$.

Figg. 352 a, d, e. $6-47,1 \times(20,3) 25,6-23,8 \times 14,0$.

Fig. 352 c. $\quad 5 \frac{3}{4}-40,0 \times(19,7) 24,8-21,9 \times 13,7$.

Koll. O. SEMPER. Ton Sonson, Nen-Granada. Zwei Stiicke.

Fig. 352f. $\quad 55 / 8-42,9 \times(20,0) 25,6-24,2 \times 13,8$.

$$
\text { .. } \quad 352 \mathrm{~g} . \quad 5 \% \frac{3}{4}-42,7 \times(24,5) 24,5-22,2 \times 12,8 \text {. }
$$

Merkwürdiger ist noch, daf diese schöne Art bisher nicht wiedergefunden zu sein scheint.

\section{Subgenus Laeorthalicus n. subg.}

Diese Untergattung wird nur durch ein Stïck vertreten, das sich in Berliner Museum ohne Namen befindet, nur mit der Fundortsangabe Rio Branco, STaUdnger. Es gibt mun sowohl in Bolivien wie in Brasilien und Paraguay einen Fluß dieses Namens.

Auf den ersten Anblick glaubt man eine zu Corona gehörige Art vor sich zu haben, da auch die Zeichnung und das Linksgewundensein dafür spricht. Unter der Lupe zeigt aber das Embryonalgewinde die charakteristische Grübchenskulptur, die freilich nur stellenweise regelmäbig sich kreuzende Reihen aufweist, vielmehr oft nur umregelmäfig geordnet ist. Die Art gehört also zur Gattung Orthaticus, innerlıalb der sie aber ihrer sonstigen Beschaffenheit nach eine besondere Untergattung bilden muf.

Das Gehäuse ist fest- aber nicht starkschalig, etwas glänzend, linksgewunden, oval-getürmt, mit fast 7 mäßig, zuletzt stärker gewölbten Windungen, die durch eine schmal berandete, zuletzt sogar schwach wulstige Naht getrennt sind, und deren letzte niedriger als das Gewinde ist. Die Mündung ist schmal verkehrt ohrförmig, der Mundrand ist in der Mitte etwas abgeflacht, scharf, nur sehr wenig kur umgeschlagen, mach mten erweitert. Der Basalrand geht in einem tiefen, schmalen Bogen in die gentundene, nur wenig verdickte Spindel über.

Die Skulptur besteht aus schmalen unscheinbaren Falten, die an der Nalıt etwas schärfer ausgeprägt sind. Nur vereinzelt sind überaus feine Spiralfurchen zu erkennen. Der Name ist dem griechischen Ireios entlehnt.

\section{L. reginceformis n. sp).}

Taf. XXII, Figg. 353 a, b, c.

Zn der obigen Beschreibung füge ich über Färbung und Zeichnung folgendes hinzu. 
Das Embryonalgewinde hat $23 / 4$ Windungen. Die erste Windung ist weißlich, oben schmal braun berandet, die damn folgenden sind bräınlich und mit einer bläulichgranen Zone an der Naht versehen, die bald durch brame Streifen gegliedert wird, welche Streifen sich dann verlängern; zugleich tritt Band 2 als schmaler braumer Streifen auf, das sich bis zu $4 \frac{1}{2}$ Windungen in mehr weniger deutlich gegliederter Form erhält, dann verschwindet. Die auf das Embryonalgewinde folgende Zeichnung auf granem bis gelblichgranem Grundton besteht aus zuerst braumen, dann dunkel blaugrauen, nach vorn weiß berandeten, etwas verbreiterten Streifen, welche an Stelle von Band 2 entweder winklig vorspringen oder treppenartig abgestuft sind, die aber auf der letzten Hälfte der letzten Windung durch schmale, dicht gedrängte, etwas dunklere Streifen als die Grundfarbe ersetzt werden. Auf den beiden letzten Windungen ist die Färbung von der Stelle des Band 2 ab bis zur Basis gelblich olivenfarbig und nur durch das heller gefärbte, schmale Band 3 unterbrochen. Der Mundrand ist außen hell, innen lebhaft kastanienbraun gefärbt, das Innere ist anfangs weißlich, dann blänlichgrau mit durchscheinender Zeichnung. Der Callus ist purpurbraun wie der untere Teil der Spindel, die nur oben weiß ist.

$$
6^{7} / 8-51,3 \times(19,6) 23,0-21,6 \times 10,9 .
$$

\section{Genus Liguus MoNTF.}

Zu dieser von PuLSBRY eingehend beschriebenen Gattung, deren Arten gut beschrieben und durch viele Abbildungen erläntert sind, will ich nur weniges bemerken.

Das Embryonalgewinde unterscheidet sich von dem der Gattung Corona durch folgendes. Es ist schmäler angelegt, und die Windungen sind nicht so riemenförmig aufgerollt bezw. oben nicht so stumpfkantig. Die Skulptur derselben besteht aus sehr feiner Streifung, etwas kräftigeren Falten an der Naht und zuweilen auch am Unterteil der Windungen, und in der Mittelpartie treten ab und zu feine Spiralfurchen auf, auch stellenweise Spuren einer Stäbchenskulptur.

Die spätere Skulptur besteht aus feinen, unscheinbaren Falten, die bei größeren Stïcken auf der letzten Windung etwas schärfer ausgeprägt und regelmäßig gereiht sind, so daß das Gehäuse hier meist ein gerieftes Ansehen erhält.

Die Vindungen sind meist durch eine schmale, angepreßte Naht getrennt. Eine wesentliche Abweichung von der Gattung Corona bietet die in ihrer Ausbildung sehr veränderliche Spindel. Sie ist ziemlich gerade oder selbst mehr weniger eingebogen, in sich mehr weniger gewunden, nach innen zu oben mit einer Falte oder der Länge nach mit einer Verdickung und selbst mit einem leistenförmigen Anwuchs versehen, wobei 
aber immer, im Gegensatz zu Corona, der untere Teil stärker entwickelt ist als der obere. Durch den leistenartigen Anwuchs wird das Achatinaartige Abgestutztsein der Spindel bewirkt, das aber nicht immer vorhanden ist. Vergleicht man die jungen Stücke von Corona mit denen von Ligmus, so macht sich sofort die von Anfang an verschiedene Bildung der Spindel bemerkbar, die bei Corona stark gewunden ist und einen gesclıweiften, nicht geraden Verlanf nimmt.

Wie ich schon bemerkte, hat PILSBRY die einzelnen Arten dieser Gattung so eingehend beschrieben und vielseitig abgebildet, daßs ich von einer Auffülnung derselben füglich absehen kamn, zumal das Material unseres Museums nur ganz ausnahmsweise mit genauen Fundorten versehen ist. Ich werde nur von den drei Hauptarten einige Beispiele für die Bildung des Embryonalgewindes, des Jugendzustandes und der Spindel geben, letztere in halber Drehung, um die Bildung besser zu zeigen. Für das Embryonalgewinde gilt für alle Arten die Fig. 352.

\section{L. virgineus L.}

Taf. XXXIII, Figg. 464/467, 469.

P., p. 162, Taf. 56, Figg. 58/69.

1. Port an Prince, Haiti. G. KeIted jr. leg. 1901. Zwei Stücke. Figg. 464, 465 .

2. Koll. Scholvien. Ohne genanen Fundort. Figg. 466, 467, 469.

\section{L. fresciutus MÜLLER.}

Taf. XXI, Figg. 332, 332 a, b; Taf. XXXII, Figg. 453, $455 \mathrm{a} / \mathrm{c}$. P., p. 166, Taf. 57/60; Taf. 55, Fig. 54.

RoLLe vend. Guantamana, Cuba. Neun stücke, von denen das größte folgende Maße hat.

$$
8-67,6 \times(28,9) 33,0-29,1 \times 15,8 .
$$

Trotz der Größse ist die Spindel wie bei Fig. 453 gebildet. Jüngere Stücke geben in Fig. 332 die Form des Embryonalgewindes, in den übrigen Figuren die allgemeine Form und die Spindelbildung in ihren besonderen Verschiedenheiten wiecier.

L. blainiamus POEY.

Tif. XXXIII, Fig. 463.

P., p. 166, Taf, 55, Figg. 55/57.

Koll. Scholvien. Florida (?). Ein Stïck. 


\section{Erklärung der Abbildungen.}

\section{Figur}

Tafel I.

1 Zebra princeps, Nr. 1

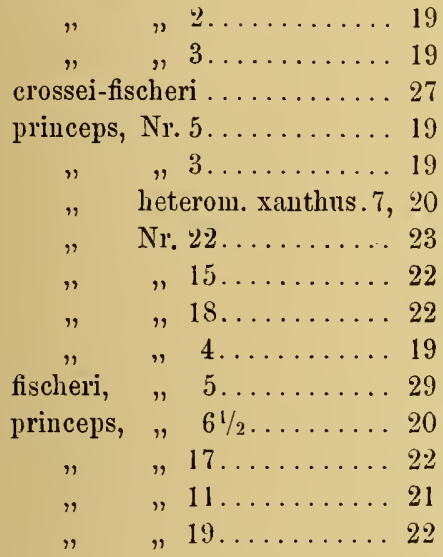

\section{Tafel II.}

17 Zebra crossei-fischeri .......... 27

1s " fischeri, $\mathrm{Nr}, 2 \ldots \ldots \ldots \ldots 28$

$19 / 20, \quad$ crossei,, $3 \ldots \ldots \ldots \ldots .26$

$21 \quad, \quad$ princeps,, $22 \ldots \ldots \ldots \ldots 23$

$22 / 3 \quad$ fischeri,, $2 \ldots \ldots \ldots \ldots 2 \mathrm{~S}$
$" \quad, 4 \ldots \ldots \ldots \ldots .29$

princeps,, $14 \ldots \ldots \ldots \ldots .21$

, $13 \ldots \ldots \ldots 21$

, $16 \ldots \ldots \ldots 22$

, $25 \ldots \ldots \ldots 24$

fischeri,, $4 \ldots \ldots \ldots \ldots 29$ $, \quad, \quad 1 \ldots \ldots \ldots \ldots .28$ princeps,, $20 \ldots \ldots \ldots \ldots .23$

\section{Tafel 11 .}

$33 / 4$ Zebra fischeri, Nr. 6 . . . . . . . 29 $35 / 6$ " delphinus; f. nebulosus, Nr. 131 $37 \quad, \quad$ fischeri, $\mathrm{Nr} .6 \ldots \ldots \ldots 29$ maculiferus
Figur

Seite

39/40 Zebra delphinus, f. nebulosus, Nr. 231 41

" " " " " $\quad 331$

$42 \quad " \quad " \quad$ "vividus, Nr. 4 . 35

$43 / 4 \quad " \quad$ " "nebulosus,

$45 \quad$ "delphinus, f. nebulosus heterom.melanochilus, $\mathrm{Nr} .133$

46,48 " delphinus, f. nebulosus heterom. pumilio, Nr. 1 . 33

$47 \quad$ "delphinus, f. nebulosus, Nr. 632

$49 / 50 \quad " \quad, \quad, \quad, \quad, 1132$

\section{Tafel IV.}

51 Zebra delphinus, f. nebulosus

heterom. pumilio, Nr. $4 \ldots 34$

$52 / 3$ " delphinus, f. vividus, Nr. 2. . 34

$54 \quad, \quad$ selectus, $\mathrm{Nr} 1 \ldots \ldots \ldots . \ldots 37$

$55 / 7$, delphinus, f. vividus, Nr. 1 . 34

$5 \mathrm{~S} \quad, \quad$ selectus, Nr. $1 \ldots \ldots \ldots . \ldots 37$

59 , , delphinus, f. vividus, Nr. 1 . 34

$60 / 2 \quad, \quad$ richardsoni ........... 36

$63 \quad, \quad$ selectus, Nr. $2 \ldots \ldots \ldots \ldots . .37$

$64 / 7 \quad " \quad$ elegans,, $2 \ldots \ldots \ldots \ldots . .39$

\section{Tafel V.}

6S/9 Zebra nobilis, Nr, $2 \ldots \ldots \ldots \ldots .40$

$70 / 1 \quad, \quad, \quad$ f. pallida ........4 40

$72 / 3 \quad " \quad$ livens $\ldots \ldots \ldots \ldots \ldots \ldots \ldots 42$

$74 / 7 \quad " \quad$ f. aberralls, Nr. 1 . 43

$7 S \quad$ " quagga, f. turrita ....... 42

$79 / 80$ " livens, f. aberrans, Nr. 1 . 44

$81 / 2 \quad, \quad, \quad " \quad, \quad, 2 \ldots 44$

\section{Tafel VI.}

S3/4 Zebra princeps, f. pilsbryi, Nr. $2 \ldots 47$

$85 / 6 \quad$ " $\quad$ " $\quad, \quad, 4 \ldots 47$

ST/S $\quad " \quad$ " $\quad$ " $\quad$ " $1 \ldots 47$ 


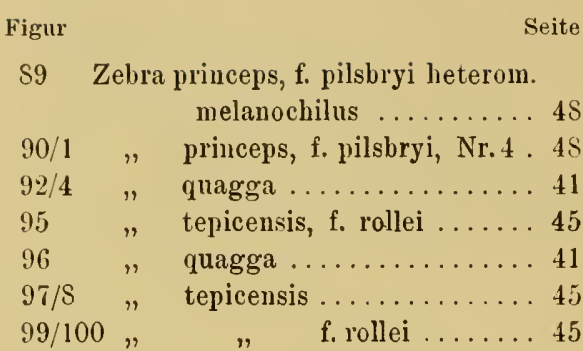

\section{Tafel VII.}

101/3 Zebra lividus, Nr. 1 b . . . . . . 49

$104 / 5 \quad " \quad, \quad, 4 \ldots \ldots \ldots \ldots 49$

$104 \frac{1 / 2}{"}$ "hackeri .............. 50

$106, "$ lividns, Nr. 1 c....... 49

$107 \quad "$ hackeri ............. 50

$108 \quad " \quad$ " heterom. xanthus. 51

$109 / 11 \quad " \quad, \quad \ldots \ldots \ldots \ldots .50$

\section{Tafel VIII.}

$112 / 5$ Zebra zoniferus, Nr. $1 \ldots \ldots \ldots .51$

$116 / 7 \quad " \quad " \quad$ f. major, Nr. 1..52

$11 \mathrm{~S} / 9 \quad " \quad " \quad$ Nr.1......51

120/3 " " $"$ f. enchrous, Nr. 152

$124 / 6 \quad " \quad " \quad$ "major, Nr. 2.. 52

$127 \quad " \quad " \quad$ "euchrous, Nr. 152

\section{Tafel IX.}

12S/9 Zebra zoniferus, f, euchrons, Nr. 253 $130 / 43 \quad " \quad$ " "naesiotes, " 153 $144 / 5 \quad " \quad " \quad$ " " " 255

\section{Tafel $\mathbf{X}$.}

146/7 Zebra vexans.............. 56 14S/9 " pulchellus, f. prototypus,

Nr. $1 \ldots \ldots \ldots \ldots . \ldots 9$

$150 \quad "$ pulchellus, Nr. $3 \ldots \ldots .57$

$151 \quad " \quad " \quad, 8 \ldots \ldots .58$

\section{$152 / 3 \quad " \quad$ f. prototypus,}

$154 \quad "$ pulchellus, Nr. $7 \ldots \ldots \ldots 58$

$155 \quad " \quad n \quad, 4 \ldots \ldots \ldots 58$

$156 \quad " \quad " \quad " 5 \ldots \ldots \ldots 58$

$157 \quad " \quad$ f. prototypus,

Nr. $4 \ldots \ldots \ldots \ldots \ldots 59$

$15 \mathrm{~S} \quad "$ uhdeanus, $\mathrm{Nr}, 2 \ldots \ldots \ldots 63$
Figur

Seite

159/60 Zebra pulchellus, f. prototypus,

Nr. $2 \ldots \ldots \ldots \ldots \ldots$

$161 / 2 \quad " \quad$ uhdeanus, Nr. $3 \ldots \ldots 663$

$163 / 6$ " mars heterom. melanochilus 61

\section{Tafel XI.}

167 Zebra mars, f. decolor, Nr. 2, . 62

$168 \quad " \quad, \quad$ Nr. $7 \ldots \ldots \ldots \ldots 61$

$169 \quad " \quad " \quad, 5 \ldots \ldots \ldots \ldots 60$

$170, " \quad " 3 \ldots \ldots \ldots \ldots 60$

$171 \quad " \quad, \quad, 10 \ldots \ldots \ldots \ldots 61$

$172 ", \quad " 4 \ldots \ldots \ldots \ldots 60$

$173 \quad " \quad, \quad, 9 \ldots \ldots \ldots \ldots 61$

$174 ", \quad$ heterom. mclanochilus,

Nr. $4 \ldots \ldots \ldots \ldots 66$

$175 \quad, \quad$ mars, Nr. $7 \ldots \ldots \ldots \ldots 61$

$176 "$ " heterom. melanochilus,

Nr. $1 \ldots \ldots \ldots \ldots 61$

\section{Tafel XII.}

177/S Zebra sphinx, f. latestriata .... 67 $179 \quad " \quad " \quad$ "zonata, Nr.1..67 67 $180 \quad " \quad " \quad$ "turrita ......6 68 $181 \quad " \quad " \quad$ Nr. I ........66 66 $182 \quad " \quad " \quad$ f. zonata, Nr. 1 . 67 $183 / 4 \quad, \quad$ miles ................ . 64 $185 \quad " \quad$ sphinx, Nr.1........66 66 $186 / 9 \quad, \quad$ miles .............. 64

\section{Tafel XIII.}

190 Zebra longus, Nr. 3 . . . . . . . 69

$191 / 2 \quad " \quad " \quad, 2 \ldots \ldots \ldots \ldots 69$

193 " maclurae, Nr. $1 \ldots \ldots \ldots$. 0

$194 \quad " \quad " \quad, 2 \ldots \ldots \ldots 70$

$195 \quad " \quad " \quad " 4 \ldots \ldots \ldots 70$

$196 / 7 \quad " \quad " \quad, \quad, \quad, \ldots \ldots \ldots 70$

$198 \quad " \quad " \quad " \quad 1 \ldots \ldots \ldots \ldots 70$

$199 / 202 " \quad " \quad " \quad " 5 \ldots \ldots \ldots \ldots 70$

$203 " \| \quad " \quad " 6 \ldots \ldots \ldots 71$

$204 " \quad " \quad$ f. turrita, Nr. 3. . 71

$205 " \quad " \quad " \quad$ " $"$ 2. 71

$206 / 7 " \quad " \quad$ Nr. $2 \ldots \ldots \ldots .70$

\section{Tafel XIV.}

20S/9 Zebra pseudolongus .......... 71 $210 / 1 \quad, \quad$ boucardi, Nr. $2 \ldots \ldots \ldots$. 72 
Figur

\section{Tafel XX.}

310/1 Zebra varius zu Nr.11 ......994

$312 / 3 \quad$ " , Nr.11....... 93

314 " maracaibensis, f. jamaicensis, $\mathrm{Nr} .6 \ldots \ldots \ldots 91$

315 " maracaibensis, f. jamaicensis, Nr. $5 \ldots \ldots \ldots .91$

$316 \quad " \quad$ varius, $\mathrm{Nr} .6 \ldots \ldots \ldots 93$

$317 \quad, \quad$ bensoni,, $1 \ldots \ldots \ldots \ldots 94$

$318 \quad " \quad, \quad, 3 \ldots \ldots \ldots \ldots 94$

$319 / 20$ " maracaibensis, f. jamaicensis, Nr. $2 \ldots \ldots \ldots .91$

$321 \quad "$ bensoni,, $1 \ldots \ldots \ldots .94$

322 " maracailsensis, f. jamaicensis, $\mathrm{Nr} .3 \ldots \ldots \ldots 91$

323 "maracaibensis, f. jamaicensis, $\mathrm{Nr}, 4 \ldots \ldots . . . .91$

$324 \quad$ maracaibensis, f. jamaicensis, Nr. 1....... 91

$325 / 6$ " maracaibeusis, f. jamaicensis, $\mathrm{Nr}, 4 \ldots \ldots \ldots \ldots$

\section{Tafel XXI.}

Nit Ausuahme der Figg. 327 nud $332 \mathrm{a}, \mathrm{b}$ entsprechen die Abbildungen den vergrößerten Embryonalgewinden.

327 Porphyrobaphe iostomajuv., Nr.4 d 105 $327 \mathrm{a}, \mathrm{b}$ 327 e Schema für das Zählen der Windungen

325 Myiorthalicus demisoni ...... 115

$3: 9$ Oxyortlalicus irroratus ....... 115

330 Hemibulimus iris............ 113

331 " dellnisoni, f. carns . 112 $\left.\begin{array}{l}332 \\ 332 \text { a b b }\end{array}\right\}$ Liguus fasciatus . . . . . . . 182 333 Hemibulimus excisıs ......... $10 \mathrm{~s}$ $334 \quad$ " magnificus ....... 109 335 a, b Pachytholus flori ......... 139

336 Corona rosenbergi........... 136

$337 \quad, \quad$ pfeifferi, f. cincta...... 135

335 Pachytholus pseudoiostomms.... 139

$339 \mathrm{a}, \mathrm{b}$ Corona regalis . . . . . . . . . 124

340 Metorthalicus marauhoneusis .... 156

341 Tholus buckleyi ........... . 137

342 Ietorthalicus shnttleworthi .... 157

$343 \quad, \quad$ kelletti . ...... $15 \mathrm{~S}$

344 Ortbalicus sultana .......... 142

Figur

Seite

\section{Tafel XXII.}

Die Figg. 315-351, 35:a, 353a zeigen das vergröfierte Embryoualgewinde, die ubrigen Figuren wie alle die der folgenden Tafeln das

Gehänse.

345 Trachyorthalicus fraseri... .... 152

346 Metorthalicus yatesi.......... 162

$317 \quad " \quad$ deburghiae...... 172

3 tS Clathrorthalicus wallisi ........ 150

349 Melaniorthalicus adamsoni .... . 175

350 a, b, atramentarius... 174 $351 \quad$ powisianns .... 177 $352 \mathrm{a}-\mathrm{g} \quad, \quad$ deliciosus ... . 17s $353 \mathrm{a}-\mathrm{c}$ Laeiorthalicus reginaeformis 180 354 Clathrorthalicus wallisi ....... 150 355 Corona rosenbergi........... 136 356 " pfeifferi, f. cincta, Nr. 2.135 $357 \quad " \quad, \quad, \quad, \quad, 1.135$

\section{Tafel XXIII.}

35 Porphyrobaphe iostoma heterom. albiuns, Nr. 2.......... 105

359 Porphyrobaphe iostoma heterou. inelanochilus, Nr. S........ 105

360 Porplyyrobaphe iostoma, Nr. 14 . 106

361 Hemibulimus excisns, Nr. 2..... 108

$362,364 \quad$ " magnificus ....... 109 $363 \quad$ excisus, Nr. 1.... $365 \mathrm{a}, \mathrm{b}\} \quad$ " dennisoni, F. carus . 112 367 Porphyrobaphe saturuus, Nr. 2.. 107

368

369

$$
\begin{aligned}
& \text { ". } \quad, 1 \ldots 107 \\
& \text { ", }, \quad, 3 . .107
\end{aligned}
$$

\section{Tafel XXIV.}

370 Oxyorthalicus irroratus, f. grevillei, Nr. 2... 120 irroratus, f. grevillei, Nr. 1... 119 irroratus, Nr. 3... 118 Hemibulimus iris, Nr. 1... . . 114 Oxyorthalicus irroratus, Nr. 1 . 1 is

$$
\text { " } \quad \text { f. gre- }
$$
villei, $\mathrm{Nr}, 3 \ldots 120$

376 Myiorthalicus dennisoni var. pallida, Nr. 2.... 116 
Figur

377 Myiorthalicus dennisoni, Nr. 6 .. 117 $378 / 9 \quad$ " $\quad$ var. pal-

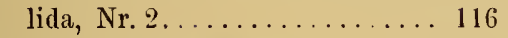
$3 S 0$ a, b Tholus buckleyi ......... 137

\section{Tafel XXV.}

$3 s 1 / 2$ Corona regina, $\mathrm{Nr}, 3 \ldots \ldots \ldots 122$ $3 \mathrm{S3} \quad " \quad, \quad, 2 \mathrm{c} \ldots \ldots \ldots 122$ $384 \quad " \quad, \quad, 2$ b...... 122 $385 \quad$ "perversa var.?, Nr. 2 . . 133 3S6/7 Pachytholus flori, Nr. 1 . . . . . 139 $38 \mathrm{C}$ Corona regina, Nr. 2 a . . . . . 1:2

\section{Tafel XXVI.}

389 Corona regina, $\mathrm{Nr}, 4 \ldots \ldots \ldots 123$ $390 \quad " \quad, \quad, \quad \ldots \ldots \ldots .123$ $391 / 2 \quad " \quad$ regalis,, $8 \ldots \ldots \ldots .125$ $393 / 4 \quad " \quad, \quad 9 \ldots \ldots \ldots 125$ $395 \quad " \quad, \quad, 7 \ldots \ldots \ldots 125$ $396 \quad " \quad, \quad, 16 \ldots \ldots \ldots \ldots 126$ $399 \quad " \quad, \quad, 14 \ldots \ldots \ldots 126$ 397/S Pachytholus pseudoiostomus, Nr. 2140

\section{Tafel XXVII.}

400 Corona perversa, Nr. $8 \ldots \ldots \ldots . .133$ $401 \quad, \quad, \quad$ ?var., Nr. 1 . . 133 $402 \quad " \quad$ regalis?, Nr. 2 ...... 127 $403 \quad "$ perversa, , $1 \ldots \ldots \ldots 132$ $404,407, \quad$ regalis, f. loroisianus, Nr.1 129 $405 \quad$ ",$\quad$ " " $406 \quad " \quad, \quad, \quad, \quad, \quad$, 130

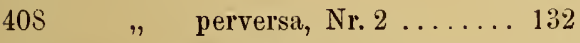
$409 \quad " \quad$ regalis, f.loroisianus, Nr.6 129 $410 \quad " \quad$ ",$\quad$,8 130 $411 \quad " \quad$ incisa, $\mathrm{Nr} .1 \ldots \ldots \ldots 131$ $412 / 3 \quad$ " $\quad$ f. machadoensis. . 131

\section{Tafel XXVIII.}

414, 416 Orthalicus sultana D ...... 144 415 417 418 , B ..... 143 " E..... 145 f. meobambensis, $\mathrm{Nr}, 9$ a... 148 sultana, f. meobambensis, Nr. 9 d... 149
Figur Seite 420 Orthalicus sultana, f. meobambensis, $\mathrm{Nr} .8 \ldots .148$ $4: 1$ 422

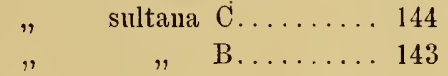

\section{Tafel XXIX.}

423 Trachyorthalicus fraseri, f. brevispira, $\mathrm{Nr} .1154$

\section{fraseri, f. bre-} vispira, Nr. 3154 fraseri, f. brevispira, Nr. 2154

Orthalicus sultana, f. meobambensis, $\mathrm{Nr} .7 \ldots \ldots 14 \mathrm{~S}$

$$
\begin{aligned}
& \text { sultana, f. meobam- } \\
& \text { bensis, Nr. } 1 \ldots \ldots .146 \\
& \text { sultana, f. meobam- } \\
& \text { bensis, var. carnea } 149 \\
& \text { sultana, f. meobam- } \\
& \text { bensis, Nr. } 1 \ldots \ldots .146 \\
& \text { sultana, f. meobam- } \\
& \text { bensis, Nr. } 5 \ldots \ldots .147
\end{aligned}
$$

\section{Tafel XXX.}

Trachyorthalicus fraseri 1 a.... 152

$$
\text { " } \quad \text { f. bre- }
$$
vispira var. modestus, Nr. 3 . 154

Trachyorthalicus fraseri, f. perplexus ............. 155

Trachyorthalicus fraseri var. lıteus, Nr. $1 \mathrm{~b} \ldots \ldots \ldots \ldots \ldots 153$

Orthalicus sultana A, Nr.4 . . 143 " $\quad " \quad \mathrm{Nr} .6 \ldots \ldots .142$ ILetorthalicus shuttleworthi, Nr. 1157 " " $\quad$ " 2158 Orthalicus sultana, Nr. $1 \ldots \ldots 142$ " $"$ f. meobambensis, $\mathrm{Nr} .4 \ldots \ldots \ldots \ldots \ldots 147$

\section{Tafel XXXI.}

441/2 Metorthalicus kelletti, Nr. 1.. 159 443 yatesi, f. galactostoma juv., Nr. I . . . . 168 444 Metorthalicus kelletti, Nr. $7 \ldots 160$ 445 446

$$
\begin{aligned}
& , \quad, 6 \ldots 160 \\
& , \quad, \quad 4 \ldots 160
\end{aligned}
$$




\begin{tabular}{|c|c|c|c|}
\hline Figur & & & Seite \\
\hline 447 & Metorthalicus & yatesi, Nr. 1d. & 165 \\
\hline $44 S$ & $"$ & kelletti, Nr. 5 . & 160 \\
\hline 449 & , & maranhonensis & 156 \\
\hline 450 & $"$ & kelletti, f. lojauıs & 161 \\
\hline 451 & $n$ & yatesi, Nr. $1 \mathrm{~b} . .$. & 165 \\
\hline
\end{tabular}

\section{Tafel XXXII.}

452 Metorthalicus leburghiae, Nr. 1. 173

453 Liguus fasciatus . . . . . . . . . . 182

454 Metorthalicus yatesi, Nr.1 e... 166

455 a, b, c Liguus fasciatus. . . . . . . . 182

456 Metorthalicus deburghiae, Nr.2 a 173 yatesi, f. vicarius. 167

, $\mathrm{Nr} .5 \ldots .167$

,

,

, f. galacto.

stoma, $\mathrm{Nr}, 2 \ldots 168$

yatesi, Nr. 1 c ... 165
Figur Seite

461 Metortlalicus yatesi, Nr. 4 ... 167

$462 \quad, \quad$ labeo $\ldots \ldots \ldots \ldots 169$

\section{Tafel XXXIII.}

463 Liguns blainianus . . . . . . . 182

$464 / 7,469, \quad$ virgineus . . . . . . . . IS2

$46 \mathrm{~S}$ Melaniorthalicus approximatus. $17 \mathrm{~S}$

$470 / 1 \quad, \quad$ atramentarius,

Nr. 1 . . . . 175

$472 / 3 \quad, \quad$ powisiallus,

$474 / 5 \quad, \quad$ atramentarius,

Nr. $1 \ldots . .175$

476 Metortlalicus yatesi, f. grandis 168

477 Melaniorthalicus arlamsoni .... 177

478 powisianus, 


\section{Register.}

1. Die mit * versehenen Namen sind Synonyme. 2. Die eingeliammerten Namen geben die Zugehörigkeit der vorangestellten Namen an. 3. Nur die Gattungs- und Untergattungsuamen sind mit großem Anfangsbuchstaben versehen.

\begin{abstract}
aberrans n. f. (livens) .......... 43
adamsoni Gray ................ 175

adustrus n. f. (boucardi) .......... 74

albinns (maclnrae) ..................... 71

(boncardi) $\ldots \ldots \ldots \ldots \ldots \ldots$

(maracaibensis) ........... $\$ 55$

(ferussaci)............. Ss

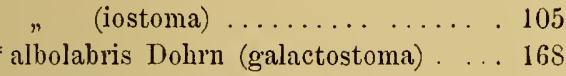

approximatus Fult............. 17S

atramentarius Pfr............ 103, 174

augusti Jousseaume ............ 155
\end{abstract}

bensoni Reeve............... 94

bifulguratus Reeve. ............ 94

blainianus Poey ............. 1S2

boncardi Pfr. ............. 72,74

brevispira Pilsb. (fraseri var.)... . . . 153 buckleyi Higgins........... 102, 137

carnea n. var. (meobambensis)....... 149 car'us Pilsb. (dennisoni var.). ....... 112 cincta n. f. (pfeifferi) ............ 135 Clathrorthalicus n. subgen. ..... 10:2, 150 * colimensis Rolle (nobilis, f. pallida) .. 40 Corona Alb. .............. 102, 120 crossei v. Mart. ............ 10, 25 crossei-fischeri n. sp. .......... 27

deburghiae Reeve............... 172

* deceptor Pilsb. (fischeri). . . . . . 11, 27 decolor Streb.......... 17, 59, 62 deliciosus n. spec.............. 178 delphinus n. sp. ............. 30
Seite

dennisoni Reeve (Hemibulimus) ..... 111

(Myiorthalicus) . 102, 115

elegans Rolle-Streb.............. 3s

elongatus Miller (irroratus var.) ..... 118

euchrons n. f. (zoniferus) . . . . . . . 52 excisus v. Mart. . . . . . . . 10ะ 108

fasciatus MÏ̈ll................. 182 ferussaci v. Mart. (maracaibensis) 11, 27, 87 fischeri v. Mart. . . . . . . . . . 10, 27

flori Jousseaume . . . . . . . . . . . . . . 139

"floridensis Pilsb. (? reses, maracaibensis) ............. 14, 84 fraseri Pfr. .............. 103, 152 * fulvescens Pfr. (delphinus, f. nebulosus) 32 * fungairinoi Hid. (Kelletti). . . . . . . . 159

galactostomus ancey (yatesi) . . . . . 167

* gloriosus Pfr. (deburghiae)......... 172 gracilis n. f. (obductus) ........... is gracilis E. A. Smith (pfeifferi var.).... 136 grandis Rolle-Streb. (yatesi) ......... 168 grevillei Sowby (irroratus var.) ...... 119 gruneri n. sp.................. 63

hackeri n. sp..............50,51 Hemibulimus v. Mart. . . . . . 102, 107

*imitator Pilsb. (maracaibensis) ... 14, 34 incisa Hupé . . . . . . . . . . . . 130 intermedius n. f. (delpliuus) . ...... 35 iostoma Sowby............ 102, $10 t$ iris Pfr. ................. 113 


\begin{abstract}
Seite
irroratus Reeve ............ 102, 11S

* isabellina v. Mart. (fischeri) ....... 27
\end{abstract}

jamaicensis Pilsb. (maracaibensis) ..... 90

kelletti Reeve ........... 103, 159

labeo Brodp. ............. . . . 169

Laeorthalicus n. subgen......... 10;, 180

latestriata 11. f. (sphinx) ... . . . . . . 6 67

* latevittata Shuttlew. (yatesi)...... I63

leucochilus C. et F.............. 94

Liguus Montfort. ............ 103, 181

livens Shuttlew. ............. 42

lividus v. Mart. ................ . 4 4

* lividus-princeps Streb. (splinx) .... 66

lojaums n. f. (Kelletti) .......... 161

* longus Pilsb. (pseudo longus)....... $₫ 1$

longus Pfr................. . 68

loroisianus Hupé (legalis var.)....... $12 S$

luteus 11. var. (fraseri) . . . . . . 108, 15\%

macandrewi Sowby ............ 94

machadoensis n. f. (incisa) . . . . . . 131

maclurae v. Mart. . . . . . . . . . . . . 69

maculiferus n. sp. . ............ 30

magnificus Pfr.-Streb. . . . . . . . . . 109

major (zoniferus)............ 52

maracaibensis Pfr. ......... 11, S4

maranhonensis Alb.......... 103, 156

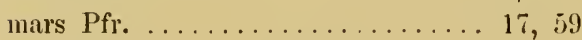

Melaniorthalicus n. subgen. ... . . 103, 173

melanochilus (princeps var.)....... 45

(lelphinus uebnlosus var.) 32

(mars var.) ........ 6 !

(maclurae var.)....... 70

(bolıcarli var.) ....... 74

(reses var.)......... $\$ 4$

(maracaibensis var.) .. 85,86

(ferussaci var.)....... SS

(iostoma var.). ....... 105

melanochilıs Valenc. (ferussaci) .... 14

* $\quad$ v. Mart. (mars) . . . 14, 59

melanostoma Shuttlew. (incisa) ...... $13 \mathrm{~S}$

meobambeusis (sultana var.) ....... 145

Metorthalicns Pilsh. .......... 103, 156

miles 1. sp. ................ 64

minor Miller (irroratus var.) ....... 115

modestus и. var. (brevispira). mïlleri n. sp.............. 46

Myiorthalicus n. subgen. . . . . . 102, 114

naesiotes n. f. (zoniferms) ......... 53

nebulosus n. f. (delphinus) ......... 31

nobilis Rolle-Streb. . . . . . . . . . . 39

obductus Shnttlew. ........... if

Orthalicus Beck. ............ 102, 140

Oxyorthalicus n. subgeu. ...... 102, 117

* Oxystyla Schlüter (Zebra) ......... 3

Pachytholus n. subgen. ....... 102, 135

pallida $n$. var. (demisoni) .......... 115

pallida n. f. (nobilis) ............ 40

* perlonga Pilsb. (? elegans var.) . . . . . 38

perplexus n. f. (fraseri) . . . . . . . . 155

perversa Swains. .............. 132

,$\quad$ fragliche Form . ......... 133

pfeifferi Hid. .............. 94, 134

phlogerus d'Orb. . . . . . . . . . . 94

pilsbryi n. f. (princeps) .......... 46,4S

*ponderosus Streb. (mars) ........ 17, 59

* ponderosus-boncardi Streb. (maclurae) 69

Porphyrobaphe Shnttlew. . . . . . 10. 10, 103

powisianus Petit ............. 177

princeps Brod. .............. is

prototypus Pilsb. (pulchellus) .... 46,58

pseudoiostomus n. sp. . . . . . . 102, 139

pseudolongus n. sp. ............ 71

pseudoobductus n. f. (maracaibensis)... 90

pulchellus spix ............... 57

punilio n. f. (delphinus nebulosus var.) 33

quagga n. sp................. 41

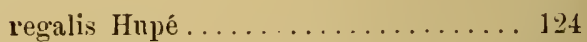

, fragliche form ... ....... 127

regina Fér. .............. 102, 121

reginaeformis 11. sp........... 103, 180

reses Say (undatus) ............ $\$ 3$

richardsoni ,11. sp. . . . . . . . . . . . 36

rollei n. f. (tepicensis). . . . . . . . . . 45

rosenbergi n. sp............ 136

Saturnus Pfr............... 106

selectus 11. sp............... 37

shuttleworthi Alb........... 103, 157

sphiux 1. sp. .............. 66 


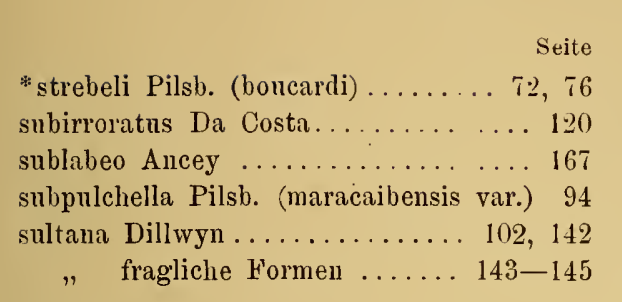

tepicensis n. sp. ............ 45

Tholus n. gen. ............ 102, 137

Trachyorthalicus 11. subgen. .. . . 103, 151

* tricinctus v. Mart. (ferussaci)........ 14

trifracta Pilsb. (princeps var.) ..... . 25

*trullisátus Shuttlew. ............ 145

turrita n. f. (quagga) . . . . . . . . . 42

$" \quad, \quad(\operatorname{sphinx}) \ldots \ldots \ldots \ldots \ldots 6 \mathrm{G}$

$" \quad, \quad$ (maclurae)..... . .... 71

uhdeanus v. Mart. . . . . . . . . . 63

undatus Brug. ............. 15, s0

varius v. Mart. . . . . . . . . . . . . . 91

vexauls $11 . \mathrm{sp} . \ldots \ldots \ldots \ldots \ldots \ldots \ldots \ldots$
Seite

vicarius Fulton (yatesi)........... 167

virgineus L. . . . . . . . . . . 103, 182

vividus n. f. (delplinus)... ....... 34

wallisi n. sp. . . . . . . . . 102, 150

* wallisianus Ptr. (iris) .......... 113

wrzesniowski Labom............. 155

xauthus (princeps var.) . . . . . . . 20

, (hackeri var.) ......... 51

, (boucardi var.)........... 74

" (ferussaci var.)........... SS

yatesi Pfr.............. 103, 163

Zebra Slinttlew. ............. 3

* zebra Müll. (mülleri) ............ 46

zebriola n. f. (boncardi) ........ . . 75

zonata 1. f. (sphinx) . . . . . . . . 67

zoniferus Streb. .............. 51

, $\quad$ 1. f. (boucardi) .......... 75 



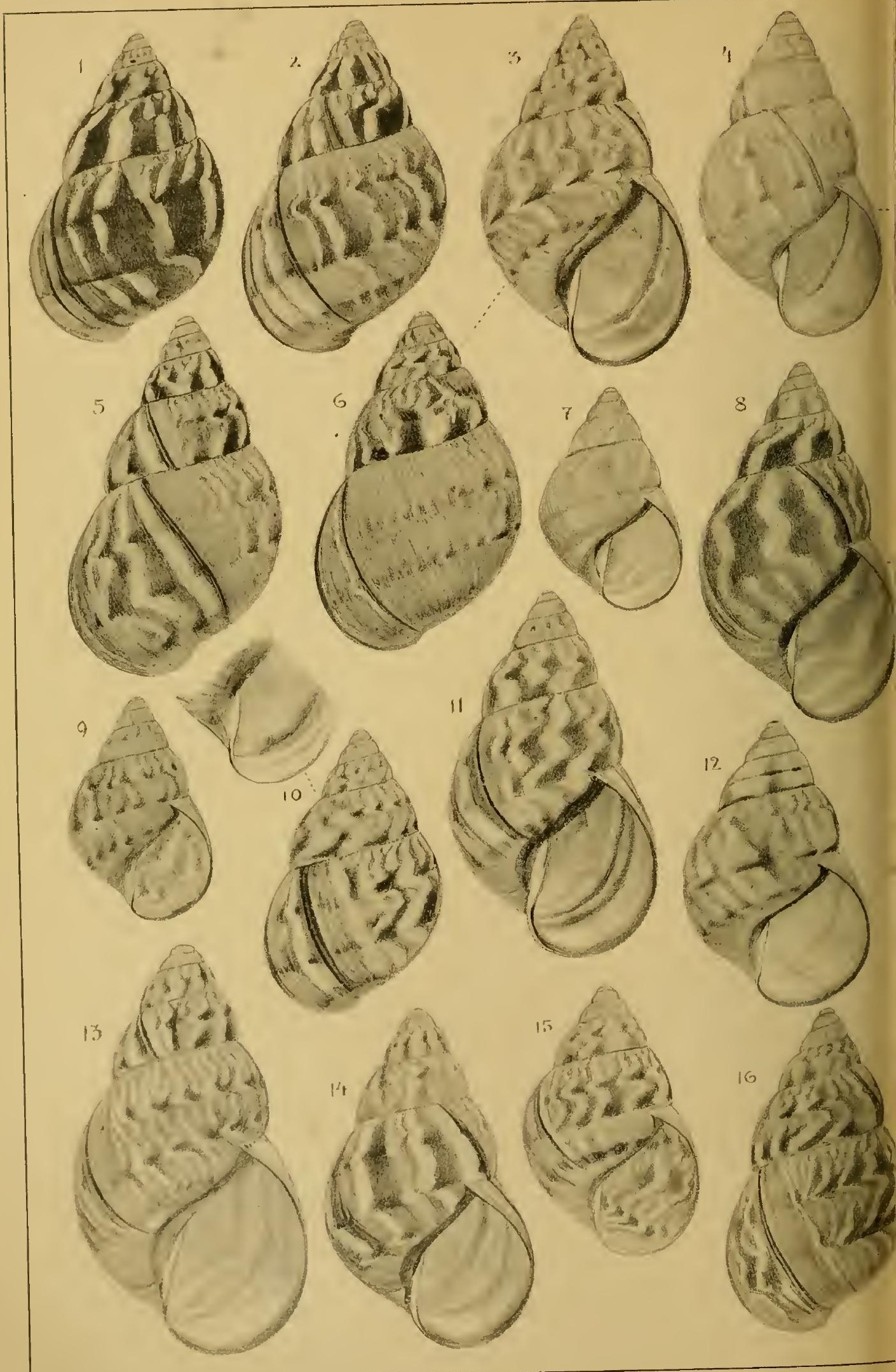




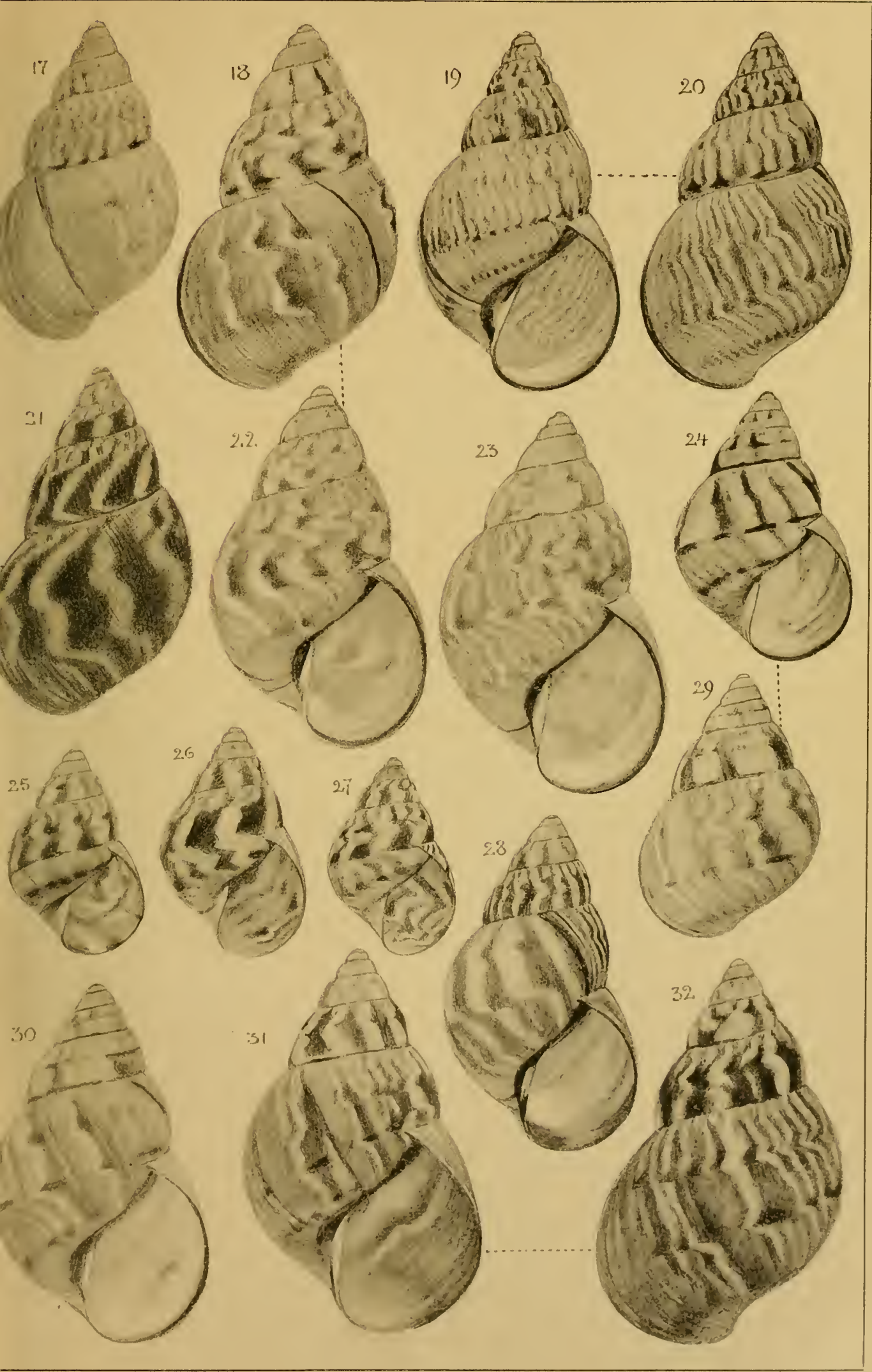





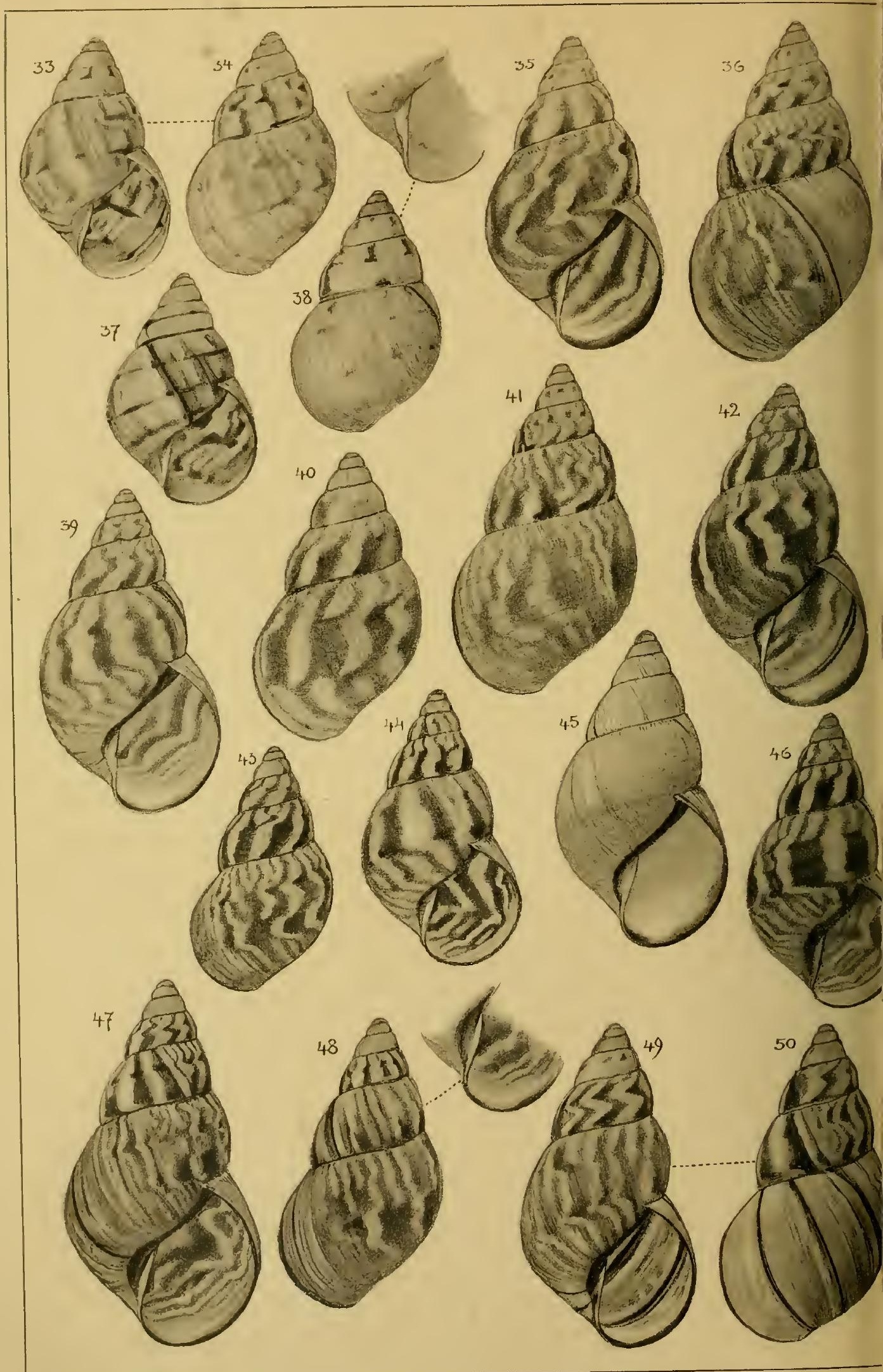




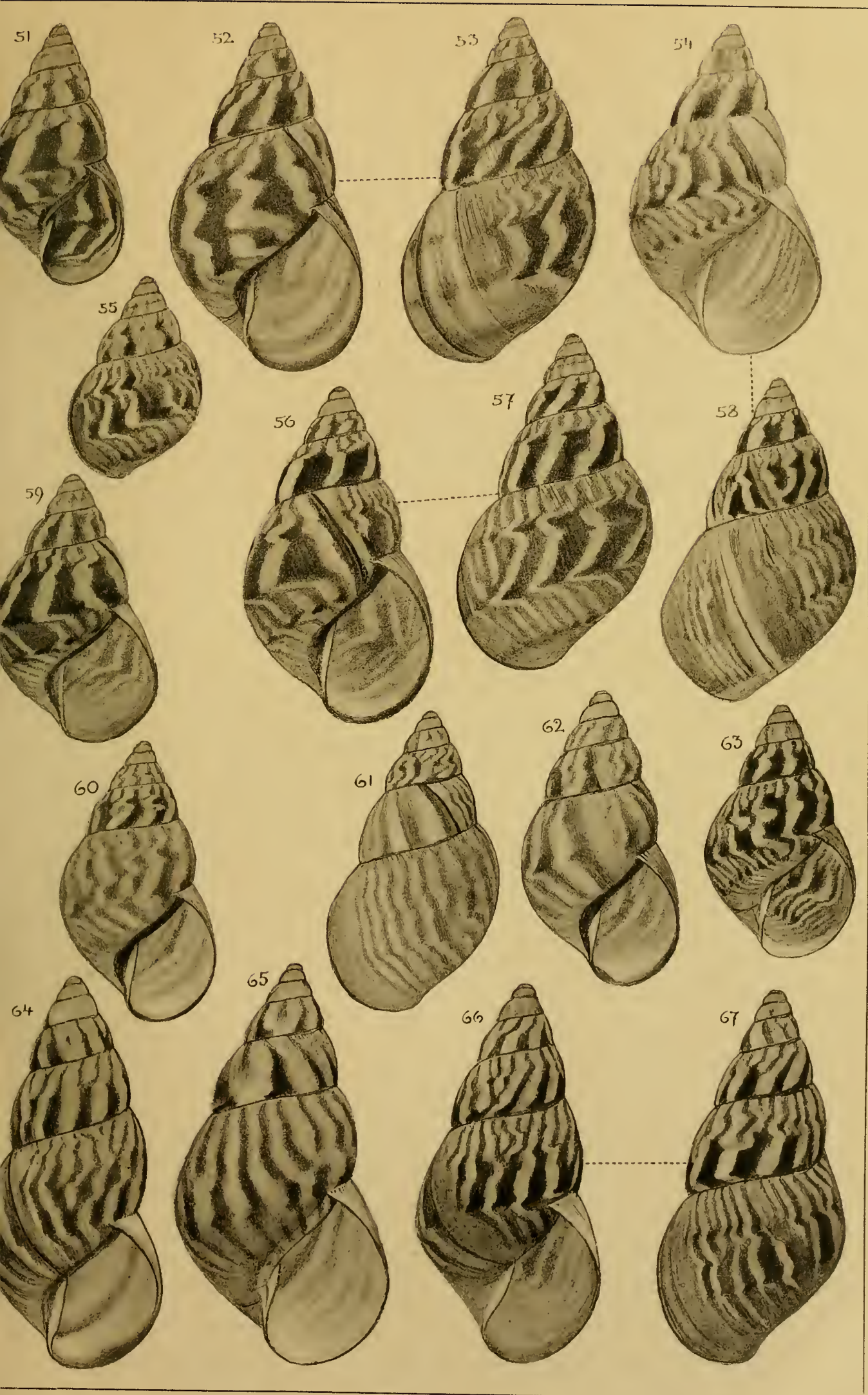





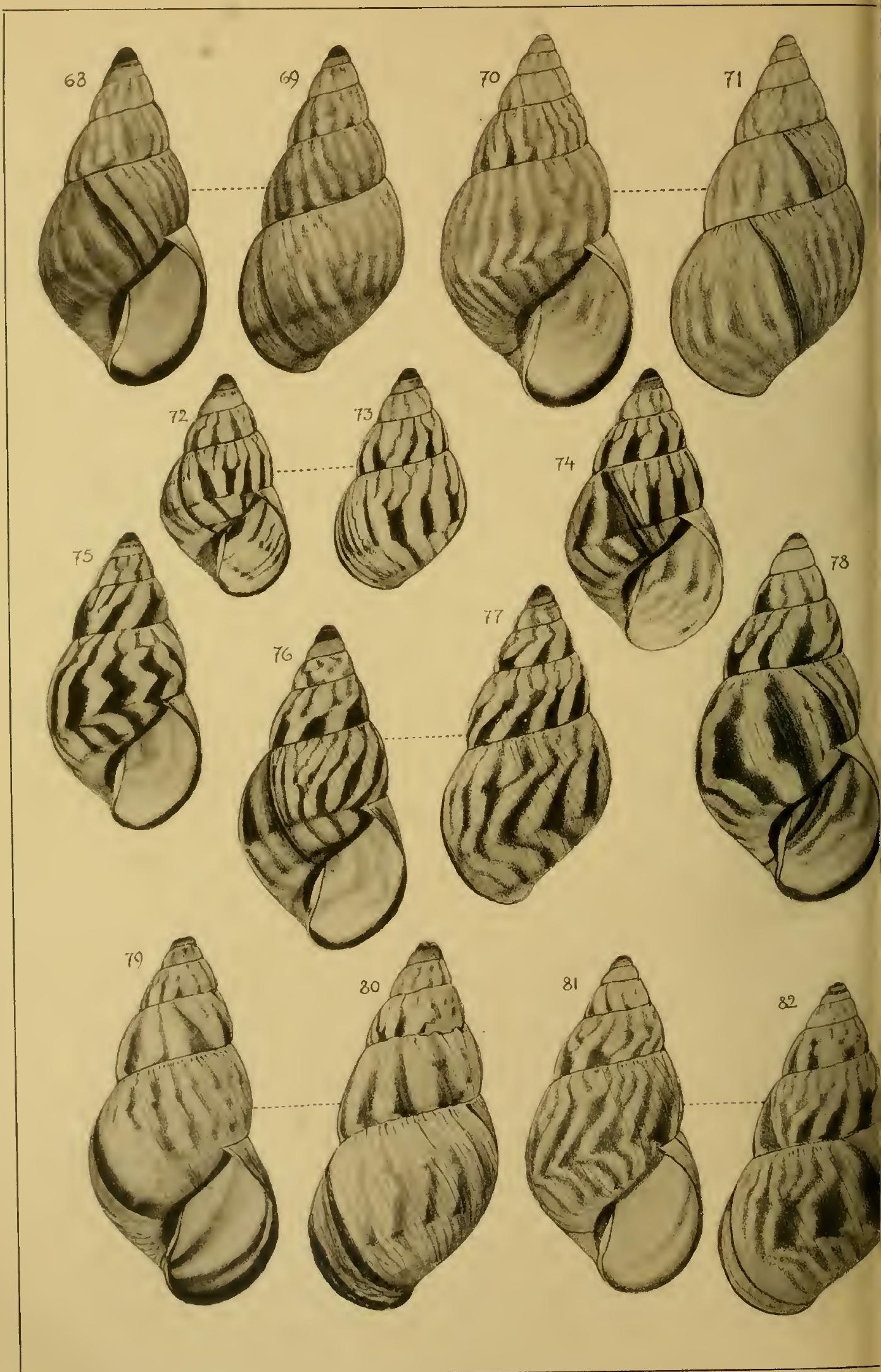






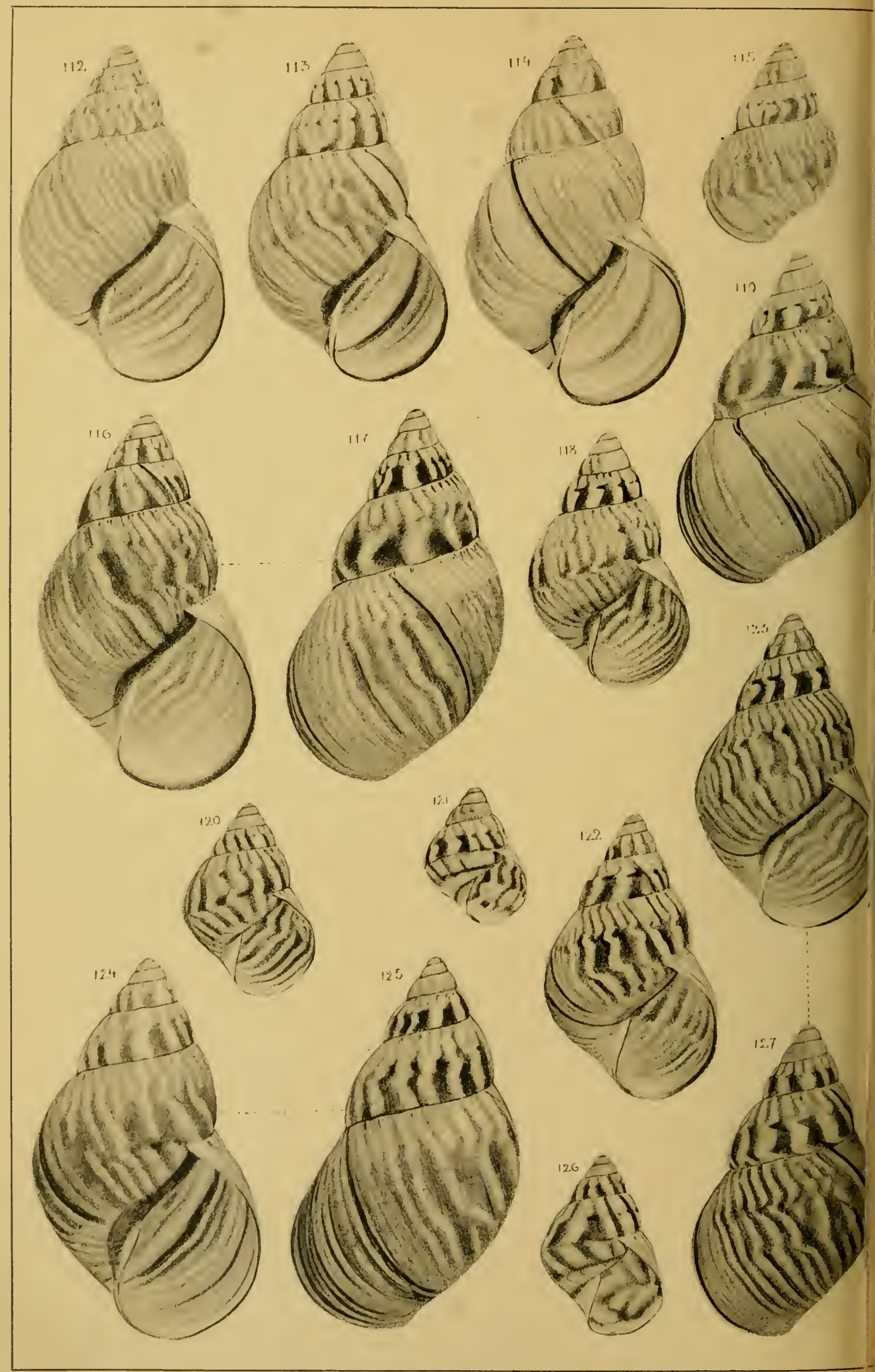




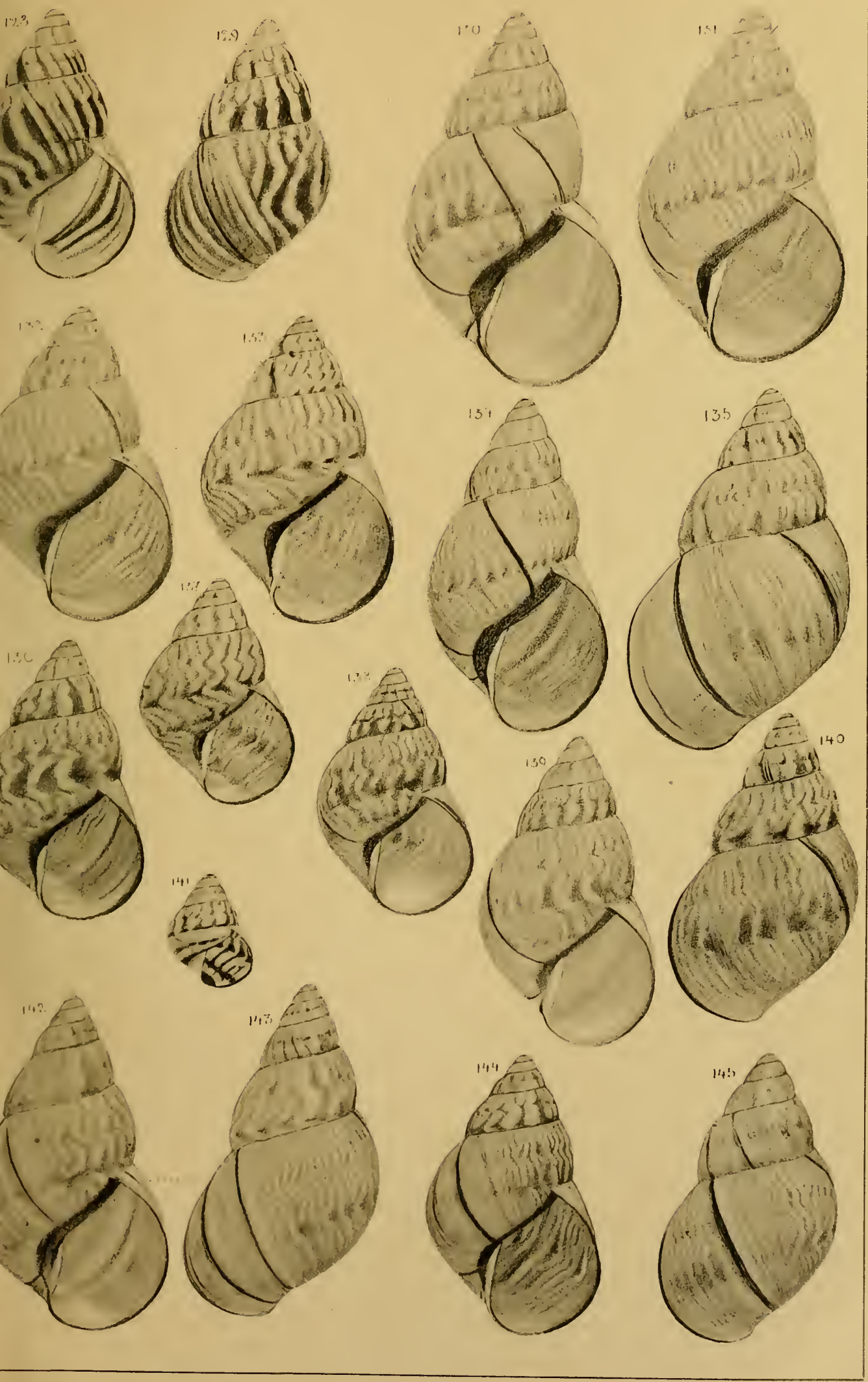

Knackstedt \& Näther, G. m. b. H., Hamburg. 


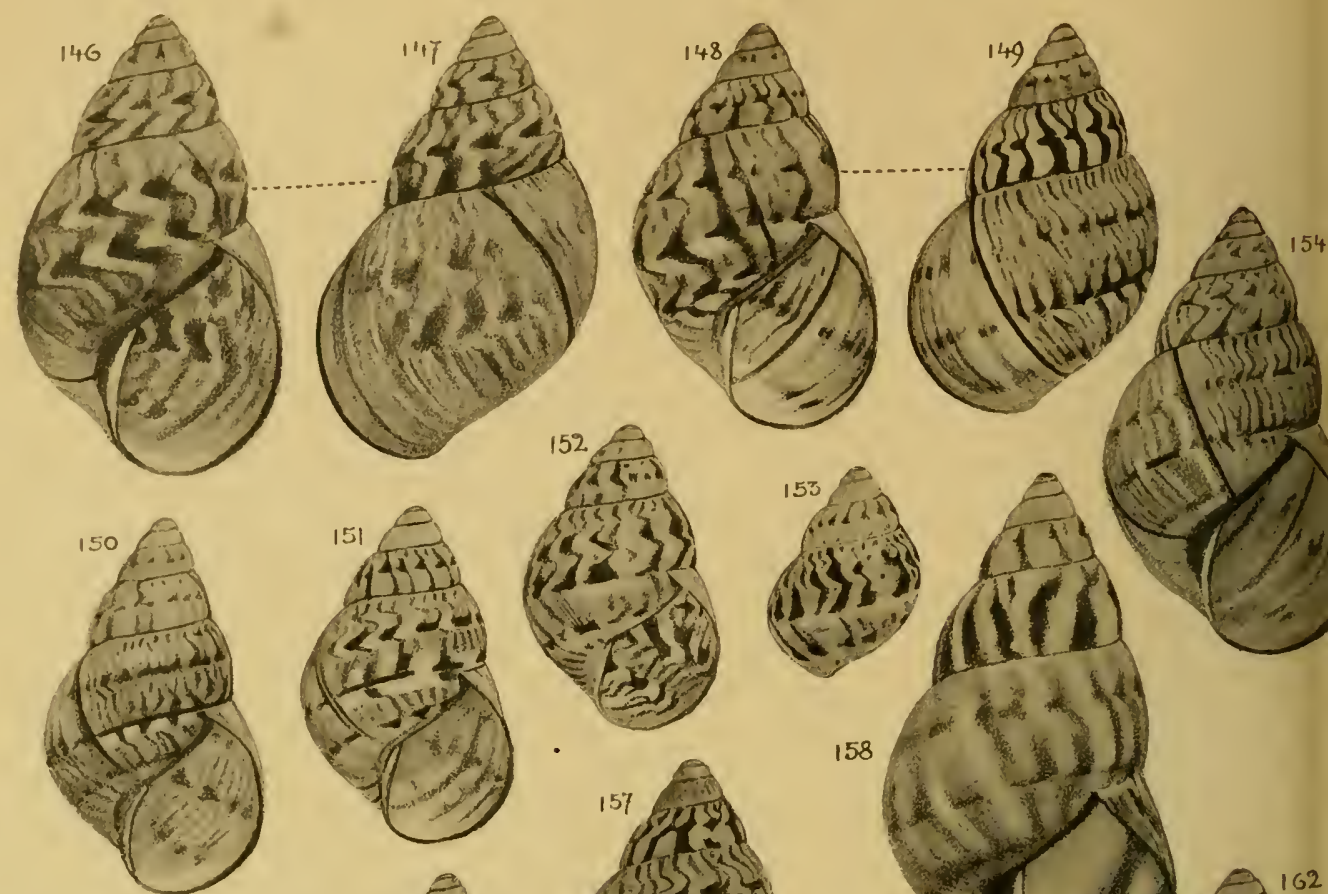

कांको

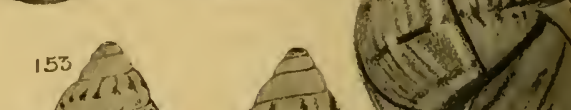

cदs 35

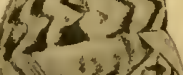

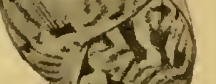

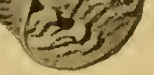

(1) 1.9$)$

$\left.(-1 y)(1) 1)^{1}\right)$
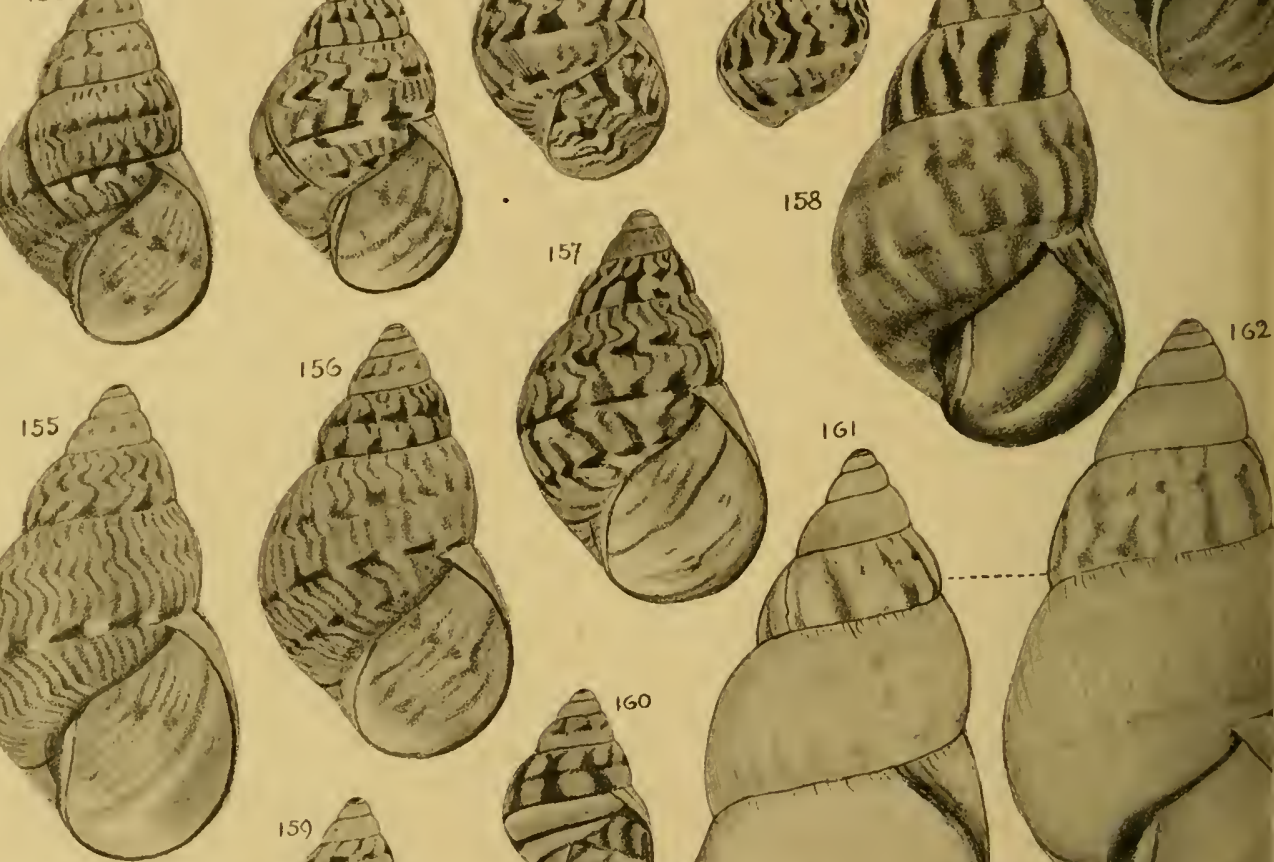

158

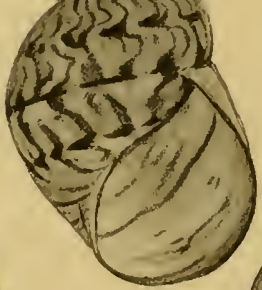

$163 \Leftrightarrow$ (5)
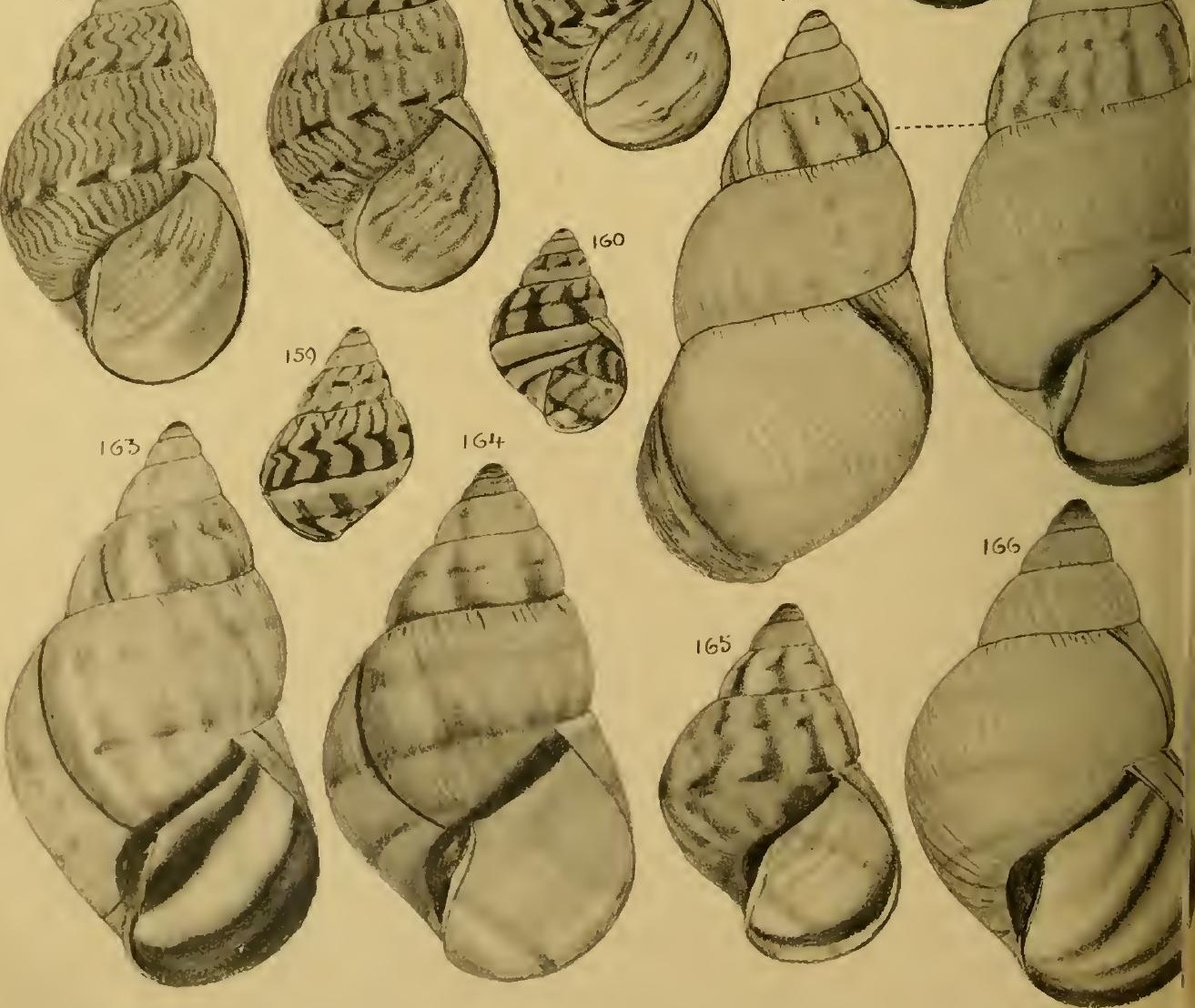


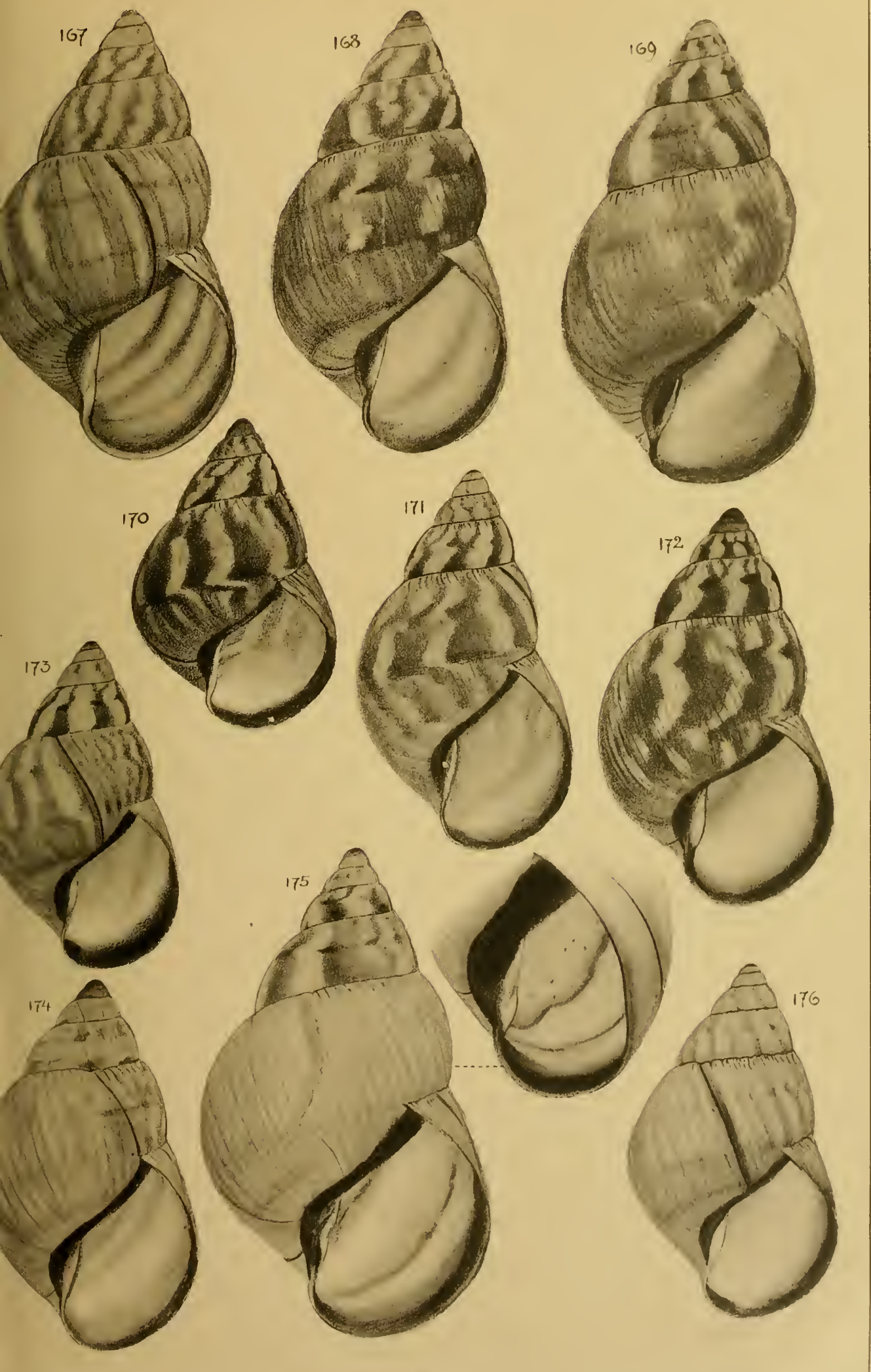





$$
\text { . }
$$




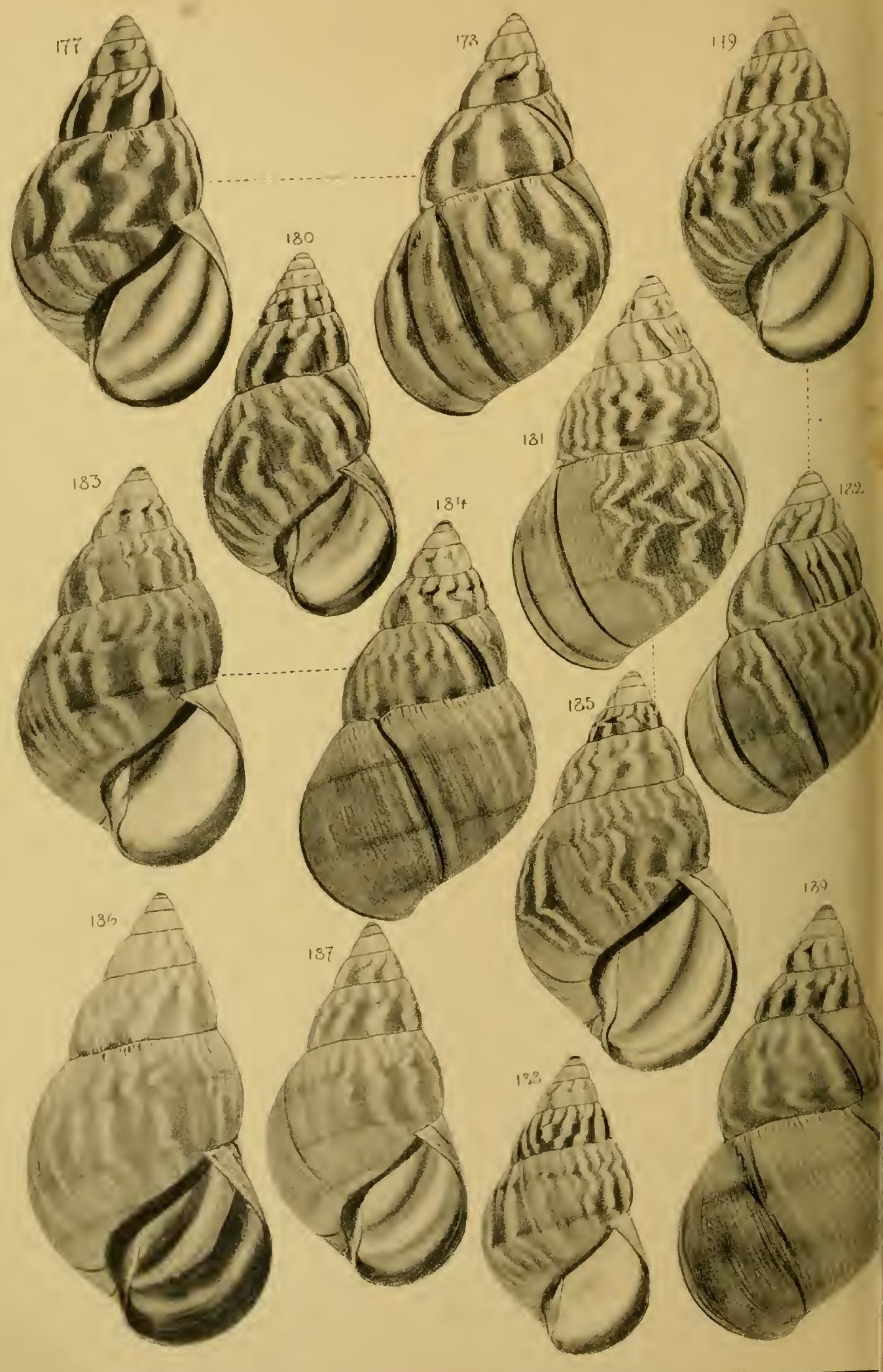




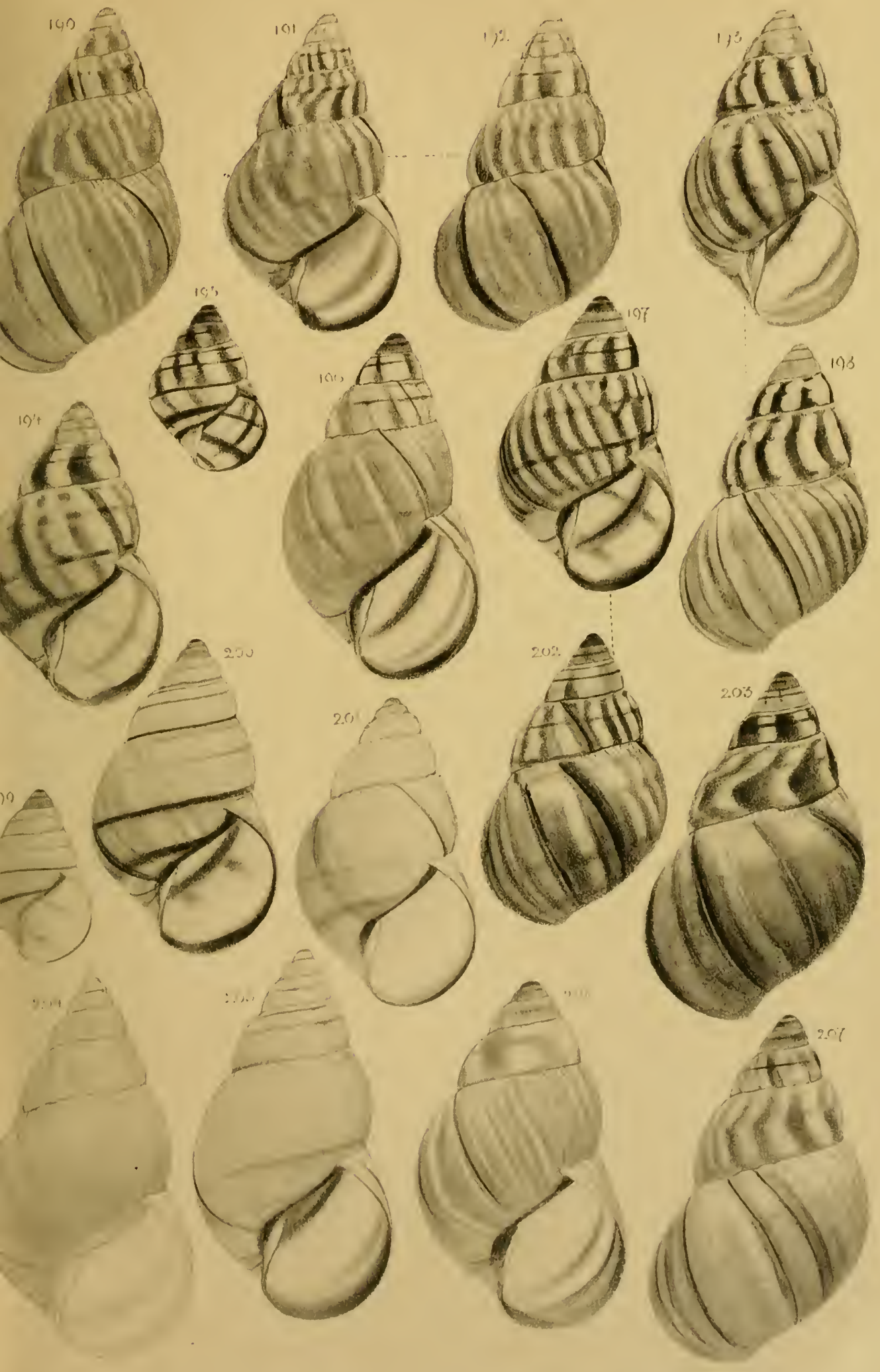





\section{.}




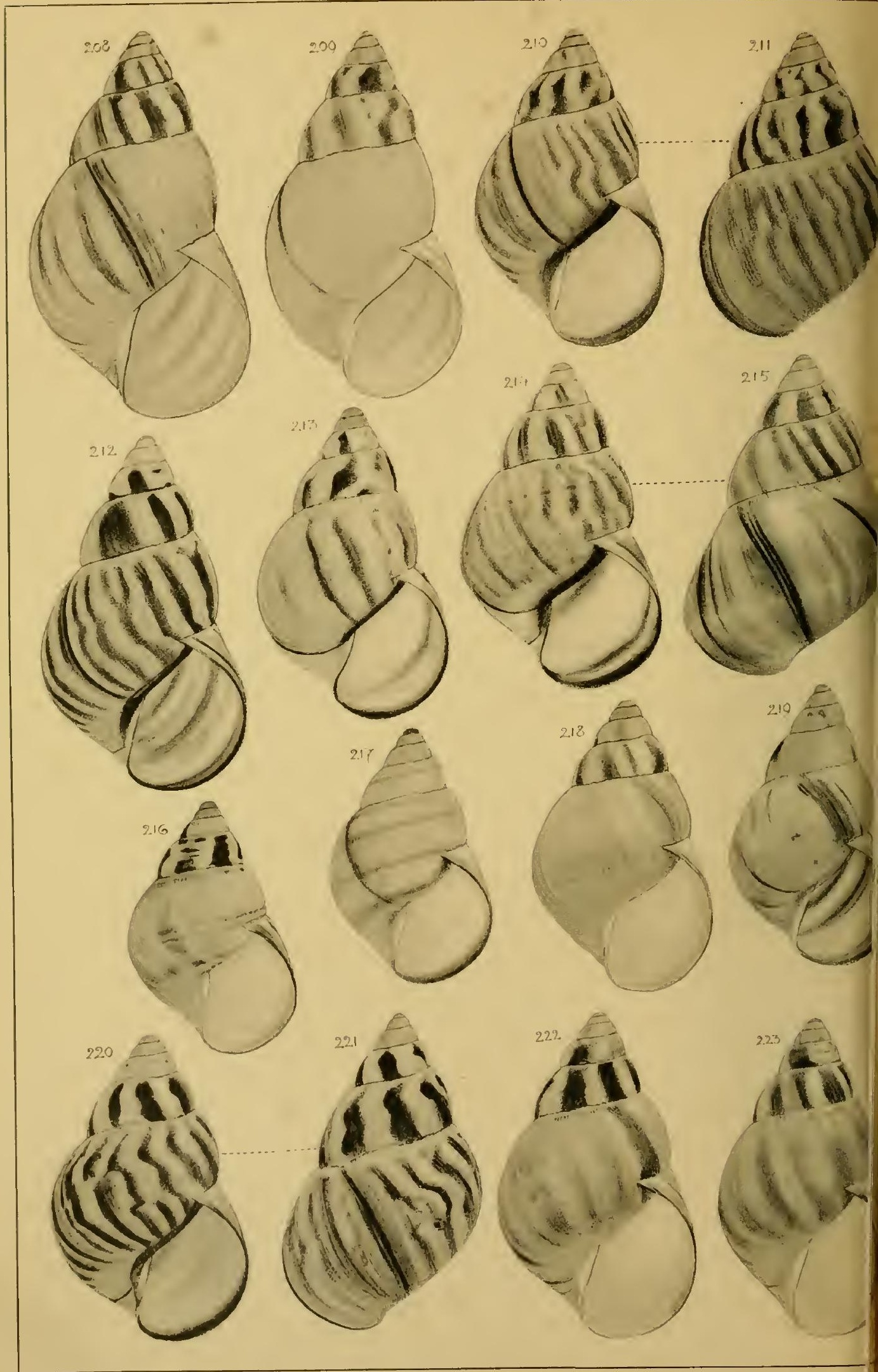




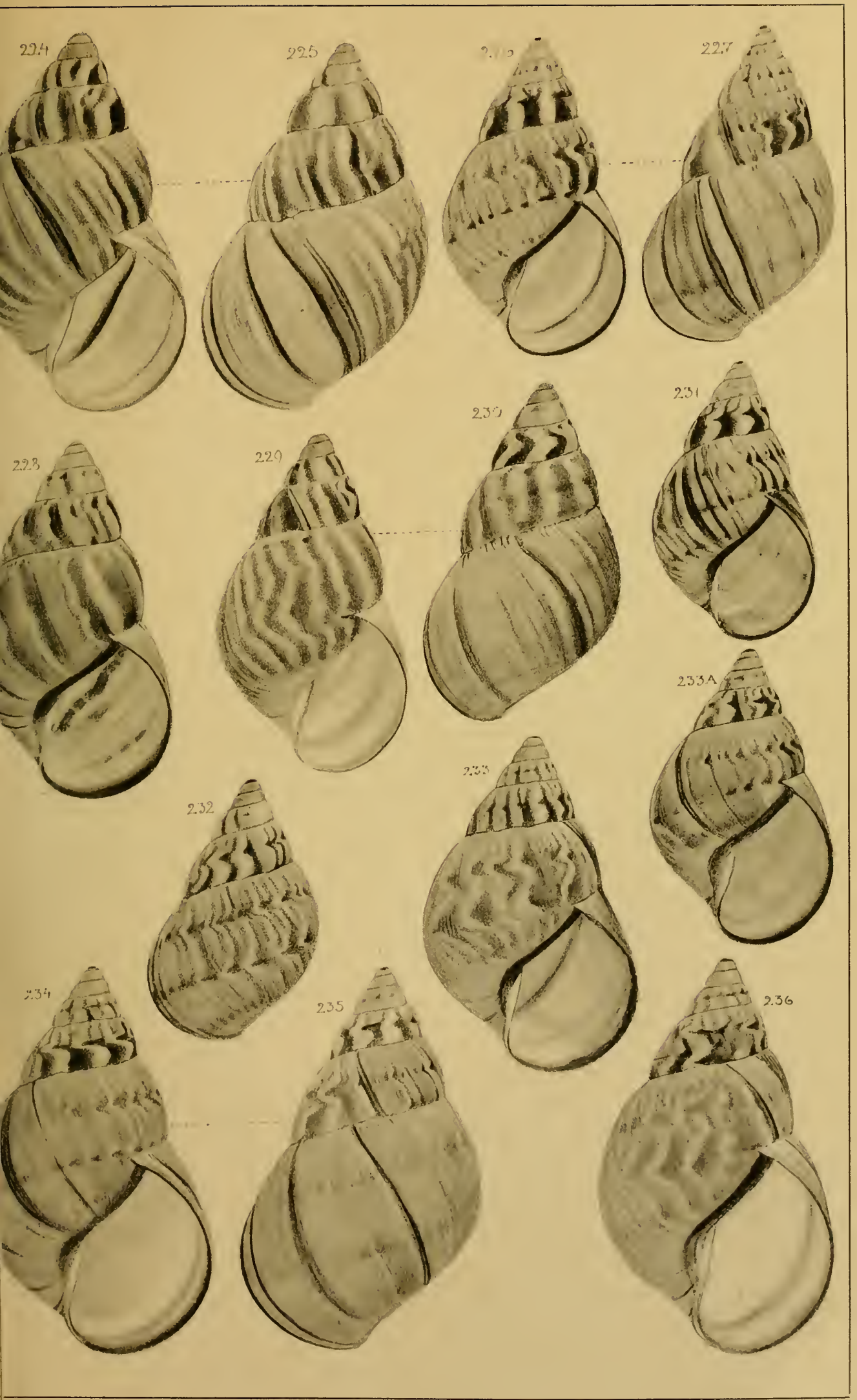




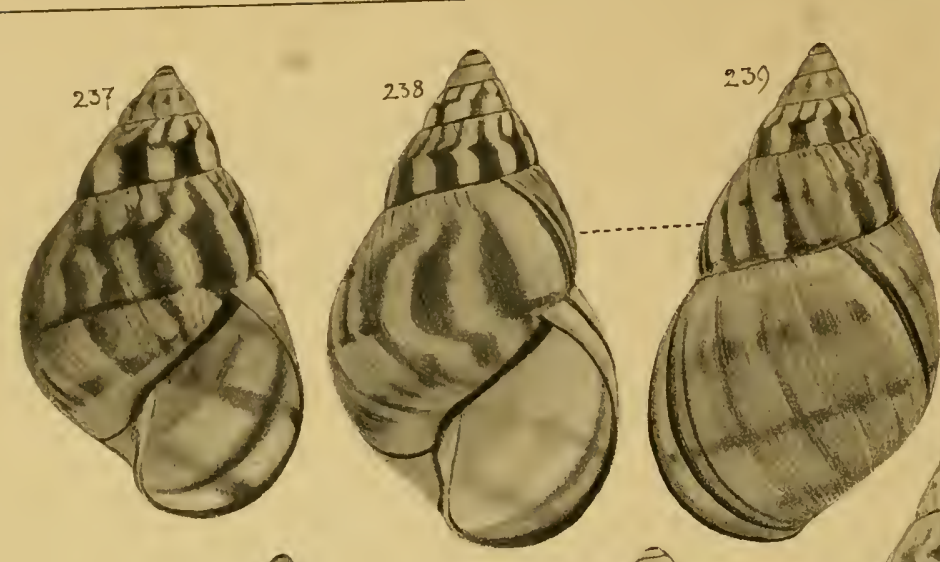

240 दाय

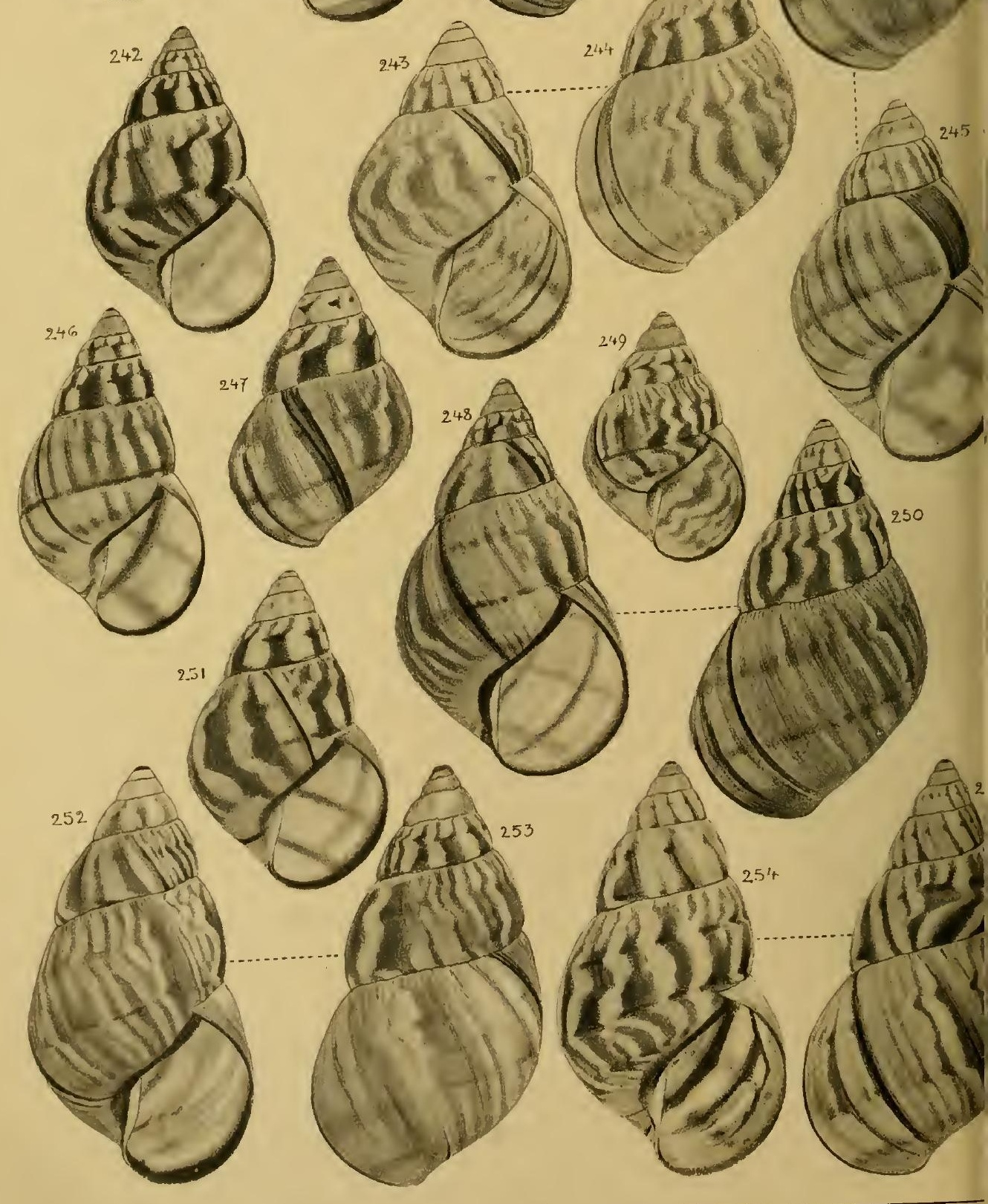




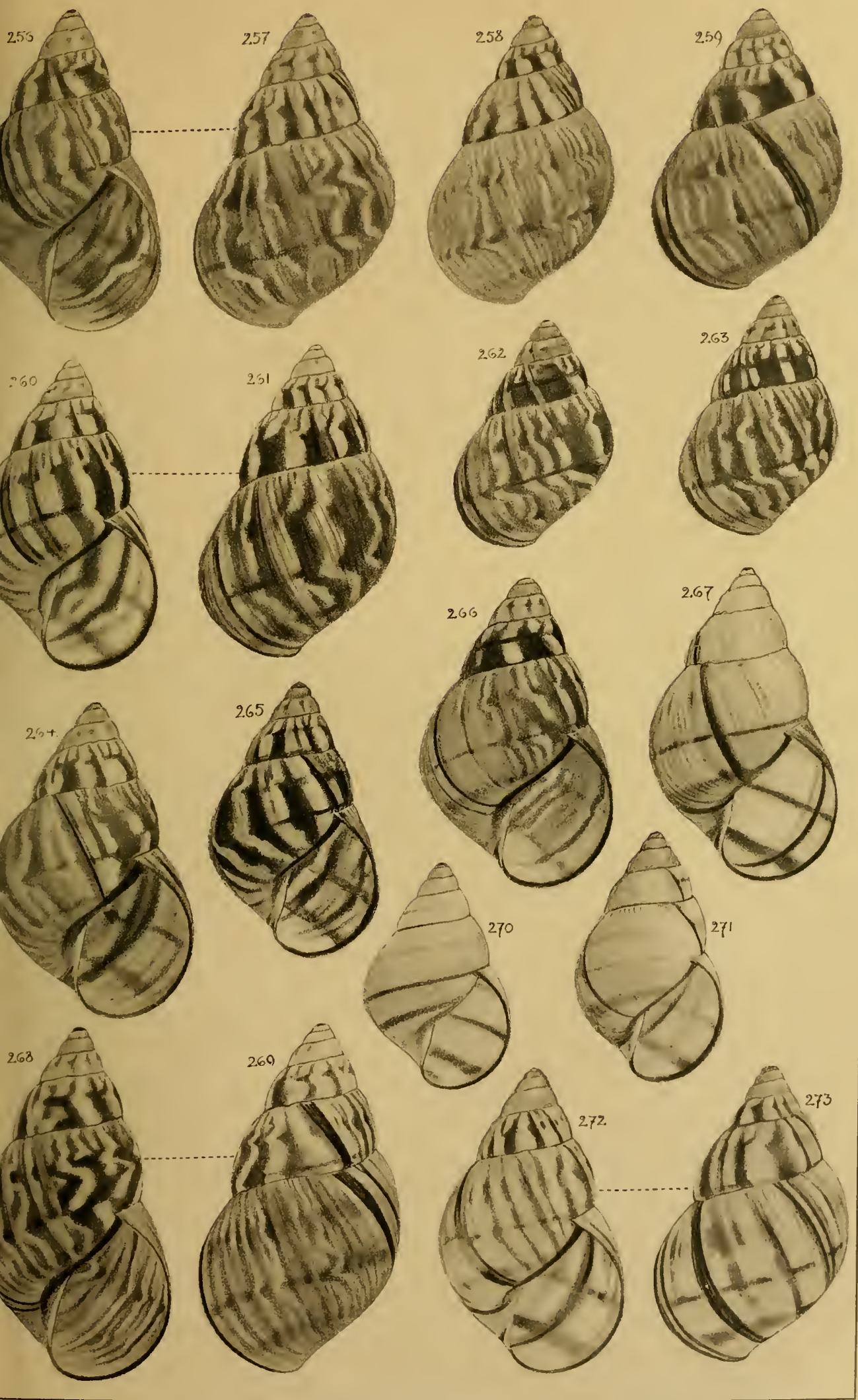





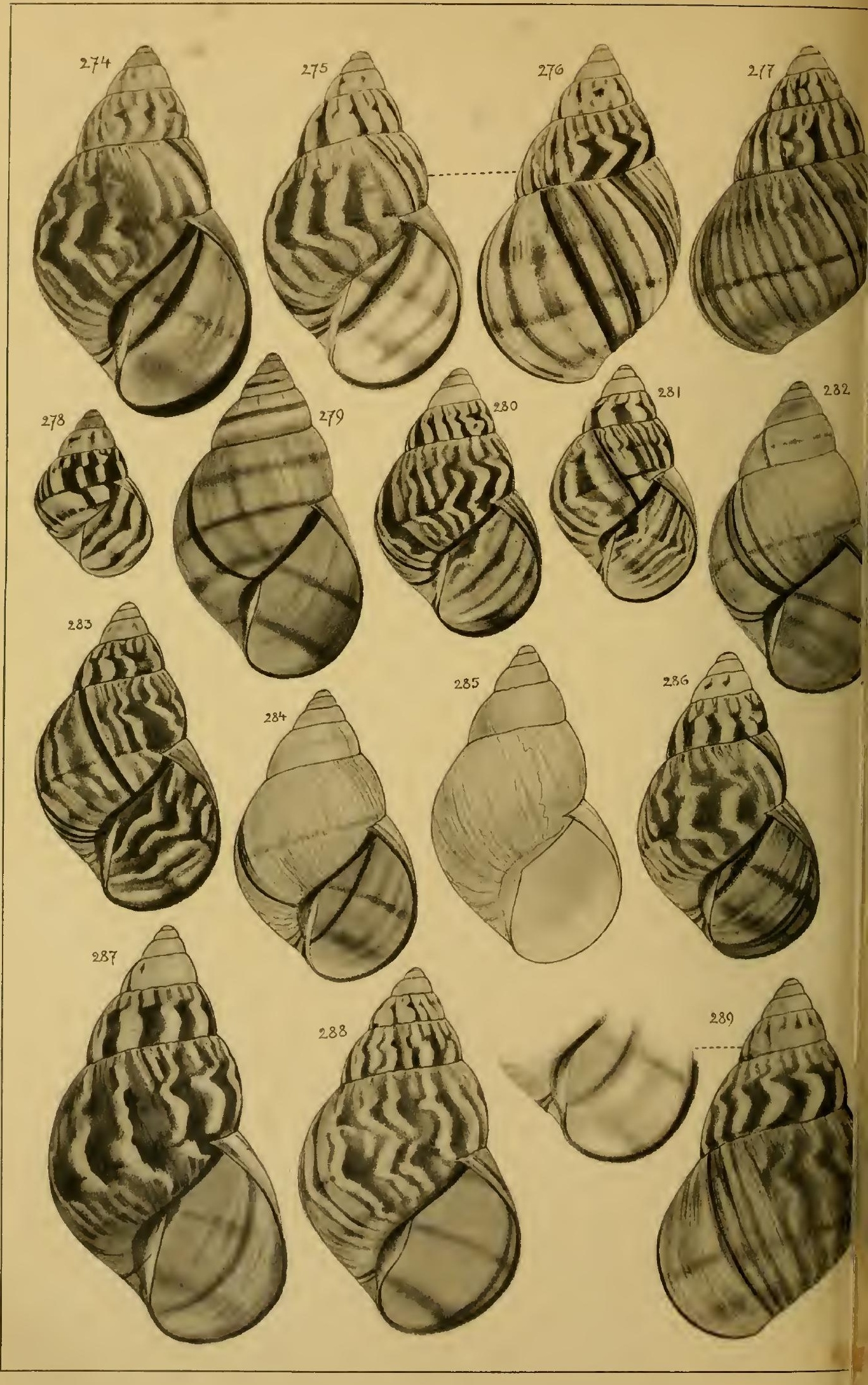




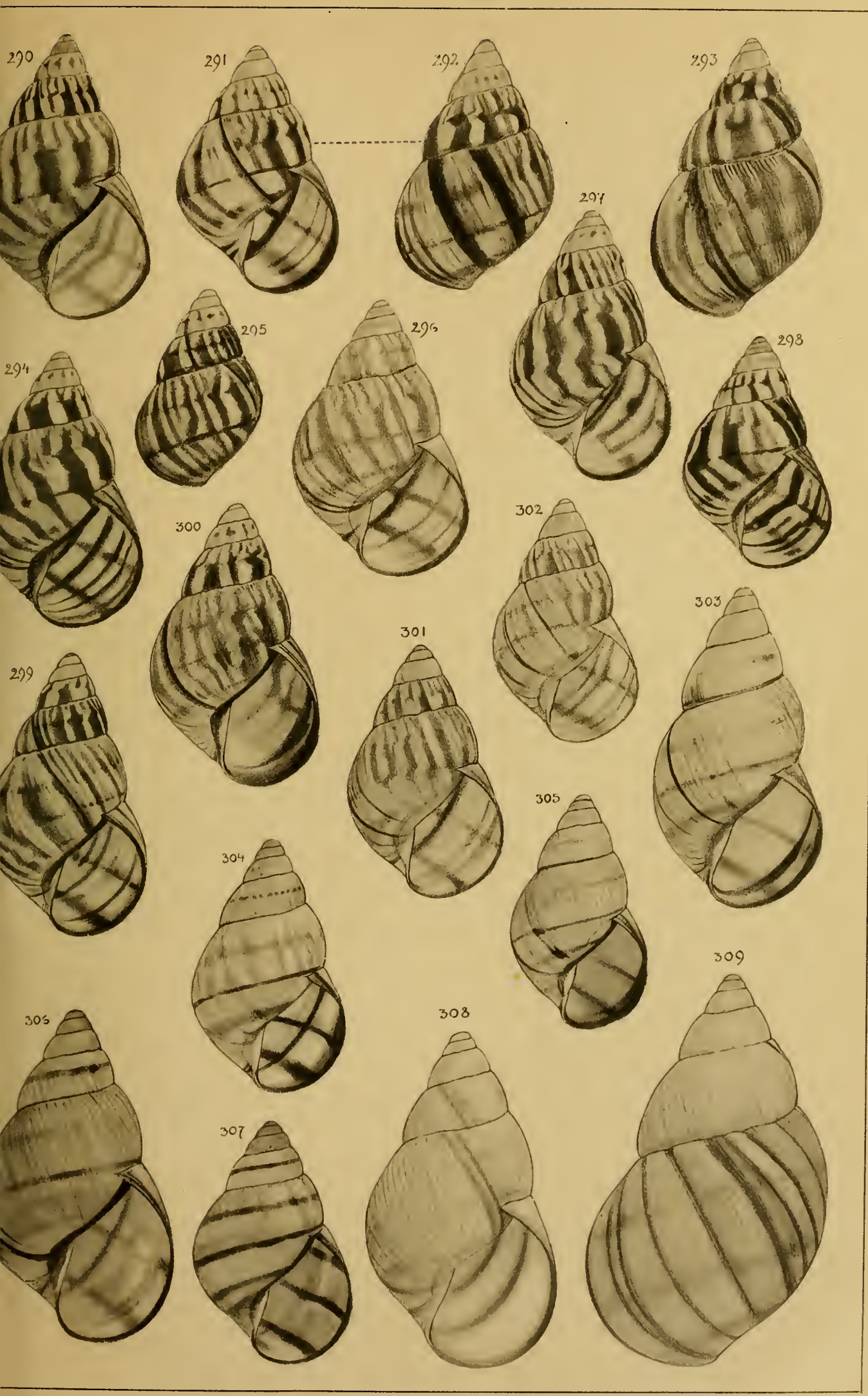





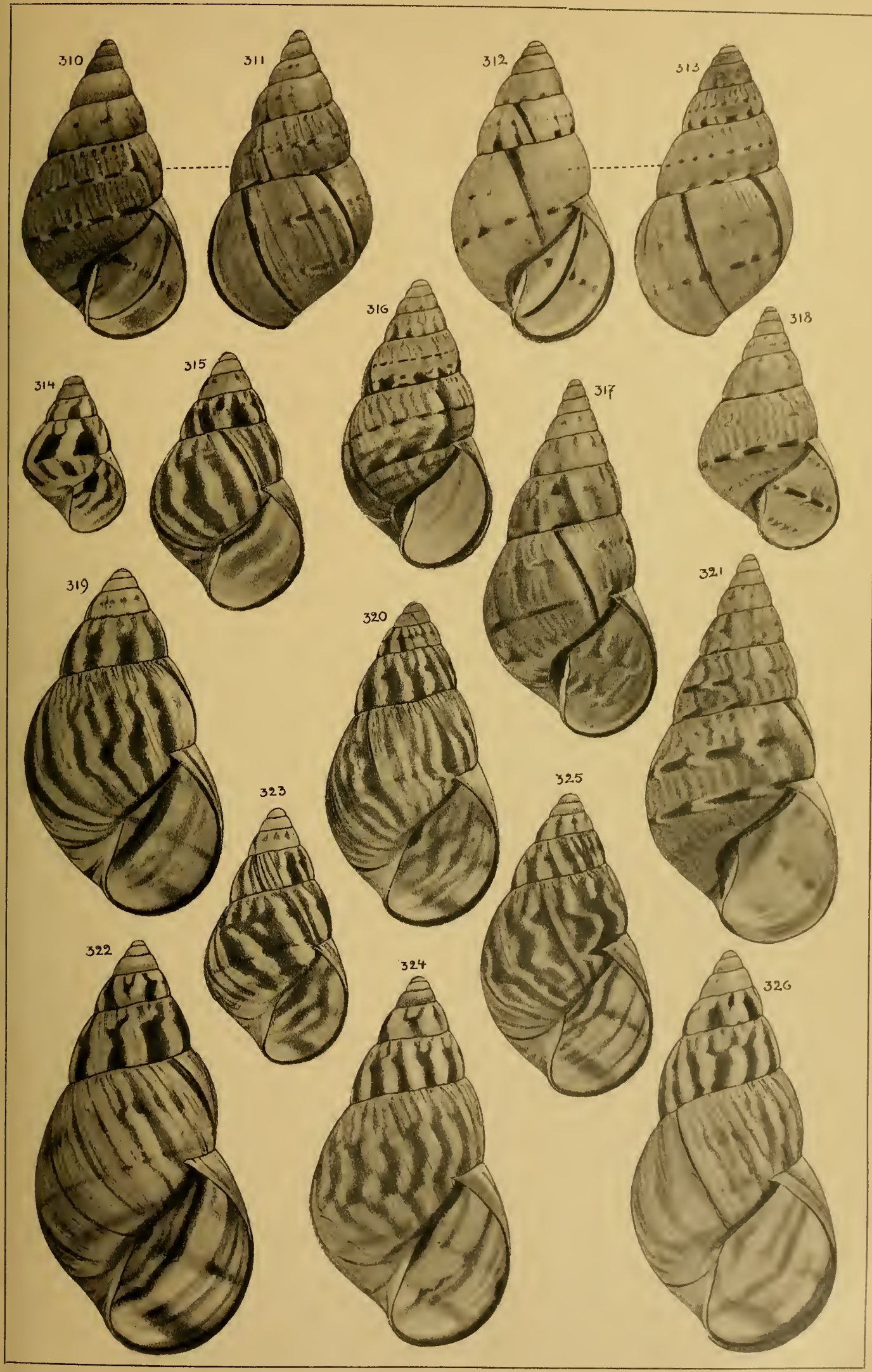





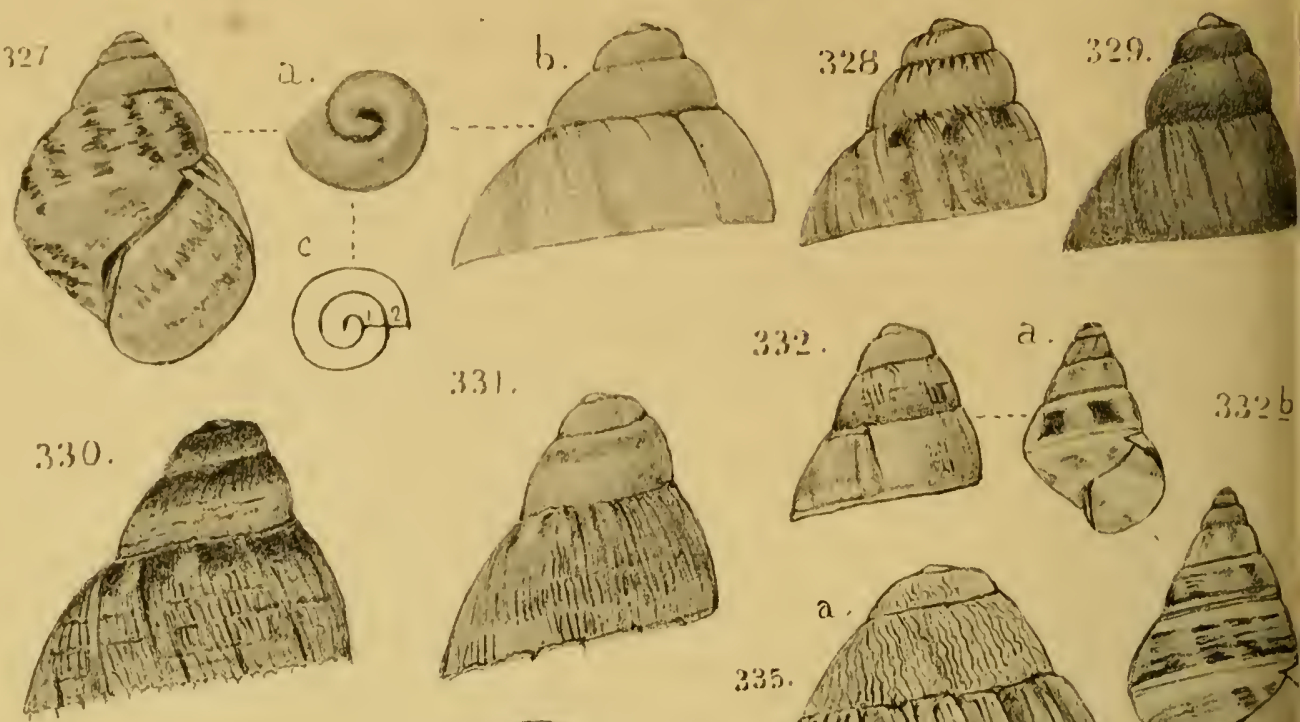

$3.3 \cdot 26$
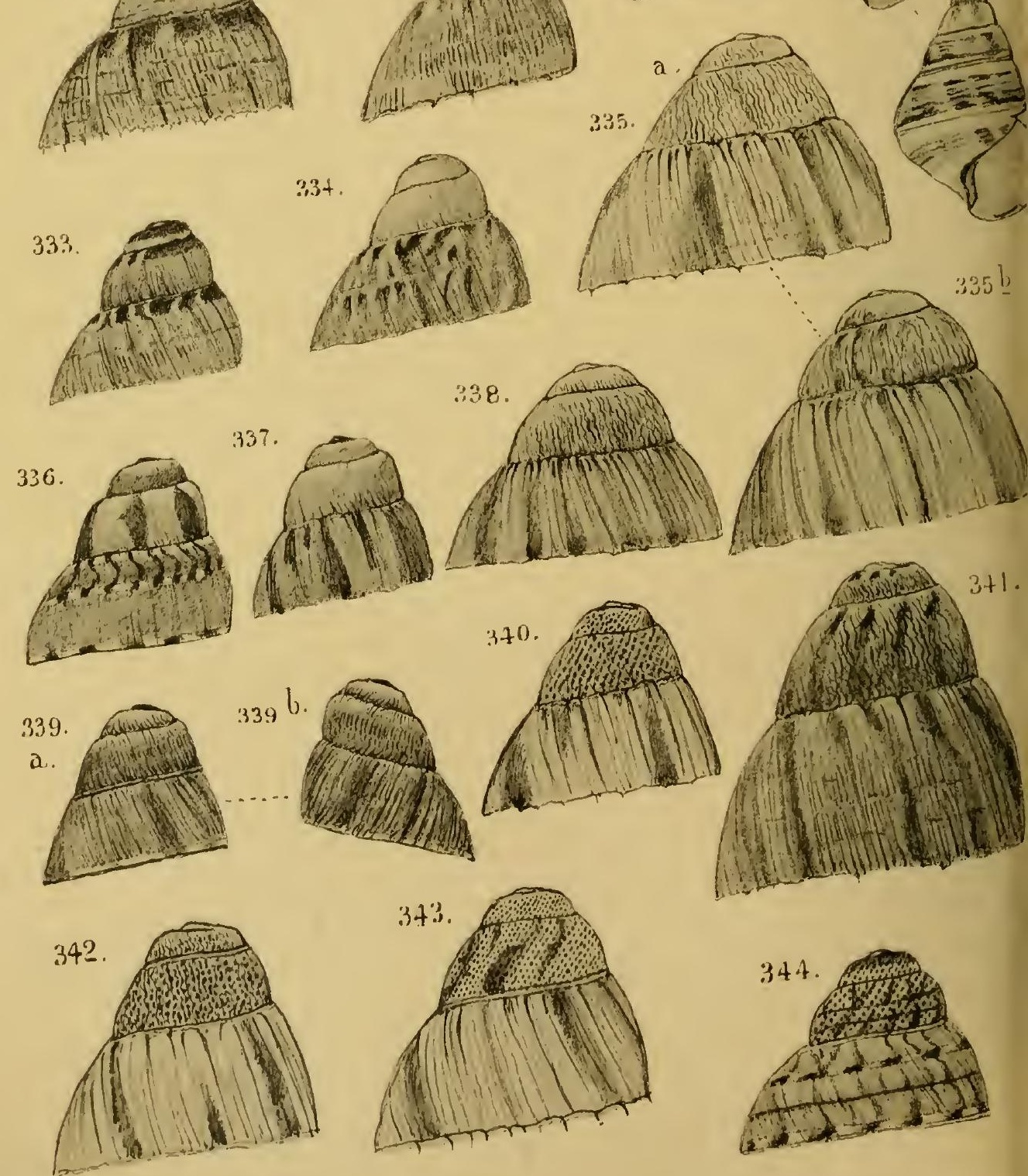

. 


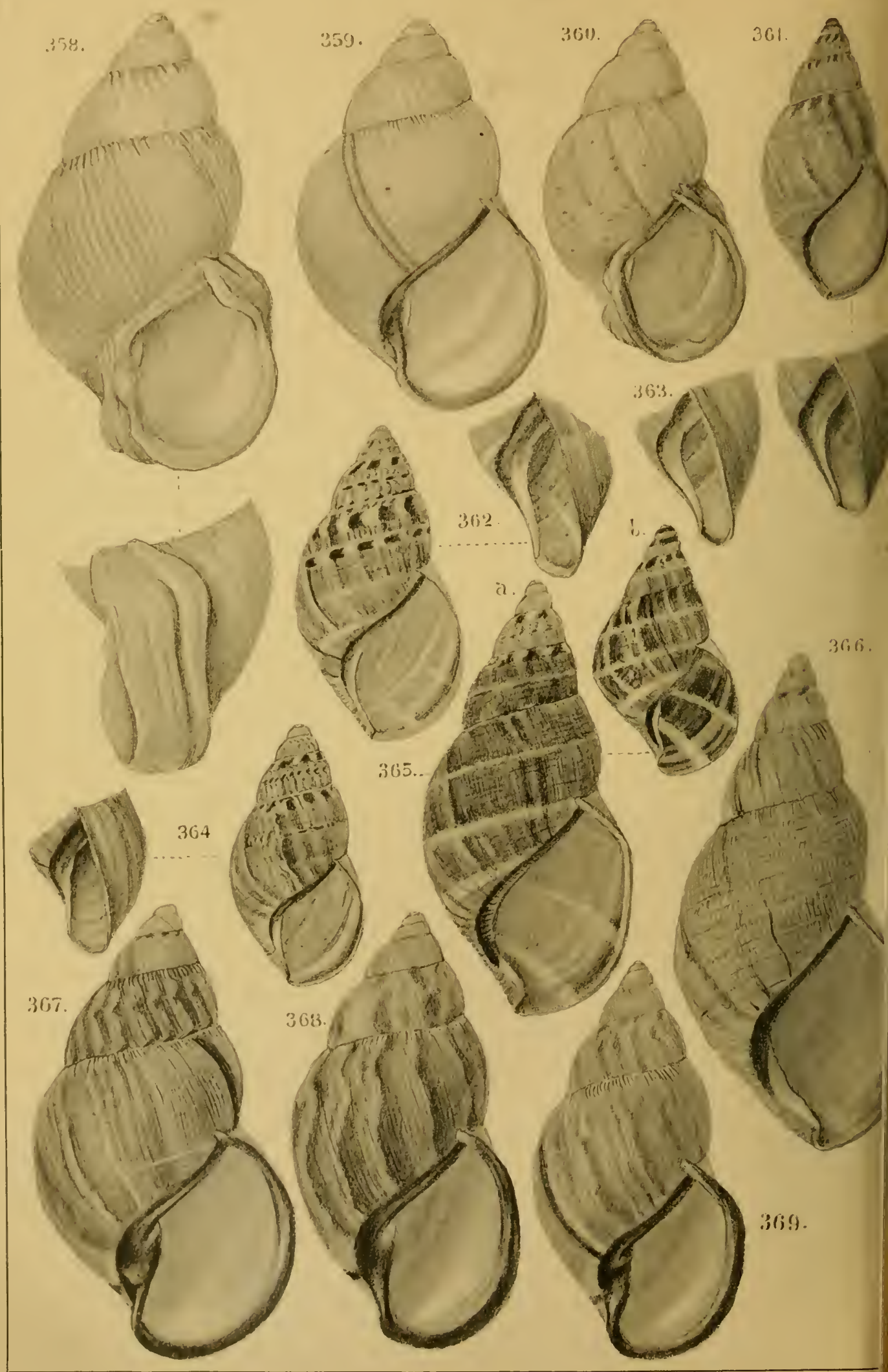





\section{.}




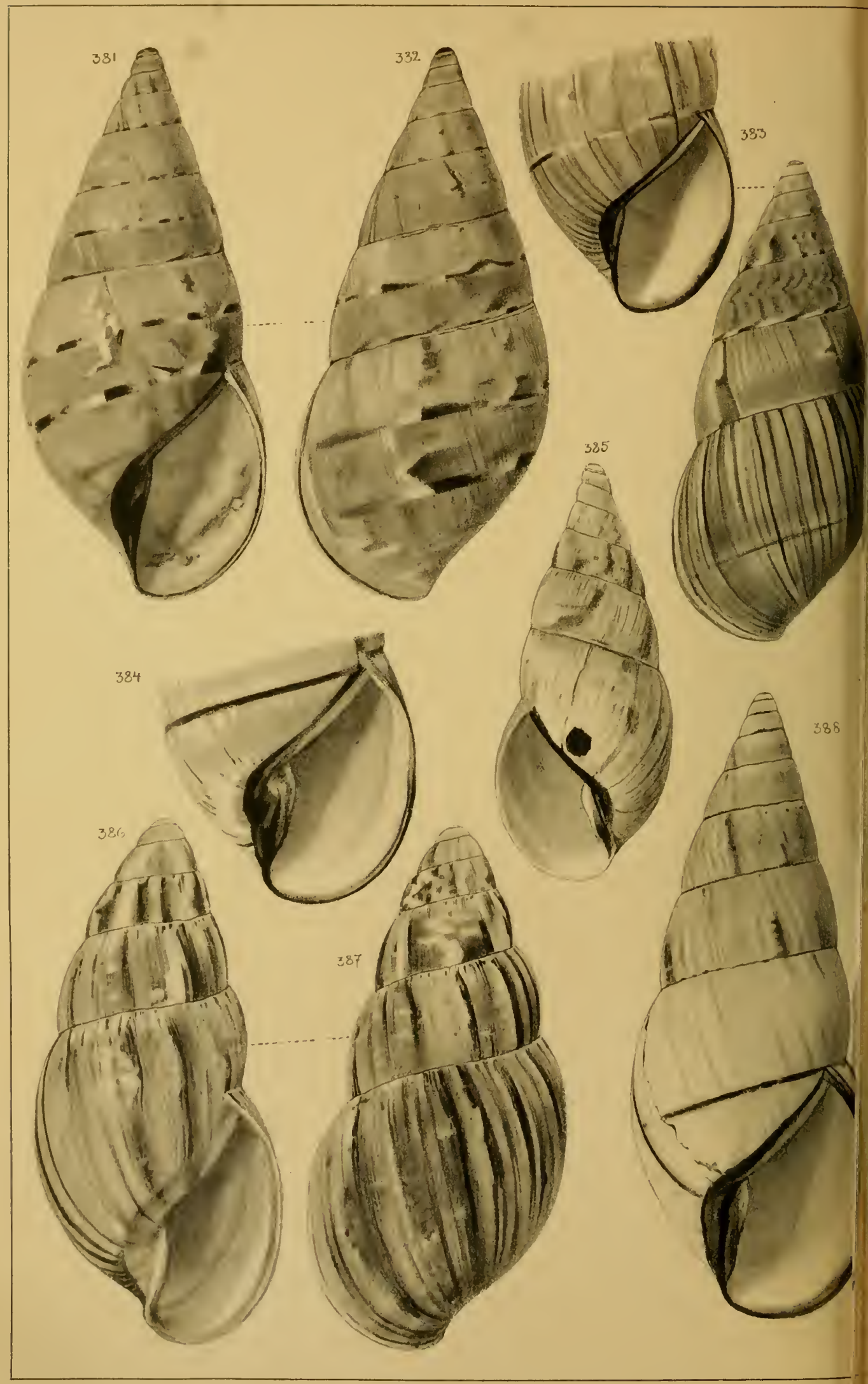




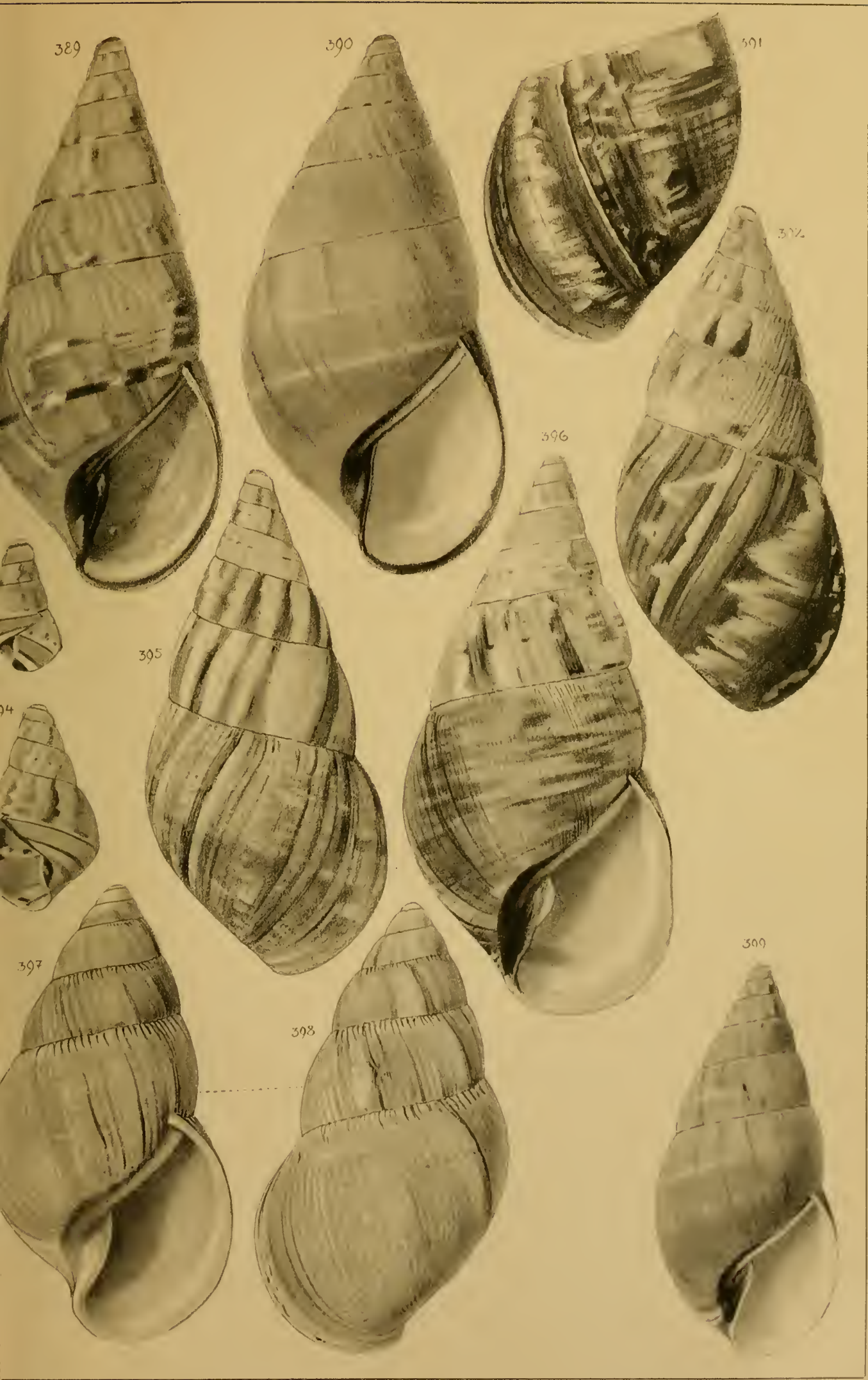





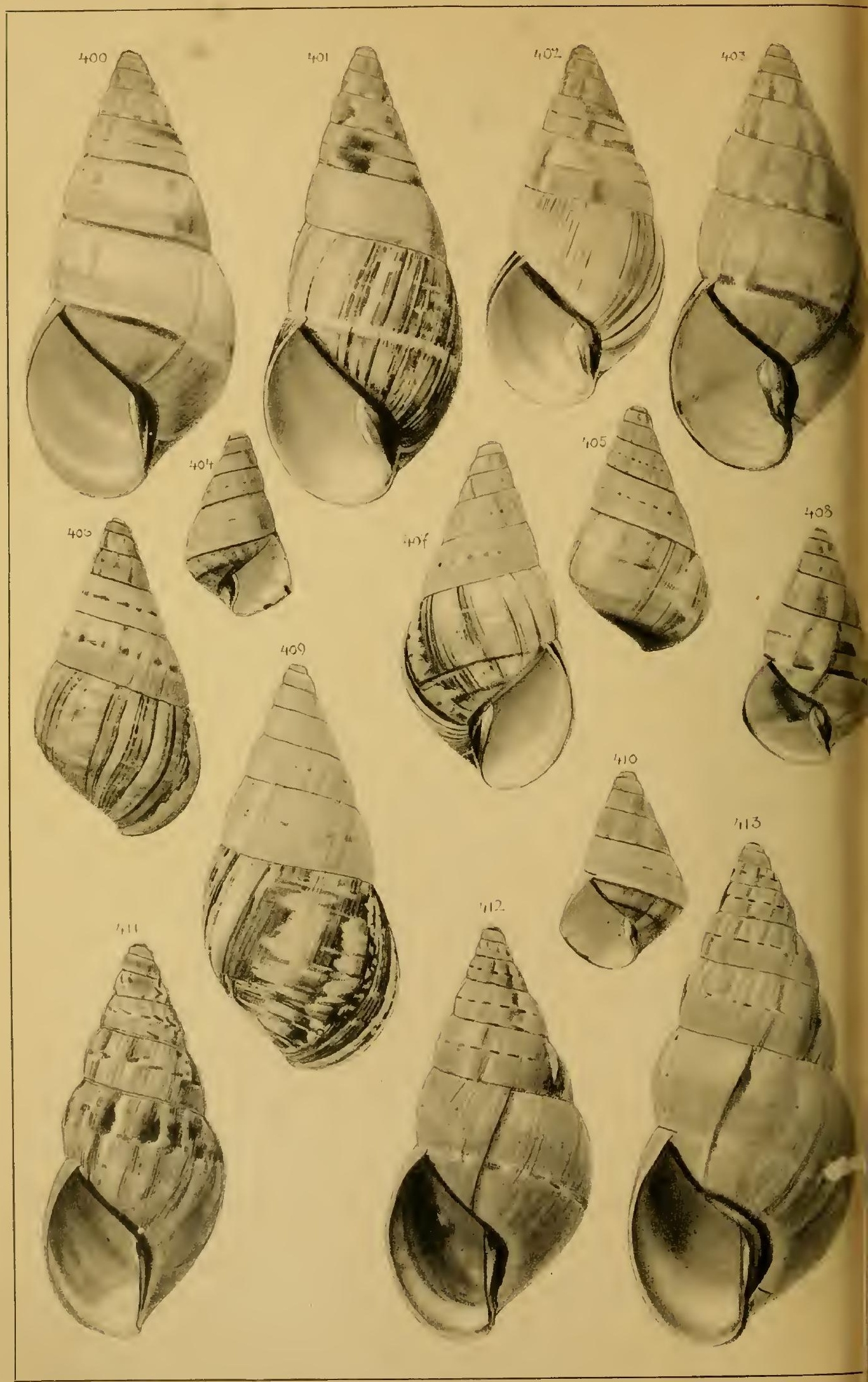




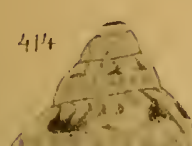
$\frac{1}{2}$

se y.
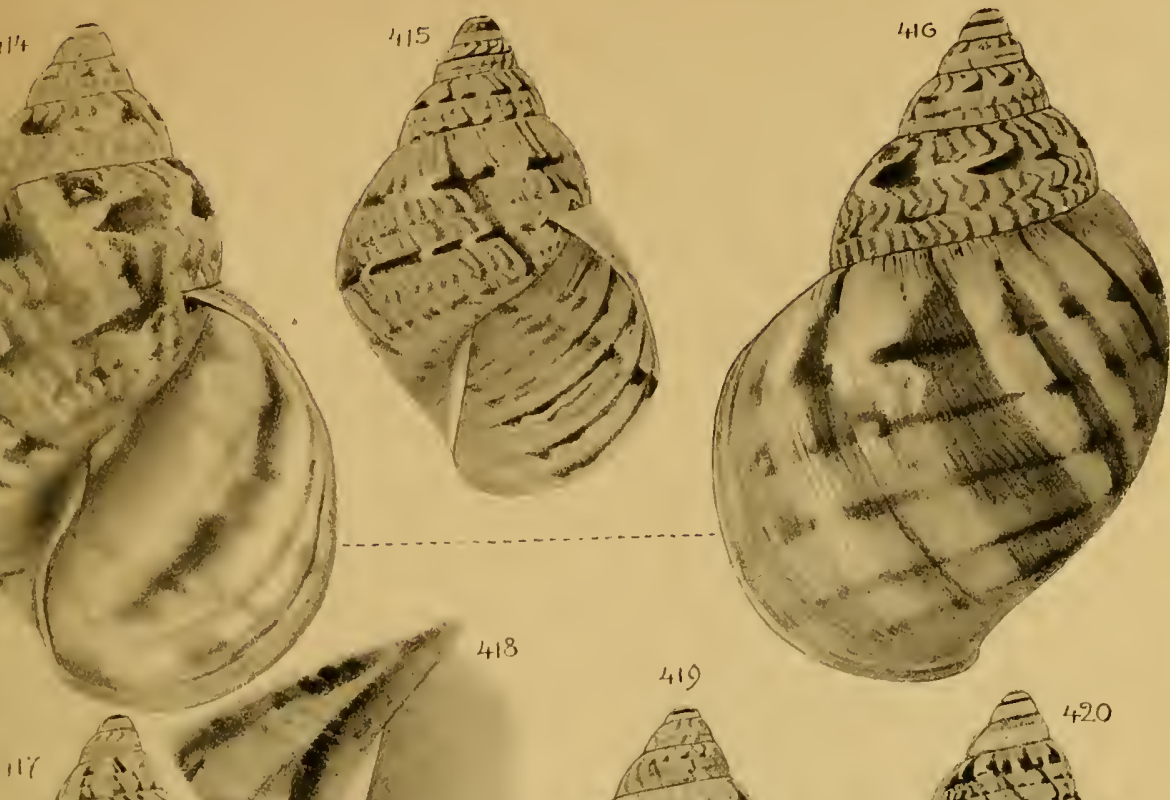

s.

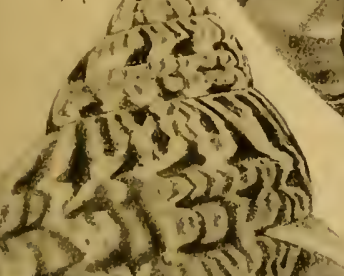

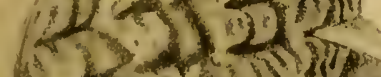
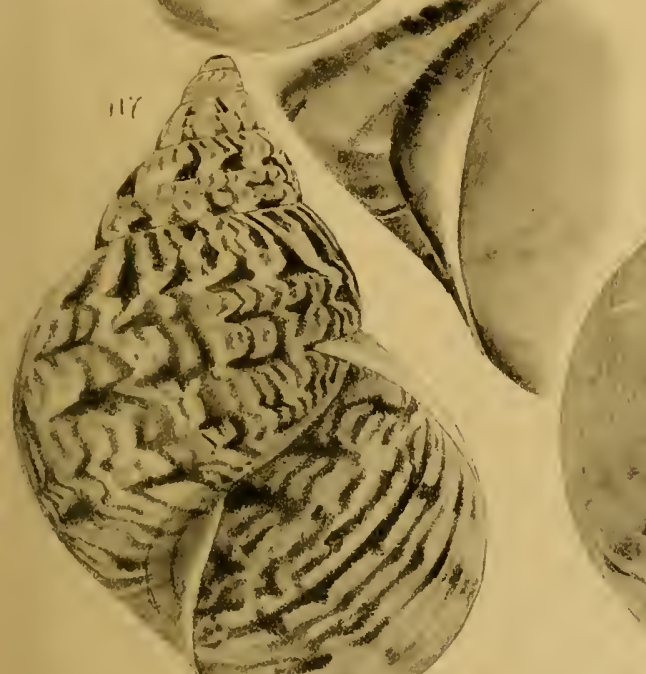



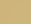

. 


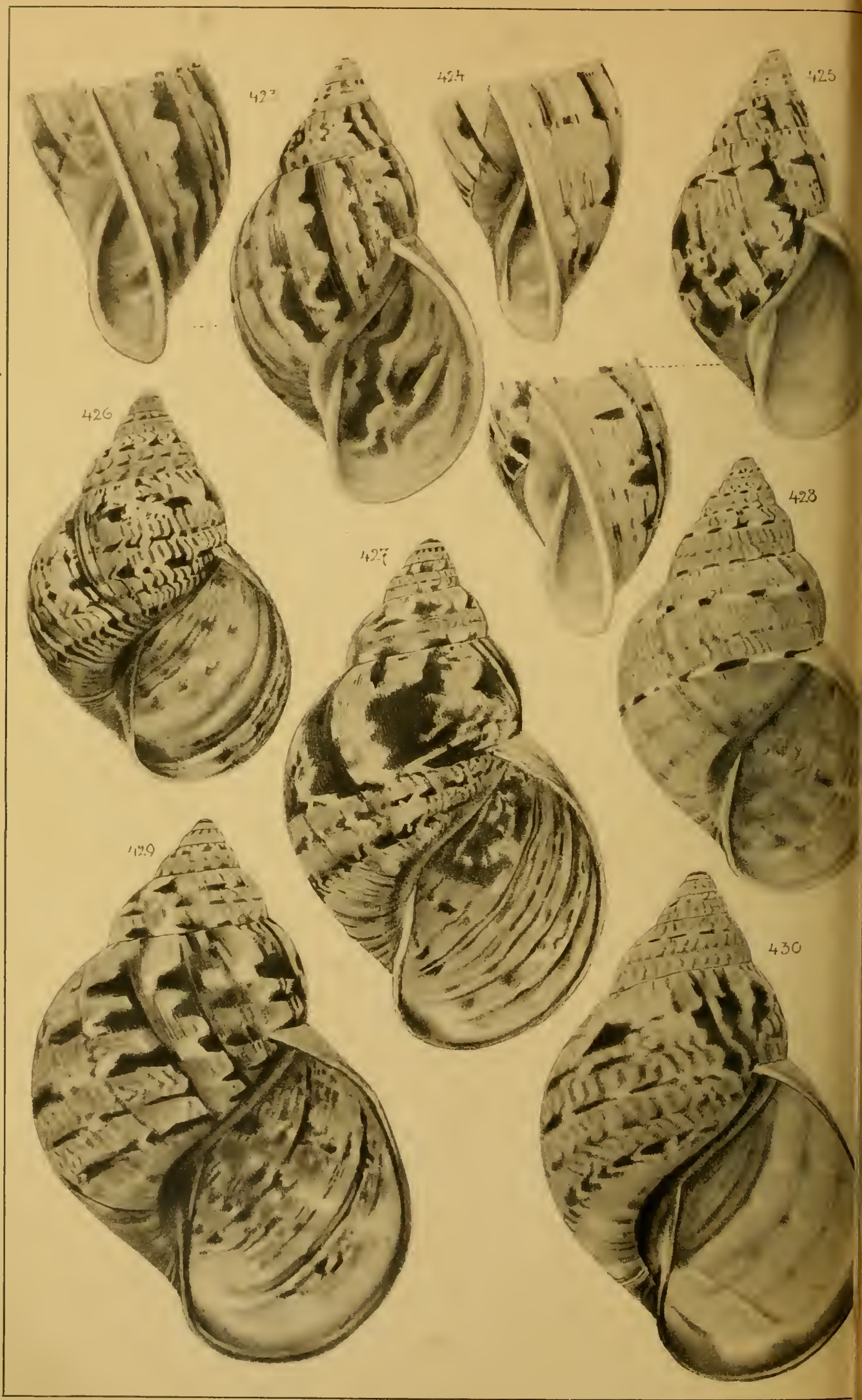




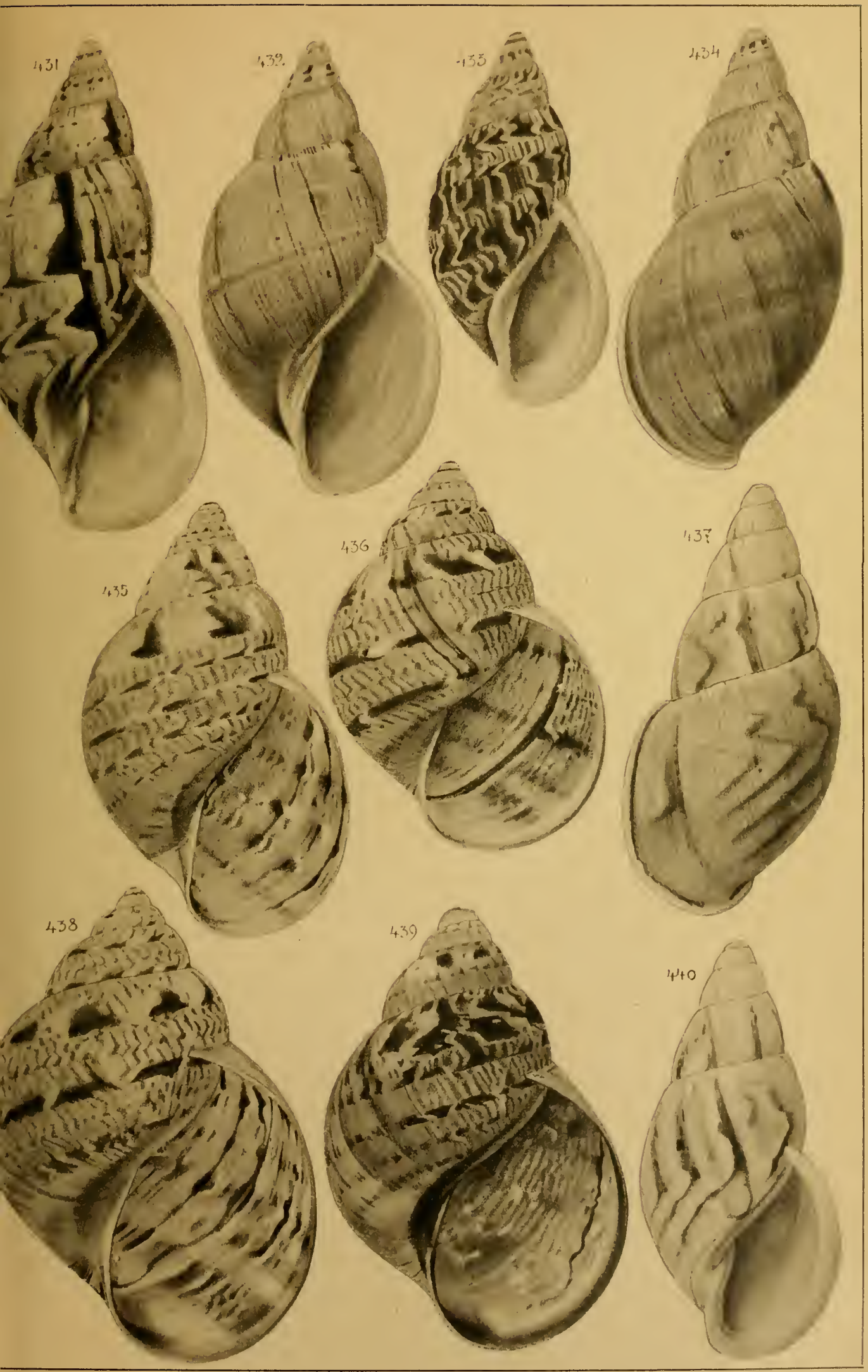






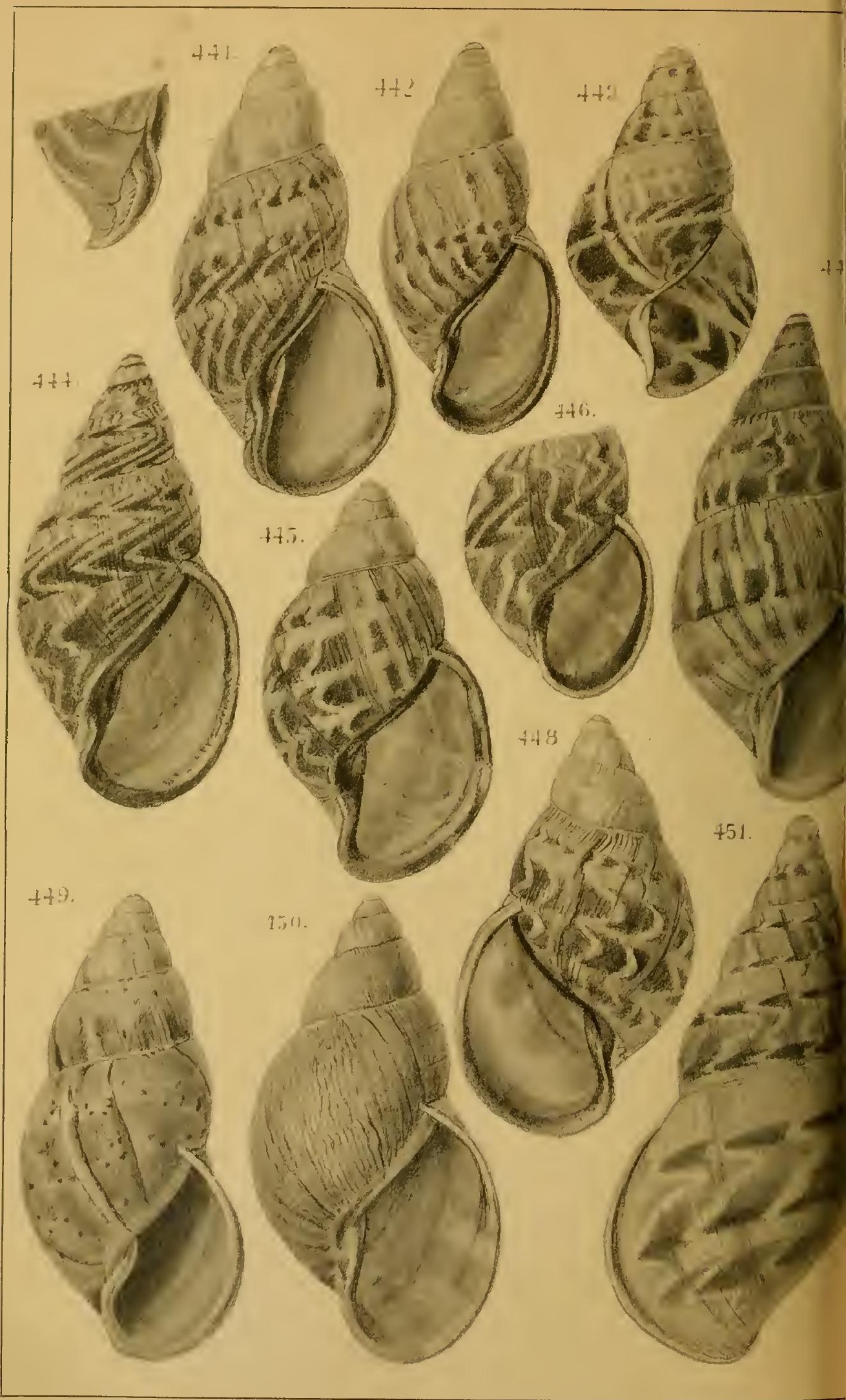




Gedruckt bei Lütcke \& Wulff, E. H. Senats Buchdruckern.

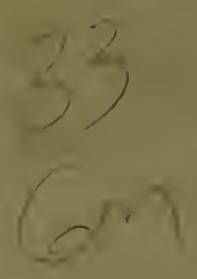




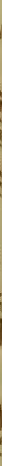

Nol1n

IRARIES

SMITHSONIAN
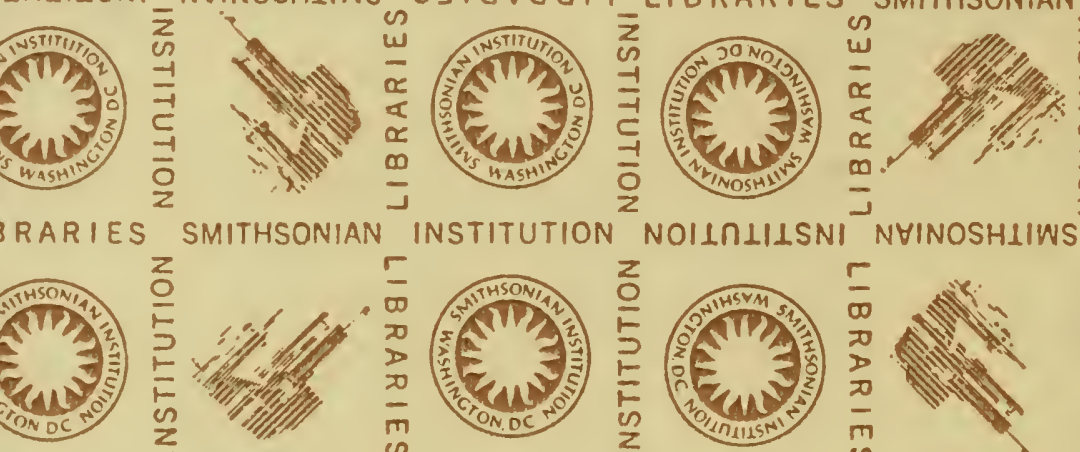

\section{IINIIISN}
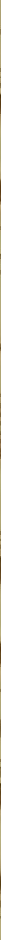

RARIES SMITHSONIAN INSTITUTION
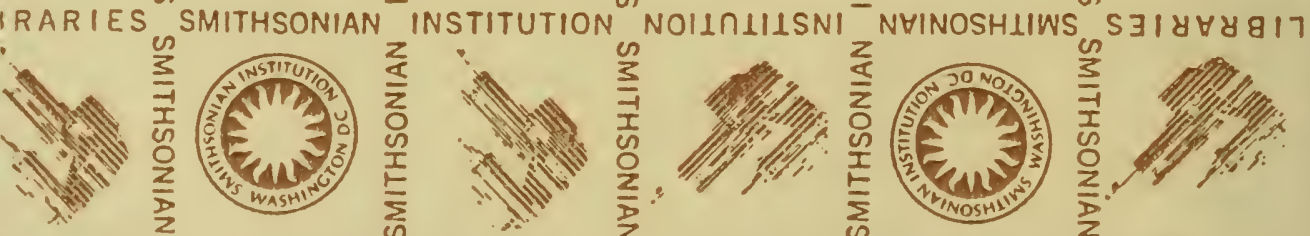

LIBRI
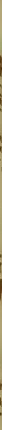

RARIES

SMITHSONIAN

INSTITUTION

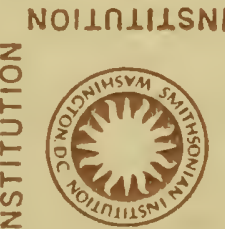

$5318 \forall 4817$

Nolln
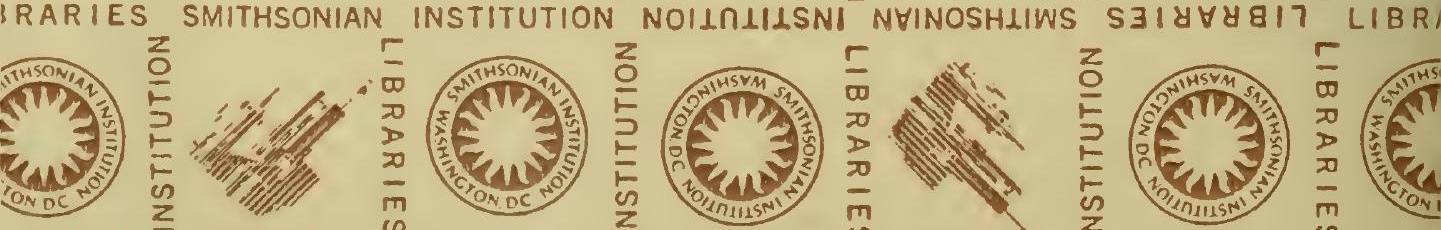

INIIISNI NHINOSHLIWS SJIYYY817 LIBRARIES SMITHSONIAN

EINSTITUTION NOIIN
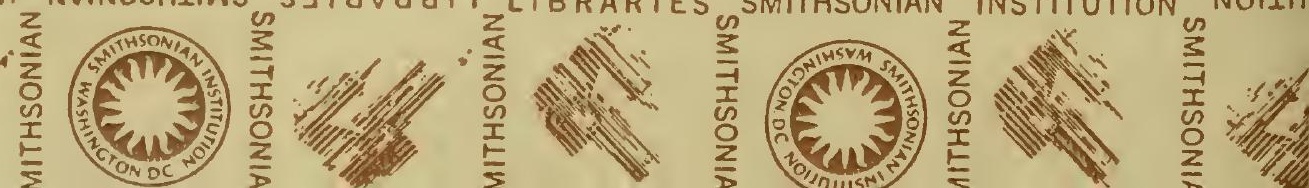
